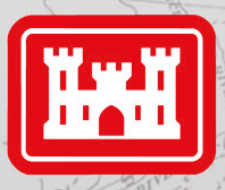

US Army Corps of Engineers ${ }_{\otimes}$

\title{
Hydrodynamics in the Morganza Floodway and Atchafalaya Basin Report 2: Phase 2
}

A Report for the U.S. Army Corps of Engineers, MRG\&P

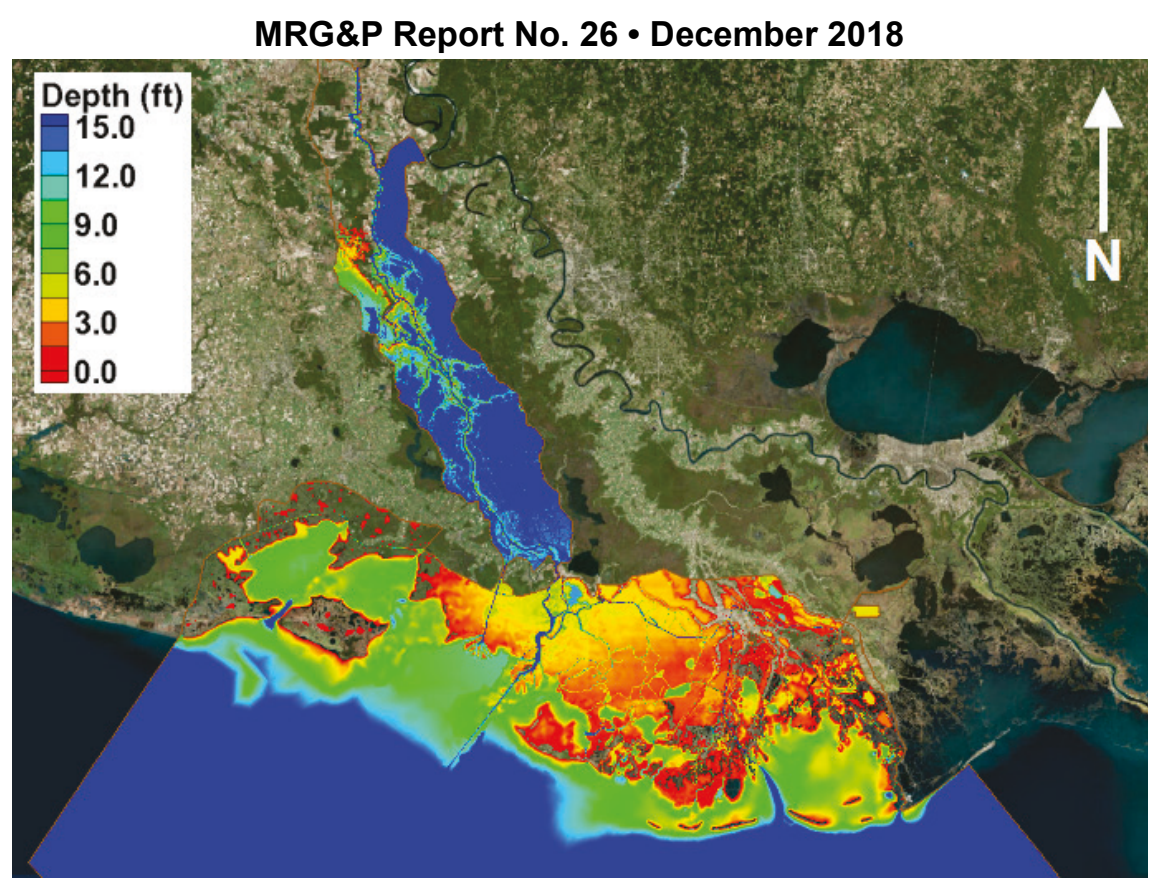

\section{$\mathrm{MRG} \& \mathrm{P}$}

Mississippi River Geomorphology \& Potamology Program 


\section{Hydrodynamics in the Morganza Floodway and Atchafalaya Basin, Report 2: Phase 2}

A Report for the U.S. Army Corps of Engineers, MRG\&P

Gary L. Bell, David D. Abraham, and Nathan D. Clifton

Coastal and Hydraulics Laboratory

U.S. Army Engineer Research and Development Center

3909 Halls Ferry Road

Vicksburg, MS 39180-6199

Final report

Approved for public release; distribution is unlimited.

Prepared for U.S. Army Corps of Engineers, Mississippi Valley Division Mississippi River Geomorphology and Potamology Program 1400 Walnut Street

Vicksburg, MS 39180

Under Project No. 127672, "Multi-Dimensional Modeling of Mississippi River" 


\section{Abstract}

The Morganza Floodway and the Atchafalaya Basin located in Louisiana west of the Mississippi River were evaluated using a two-dimensional Adaptive Hydraulics model. The study was conducted to determine the extent and timing of flood inundation throughout the study area. The input hydrograph covered a range of flows through the Morganza Control Structure that included the 2011 flood as well as the low end of flow values up to the Standard Project Flood of 600,000 cfs. Hydraulic roughness values were set for pre-2011 flood conditions. Prior to this study, a Phase 1 initial model study was completed that included only the Morganza Floodway down to Highway 190. This study (Phase 2) incorporates the Phase 1 study area along with the system south of Highway 190 down to Morgan City as well as the entire Atchafalaya Basin from Simmesport to Calumet. After the model was calibrated to the 2011 flood event, three separate alternative simulations were performed. These alternatives are the beginning of a collection of runs that detail how the floodways will respond given certain boundary conditions.

DISCLAIMER: The contents of this report are not to be used for advertising, publication, or promotional purposes. Citation of trade names does not constitute an official endorsement or approval of the use of such commercial products. All product names and trademarks cited are the property of their respective owners. The findings of this report are not to be construed as an official Department of the Army position unless so designated by other authorized documents. 


\section{Contents}

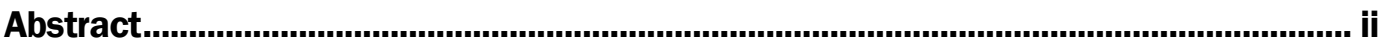

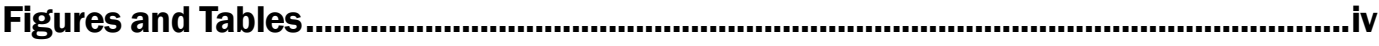

Preface

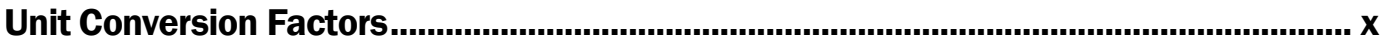

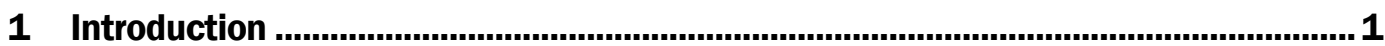

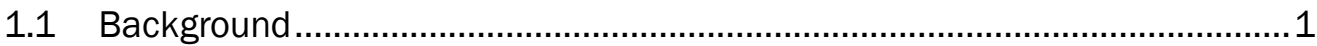

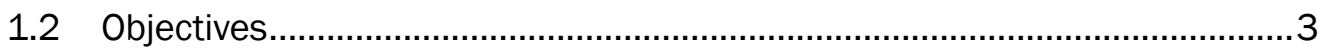

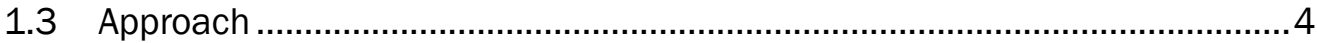

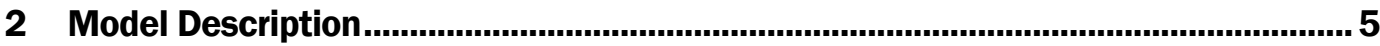

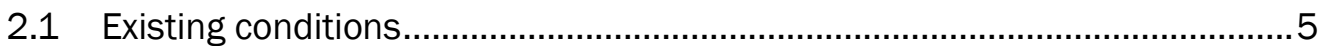

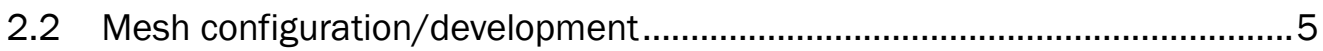

2.3 U.S. Geological Survey (USGS) gage data and boundary condition data.......... 11

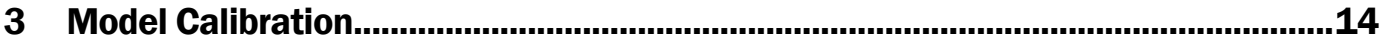

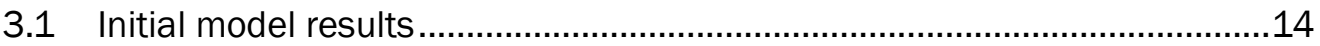

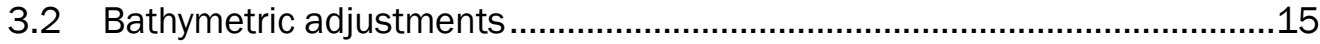

3.3 Mesh convergence sensitivity test.......................................................... 18

3.4 Model downstream boundary change and adaption adjustment

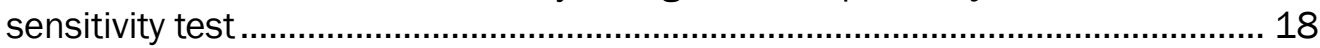

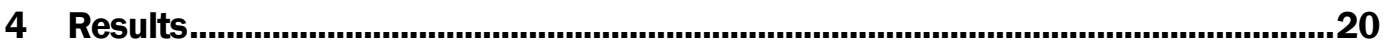

4.12011 flood event model calibration results.............................................. 20

4.2 Project design flow simulation ................................................................. 41

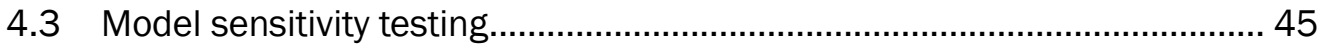

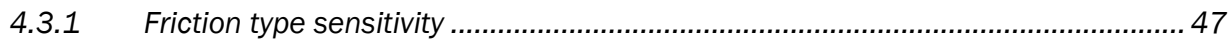

4.3.2 Project design flow - friction sensitivity testing ...................................................65

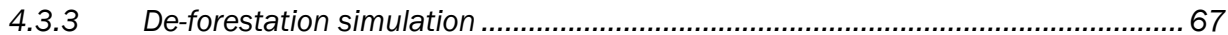

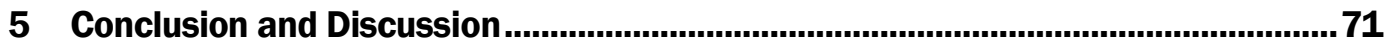

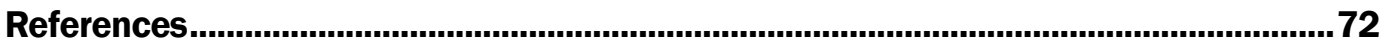

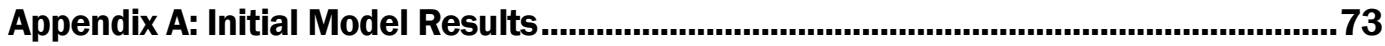

Appendix B: Bathymetric Adjustment Model Results ...............................................91

Appendix C: Mesh Convergence Sensitivity Model Results ...................................... 107

Report Documentation Page 


\section{Figures and Tables}

\section{Figures}

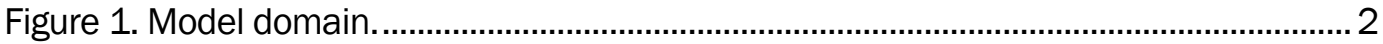

Figure 2. Morganza/Atchafalaya Floodway location.......................................................... 3

Figure 4. Model elevations. ..............................................................................................

Figure 5. Example location of the numerical mesh. ……...................................................11

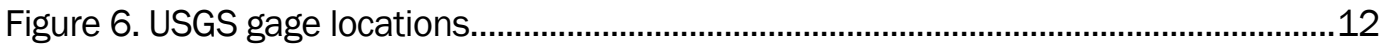

Figure 7. Locations where elevation values were lowered by $5 \mathrm{ft}$.....................................16

Figure 8. Locations where elevation values were lowered by $15 \mathrm{ft}$...................................... 17

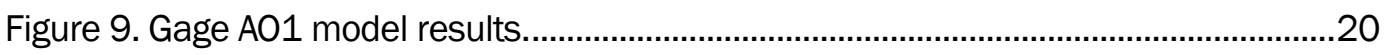

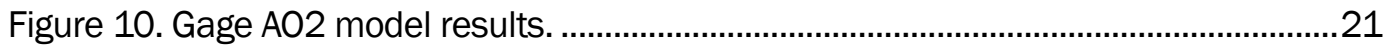

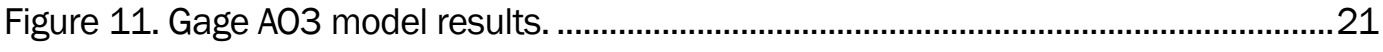

Figure 12. Gage AO4 model results. .............................................................................2

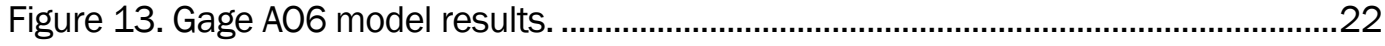

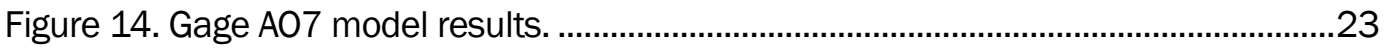

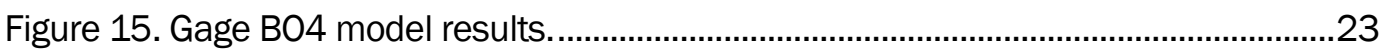

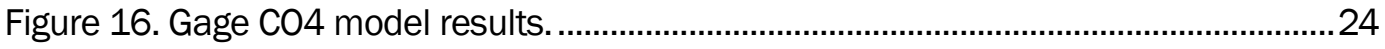

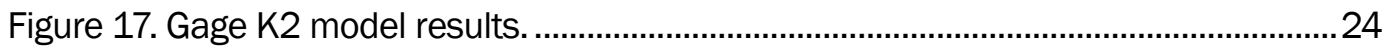

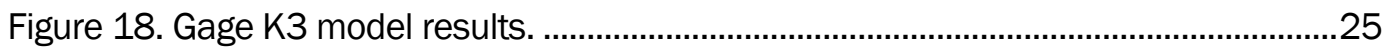

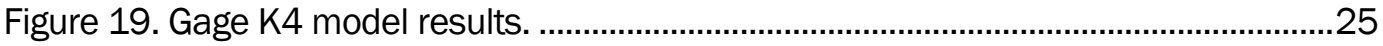

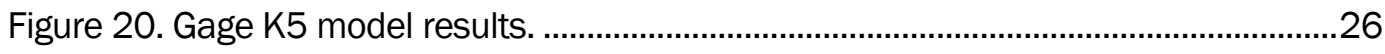

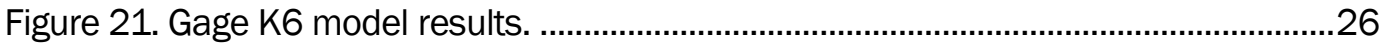

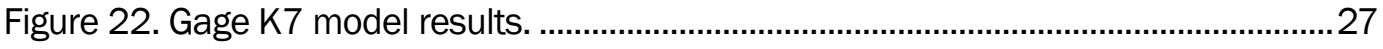

Figure 23. Gage K8 model results. ........................................................................... 27

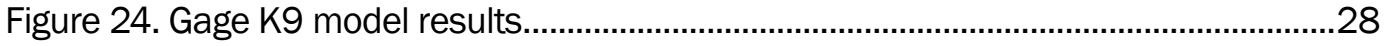

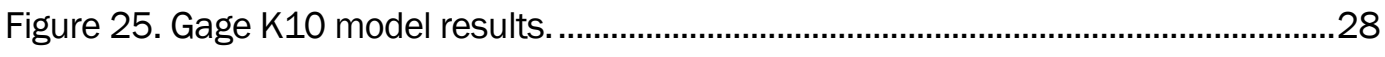

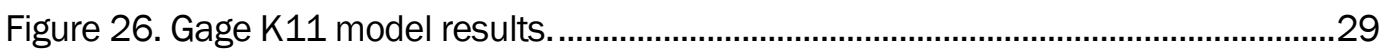

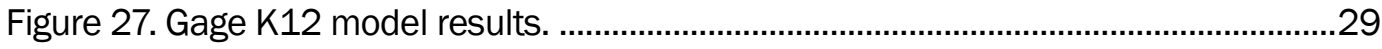

Figure 28. Gage K13 model results.........................................................................30

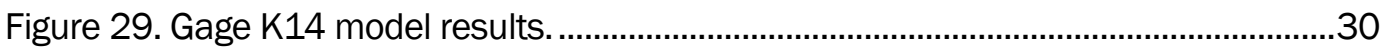

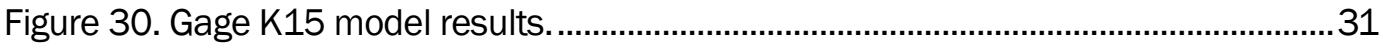

Figure 31. Gage K16 model results. ............................................................................. 31

Figure 32. Gage K17 model results. .........................................................................32

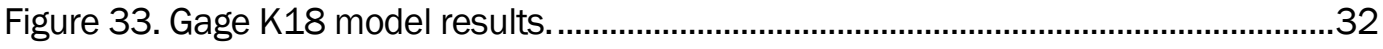

Figure 34. Gage K19 model results................................................................................33

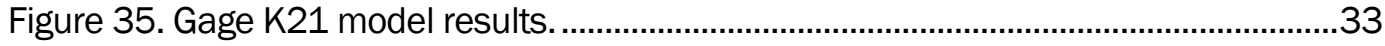

Figure 36. Water surface elevation at Wax Lake Outlet. ..................................................34 
Figure 37. Water surface elevation at Morgan City Outlet................................................34

Figure 38. Discharge at Wax Lake Outlet. ........................................................................35

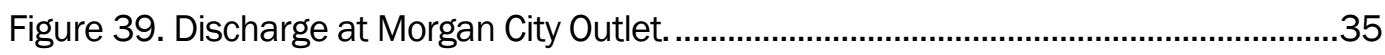

Figure 40. Relative gage accuracy (model results compared to measured data)..............36

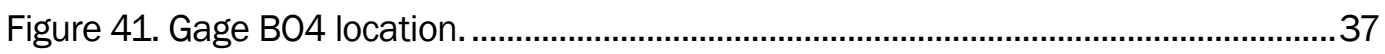

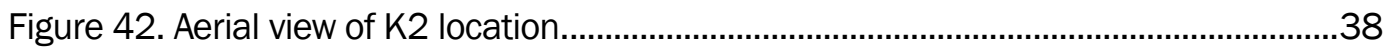

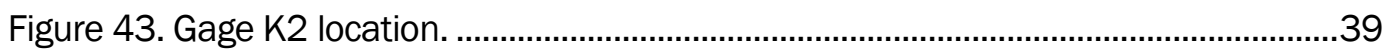

Figure 44. Water depth at day 10 of the 2011 flood event simulation............................... 41

Figure 45. Locations of cross section arcs to be analyzed.................................................42

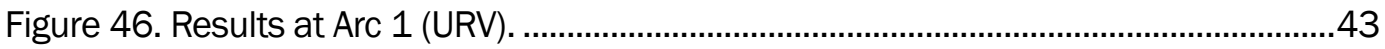

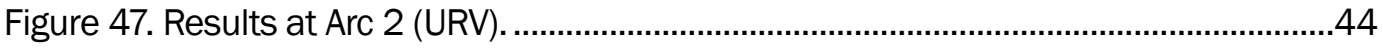

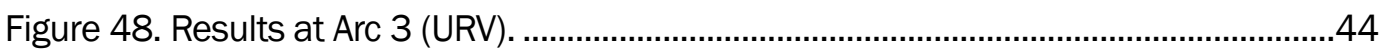

Figure 49. Water depth during the project flood event simulation at day $10 \ldots \ldots . . . . . . . . . . . . .45$

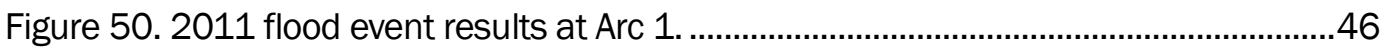

Figure 51. 2011 flood event results at Arc 2 .................................................................46

Figure 52. 2011 flood event results at Arc 3 ................................................................. 47

Figure 53. Gage AO1 model results. ............................................................................... 48

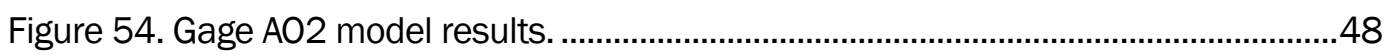

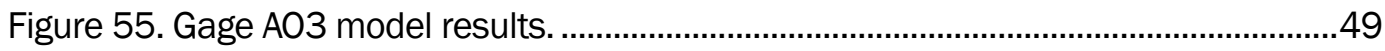

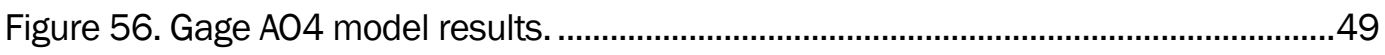

Figure 57. Gage AO6 model results............................................................................50

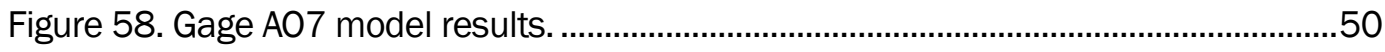

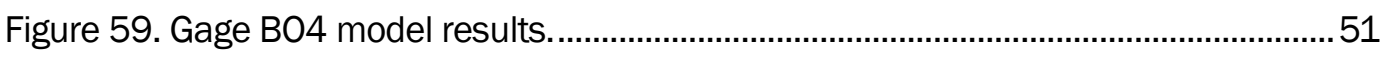

Figure 60. Gage $\mathrm{CO} 4$ model results...............................................................................51

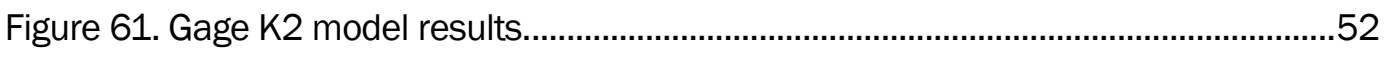

Figure 62. Gage K3 model results. ............................................................................52

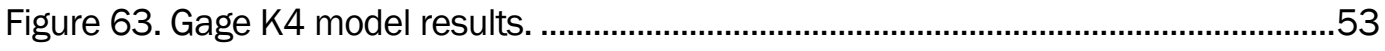

Figure 64. Gage K5 model results. ...............................................................................53

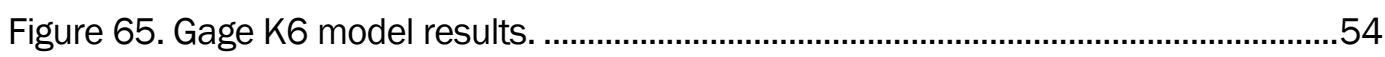

Figure 66. Gage K7 model results. ............................................................................54

Figure 67. Gage K8 model results.................................................................................55

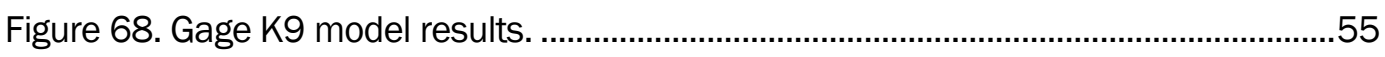

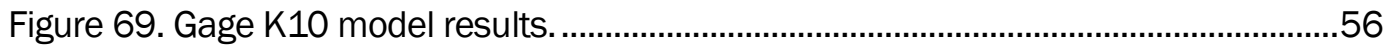

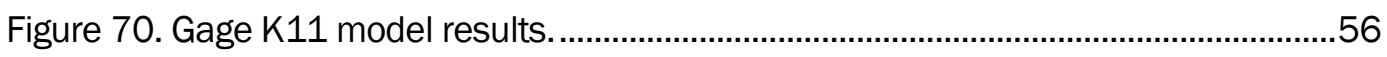

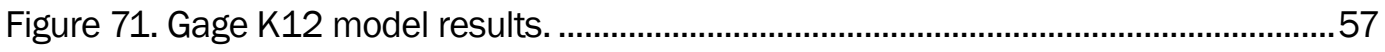

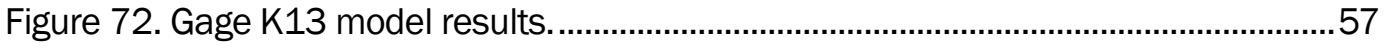

Figure 73. Gage K14 model results..............................................................................58

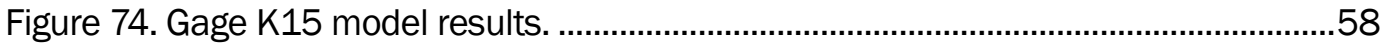

Figure 75. Gage K16 model results..........................................................................59 


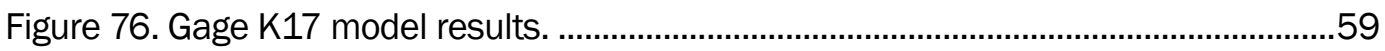

Figure 77. Gage K18 model results. ...........................................................................60

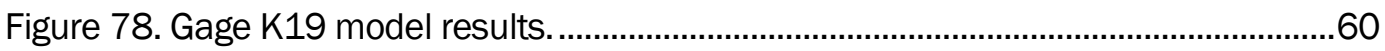

Figure 79. Gage K21 model results. ...........................................................................61

Figure 80. USGS gage at Wax Lake Outlet (water surface elevation)................................61

Figure 81. USGS gage at Morgan City Outlet (water surface elevation)..............................62

Figure 82. USGS gage at Wax Lake Outlet (discharge). ...................................................62

Figure 83. USGS gage at Morgan City Outlet (discharge). .................................................63

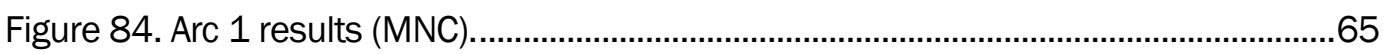

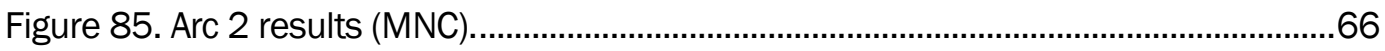

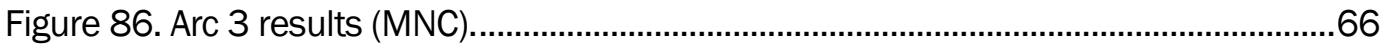

Figure 87. Location of simulated cleared out trees areas................................................68

Figure 88. Results from cleared out trees simulation at Arc 1..........................................69

Figure 89. Results from cleared out trees simulation at Arc 2 .......................................69

Figure 90. Results from cleared out trees simulation at Arc 3..........................................70

Figure 91. Project flood event water depth at day 11 of the simulation..............................70

Figure A-1. Initial Model domain................................................................................... 74

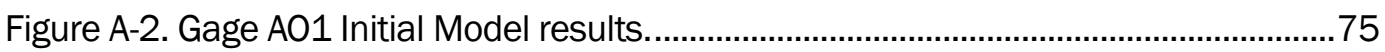

Figure A-3. Gage AO2 Initial Model results...................................................................

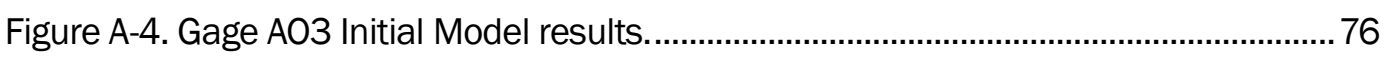

Figure A-5. Gage AO4 Initial Model results.................................................................... 76

Figure A-6. Gage AO6 Initial Model results........................................................................

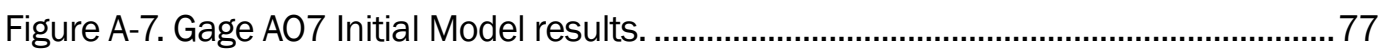

Figure A-8. Gage BO4 Initial Model results. .......................................................................

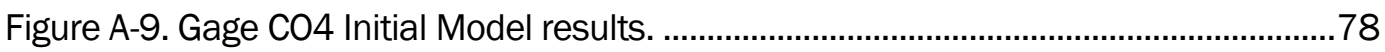

Figure A-10. Gage K2 Initial Model results.....................................................................

Figure A-11. Gage K3 Initial Model results.....................................................................79

Figure A-12. Gage K4 Initial Model results. ...................................................................8

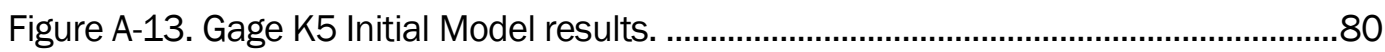

Figure A-14. Gage K6 Initial Model results...................................................................... 81

Figure A-15. Gage K7 Initial Model results. ..................................................................... 81

Figure A-16. Gage K8 Initial Model results...............................................................82

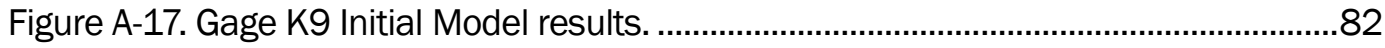

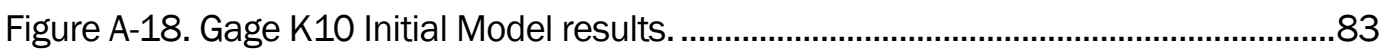

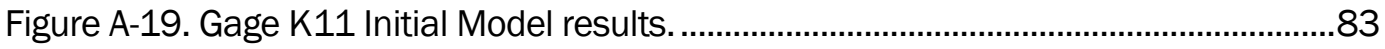

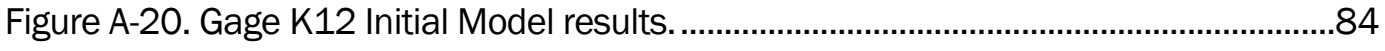

Figure A-21. Gage K13 Initial Model results. ...................................................................84

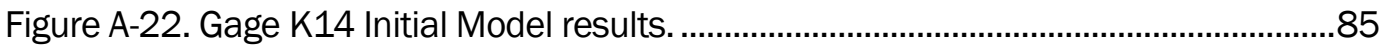

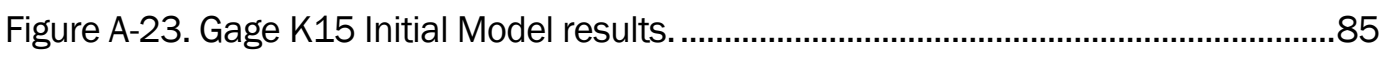




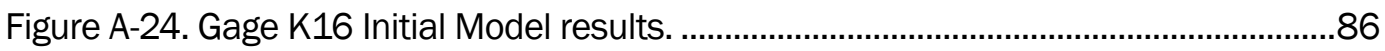

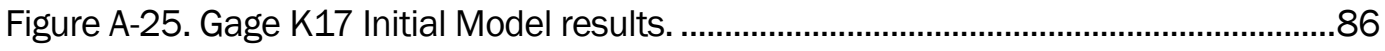

Figure A-26. Gage K18 Initial Model results................................................................. 87

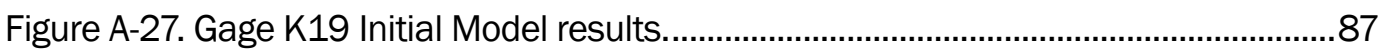

Figure A-28. Gage K21 initial model results. ..............................................................8

Figure A-29. USGS gage at Wax Lake Outlet (water surface elevation). ..............................88

Figure A-30. USGS gage at Morgan City Outlet (water surface elevation). ..........................89

Figure A-31. USGS gage at Wax Lake Outlet (discharge)...................................................89

Figure A-32. USGS gage at Morgan City Outlet (discharge)................................................90

Figure B-1. Gage AO1 Bathymetric Adjustment Model results............................................91

Figure B-2. Gage AO2 Bathymetric Adjustment Model results..............................................92

Figure B-3. Gage AO3 Bathymetric Adjustment Model results.........................................92

Figure B-4. Gage AO4 Bathymetric Adjustment Model results.........................................93

Figure B-5. Gage A06 Bathymetric Adjustment Model results........................................93

Figure B-6. Gage AO7 Bathymetric Adjustment Model results..........................................94

Figure B-7. Gage BO4 Bathymetric Adjustment Model results............................................94

Figure B-8. Gage CO4 Bathymetric Adjustment Model results............................................95

Figure B-9. Gage K2 Bathymetric Adjustment Model results............................................95

Figure B-10. Gage K3 Bathymetric Adjustment Model results...........................................96

Figure B-11. Gage K4 Bathymetric Adjustment Model results..........................................96

Figure B-12. Gage K5 Bathymetric Adjustment Model results. .........................................97

Figure B-13. Gage K6 Bathymetric Adjustment Model results..............................................97

Figure B-14. Gage K7 Bathymetric Adjustment Model results...........................................98

Figure B-15. Gage K8 Bathymetric Adjustment Model results.............................................98

Figure B-16. Gage K9 Bathymetric Adjustment Model results............................................99

Figure B-17. Gage K10 Bathymetric Adjustment Model results.........................................99

Figure B-18. Gage K11 Bathymetric Adjustment Model results...................................... 100

Figure B-19. Gage K12 Bathymetric Adjustment Model results..................................... 100

Figure B-20. Gage K13 Bathymetric Adjustment model results....................................... 101

Figure B-21. Gage K14 Bathymetric Adjustment Model results. ...................................... 101

Figure B-22. Gage K15 Bathymetric Adjustment Model results....................................... 102

Figure B23. Gage K16 Bathymetric Adjustment Model results. .................................... 102

Figure B-24. Gage K17 Bathymetric Adjustment Model results........................................ 103

Figure B-25. Gage K18 Bathymetric Adjustment Model results. ...................................... 103

Figure B-26. Gage K19 Bathymetric Adjustment Model results....................................... 104

Figure B-27. Gage K21 Bathymetric Adjustment Model results....................................... 104

Figure B-28. USGS Gage at Wax Lake Outlet (water surface elevation). ........................... 105

Figure B-29. USGS Gage at Morgan City Outlet (water surface elevation)....................... 105

Figure B-30. USGS Gage at Wax Lake Outlet (discharge)................................................. 106 


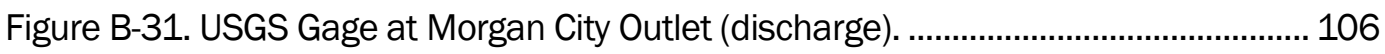

Figure C-1. Gage A01 Mesh Convergence Sensitivity Model results.................................. 107

Figure C-2. Gage AO2 Mesh Convergence Sensitivity Model results................................ 108

Figure C-3. Gage AO3 Mesh Convergence Sensitivity Model results................................ 108

Figure C-4. Gage AO4 Mesh Convergence Sensitivity Model results............................... 109

Figure C-5. Gage AO6 Mesh Convergence Sensitivity Model results................................ 109

Figure C-6. Gage AO7 Mesh Convergence Sensitivity Model results................................. 110

Figure C-7. Gage BO4 Mesh Convergence Sensitivity Model results................................ 110

Figure C-8. Gage CO4 Mesh Convergence Sensitivity Model results. .............................. 111

Figure C-9. Gage K2 Mesh Convergence Sensitivity Model results.................................. 111

Figure C-10. Gage K3 Mesh Convergence Sensitivity Model results. ............................... 112

Figure C-11. Gage K4 Mesh Convergence Sensitivity Model results. ............................. 112

Figure C-12. Gage K5 Mesh Convergence Sensitivity Model results. ............................. 113

Figure C-13. Gage K6 Mesh Convergence Sensitivity Model results. .............................. 113

Figure C-14. Gage K7 Mesh Convergence Sensitivity Model results. .............................. 114

Figure C-15. Gage K8 Mesh Convergence Sensitivity Model results. .............................. 114

Figure C-16. Gage K9 Mesh Convergence Sensitivity Model results. ............................... 115

Figure C-17. Gage K10 Mesh Convergence Sensitivity Model results.............................. 115

Figure C-18. Gage K11 Mesh Convergence Sensitivity Model results............................ 116

Figure C-19. Gage K12 Mesh Convergence Sensitivity Model results............................. 116

Figure C-20. Gage K13 Mesh Convergence Sensitivity Model results............................. 117

Figure C-21. Gage K14 Mesh Convergence Sensitivity Model results. .............................. 117

Figure C-22. Gage K15 Mesh Convergence Sensitivity Model results............................ 118

Figure C-23. Gage K16 Mesh Convergence Sensitivity Model results.............................. 118

Figure C-24. Gage K17 Mesh Convergence Sensitivity Model results. ............................ 119

Figure C-25. Gage K18 Mesh Convergence Sensitivity Model results............................. 119

Figure C-26. Gage K19 Mesh Convergence Sensitivity Model results.............................. 120

Figure C-27. Gage K21 Mesh Convergence Sensitivity Model results............................... 120

Figure C-28. USGS Gage at Wax Lake Outlet (water surface elevation). ........................... 121

Figure C-29. USGS Gage at Morgan City Outlet (water surface elevation). ....................... 121

Figure C-30. USGS Gage at Wax Lake Outlet (discharge)................................................ 122

Figure C-31. USGS Gage at Morgan City Outlet (discharge). .......................................... 122

\section{Tables}

Table 1. List of simulated hydraulic roughness parameters................................................ 8

Table 2. Summary of RMSE and model error (feet)...............................................................40

Table 3. Reference table for flow values/days................................................................43

Table 4. Summary of RMSE and model error (feet)...........................................................64 


\section{Preface}

The research documented in this report was conducted as part of the Mississippi River Geomorphology and Potamology (MRG\&P) Program, under Project Number 127672, "Multi-Dimensional Modeling of Mississippi River.” The MRG\&P Technical Director was Dr. Ty V. Wamsley. The MVD Commander was MG Richard G. Kaiser. The MVD Director of Programs was Mr. James Bodron.

The Mississippi River Commission provided Mississippi River engineering direction and policy advice. The Commission members were MG Richard G. Kaiser, USACE, President; the Honorable Sam E. Angel; the Honorable James Reeder; the Honorable Norma Jean Mattei, PhD; RDML Shepard Smith, National Oceanic and Atmospheric Administration; MG Mark Toy, USACE LRD; and BG Paul E. Owen, USACE SWD.

At the time of publication of this report, Mr. Keith Flowers was Chief, Rivers and Estuaries. Mr. Jeffrey R. Eckstein was the Deputy Director of the U.S. Army Engineer Research and Development Center (ERDC), Coastal and Hydraulics Laboratory, and Dr. Ty V. Wamsley was the Director.

COL Ivan P. Beckman was the Commander of ERDC, and the Director was Dr. David W. Pittman. 


\section{Unit Conversion Factors}

\begin{tabular}{|l|c|l|}
\hline Multiply & By & To Obtain \\
\hline acres & $4,046.873$ & square meters \\
\hline feet & 0.3048 & meters \\
\hline hectares & $1.0 \mathrm{E}+04$ & square meters \\
\hline inches & 0.0254 & meters \\
\hline miles (nautical) & 1,852 & meters \\
\hline miles (U.S. statute) & $1,609.347$ & meters \\
\hline mils & 0.0254 & millimeters \\
\hline square feet & 0.09290304 & square meters \\
\hline square miles & $2.589998 \mathrm{E}+06$ & square meters \\
\hline square yards & 0.8361274 & square meters \\
\hline yards & 0.9144 & meters \\
\hline
\end{tabular}




\section{Introduction}

\subsection{Background}

The U.S. Army Corps of Engineers (USACE), Coastal and Hydraulics Laboratory (CHL), conducted a numerical model study of the Morganza Floodway (Phase 1) (Bell et al. 2017). In Phase 2, the Morganza Floodway model was expanded to include the entire Atchafalaya Basin as well as extended into the Gulf of Mexico.

The entire model domain (see Figure 1, outlined in blue) extends from the village of Hamburg, LA, at its northwest corner, to the Gulf of Mexico at its southern-most extremity. The length of the model domain is approximately 180 miles along its central longitudinal axis, and its average width is approximately 13 miles (from the East Atchafalaya Basin Project Levee [EABPL] to the West Atchafalaya Basin Project Levee [WABPL]), with a minimum of approximately 7 miles at the northern end and a maximum of approximately 18 miles at the southern end. The southern portion of the model (downstream of the Wax Lake Outlet by Calumet, LA, and the outlet at Morgan City, LA), which includes the marshes and a part of the Gulf of Mexico, is approximately $120-190$ miles wide. The northern part of the basin is divided by the Atchafalaya River and its levees, with the West Atchafalaya Basin (WAB) to the west of the river levees and the Morganza Floodway to the east of the river levees. South of Interstate 10 at a location near Butte La Rose, the Atchafalaya River levees end, and if the water level is high enough to be above the natural ground elevations, the flows from the west and east Atchafalaya basins merge. The combined flow then moves between the WABPL and the EABPL south through the Lower Atchafalaya River and the Wax Lake Outlet to the Gulf of Mexico. Figure 2 shows the model location from the upstream boundary to Morgan City and Wax lake Outlet. Figure 2 also displays the extents of the levees that run along both sides of the Atchafalaya River (extending from the upstream model boundary to $\sim 9$ miles north of Butte La Rose and 1.75 miles south of Butte La Rose for the east and west Atchafalaya River levees, respectively). If flow in the Mississippi River is high and flow in the Atchafalaya River is relatively low, then it is possible that Mississippi River floodwaters diverted into the Morganza Floodway can also move upstream (north) into the Atchafalaya River or the WAB, connected near Butte La Rose where the upstream river levees end. 
Figure 1. Model domain.

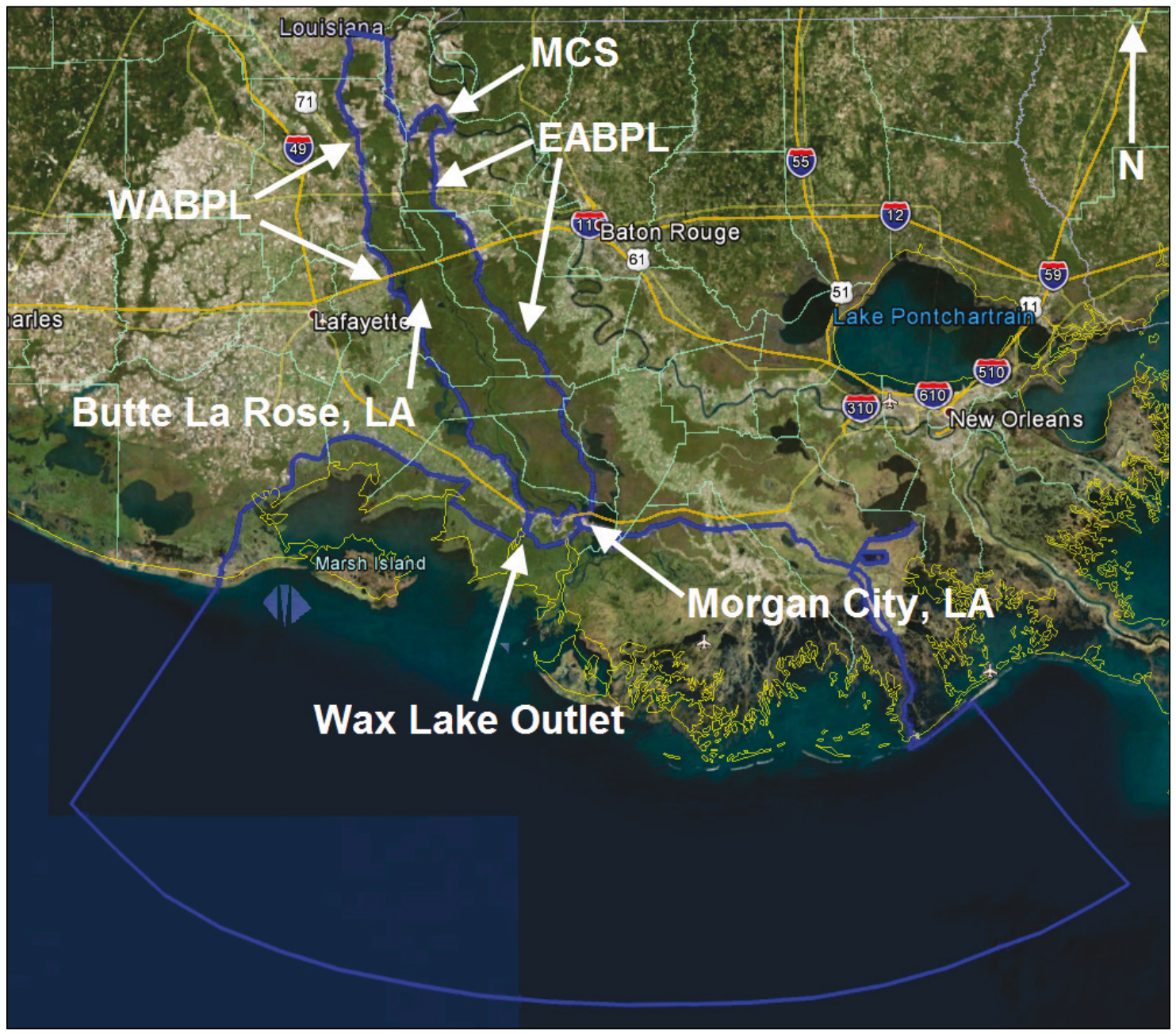


Figure 2. Morganza/Atchafalaya Floodway location.

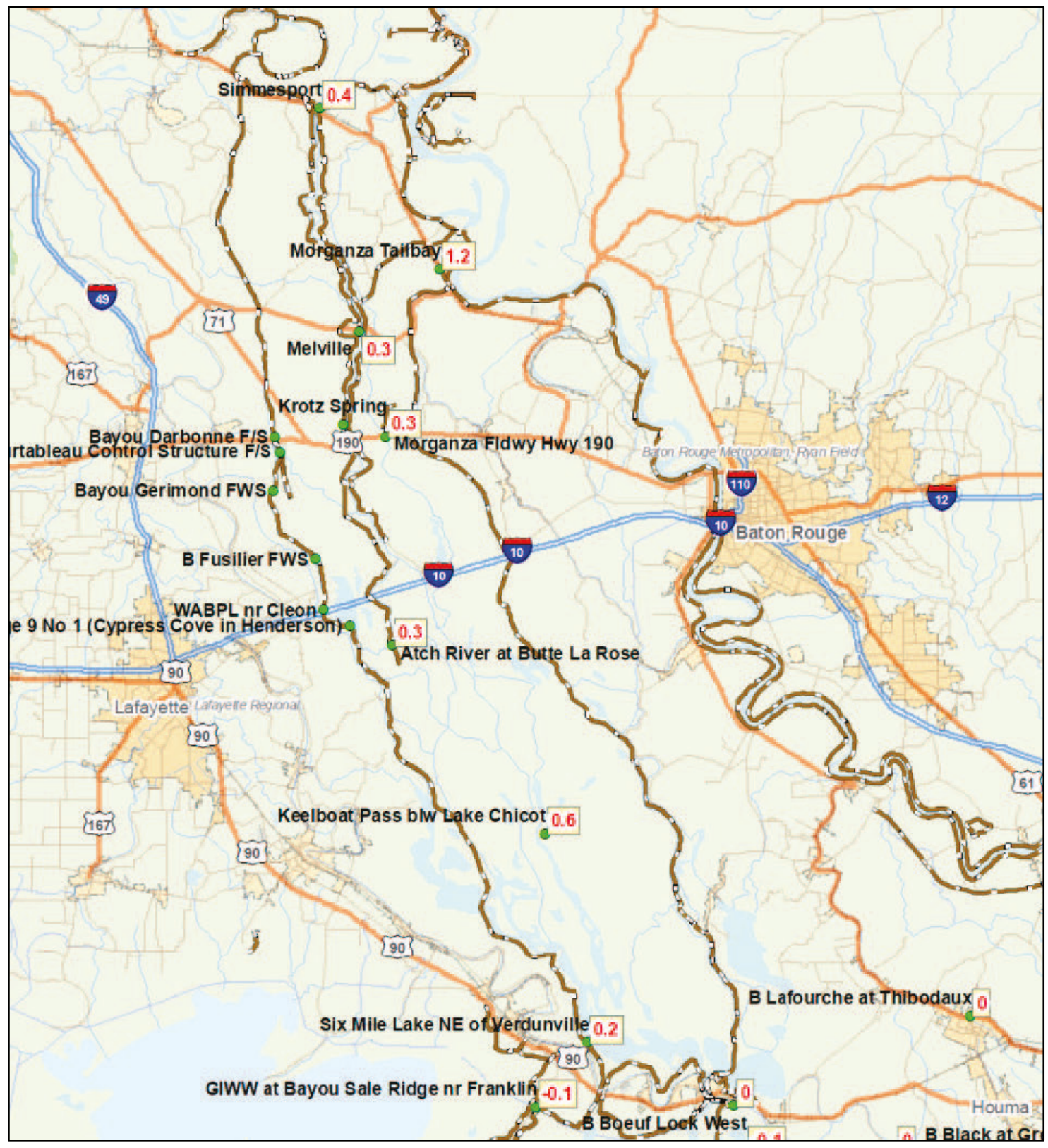

\subsection{Objectives}

The model was applied to determine the extent and timing of inundation in the floodways. In addition to the 2011 flood event (max discharges of 170 thousand cubic feet per second [kcfs] and $697 \mathrm{kcfs}$ through the Morganza Control Structure [MCS] and the Atchafalaya River, respectively), a discharge of 600,000 cubic feet per second (cfs) through the MCS (ramped up in equal increments over time) was simulated. This technical report describes the model development, acquisition of 
necessary data for calibration, and the results of model calibration. Three alternative simulations are also presented in this documentation.

\subsection{Approach}

The hydraulic model investigation was conducted using the Adaptive Hydraulics (AdH-SW2D, v4.6) numerical code to solve the twodimensional (2D), depth-averaged, shallow water equations (ERDC CHL 2017). AdH is a multi-dimensional, finite element code capable of automatically refining the unstructured computational mesh and time steps, when necessary, to resolve gradients in the flow field. AdH is the model that was used to produce a series of inundation plots for the Morganza Floodway in the Phase 1 Morganza Floodway Study. The expansion of the numerical mesh from Phase 1 was accomplished by creating the Phase 2 mesh separately, then coupling the two models to create a single mesh. Three model runs were conducted with the Phase 2 model, which included the existing conditions and two alternatives. 


\section{Model Description}

\subsection{Existing conditions}

The existing conditions model represents the settings that were in place during the 2011 flood event. The model bathymetry/topography was established with airborne lidar data and multibeam bathymetric data for most of the Atchafalaya River. Additionally, there were numerous smaller channels throughout the basin for which no bathymetric data were available. These channels were delineated by the lidar surveys such that their lateral boundaries were captured, but not the depths since lidar only provides the water surface of opaque muddy water but not the bottom. To account for hydraulic conveyance in these locations, modifications to the channels that run along the WABPL and EABPL as well as some larger channel networks within the two floodways were made in the existing conditions model. The details of the modifications can be found in Chapter 3 Model Calibration, of this report.

The existing conditions model was run through several different sensitivity analyses and tests. These ranged from adjusting the Manning's roughness coefficient throughout the model, bathymetric adjustments, model boundary changes, and mesh resolution convergence.

After the calibration of the existing conditions model, changes were made to the boundary conditions to represent the proposed alternative simulations. One scenario involved increasing flow through the MCS until a project design value of $600,000 \mathrm{cfs}$ was obtained. The other focused on the possibility of simulating deforestation in a portion of the model and analyzing the results from that change in the model's parameters.

\subsection{Mesh configuration/development}

The existing conditions mesh is comprised of $1,749,074$ nodes and $3,485,398$ elements that encompass an area of approximately 9,044,985 acres $\left(\sim 14,133\right.$ square miles $\left.\left[\mathrm{mi}^{2}\right]\right)$. Forty-seven different material types were assigned to the model (Figure 3 displays all materials on the left; the right side depicts a zoomed-in portion of the model to show an example of the elaborate material specification). The materials vary for the crop lands, wooded areas, bodies of water, levees, etc. These were denoted as separate material types in the mesh and in the boundary condition input file. The 
defined areas were selected using aerial imagery dated before the flood event. Each material type is assigned attributes of surface roughness, eddy viscosity, and adaption. In this model, most of the material types were assigned a surface roughness based on the Manning's Roughness Coefficient. The others were defined as unsubmerged rigid vegetation and assigned values of average roughness height, average stem diameter, and average stem density (in that order). Table 1 displays the range of values used for all simulations (in order from material 1 through 47) with the current best value used in the calibrated/validated model for all additional simulations. Note that "FR URV" stands for un-submerged rigid vegetation and is used to simulate the flow through trees and other vegetated areas throughout the domain. 
Figure 3. Material locations in the model domain.

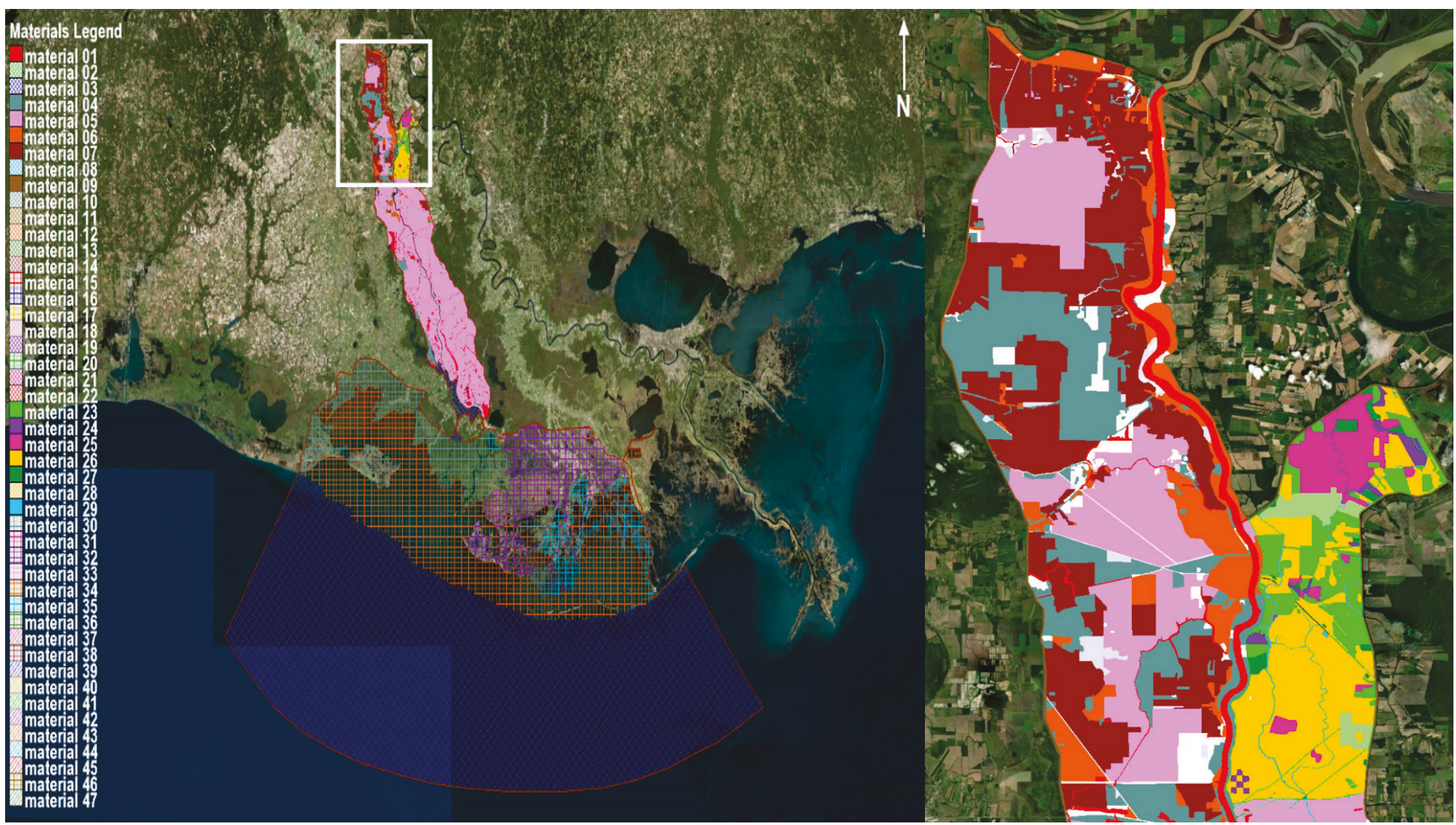


Table 1. List of simulated hydraulic roughness parameters.

\begin{tabular}{|c|c|c|c|}
\hline Material Type & Lowest Value & Highest Value & Current Best Value \\
\hline Water & 0.015 & 0.027 & 0.0162 \\
\hline Open Land & 0.028 & 0.028 & 0.028 \\
\hline $\begin{array}{l}\text { Shrubs to Small } \\
\text { Trees (FR URV) }\end{array}$ & $0.02,0.7,0.1$ & $30,2.65,0.1$ & $0.02,0.7,0.1$ \\
\hline $\begin{array}{l}\text { Select Cut Timber } \\
\text { (FR URV) }\end{array}$ & $0.02,0.9,0.1$ & $30,2.5,0.1$ & $0.02,0.9,0.1$ \\
\hline Large Timber (FR URV) & $0.02,0.7,0.1$ & $30,2,0.001$ & $0.02,0.7,0.1$ \\
\hline Open Land/Vegetation & 0.03 & 0.032 & 0.03 \\
\hline $\begin{array}{l}\text { Open Land with } \\
\text { Different Crops }\end{array}$ & 0.032 & 0.034 & 0.032 \\
\hline Berm & 0.03 & 0.03 & 0.03 \\
\hline Levee & 0.026 & 0.026 & 0.026 \\
\hline Lower Atchafalaya River & 0.02 & 0.035 & 0.035 \\
\hline East Levee Channel & 0.0162 & 0.0162 & 0.0162 \\
\hline West Channel & 0.0162 & 0.0162 & 0.0162 \\
\hline Channel near Gage K17 & 0.0162 & 0.0162 & 0.0162 \\
\hline Channel near Gage K13 & 0.0162 & 0.0162 & 0.0162 \\
\hline $\begin{array}{l}\text { Side Channel to East } \\
\text { Levee Channel }\end{array}$ & 0.0162 & 0.0162 & 0.0162 \\
\hline Channel to K9, K19 & 0.0162 & 0.0162 & 0.0162 \\
\hline Channel from K19 to Lake & 0.0162 & 0.0162 & 0.0162 \\
\hline Channel to K18 & 0.0162 & 0.0162 & 0.0162 \\
\hline Upper Basin West Channel & 0.0162 & 0.0162 & 0.0162 \\
\hline Channels South of K9 & 0.0162 & 0.0162 & 0.0162 \\
\hline Middle Atchafalaya River & 0.027 & 0.027 & 0.027 \\
\hline Upper Atchafalaya River & 0.03 & 0.03 & 0.03 \\
\hline Phase 1 Open Land & 0.03 & 0.036 & 0.036 \\
\hline $\begin{array}{l}\text { Phase } 1 \text { Shrubs to } \\
\text { Small Trees }\end{array}$ & 0.06 & 0.066 & 0.066 \\
\hline $\begin{array}{l}\text { Phase } 1 \text { Select Cut } \\
\text { Timber (FR URV) }\end{array}$ & $0.02,1.5,0.1$ & $0.02,1.7,0.1$ & $0.02,1.7,0.1$ \\
\hline Phase 1 Large Timber & $0.02,1.85,0.1$ & $0.02,2.05,0.1$ & $0.02,2.05,0.1$ \\
\hline Phase 1 Open Land/Vegetation & 0.032 & 0.038 & 0.038 \\
\hline $\begin{array}{l}\text { Phase } 1 \text { Open Land with } \\
\text { Different Crops }\end{array}$ & 0.04 & 0.046 & 0.046 \\
\hline
\end{tabular}




\begin{tabular}{|l|l|l|l|}
\hline Material Type & Lowest Value & Highest Value & Current Best Value \\
\hline Phase 1 Water & 0.028 & 0.034 & 0.034 \\
\hline Marsh Area & 0.02 & 0.045 & 0.045 \\
\hline Material 31 & 0.02 & 0.035 & 0.035 \\
\hline Material 32 & 0.02 & 0.045 & 0.045 \\
\hline Material 33 & 0.02 & 0.035 & 0.035 \\
\hline Material 34 & 0.02 & 0.035 & 0.035 \\
\hline Material 35 & 0.02 & 0.045 & 0.045 \\
\hline Birds Foot Paths & 0.02 & 0.035 & 0.035 \\
\hline Material 37 & 0.02 & 0.035 & 0.035 \\
\hline Material 38 & 0.02 & 0.035 & 0.035 \\
\hline Material 39 & 0.02 & 0.035 & 0.035 \\
\hline Material 40 & 0.02 & 0.035 & 0.035 \\
\hline Material 41 & 0.02 & 0.035 & 0.035 \\
\hline Deep Ocean & 0.02 & 0.035 & 0.035 \\
\hline Material 43 & 0.02 & 0.035 & 0.035 \\
\hline Material 44 & 0.02 & 0.035 & 0.035 \\
\hline Material 45 & 0.02 & 0.035 & 0.035 \\
\hline Material 46 & 0.02 & 0.035 & 0.035 \\
\hline Material 47 & 0.02 & 0.035 & 0.035 \\
\hline
\end{tabular}

The horizontal datum for the model is the State Plane Coordinate System (Louisiana South, North American Datum [NAD] 83), U.S. Survey Feet. The vertical datum is referenced to North American Vertical Datum (NAVD) 88, U.S. Survey Feet. The topographic elevations vary from approximately 50 feet $(\mathrm{ft}$ ) in the northern portions of the domain to $\mathrm{oft}$ in southern wooded/land portions of the model (Figure 4). An exception to these elevations is three small mounds/islands (Avery Island, Weeks Island, and Cote Blanche Island) whose elevations are as high as $90 \mathrm{ft}$. Bathymetry in the channels and other water bodies go below o ft in many places (reaching values of approximately $-150 \mathrm{ft}$ in the Gulf of Mexico area of the model). 
Figure 4. Model elevations.

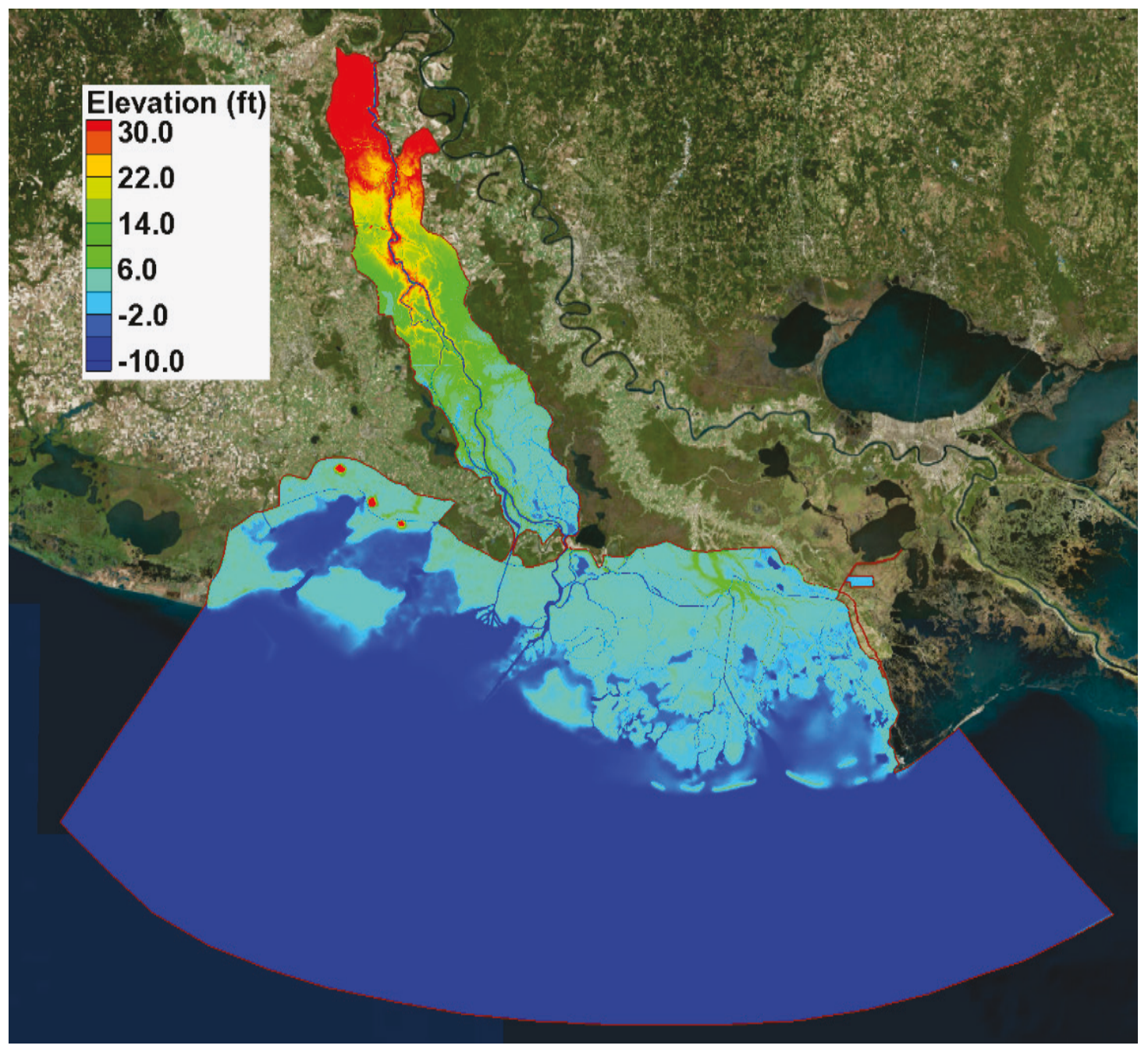

Resolution was varied to appropriately define the terrain and hydraulic features within the model domain. In Figure 5 for example, it can be seen that very fine resolution was applied to capture the East and West Atchafalaya Levees (10 ft spacing), slightly less resolution applied to the Atchafalaya River (100 ft spacing), and even less resolution was applied to open/wooded areas ( $300 \mathrm{ft}$ spacing - varies throughout domain). 
Figure 5. Example location of the numerical mesh.

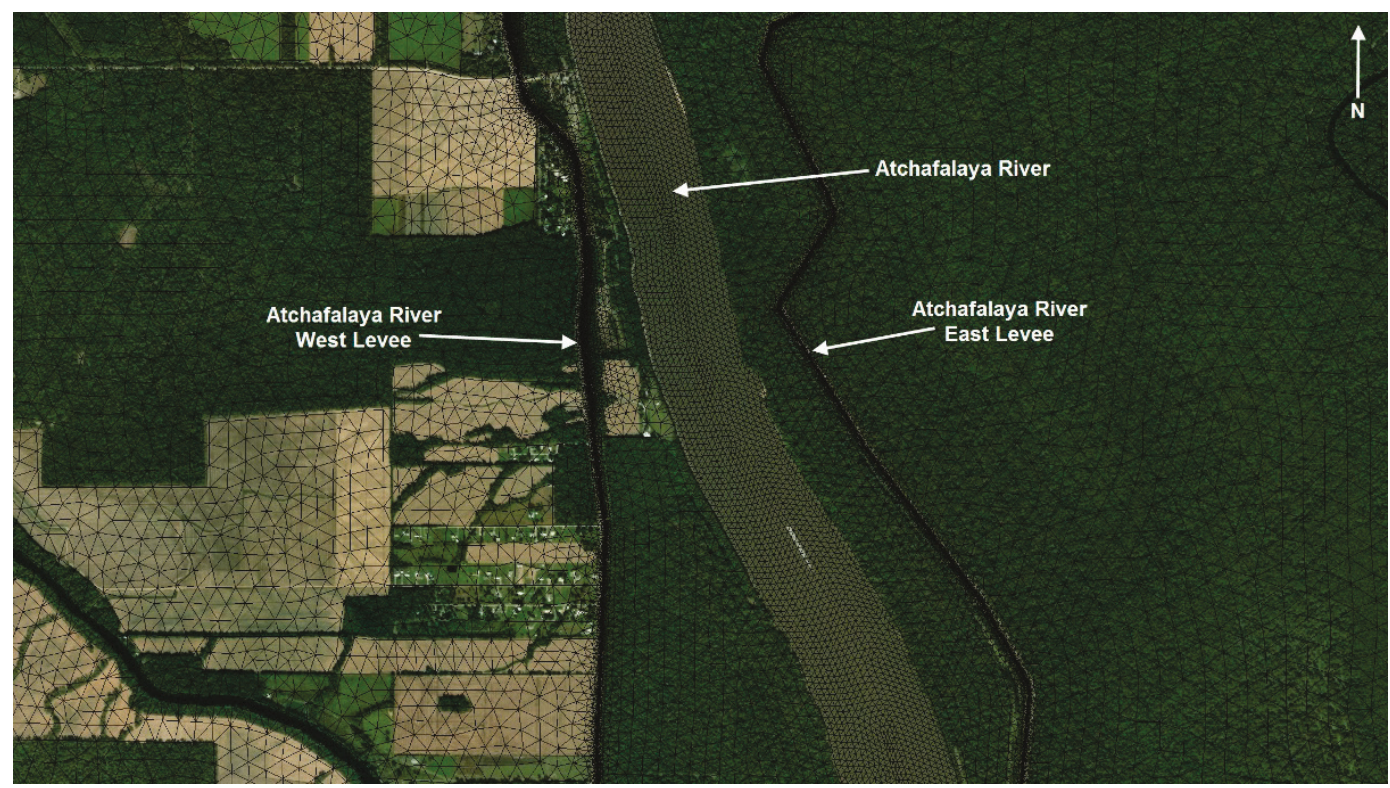

\subsection{U.S. Geological Survey (USGS) gage data and boundary condition data}

Similar to Phase 1 (Bell et al. 2017), this model was validated/calibrated by comparing the calculated water surface elevations to the measured data during the 2011 flood event. USGS pressure transducer gages were deployed throughout the basin just prior to and during the 2011 opening of the MCS and were used to assess how the model performed. Each gage was surveyed to NAVD88 Geoid 09. The gages were Hobo water level loggers $(\mathrm{o}-30 \mathrm{ft})$ corrected for air pressure via additional pressure transducers that were set out of water in the surrounding area. The location of the water level loggers can be seen in Figure 6. The "K" sensors were deployed in water. The " $\mathrm{B}$ " sensors were deployed on dry ground and later became inundated. The "CO" sensors were deployed in the water. The "AO" sensors are the same ones used in the Phase 1 study. The order the gages were placed in the figures/tables of the gages is not specific in any way. 
Figure 6. USGS gage locations.

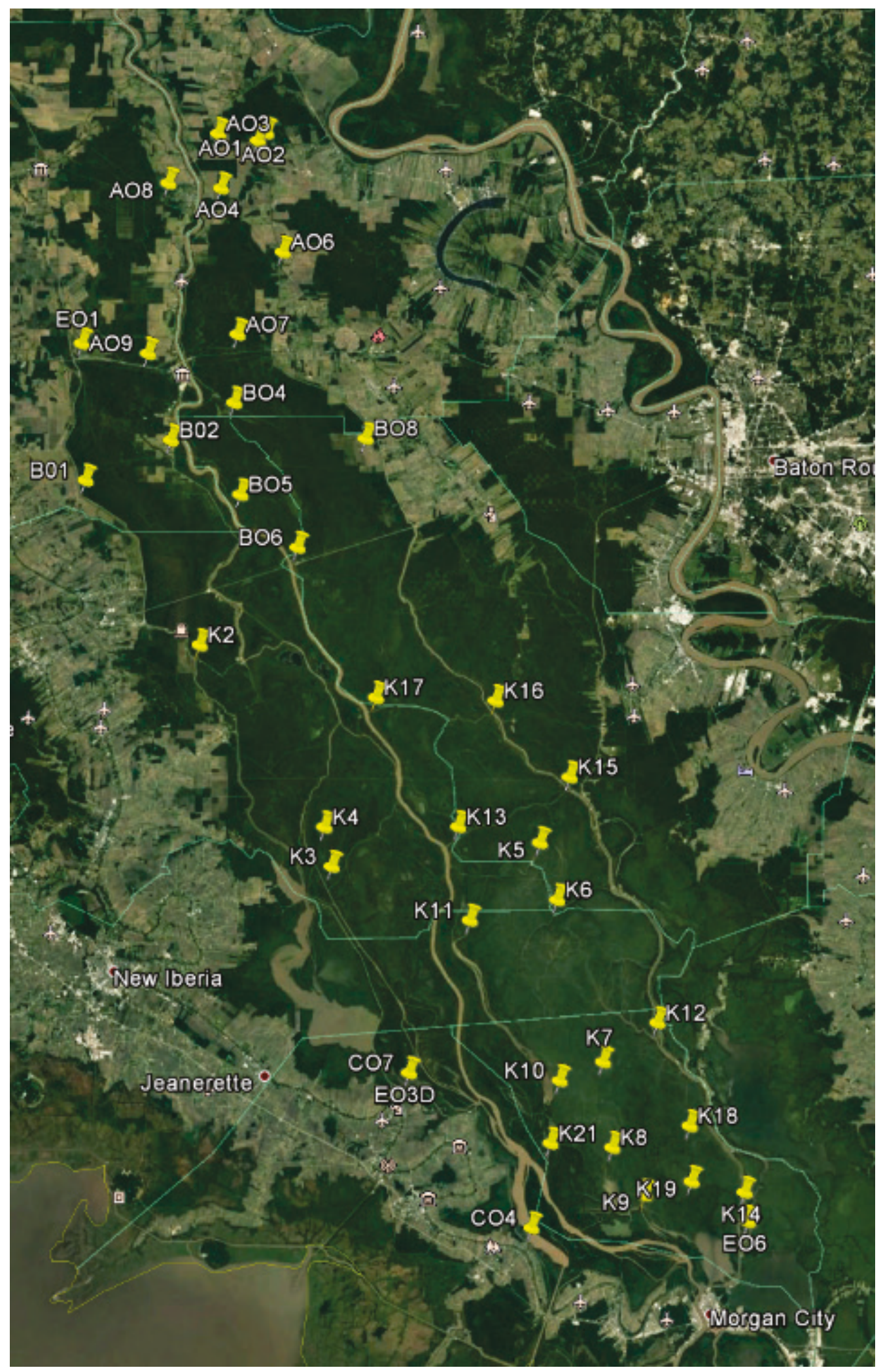


For the inflow boundary conditions, the values provided in Table 10 "Revised discharge for 2011 flood based on physical model discharge rating" from Maynord's TR-14-1 were used for the flow through the MCS (Maynord 2014). The peak flow through the MCS for the 2011 flood was approximately $170,000 \mathrm{cfs}$. The flow through the Atchafalaya River at the time of peak MCS discharge was 664,000 cfs (maximum flow through the Atchafalaya River throughout the entire simulation was 697,000 cfs). Inflow values for the Atchafalaya River were obtained from the USGS gage located at Simmesport, LA. The tailwater boundary conditions at Calumet, LA, and Morgan City, LA, used USGS gages that collected data through the 2011 flood event. The model simulation begins on 14 May 2011 at 1600 (opening of the MCS) and runs to 16 June 2011 at 0800. 


\section{Model Calibration}

Four stages of model adjustments were made during the calibration process. An initial model domain (smaller than previously documented) was developed. Bathymetric adjustments were then made to correct for incorrect or uncertain bathymetry. Mesh convergence tests were performed, adjusting mesh resolution in several areas. Finally, the model downstream boundary was moved to the Gulf of Mexico to utilize known tidal elevations for the model boundary condition. These steps are detailed in the following sections.

\subsection{Initial model results}

Due to uncertainties about the needed model extents, the initial model for this Phase 2 study defined the southern boundary of the model at Morgan City and Wax Lake outlet. There were gages in both of these outlets for measured flow and stage data. The domain of this initial model can be seen in Figure A-1 of Appendix A. The model contained 1,424,134 nodes and 2,838,135 elements that covered 837,532 acres $\left(1,309 \mathrm{mi}^{2}\right)$. This model was simulated with the parameters mentioned previously (for the 2011 flood event). However, bed roughness parameters were not necessarily set to the "current best value" in this simulation.

The initial starting conditions for this modeling effort were determined by running a spin-up version of the model using the flow and tailwater data from the Atchafalaya River for a little over 2 months ( $~ 74$ days) leading up to the opening of the MCS (14 May 2011 at 16:00:00). As in Phase 1, the measured gage data in the Morganza Floodway north of Highway 190 (AO1 - $\mathrm{AO} 7$, excluding a non-existent $\mathrm{AO}_{5}$ ) were plotted against the numerical model results for calculated water surface elevation (Figure A-2 - Figure A-7). Some of these plots display the modeled data being off from the measured data by several feet. These results are for the initial modeling effort and are here to serve as a benchmark for the starting position of the project. Furthermore, multiple gages with measured data from the 2011 flood event located in the Morganza Floodway south of Highway 190 as well as in the Atchafalaya Basin were plotted with the model results (Figure A-8 - Figure A-27).

At the downstream boundary of this initial model, the stages and flows can be seen in Figure A-28 - Figure A-31 for Wax Lake outlet and Morgan City 
outlet (respectively). Note that the flow values were computed using Surface-water Modeling System (SMS ) that used the model computed depth and velocity to produce a flux value. These SMS computations are very close approximations but not necessarily the exact values.

\subsection{Bathymetric adjustments}

There were multiple locations where the lidar data that were collected provided the water surface elevation instead of the bottom bed elevation. To correct this error and provide for proper hydraulic conveyance, elevations that were in these locations where dropped by $5 \mathrm{ft}$ (denoted by the red lines in Figure 7). This value was chosen based on knowledge of the area and engineering judgment. In the south-eastern section of the Atchafalaya Basin, there is a channel that runs along the EABPL. This channel clearly operates as a navigation channel, so the elevations were dropped by $15 \mathrm{ft}$. The same goes for a channel that breaks away from the Atchafalaya River and passes through Butte La Rose, LA, as it continues down until it reconnects with the Atchafalaya River just north-west of Wax Lake Outlet. Figure 8 shows the locations with the red lines.

The model had the same domain as was in Figure A-1 (located in Appendix A). Note that there were also some changes from the initial model for roughness values and/or unsubmerged vegetation parameters in this simulation. After all of these changes (channel bathymetry and roughness values), a new spin-up run was conducted, as discussed in the previous section to obtain a more accurate initial condition hot start.

In Appendix B, the gage data (measured vs. modeled) can be viewed in Figure B-1 - Figure B-27 for these "Bathymetric Adjustments" simulations. The water surface elevation and flows at Wax Lake outlet and Morgan City outlet, respectively, can be viewed in Figure B-28 - Figure B31. Note that these simulations (similar to the "Initial Model Results" simulations) do not extend their boundaries to the Gulf of Mexico. 
Figure 7. Locations where elevation values were lowered by $5 \mathrm{ft}$.

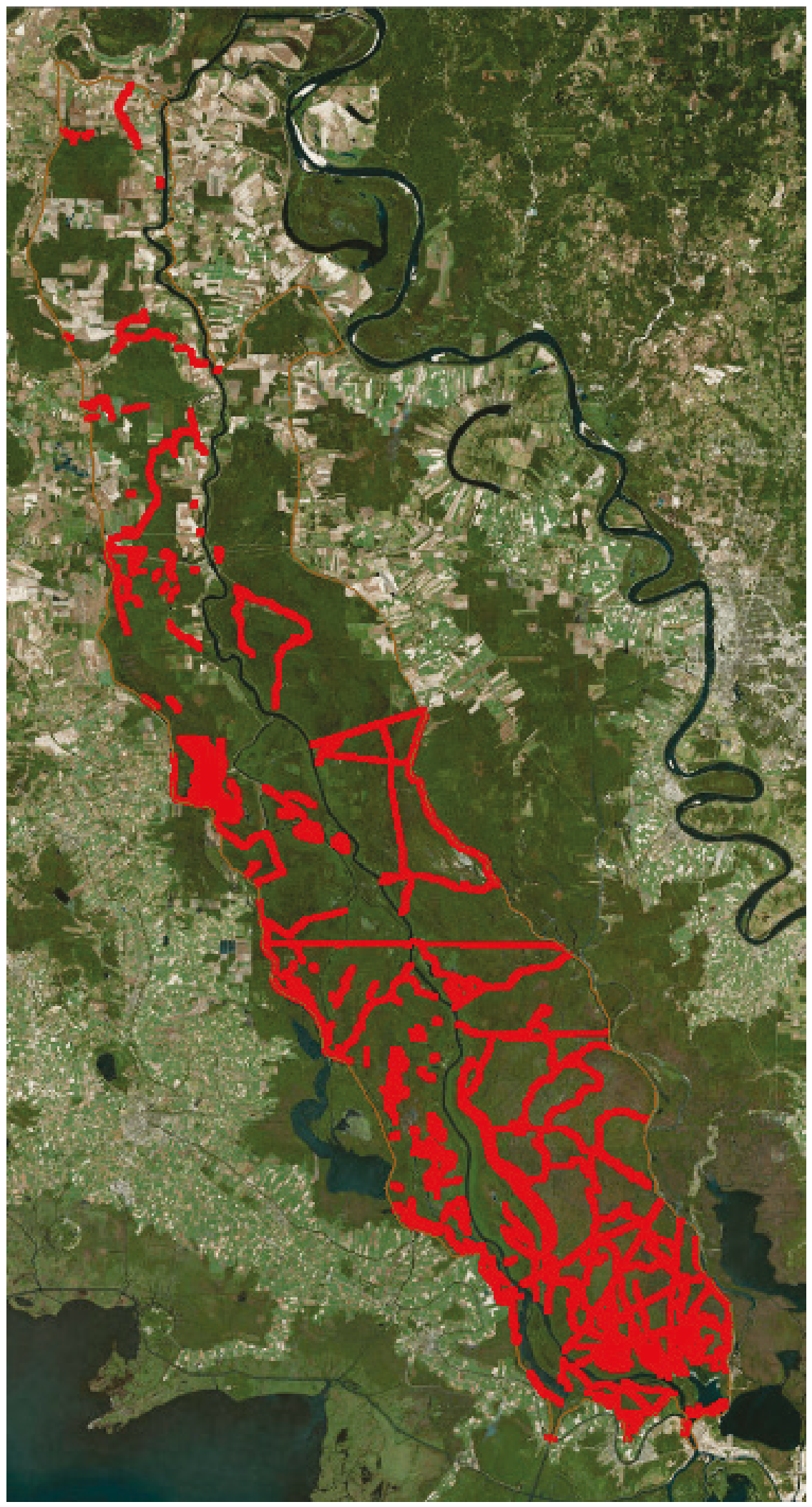


Figure 8. Locations where elevation values were lowered by $15 \mathrm{ft}$.

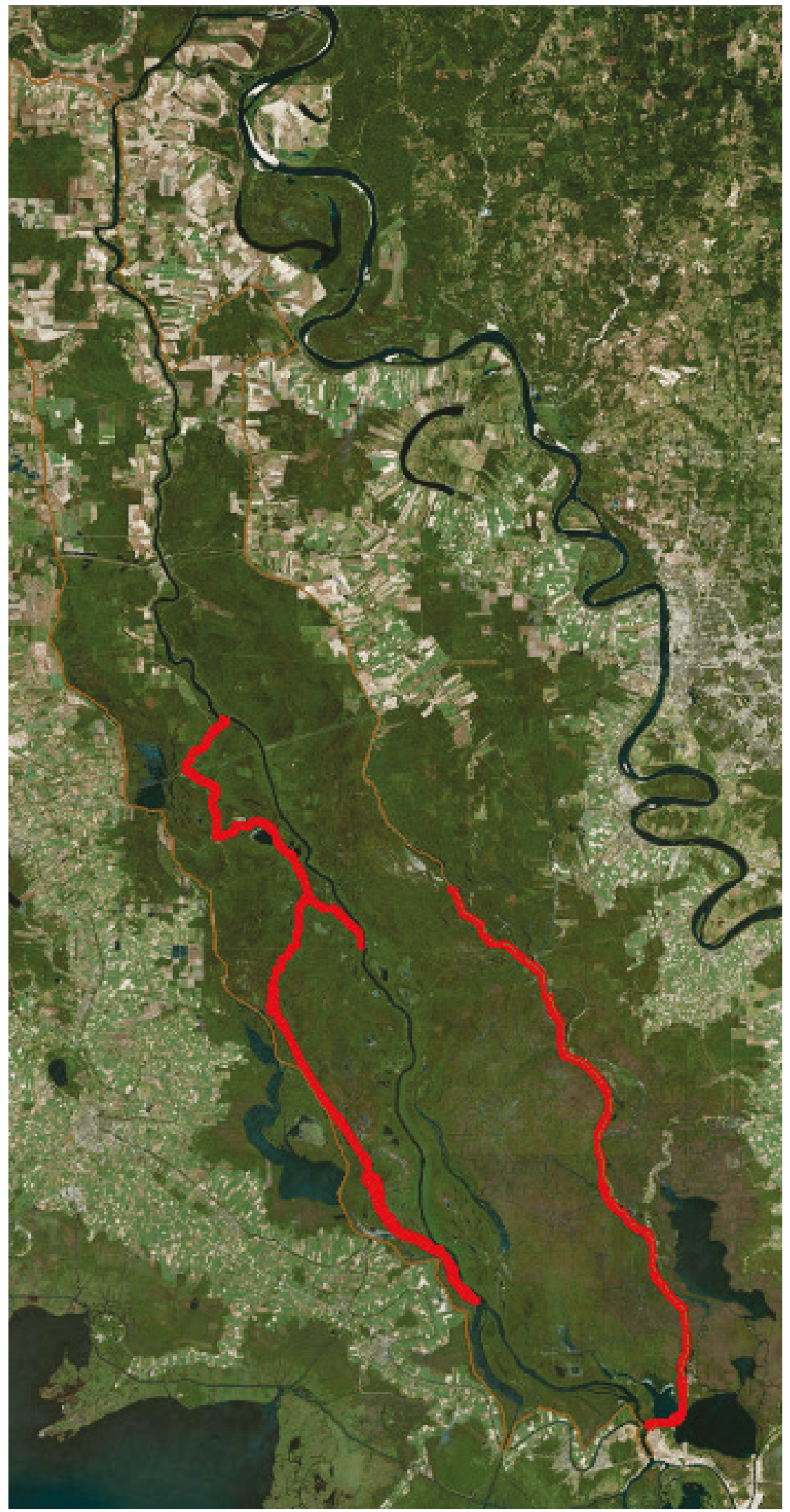




\subsection{Mesh convergence sensitivity test}

Although the modeled results in Appendix B are within a decent range of agreement with the measured data (in most locations the differences are within $1 \mathrm{ft}$ ), it was decided that a sensitivity analysis would be conducted on the mesh resolution. This test would determine if a more refined mesh $(5,686,402$ nodes and 2,838,135 elements; an increase of $\sim 300 \%)$ would provide better model versus measured comparisons than the previous mesh resolution. This change was applied to the entire domain of the model (the downstream boundaries are still Wax Lake and Morgan City outlets). The results showed that the refined mesh produced overall better modeled results (more agreeable with the measured data). These results can be found in Appendix C. In general, the results from the mesh convergence sensitivity simulation produced more accurate water depths from the 2011 event than the model results shown in Appendix B (Bathymetric Adjustments).

\subsection{Model downstream boundary change and adaption adjustment sensitivity test}

The last stage of calibration was completed by extending the downstream model boundary to the Gulf of Mexico. This was accomplished by merging the model mentioned in the Mesh Convergence Sensitivity Test with a previously completed coastal application 2D AdH model study (McAlpin et al. 2013). The upstream boundary of the coastal model is located at Morgan City and Wax Lake outlets, which allowed for a relatively simple merging process of the two models. The Wax Lake outlet and Morgan City downstream boundaries were known for the 2011 event, but for higher flows there were no data available. Since the boundary at the ocean is known for all river flow conditions, it was used as the downstream boundary condition for this model.

Along with the domain being extended, spatial mesh adaption parameters were also calibrated. These parameters included the error tolerance (used as a limiting value that will trigger mesh adaption at areas in the model that exceed the set value) at each location in the model as well as the maximum levels of refinement (ERDC CHL 2017). In essence, these parameters controlled where the model refined the mesh based on the conditions present at each node. The goal was to allow the numerical code to refine the mesh to the proper refinement in order to reach a solution that was the same as the "Mesh Convergence Sensitivity Test" results. This would 
confirm that the model had adequate refinement across the domain and that the refinement levels were sufficient to provide converging solutions.

The extended domain along with the mesh adaption parameters was then used for the final calibrated model discussed in previous sections (Chapters 1-2). The final calibration results will be shown in the next chapter. 


\section{Results}

\subsection{1 flood event model calibration results}

The results presented in this section represent the extended downstream boundary model domain as well as the incorporated bathymetric adjustments discussed in previous sections. It was found that by adjusting the automatic mesh adaption parameters, the model could obtain virtually the same solution as the mesh convergence sensitivity simulation without quadrupling the model size/space, computational load, simulation time, etc. (refer to Appendix C) and thus are included in the following results. The 2011 flood event was simulated for the model, and results for water surface elevation and discharge are presented in Figure 9 - Figure 39 (the model computed values are the series named "URV"). Note the agreeable results between the values produced by the model compared to the measured values. In Figure 40, the gages have been plotted to show if the simulated water surface elevation values are within $1 \mathrm{ft}$ of the measured values (green pins) or if they are $1 \mathrm{ft}$ or more off from the measured values (red pins). This is to give an idea of the spatial variability across the domain. Note that these differences do not include the initial conditions.

Figure 9. Gage AO1 model results.

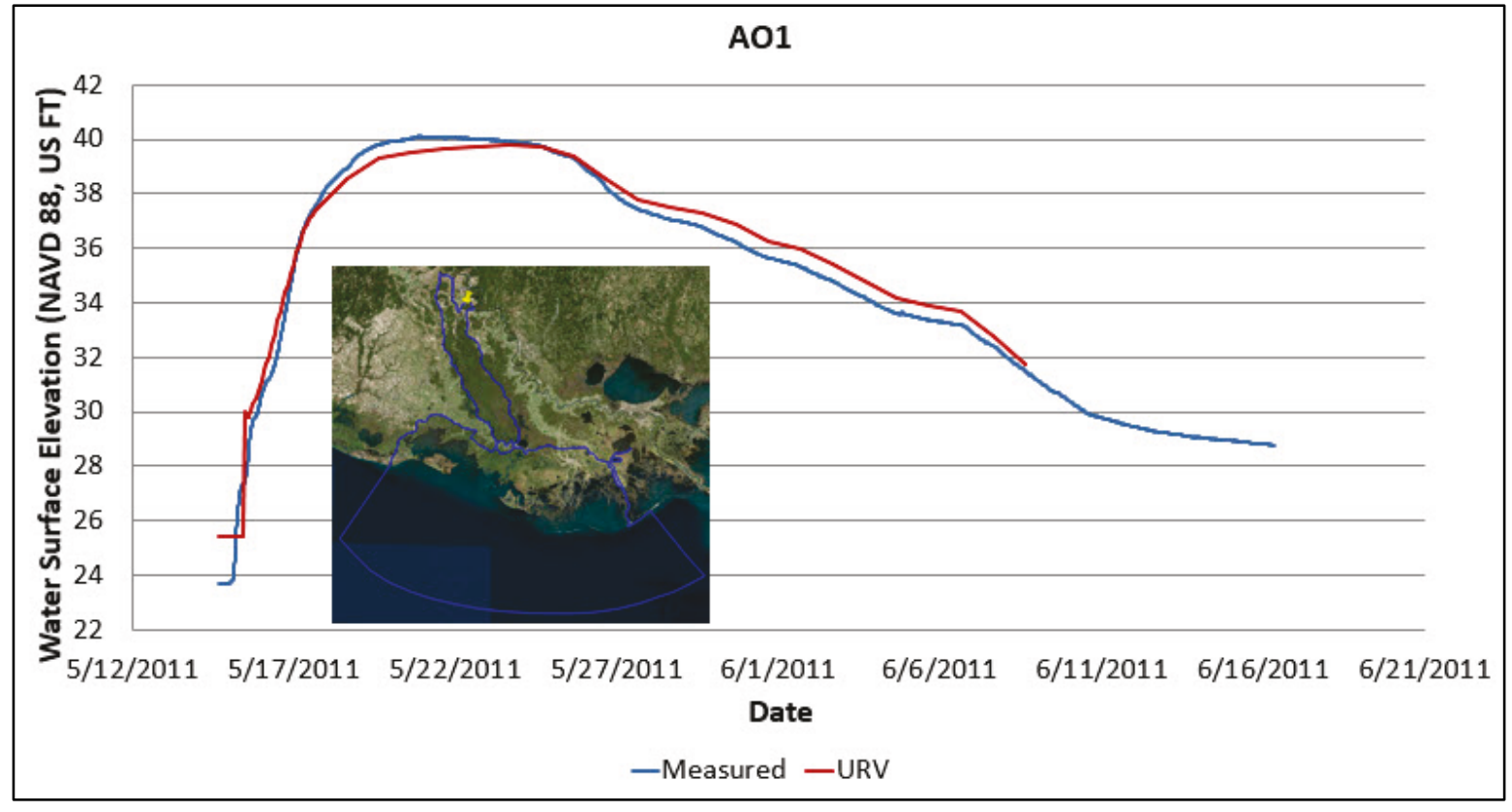


Figure 10. Gage AO2 model results.

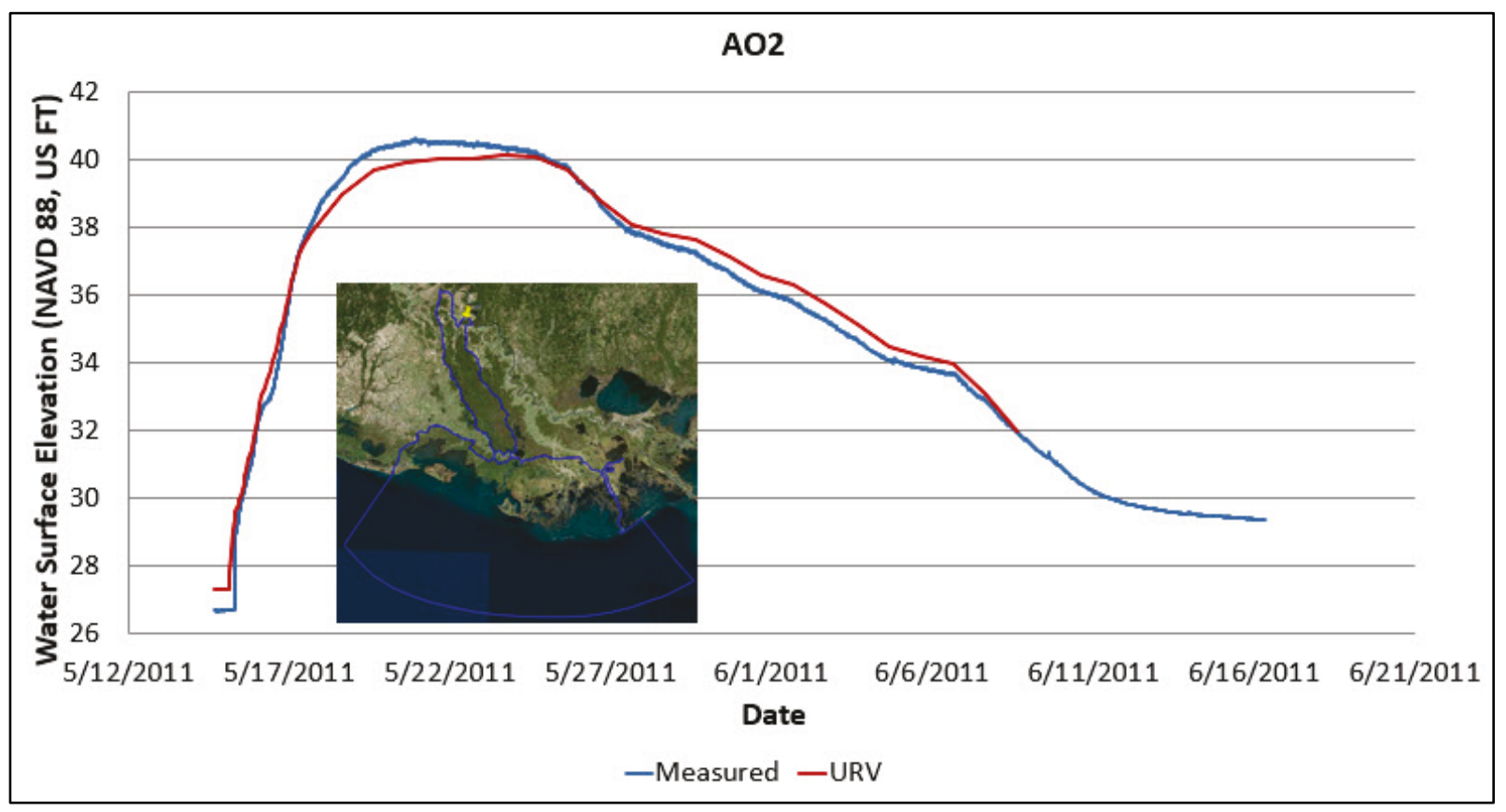

Figure 11. Gage A03 model results.

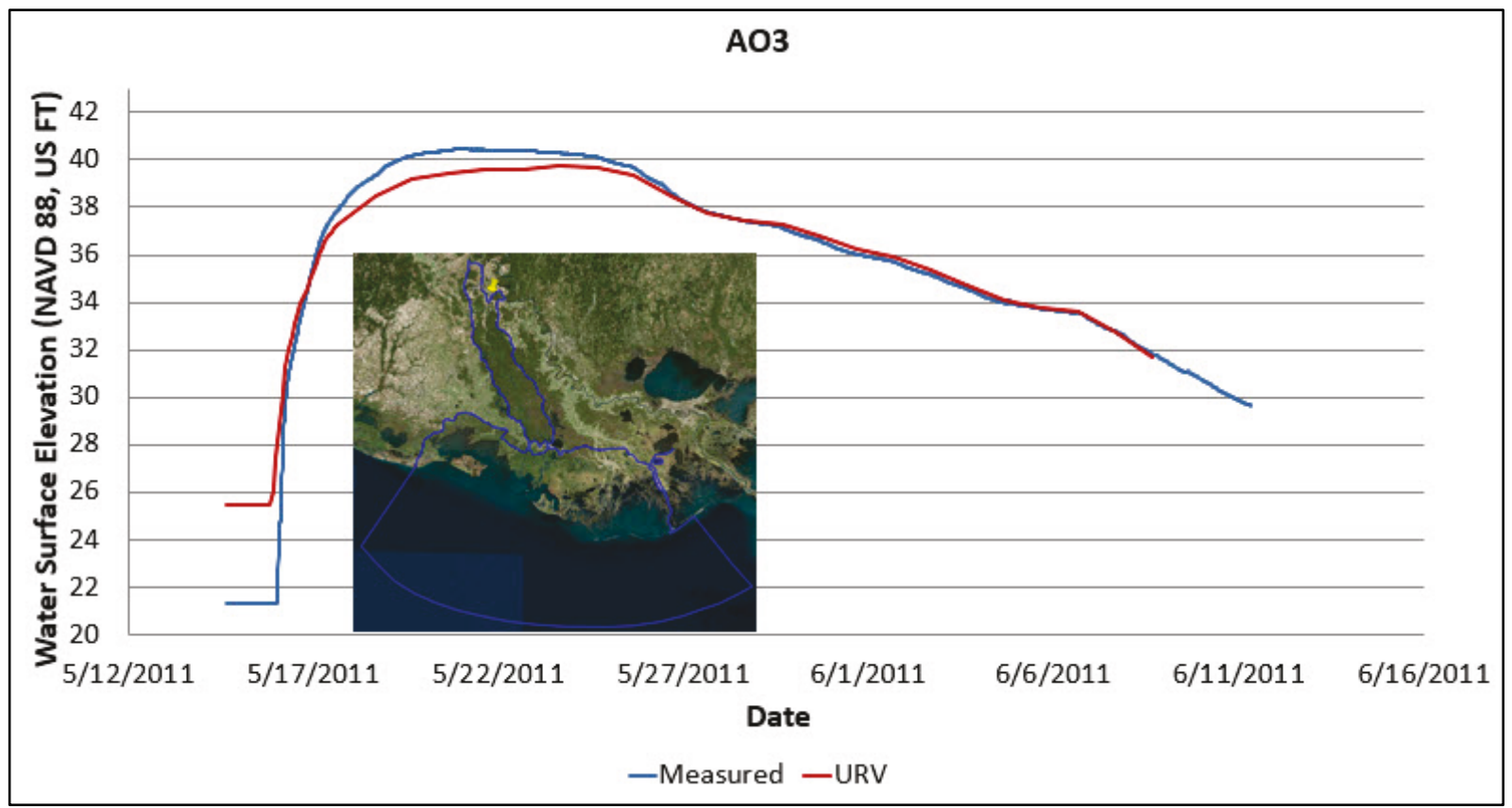


Figure 12. Gage AO4 model results.

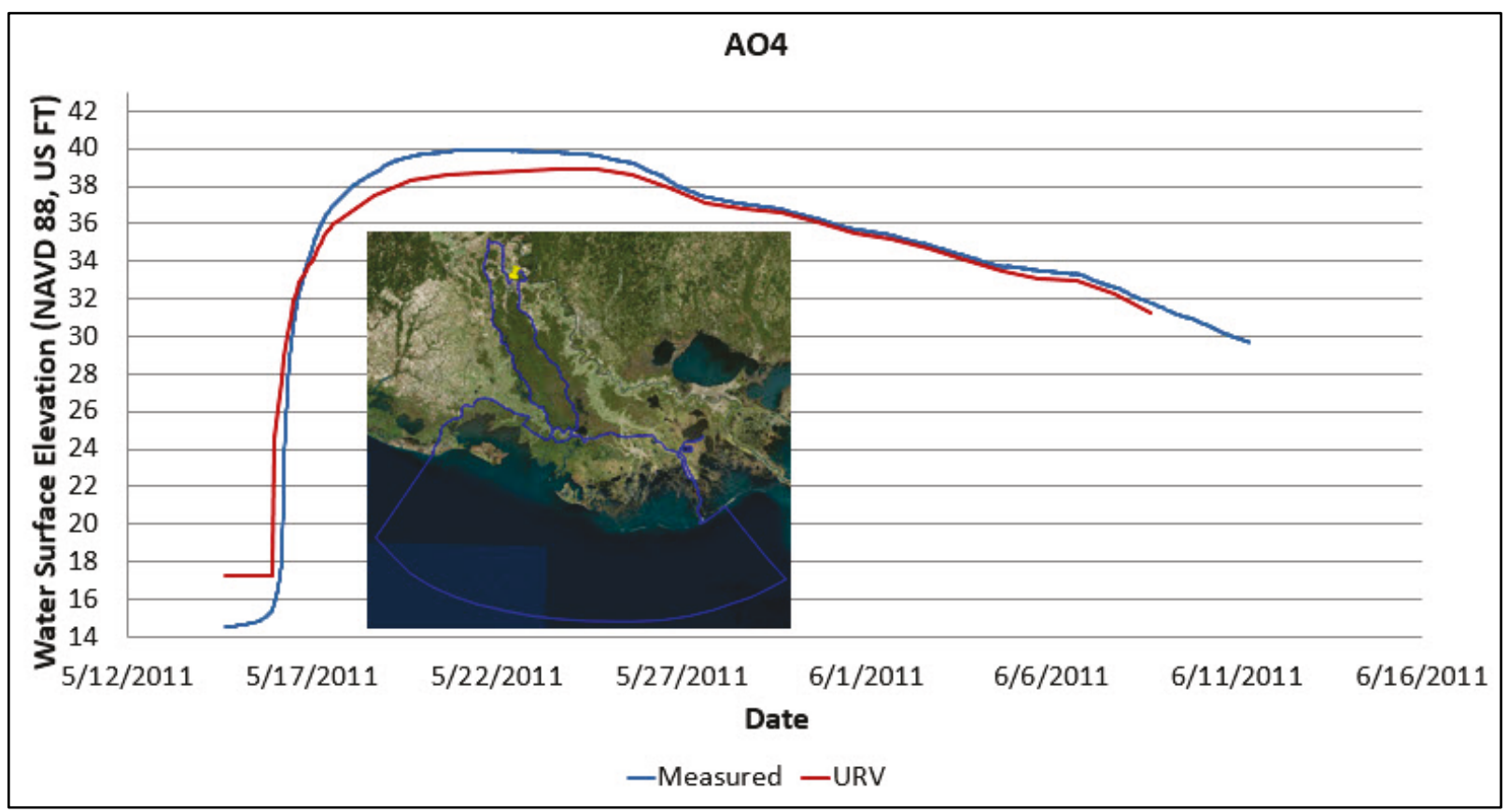

Figure 13. Gage A06 model results.

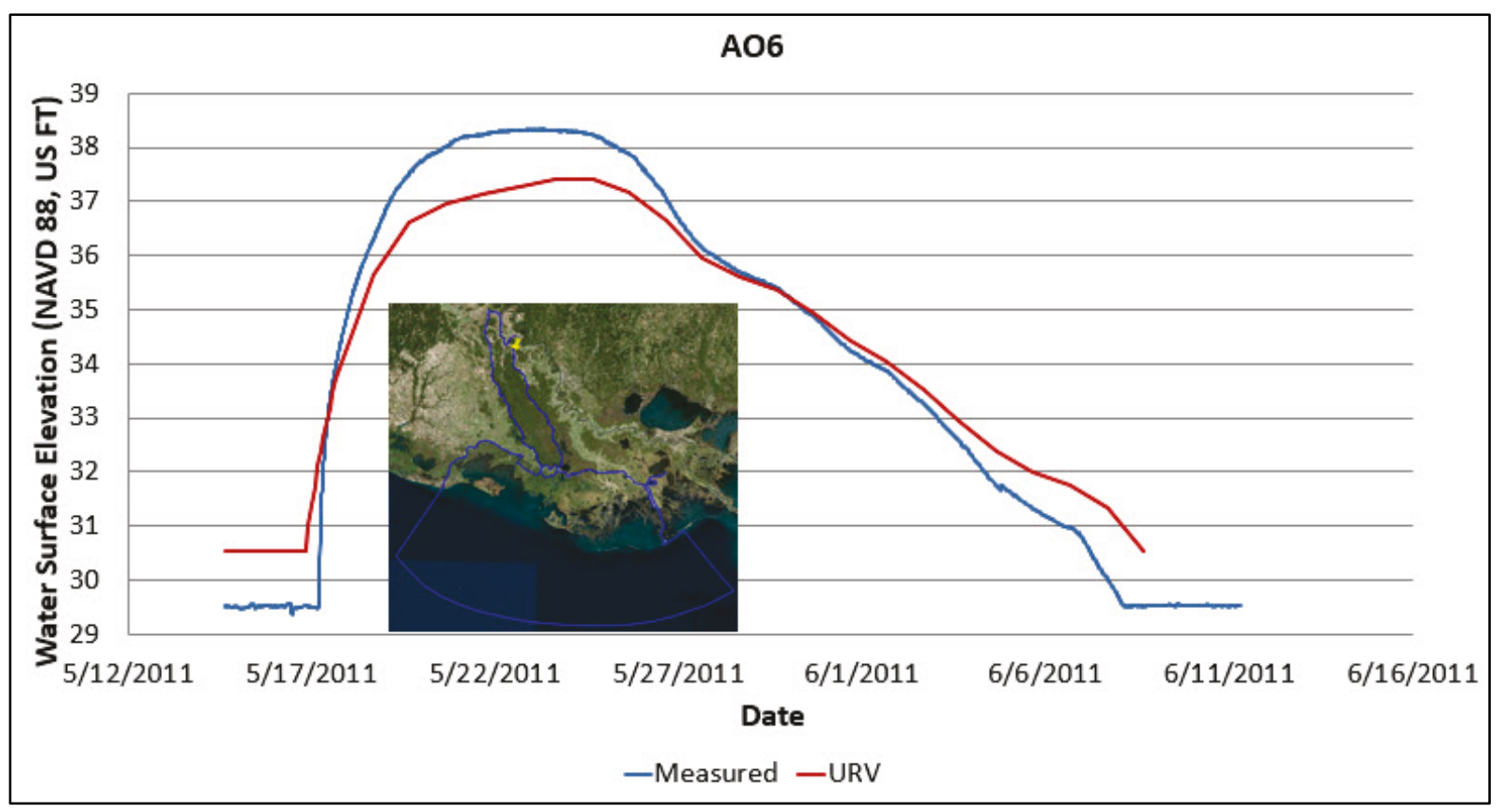


Figure 14. Gage A07 model results.

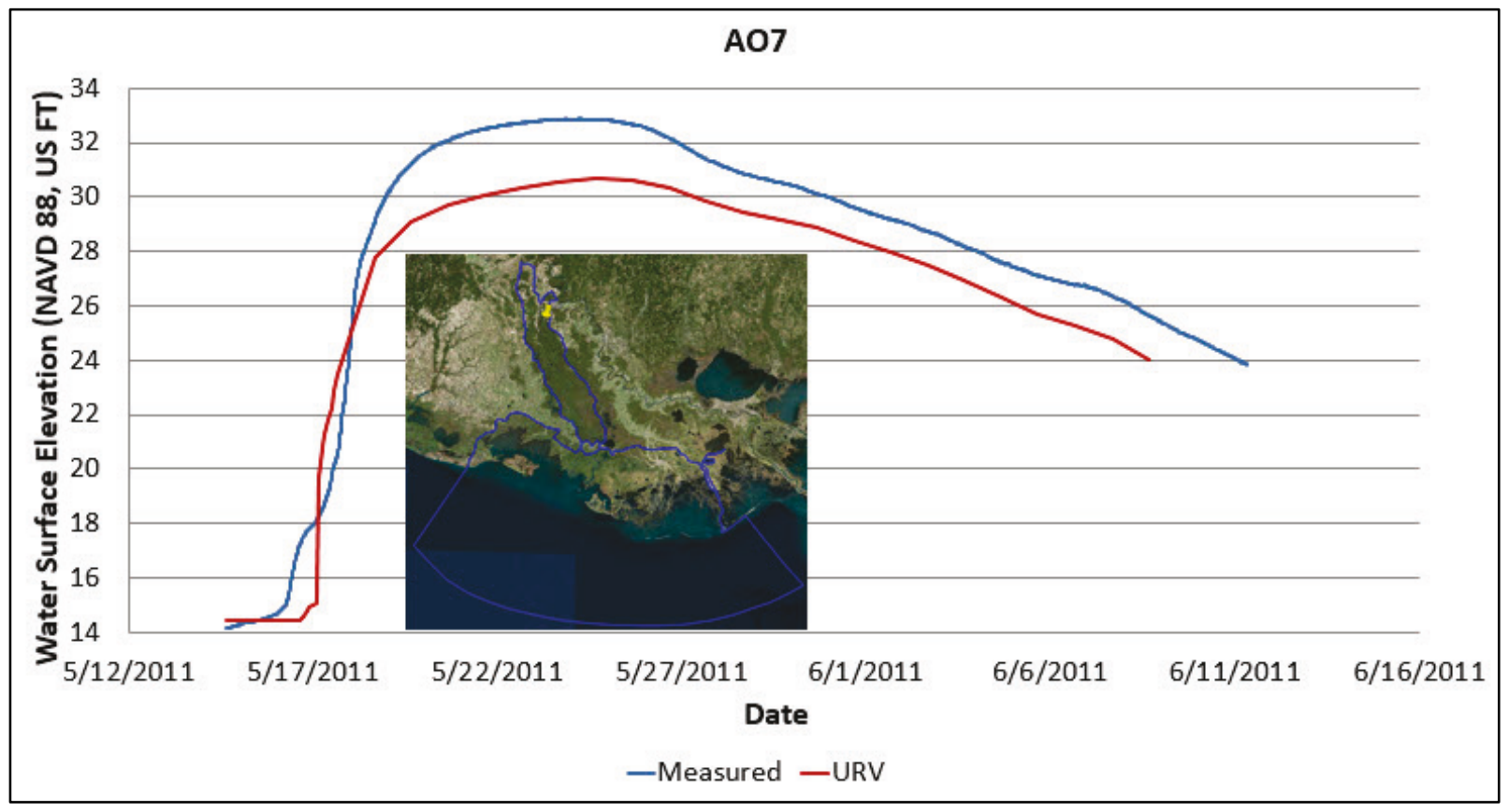

Figure 15. Gage B04 model results.

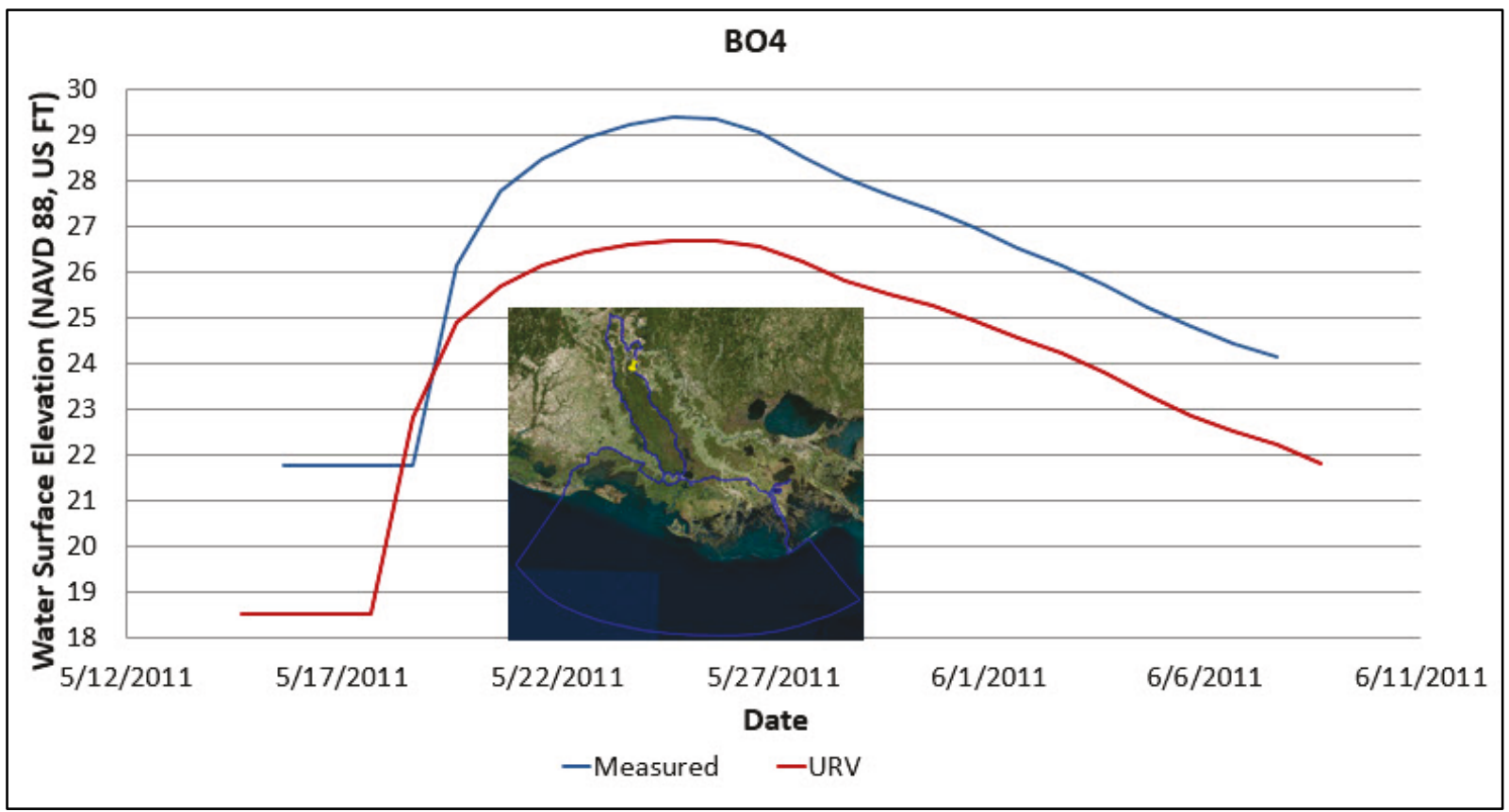


Figure 16. Gage CO4 model results.

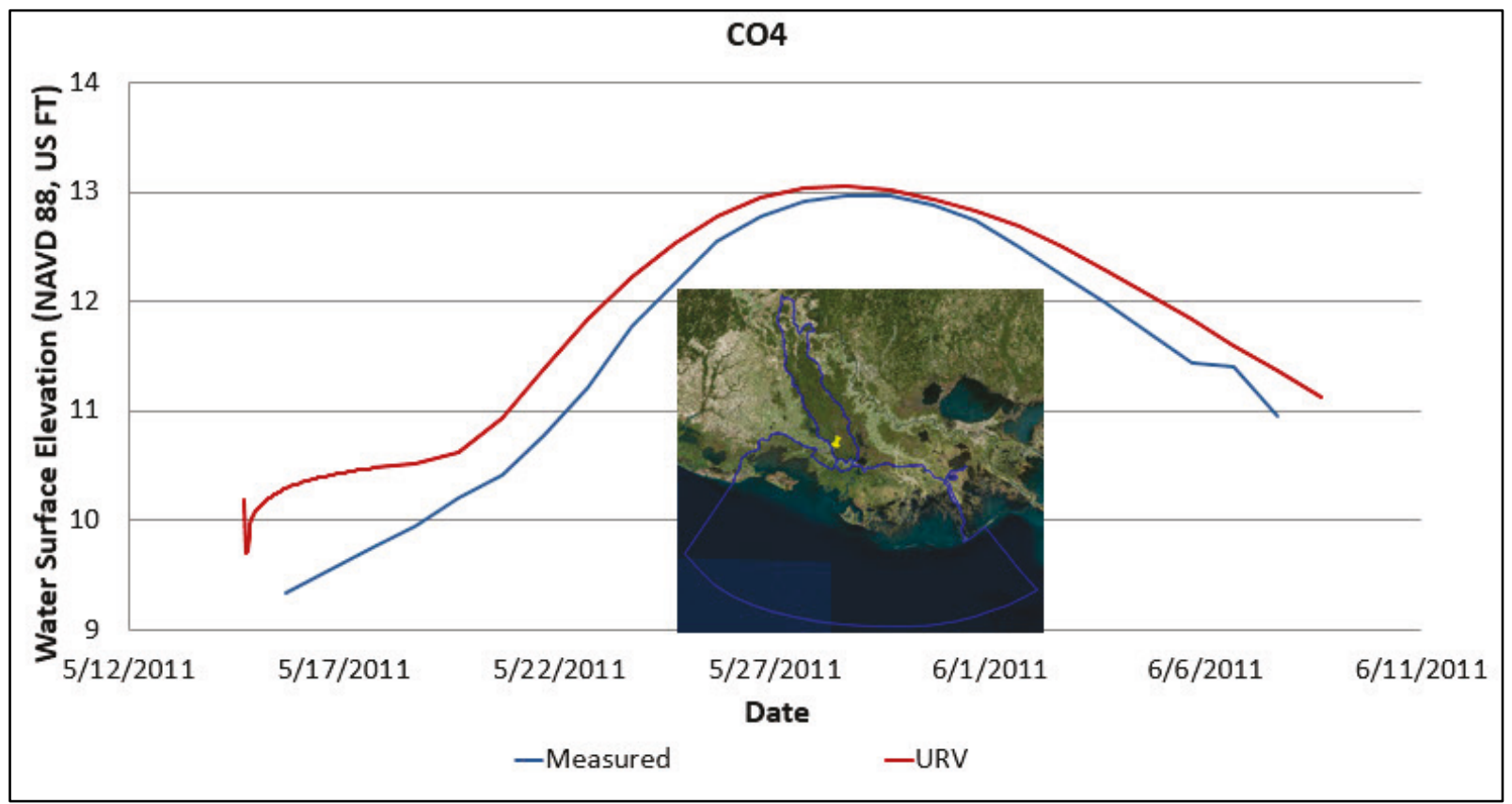

Figure 17. Gage K2 model results.

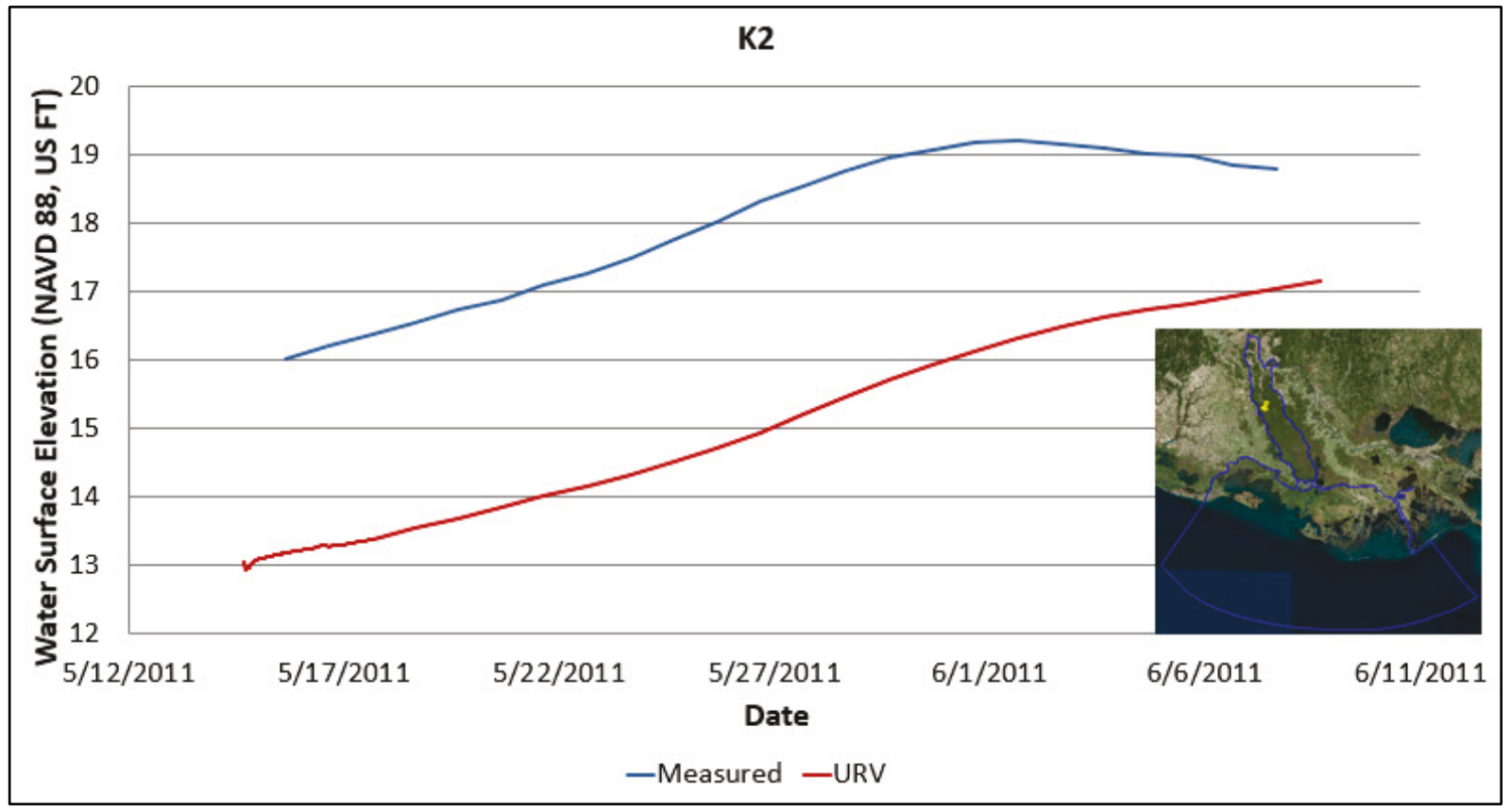


Figure 18. Gage K3 model results.

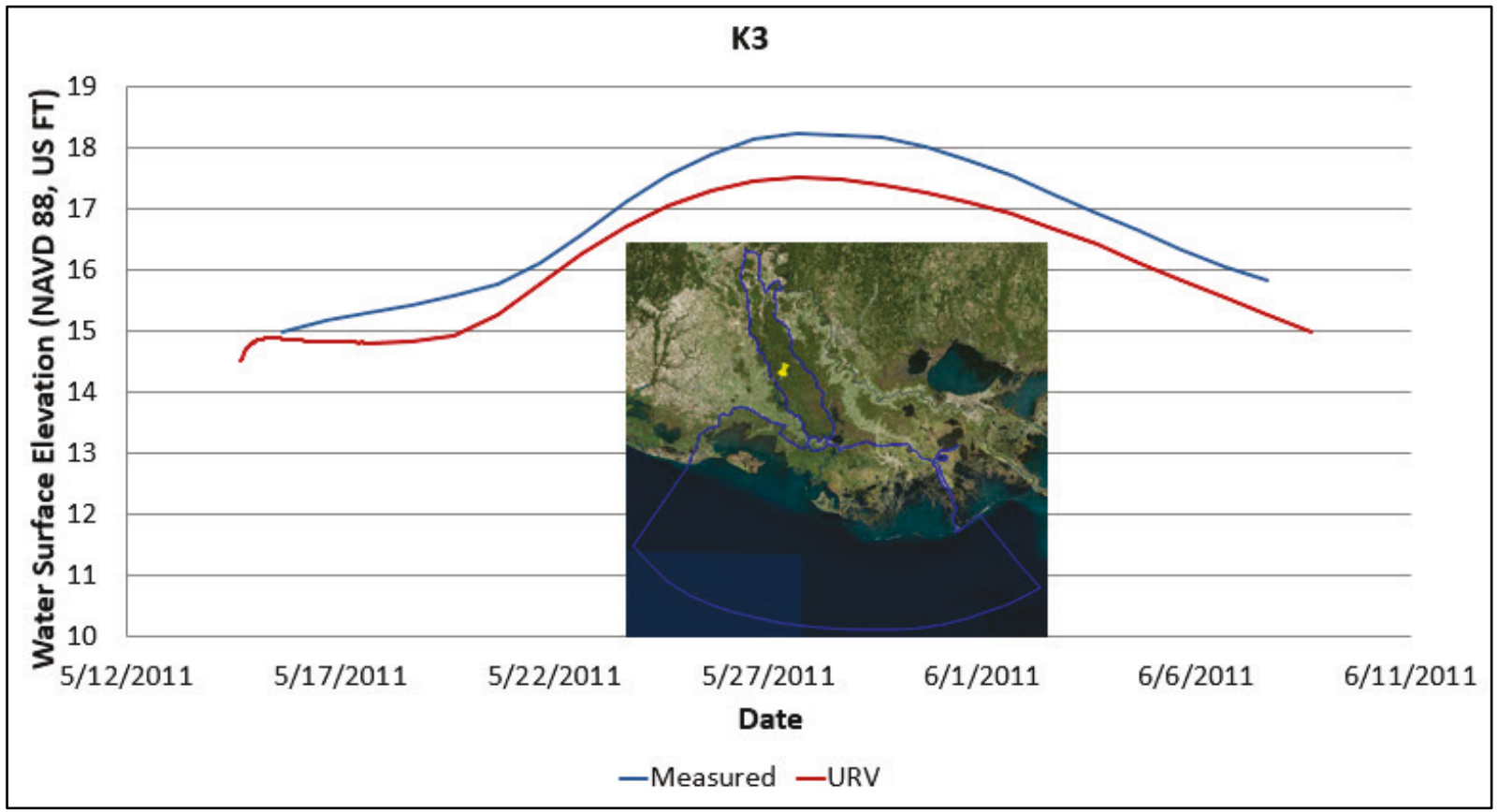

Figure 19. Gage K4 model results.

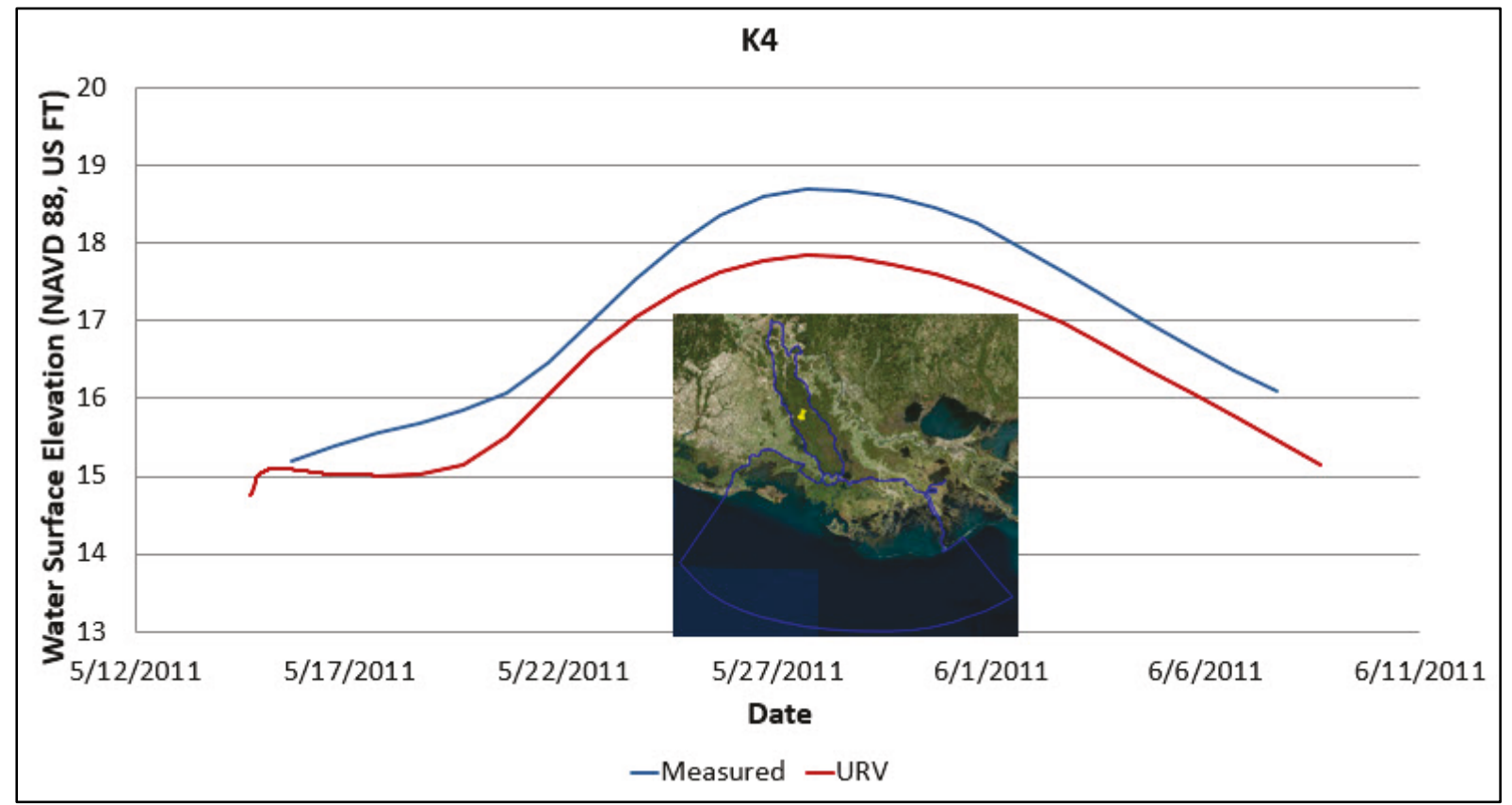


Figure 20. Gage K5 model results.

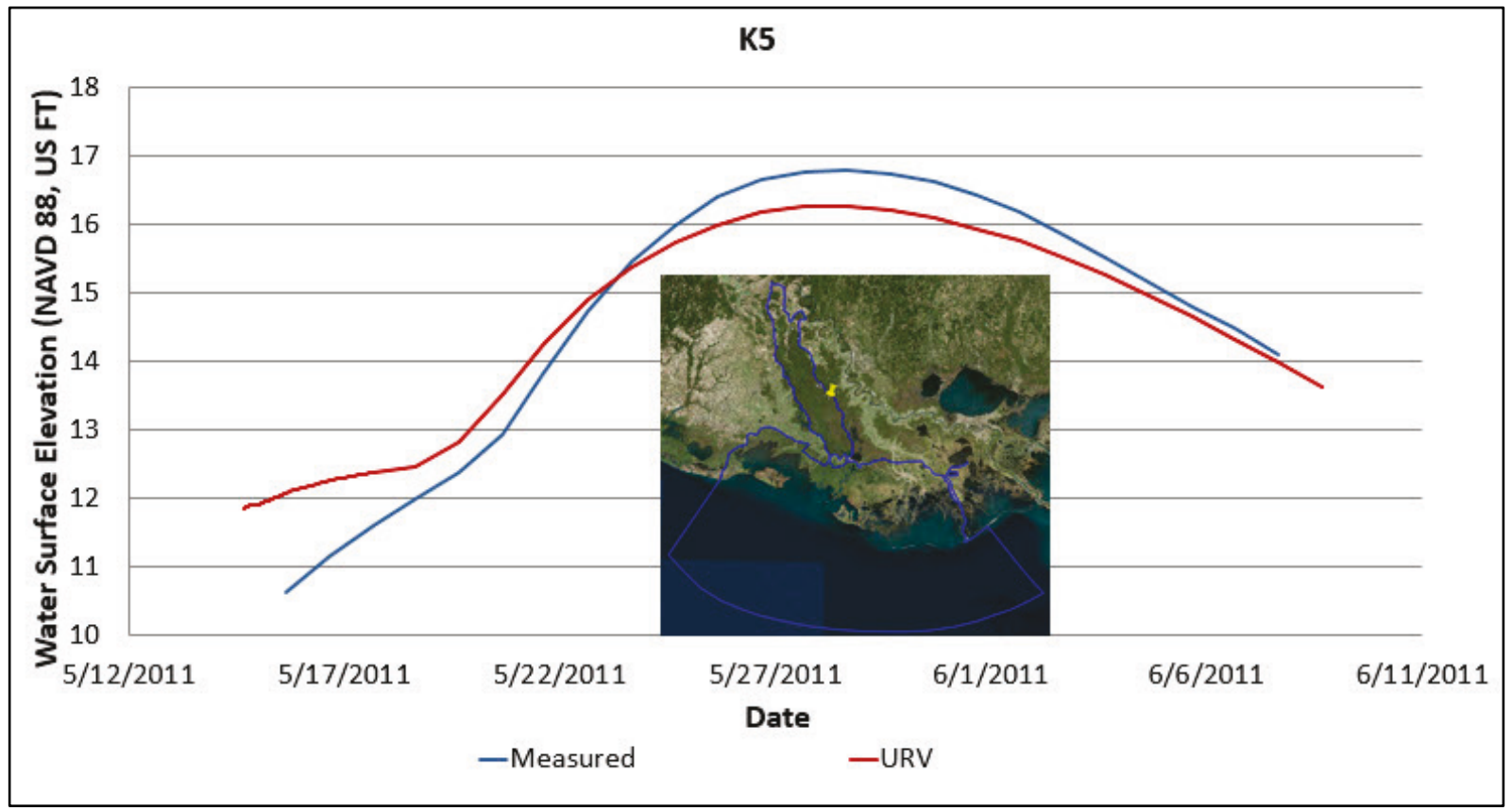

Figure 21. Gage K6 model results.

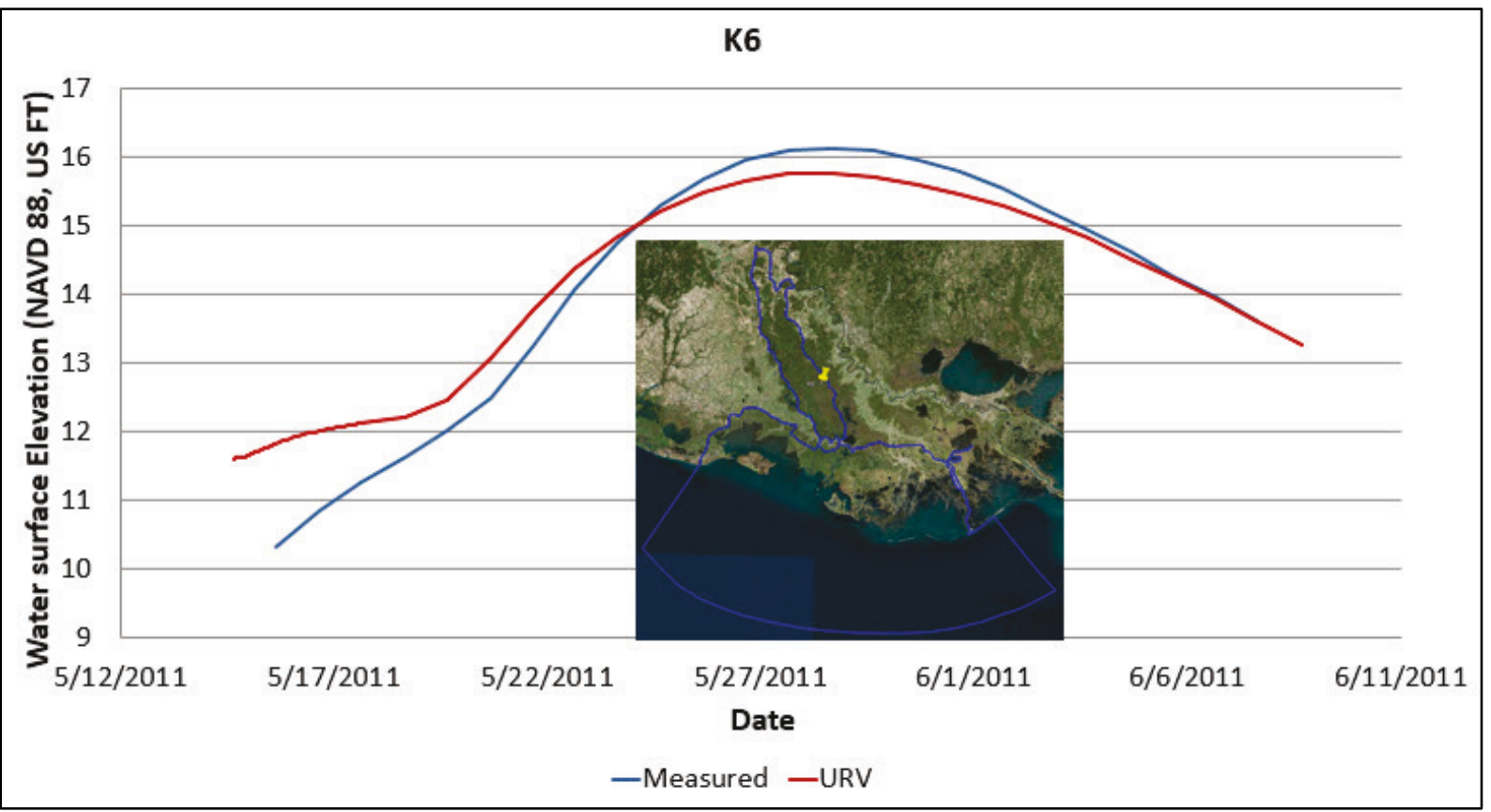


Figure 22. Gage K7 model results.

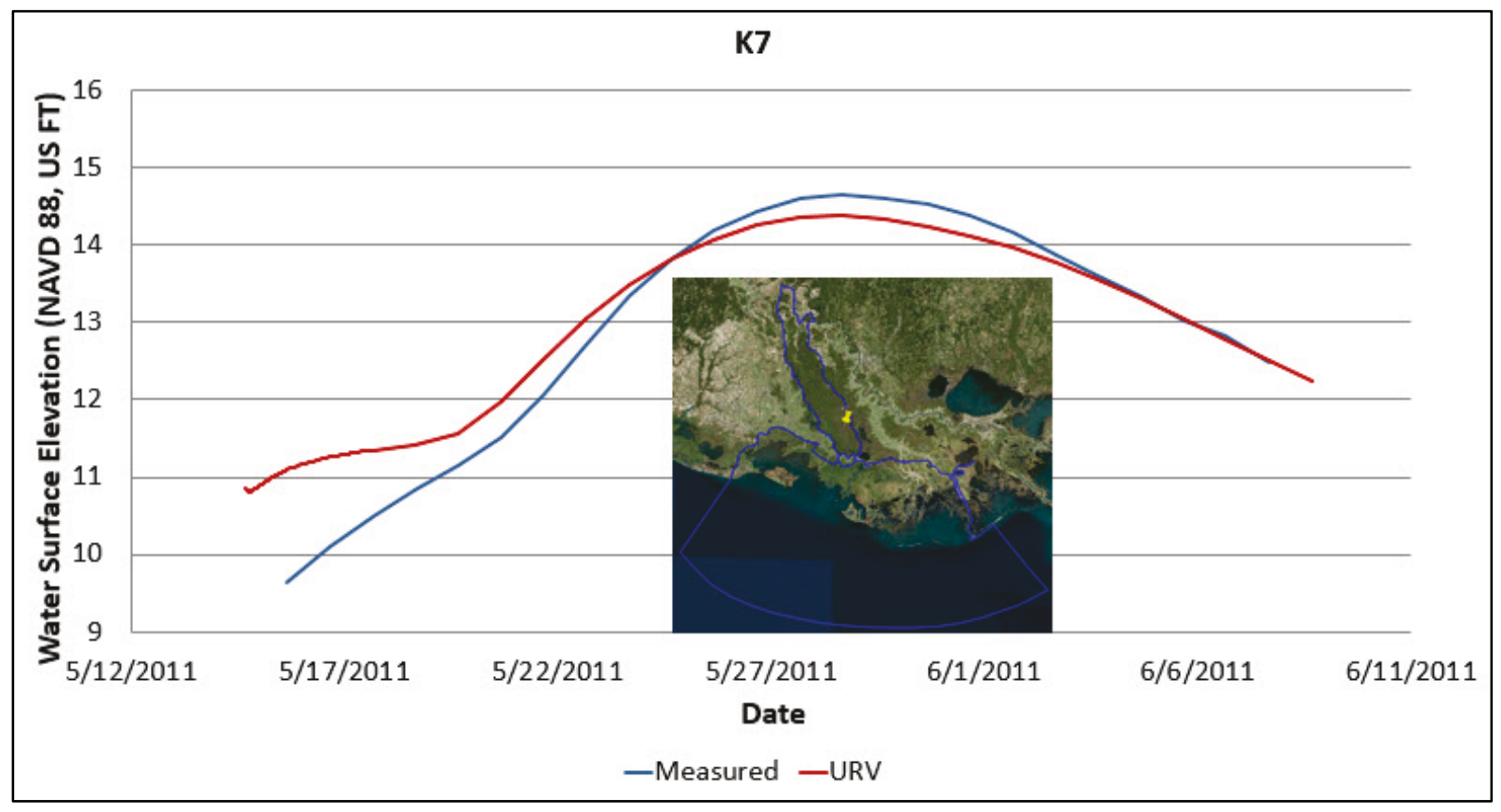

Figure 23. Gage K8 model results.

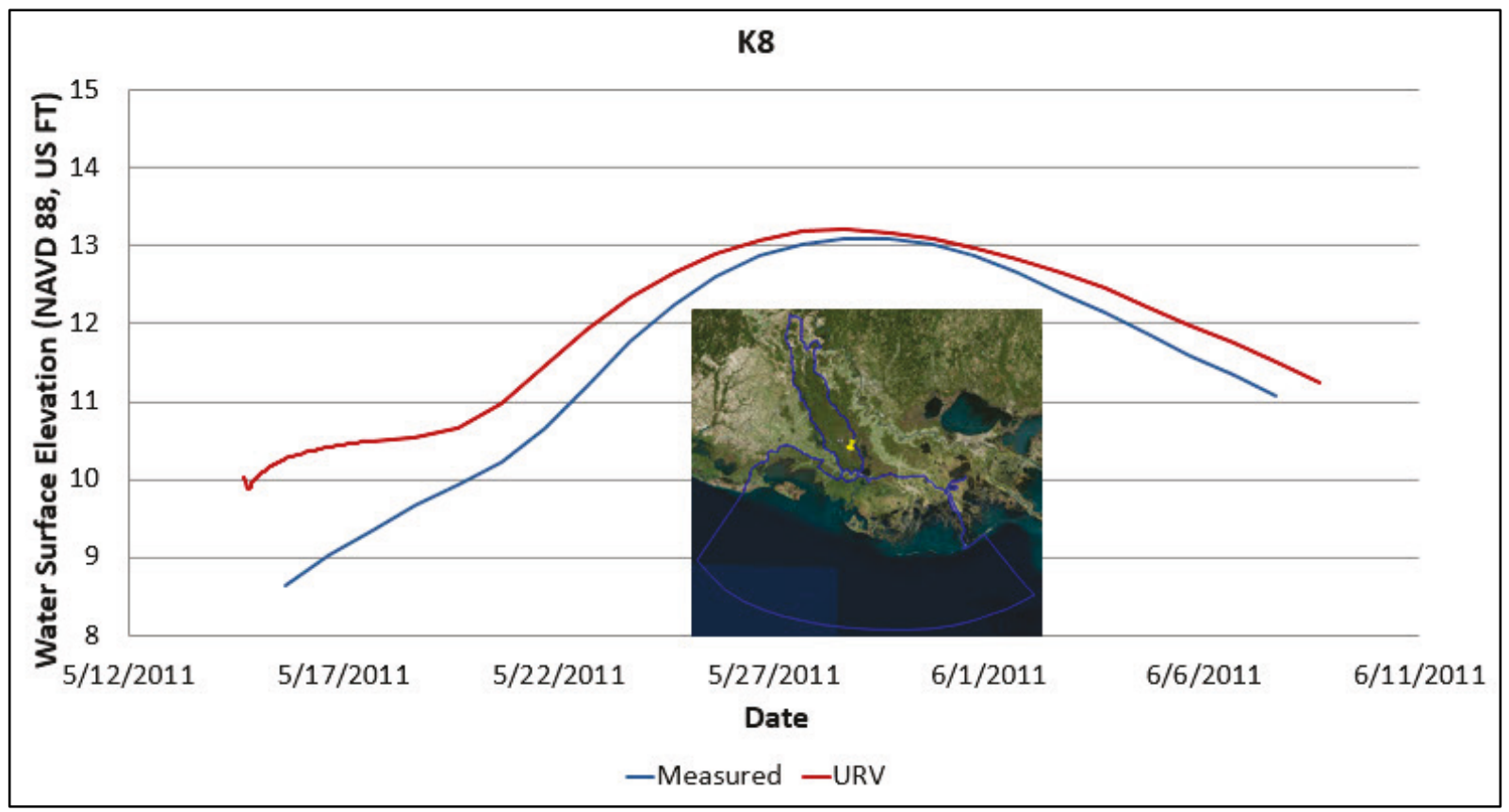


Figure 24. Gage K9 model results.

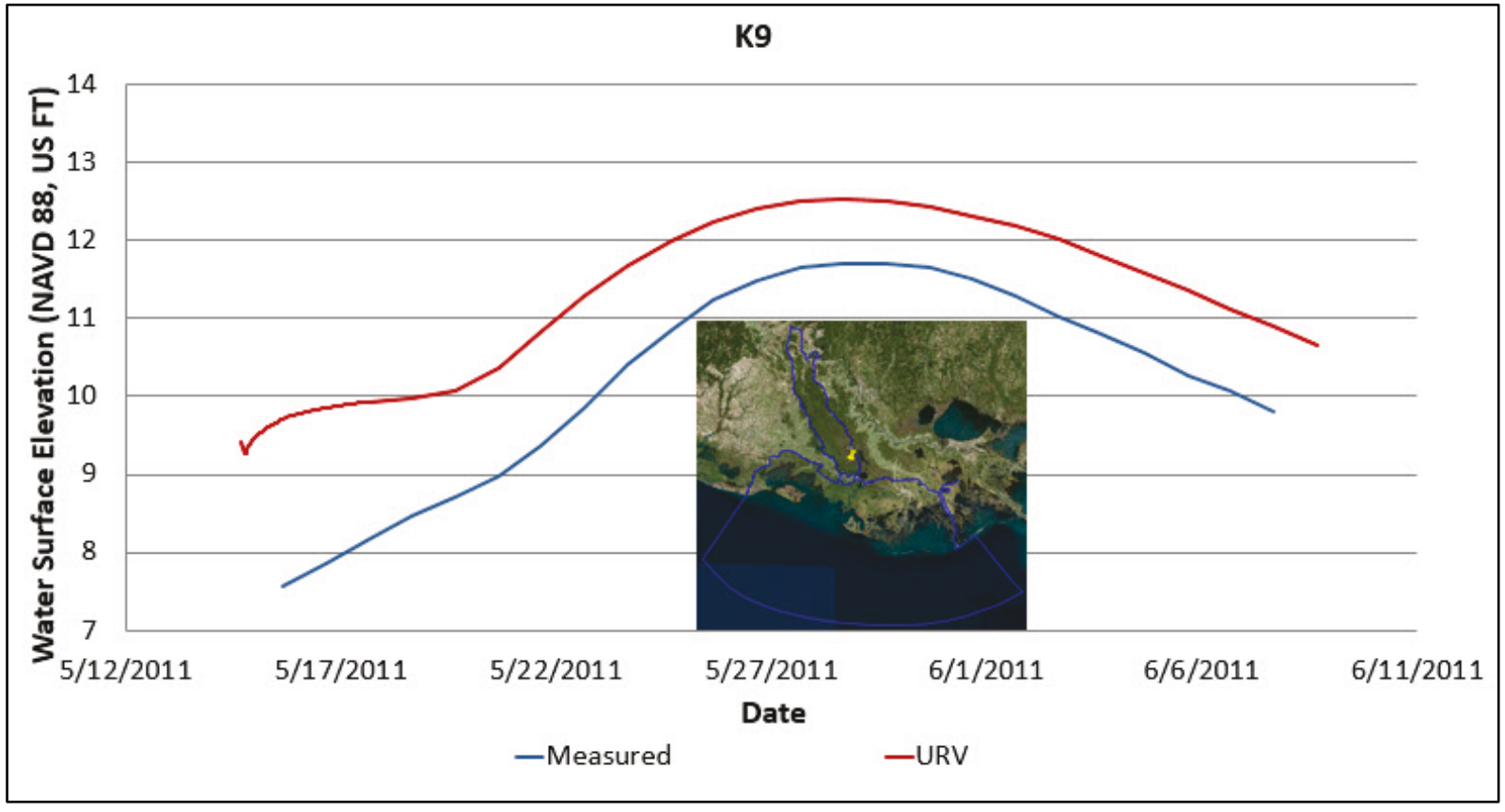

Figure 25. Gage K10 model results.

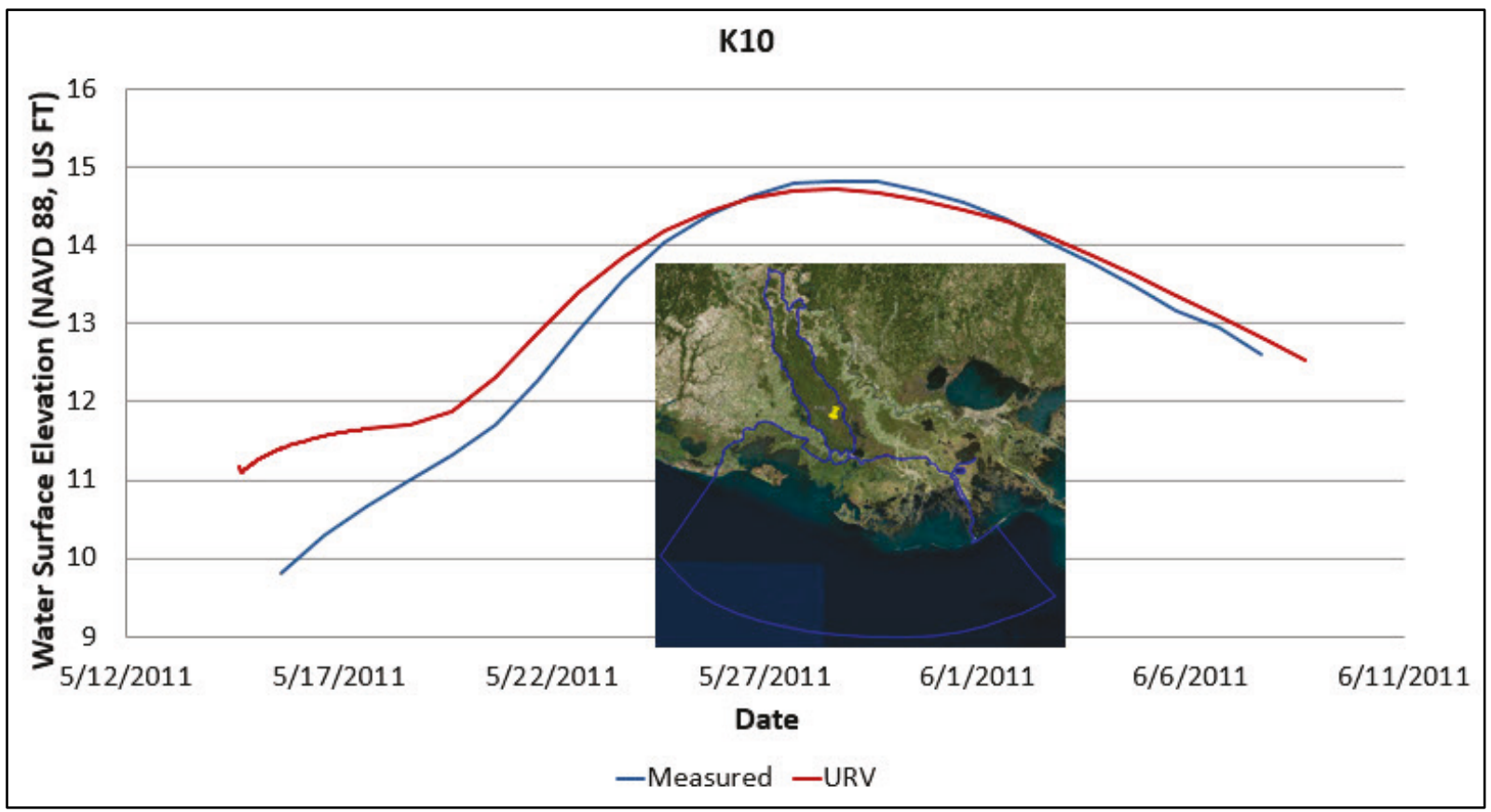


Figure 26. Gage K11 model results.

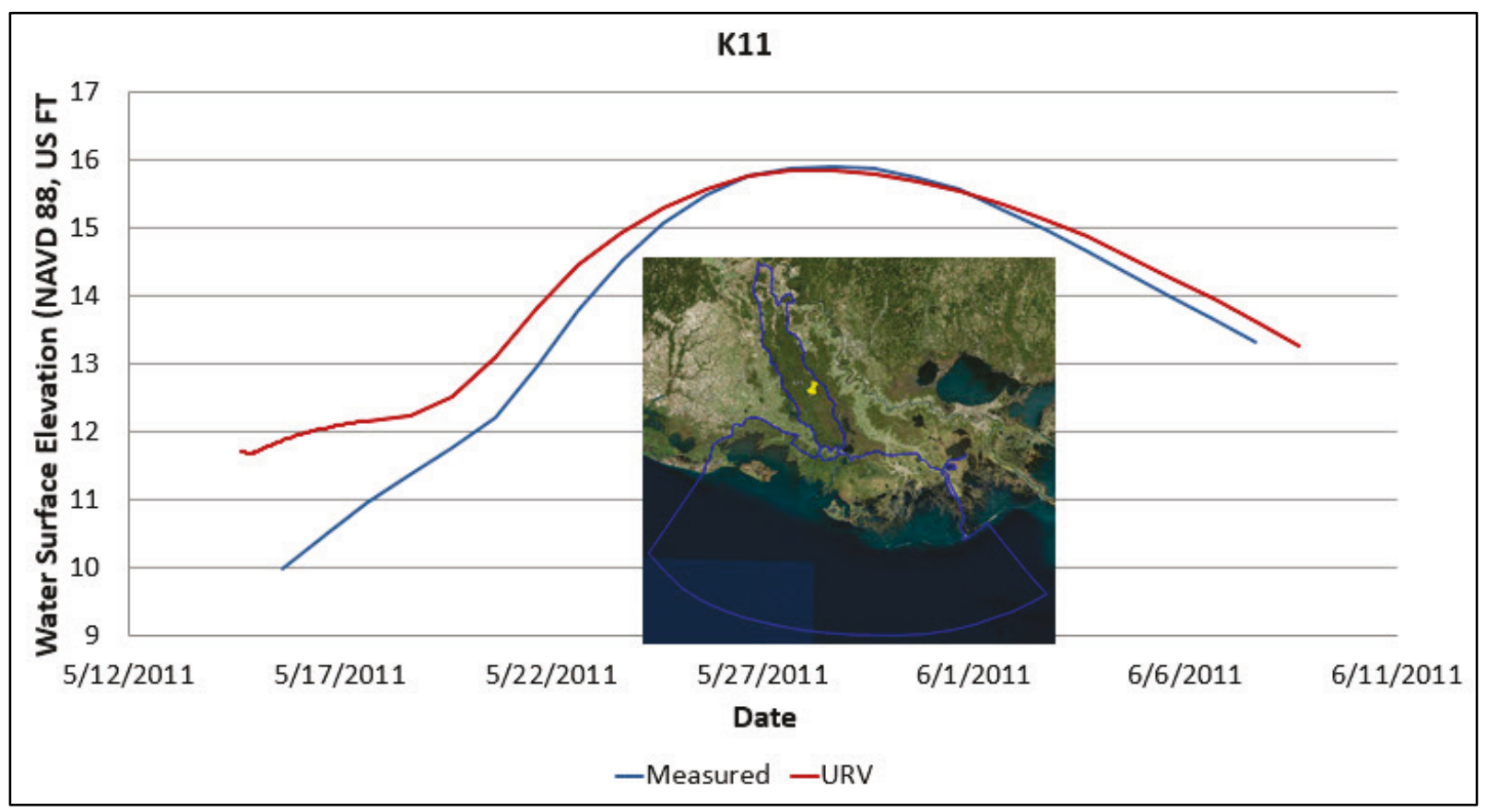

Figure 27. Gage K12 model results.

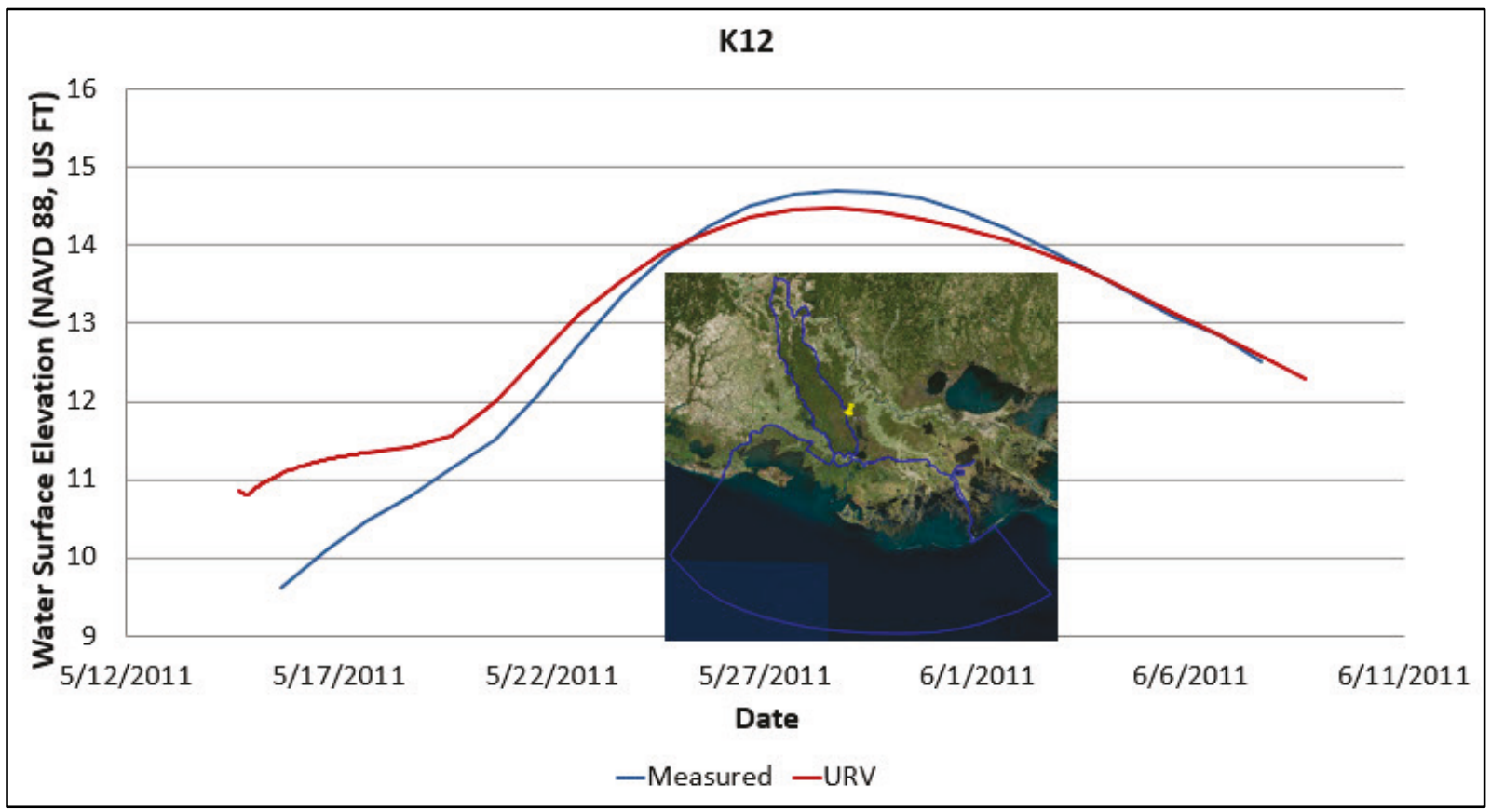


Figure 28. Gage K13 model results.

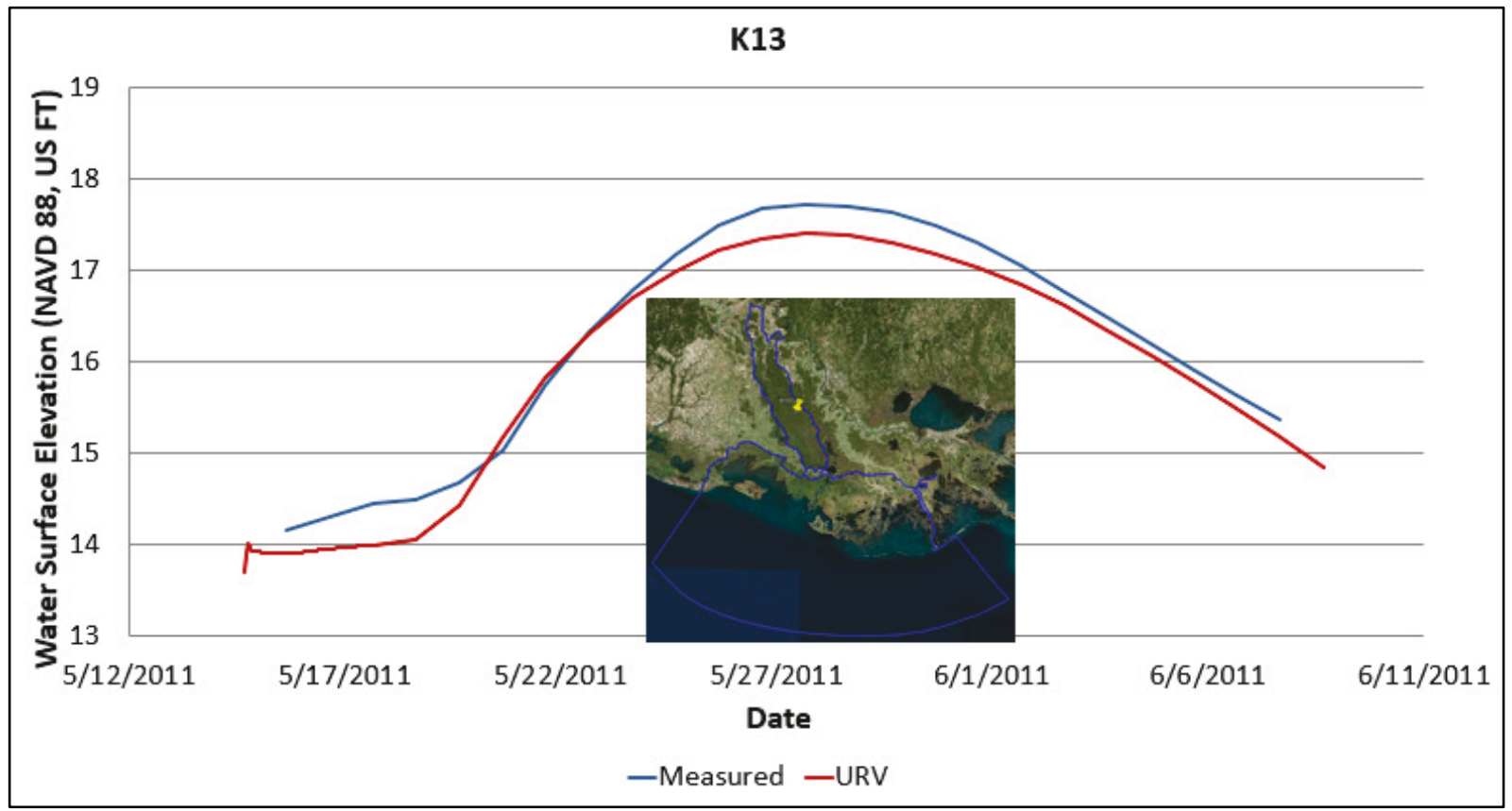

Figure 29. Gage K14 model results.

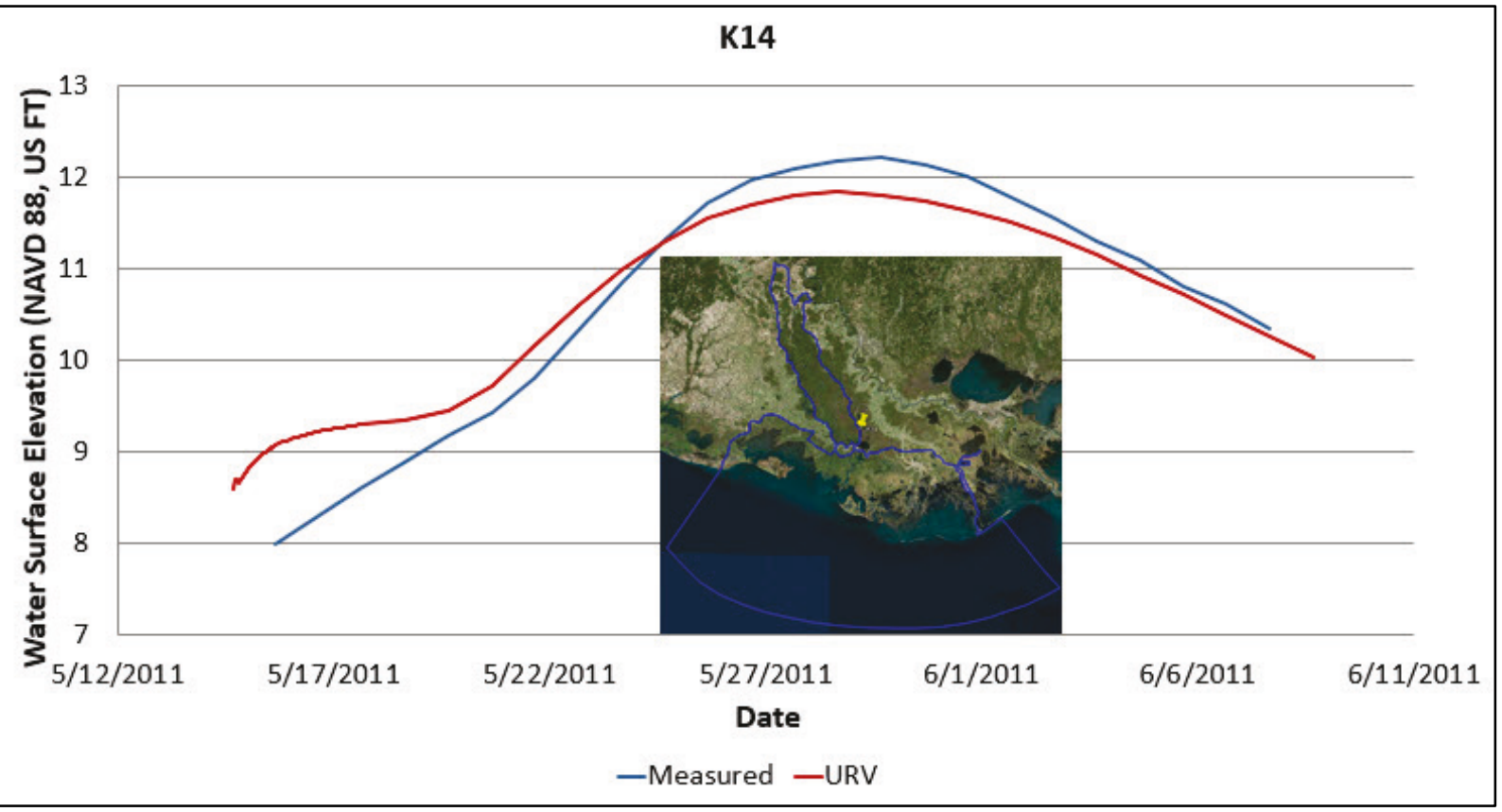


Figure 30. Gage K15 model results.

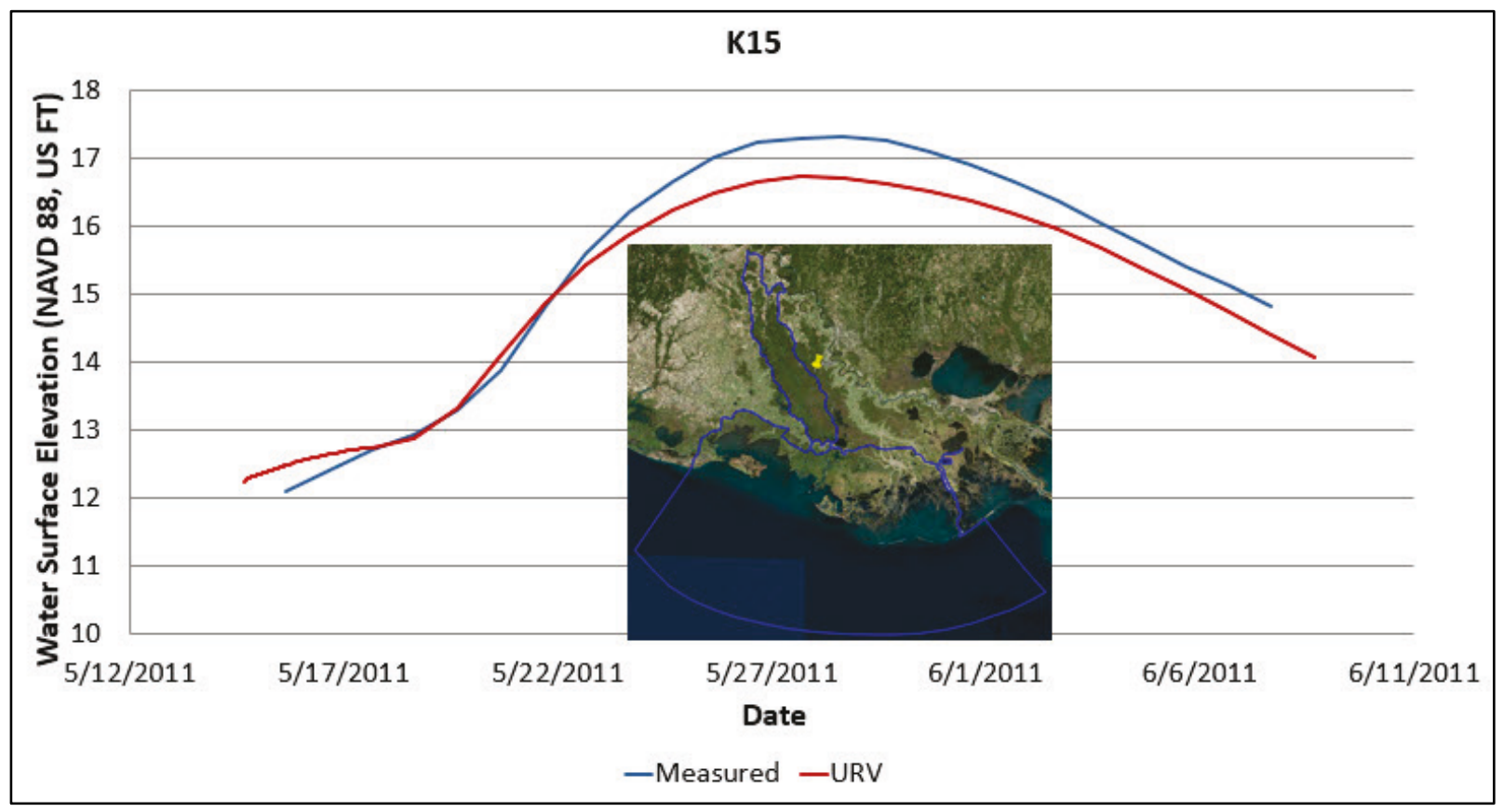

Figure 31. Gage K16 model results.

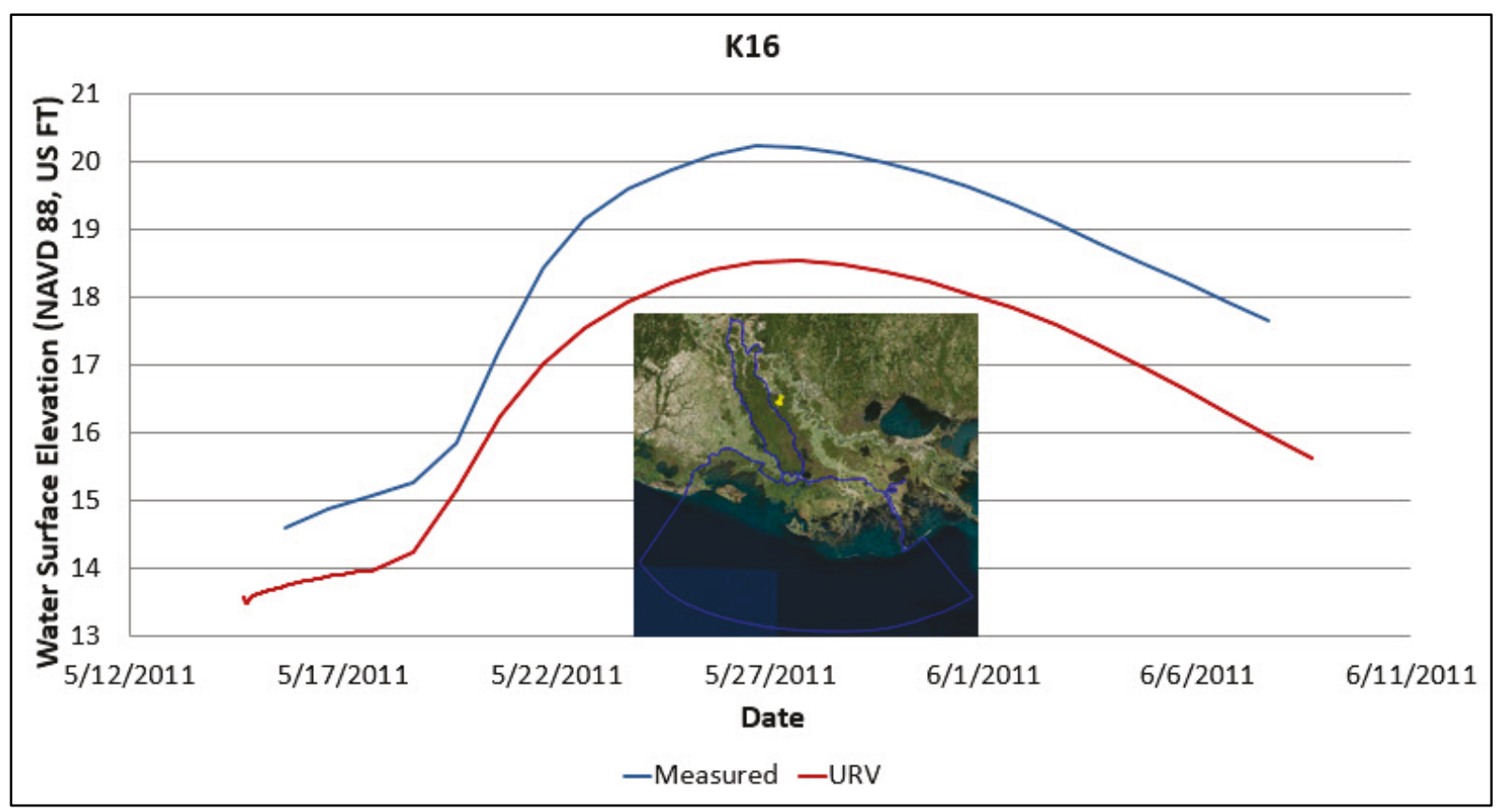


Figure 32. Gage K17 model results.

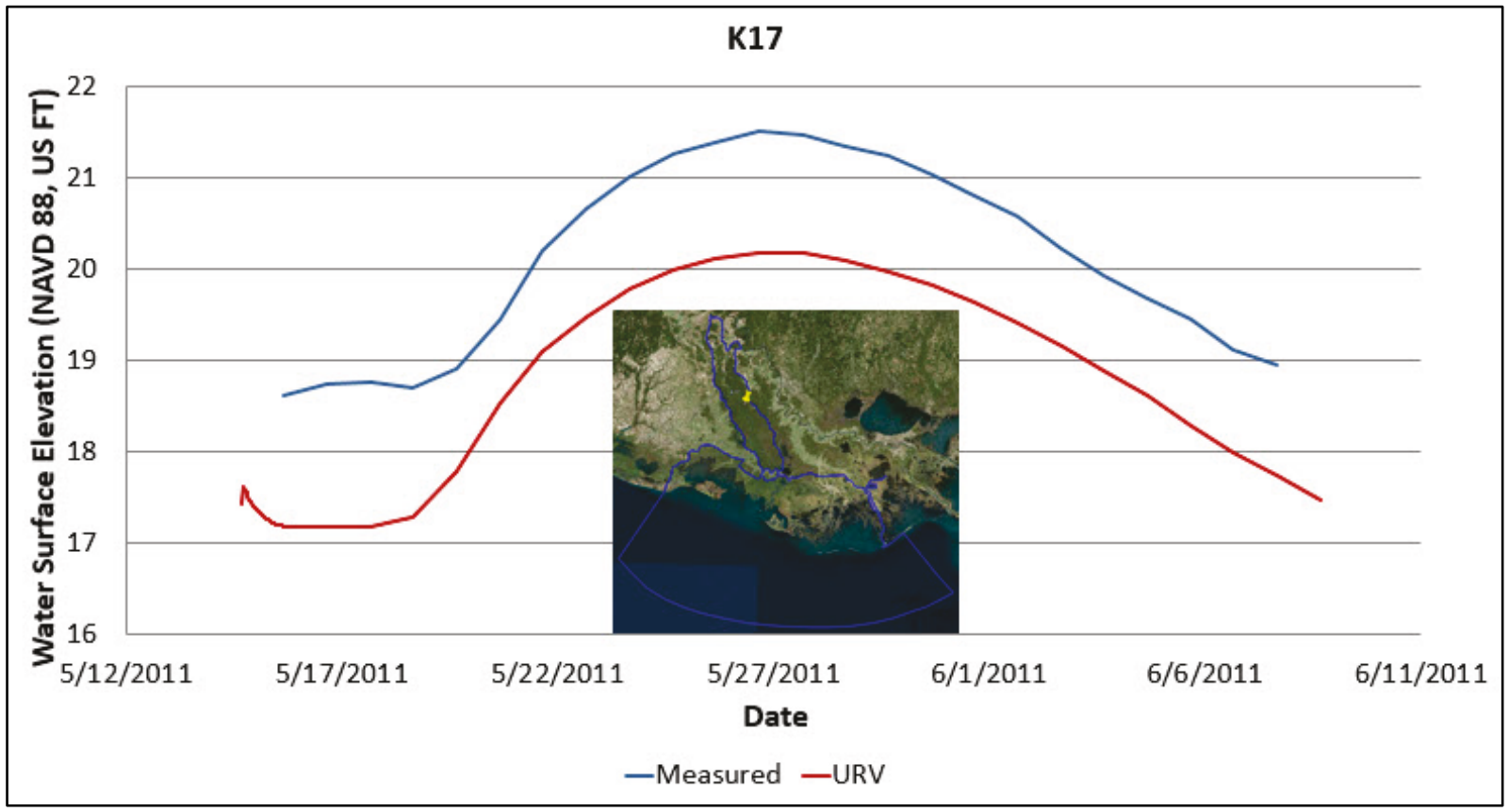

Figure 33. Gage K18 model results.

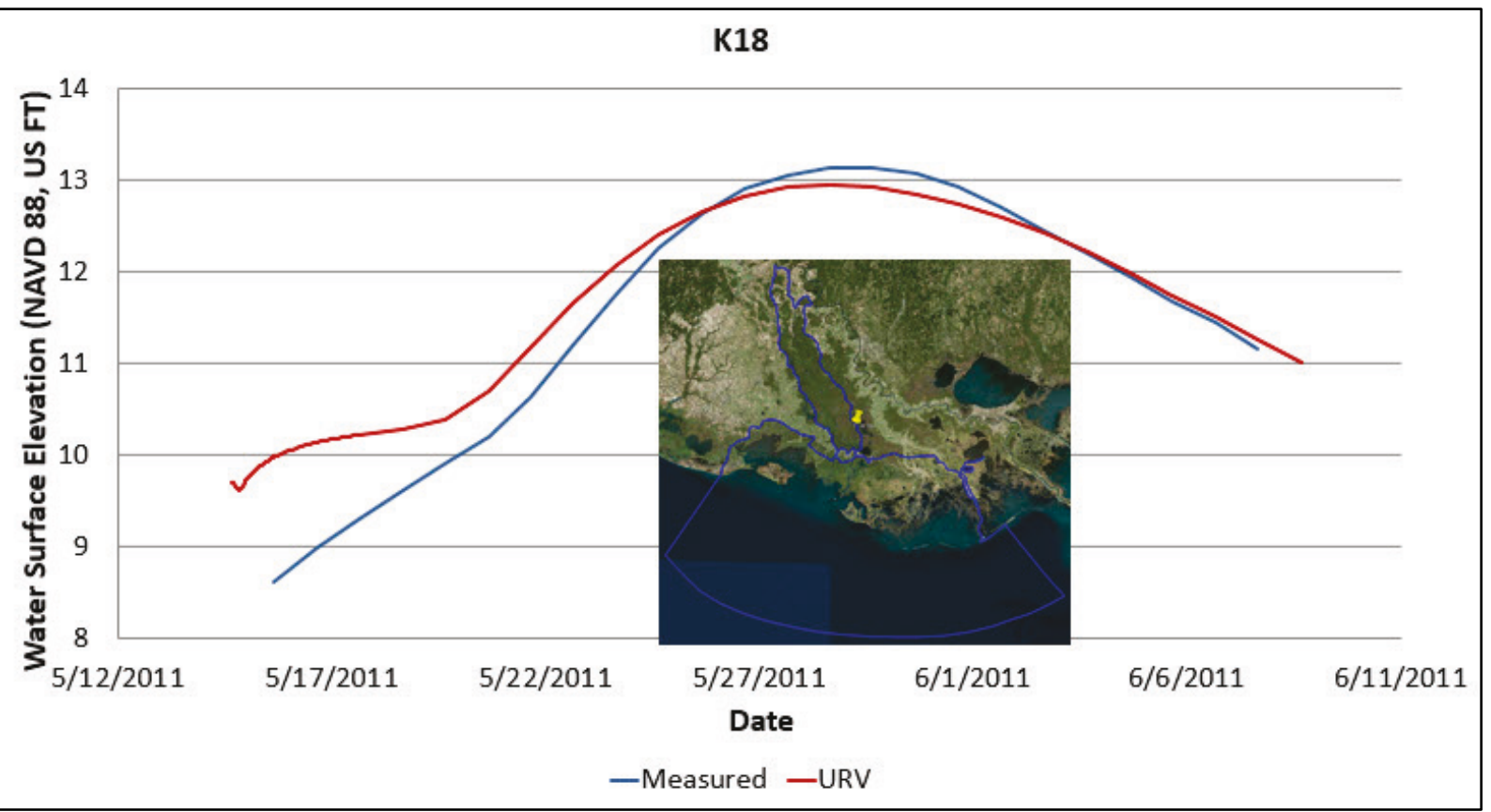


Figure 34. Gage K19 model results.

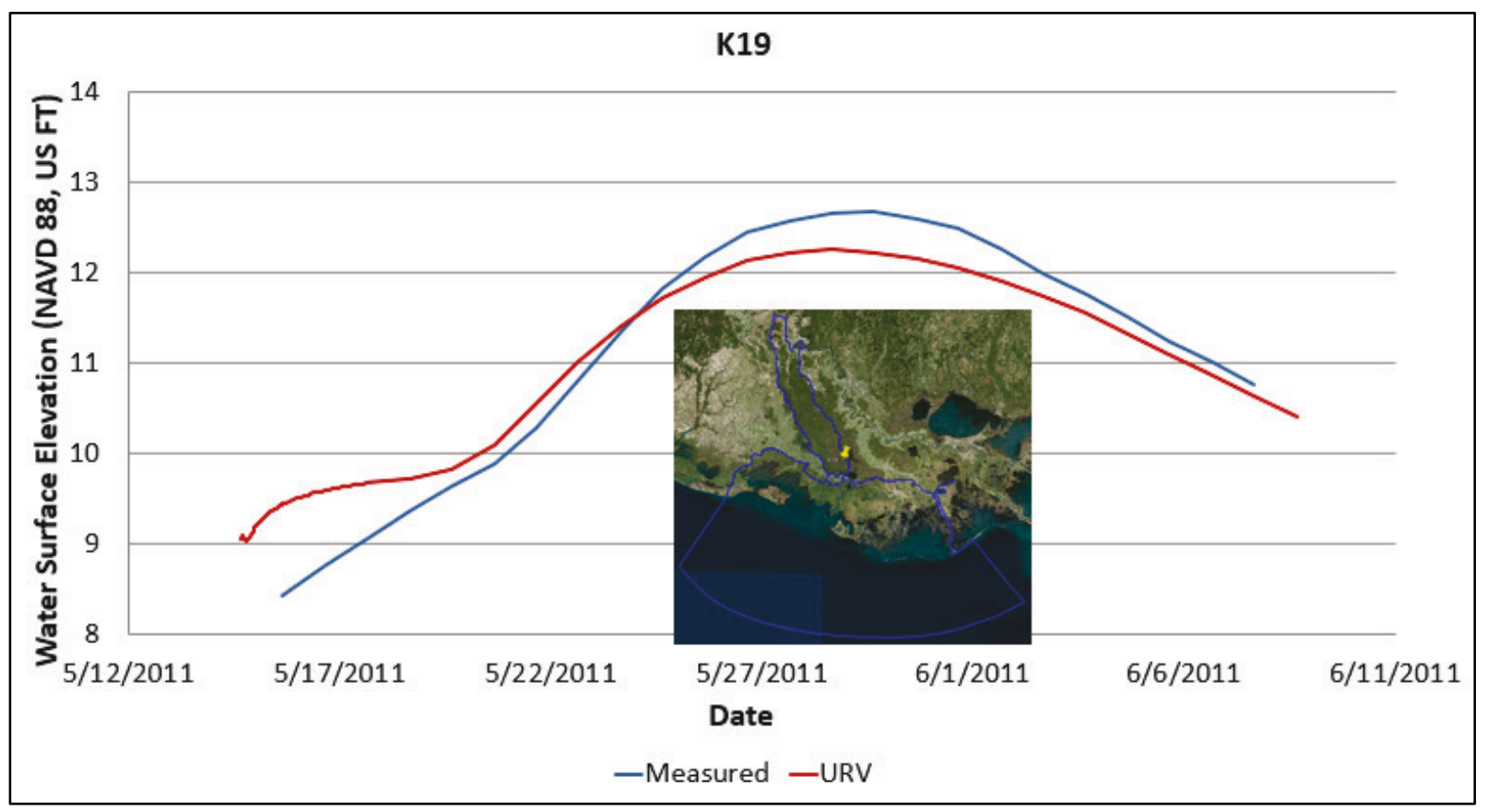

Figure 35. Gage K21 model results.

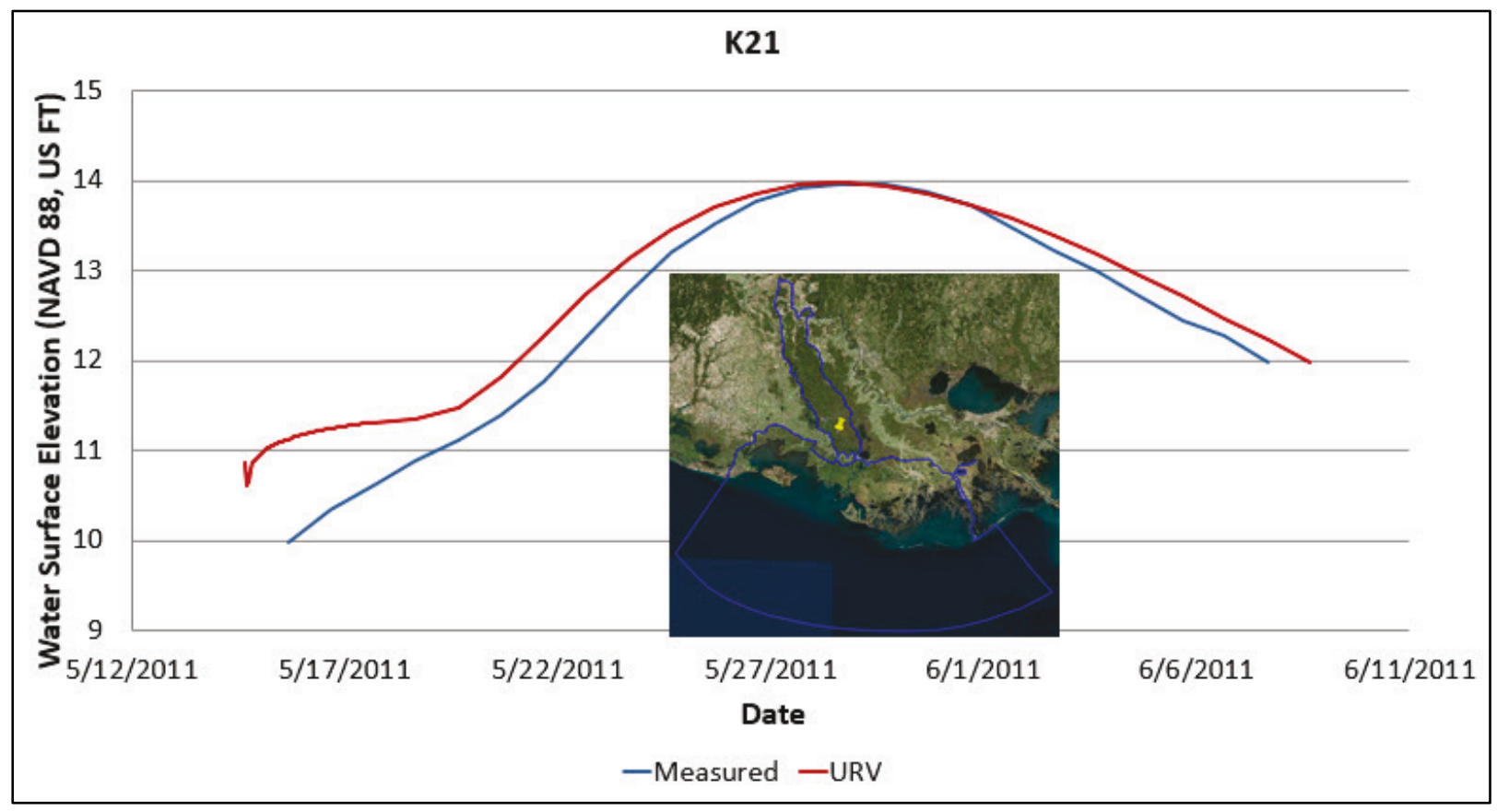


Figure 36. Water surface elevation at Wax Lake Outlet.

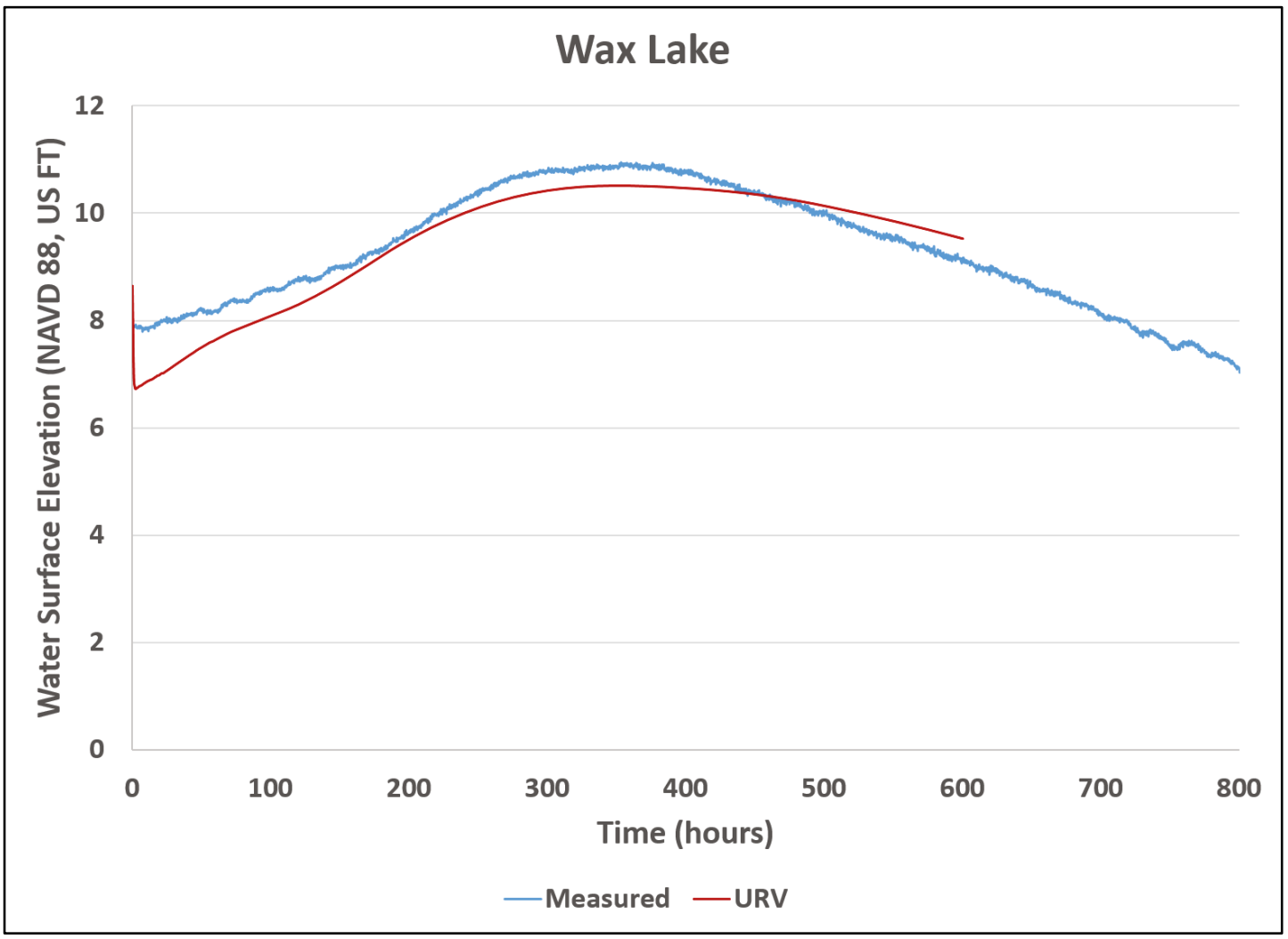

Figure 37. Water surface elevation at Morgan City Outlet.

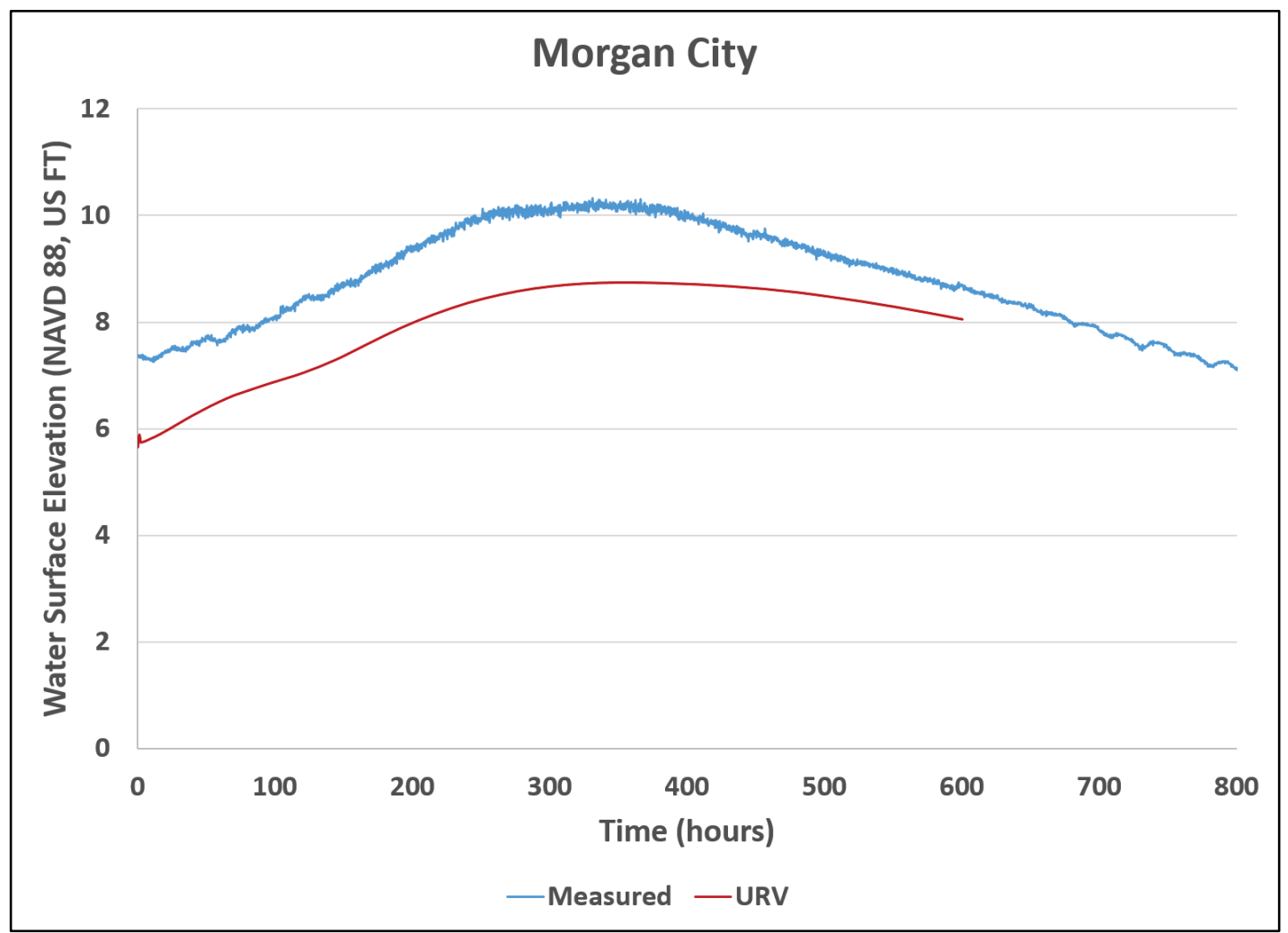


Figure 38. Discharge at Wax Lake Outlet.

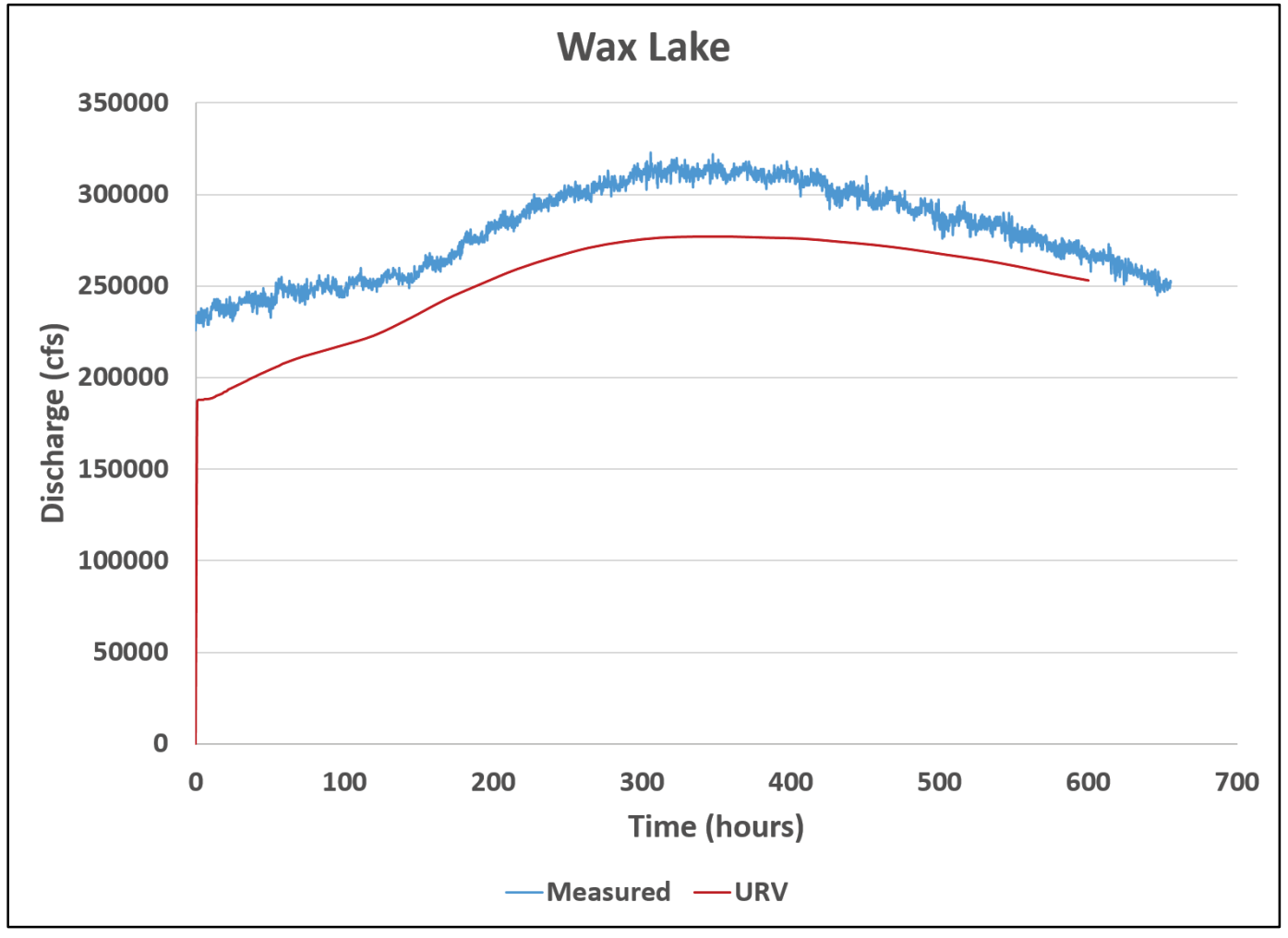

Figure 39. Discharge at Morgan City Outlet.

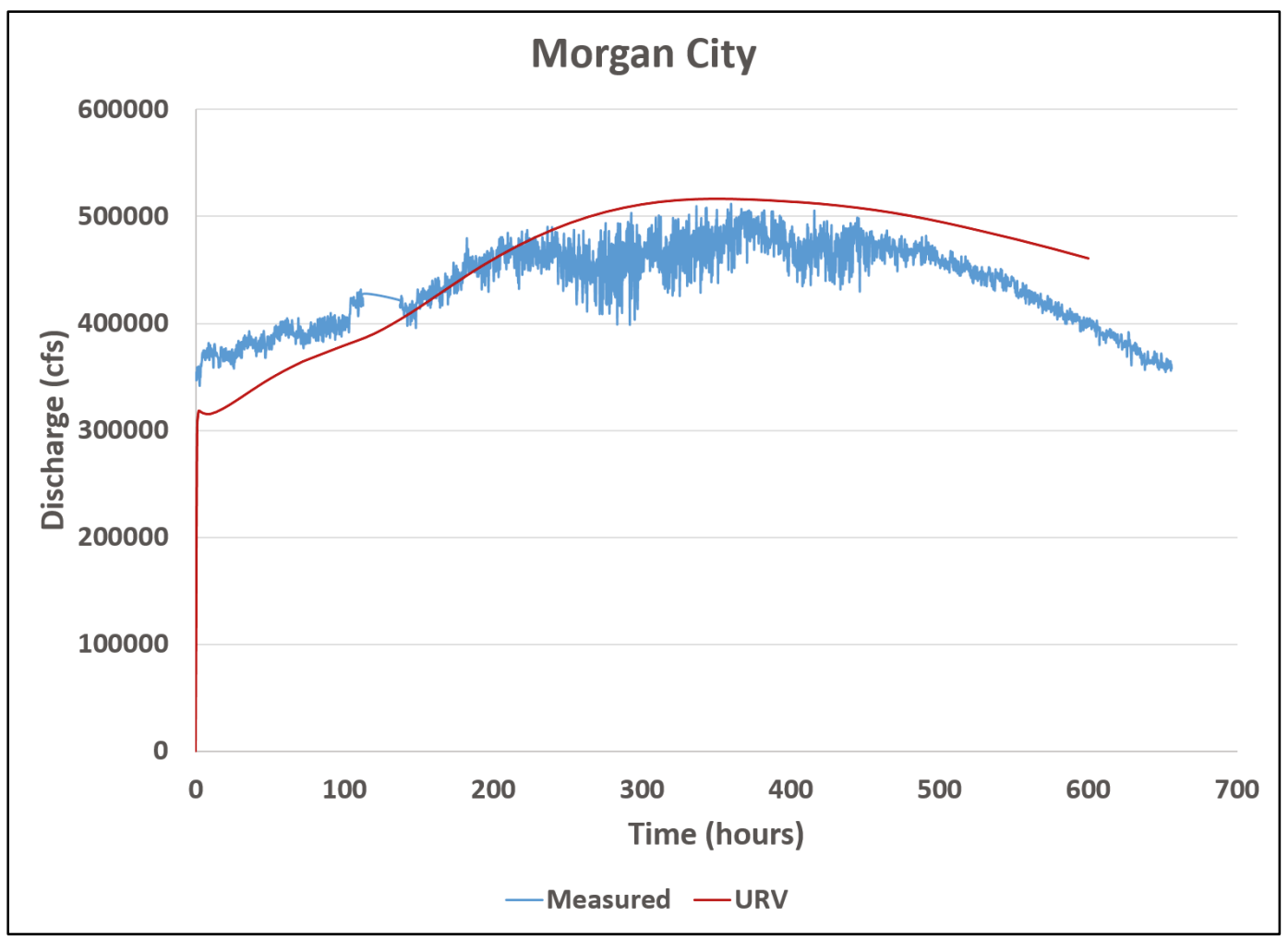


Figure 40. Relative gage accuracy (model results compared to measured data).

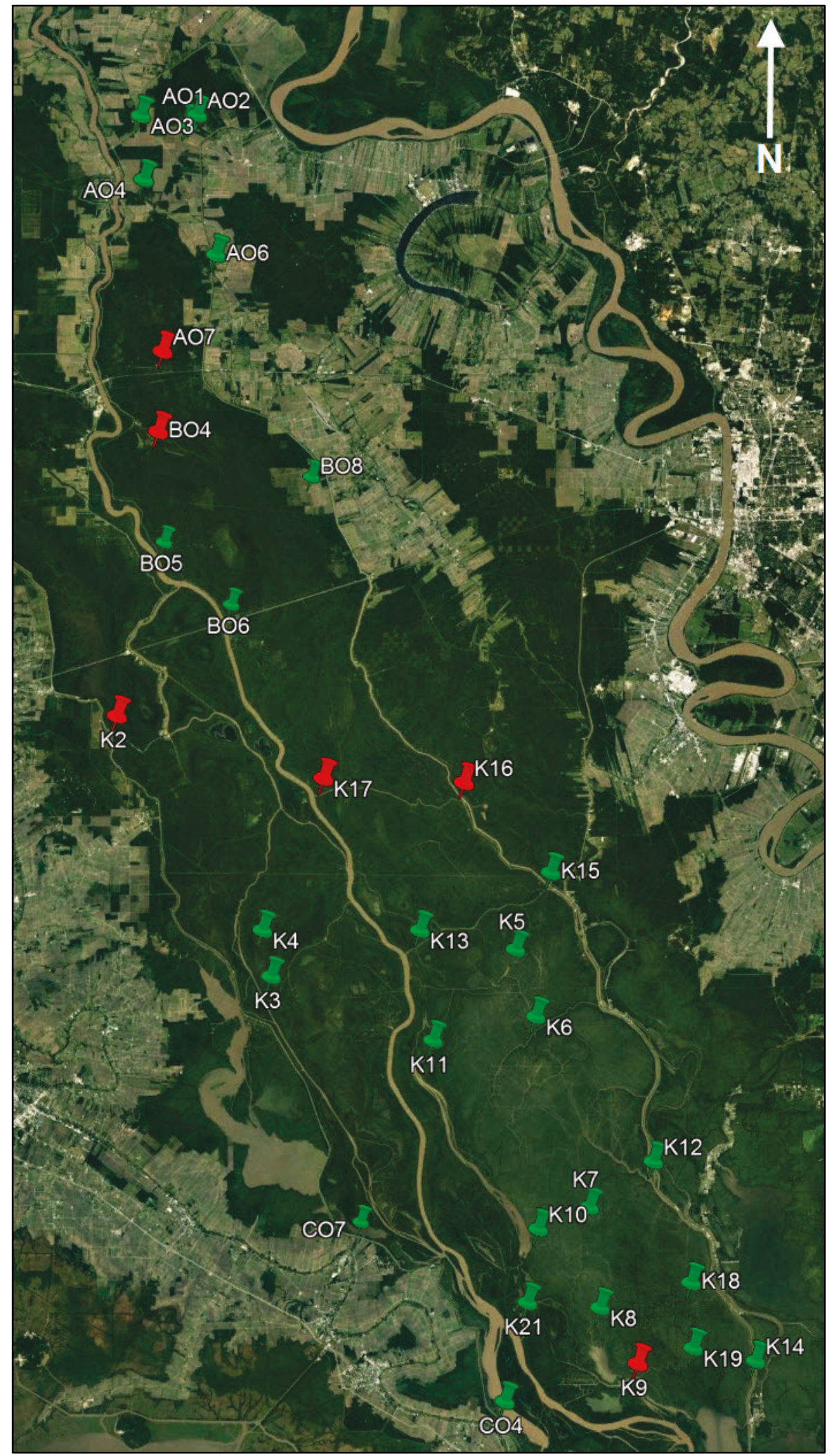


There are a couple of gages (BO4 and K2) that have much less accurate results over the entire simulation period than the other comparisons sites. Gage $\mathrm{BO}_{4}$ has some differences for the initial period of the simulation. This gage was also placed on dry land near a roadway before the flood waters reached this location (see Figure 41). Gage K2 was located on the western border of the model in a channel that runs along the WAPBL (see Figure 42). Several sources for these discrepancies are possible. The model may not properly capture hydraulic connectivity throughout the entire domain (likely due to resolution deficiencies in some areas) for extreme flood events. There could be some associated error with the gage placement (see Figure 43) due to possible flow accelerations and/or constrictions through the bridge piers and other unknown submerged bridge features. It is also possible that the discrepancies at these two sites are associated with a local instrumentation error given that the rest of the gages throughout the entire domain compare more favorably to the model results.

Figure 41. Gage BO4 location.

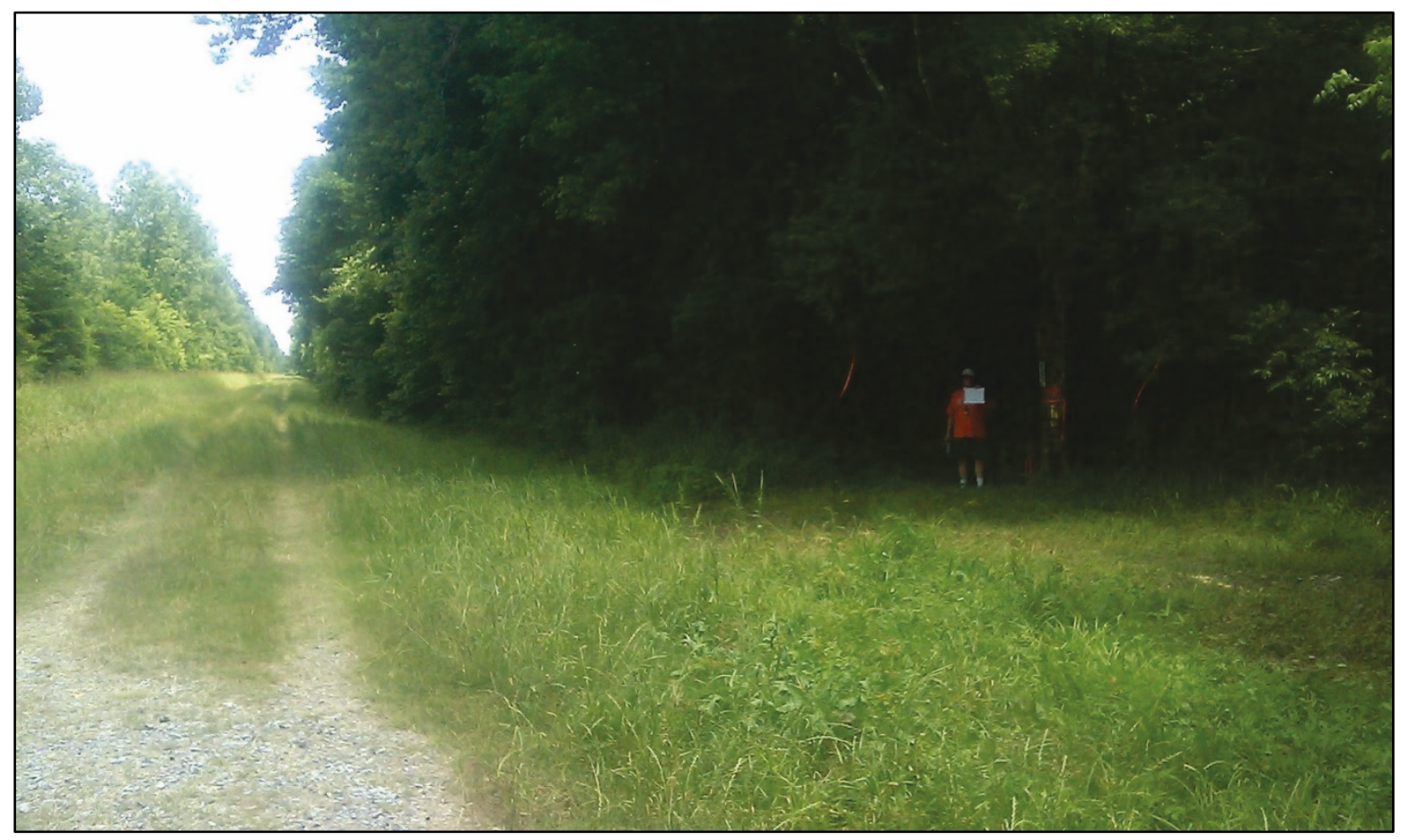


Figure 42. Aerial view of K2 location.

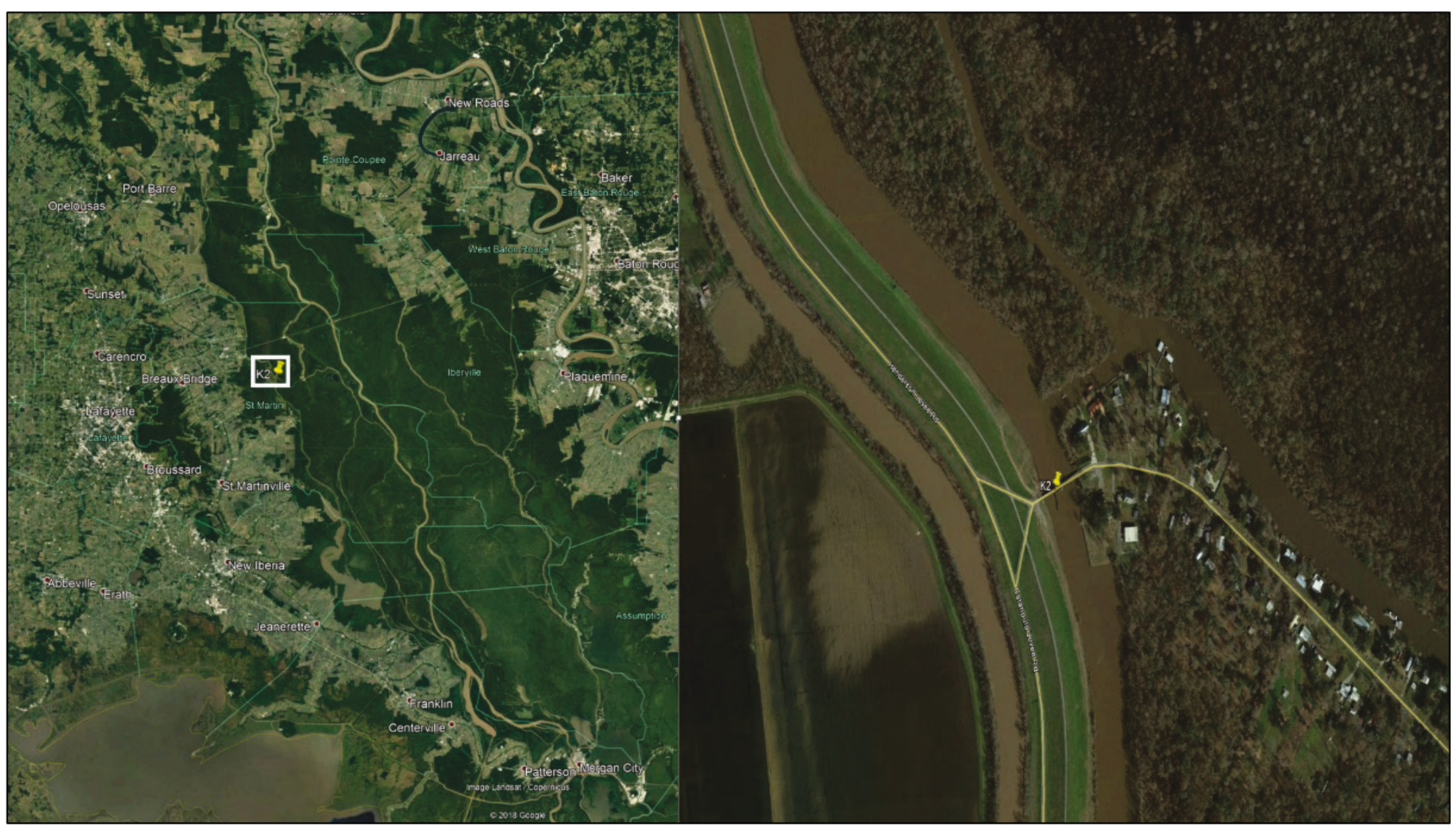


Figure 43. Gage K2 location.

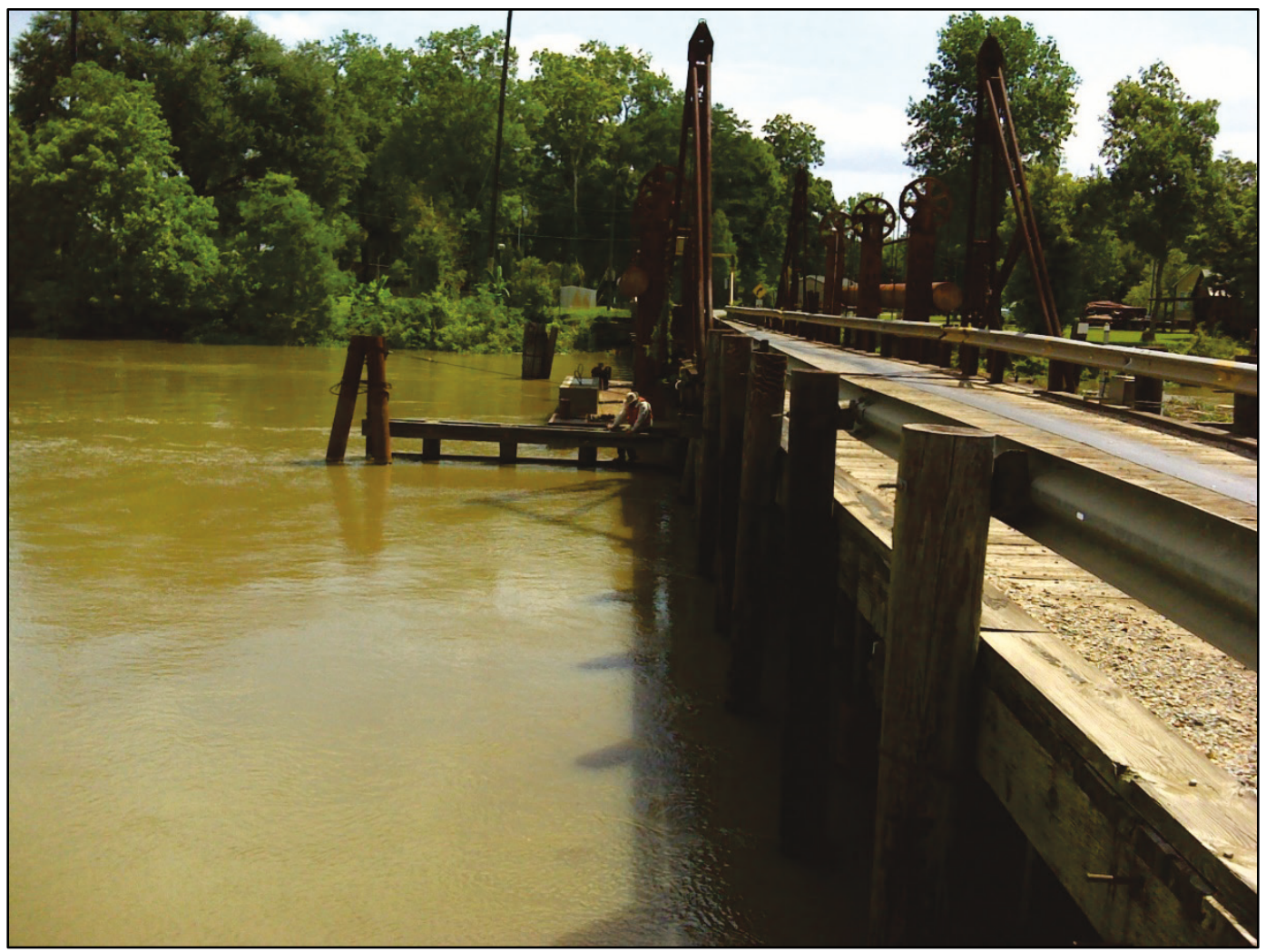

The root mean square error (RMSE) was calculated at each gage for the duration of the simulation. The daily summed RMSE (Column A), RMSE for each gage throughout the entire simulation (Column B), and the maximum/minimum error for each gage (Column $\mathrm{C}$ and Column $\mathrm{D}$, respectively) can be seen for all gages together in Table 2. These results are the best comparisons to measured data for the 2011 flood event model calibration. The spatial variability of error is random throughout the domain of the model as shown in Column B. This randomness means that there was no spatial pattern of the model having more error in one location than another. With regards to temporal error, generally the error decreased as time moved forward throughout the entire simulation as shown in Column A. Note that the initial conditions are included in each of the values presented in Table 2 . 
Table 2. Summary of RMSE and model error (feet).

\begin{tabular}{|c|c|}
\hline \multicolumn{2}{|c|}{ Column A } \\
\hline \multicolumn{2}{|c|}{ Daily Summed RMSE } \\
\hline 5/15/11 16:00 & 1.66 \\
\hline $5 / 16 / 1116: 00$ & 1.41 \\
\hline $5 / 17 / 1116: 00$ & 1.32 \\
\hline $5 / 18 / 1116: 00$ & 0.97 \\
\hline $5 / 19 / 1116: 00$ & 0.99 \\
\hline $5 / 20 / 1116: 00$ & 1.08 \\
\hline $5 / 21 / 1116: 00$ & 1.13 \\
\hline $5 / 22 / 1116: 00$ & 1.11 \\
\hline $5 / 23 / 1116: 00$ & 1.08 \\
\hline $5 / 24 / 1116: 00$ & 1.07 \\
\hline $5 / 25 / 1116: 00$ & 1.06 \\
\hline $5 / 26 / 1116: 00$ & 1.04 \\
\hline $5 / 27 / 1116: 00$ & 1.00 \\
\hline $5 / 28 / 1116: 00$ & 0.98 \\
\hline 5/29/11 16:00 & 0.97 \\
\hline $5 / 30 / 1116: 00$ & 0.94 \\
\hline $5 / 31 / 1116: 00$ & 0.91 \\
\hline $6 / 1 / 1116: 00$ & 0.88 \\
\hline $6 / 2 / 1116: 00$ & 0.84 \\
\hline $6 / 3 / 1116: 00$ & 0.81 \\
\hline $6 / 4 / 1116: 00$ & 0.80 \\
\hline $6 / 5 / 1116: 00$ & 0.81 \\
\hline $6 / 6 / 1116: 00$ & 0.80 \\
\hline $6 / 7 / 1116: 00$ & 0.82 \\
\hline
\end{tabular}

\begin{tabular}{|c|c|}
\hline \multicolumn{2}{|c|}{ Column B } \\
\hline \multicolumn{2}{|c|}{$\begin{array}{l}\text { RMSE for each Gage } \\
\text { throughout Entire Simulation }\end{array}$} \\
\hline AO1 & 0.60 \\
\hline $\mathrm{AO2}$ & 0.42 \\
\hline $\mathrm{AO3}$ & 1.23 \\
\hline AO4 & 0.98 \\
\hline A06 & 0.74 \\
\hline $\mathrm{AO7}$ & 1.78 \\
\hline K5 & 0.55 \\
\hline K7 & 0.49 \\
\hline K4 & 0.66 \\
\hline K2 & 2.92 \\
\hline BO4 & 2.31 \\
\hline $\mathrm{CO} 4$ & 0.45 \\
\hline К9 & 1.25 \\
\hline K14 & 0.41 \\
\hline K13 & 0.25 \\
\hline K17 & 1.24 \\
\hline K16 & 1.47 \\
\hline K15 & 0.41 \\
\hline K3 & 0.56 \\
\hline K18 & 0.49 \\
\hline K19 & 0.40 \\
\hline K21 & 0.42 \\
\hline K10 & 0.55 \\
\hline K11 & 0.69 \\
\hline K12 & 0.49 \\
\hline K6 & 0.52 \\
\hline K8 & 0.66 \\
\hline Total Average & 0.85 \\
\hline
\end{tabular}

\begin{tabular}{|c|c|}
\hline \multicolumn{2}{|c|}{ Column C } \\
\hline \multicolumn{2}{|c|}{ Maximum Error for each Gage } \\
\hline A01 & 0.52 \\
\hline $\mathrm{AO2}$ & 0.63 \\
\hline $\mathrm{AO3}$ & 0.96 \\
\hline $\mathrm{AO4}$ & 1.29 \\
\hline AO6 & 1.09 \\
\hline A07 & 2.84 \\
\hline K5 & 0.54 \\
\hline K7 & 0.28 \\
\hline K4 & 0.88 \\
\hline K2 & 3.40 \\
\hline BO4 & 3.26 \\
\hline $\mathrm{CO} 4$ & -0.06 \\
\hline К9 & -0.78 \\
\hline K14 & 0.41 \\
\hline K13 & 0.45 \\
\hline K17 & 1.59 \\
\hline K16 & 1.71 \\
\hline K15 & 0.62 \\
\hline K3 & 0.75 \\
\hline K18 & 0.23 \\
\hline K19 & 0.45 \\
\hline K21 & 0.03 \\
\hline K10 & 0.14 \\
\hline K11 & 0.08 \\
\hline K12 & 0.25 \\
\hline K6 & 0.38 \\
\hline К8 & -0.07 \\
\hline
\end{tabular}

\begin{tabular}{|c|c|}
\hline \multicolumn{2}{|c|}{ Column D } \\
\hline \multicolumn{2}{|c|}{ Minimum Error for each Gage } \\
\hline A01 & -1.77 \\
\hline AO2 & -0.69 \\
\hline AO3 & -4.13 \\
\hline AO4 & -2.80 \\
\hline AO6 & -1.28 \\
\hline AO7 & -2.94 \\
\hline K5 & -1.45 \\
\hline K7 & -1.45 \\
\hline K4 & 0.11 \\
\hline K2 & 1.73 \\
\hline BO4 & -1.05 \\
\hline CO4 & -0.95 \\
\hline K9 & -2.14 \\
\hline K14 & -1.09 \\
\hline K13 & -0.15 \\
\hline K17 & 0.91 \\
\hline K16 & 0.69 \\
\hline K15 & -0.40 \\
\hline K3 & 0.11 \\
\hline K18 & -1.36 \\
\hline K19 & -1.01 \\
\hline K21 & -1.15 \\
\hline K10 & -1.60 \\
\hline K12 & -1.88 \\
\hline K6 & -1.46 \\
\hline & -1.51 \\
\hline & -1.63 \\
\hline
\end{tabular}


Upon reaching day 4 of the simulation ( 96 hours after the MCS was activated), the approximate peak flow of $170 \mathrm{kcfs}$ was reached. This amount of flow was released for 5 days, ranging from 163 to $170 \mathrm{kcfs}$. On day 10 the flow decreased to $151 \mathrm{kcfs}$. Day 11 saw a decrease of approximately $20 \mathrm{kcfs}$. The water depth throughout the model domain at 10 days is shown in Figure 44.

Figure 44. Water depth at day 10 of the 2011 flood event simulation.

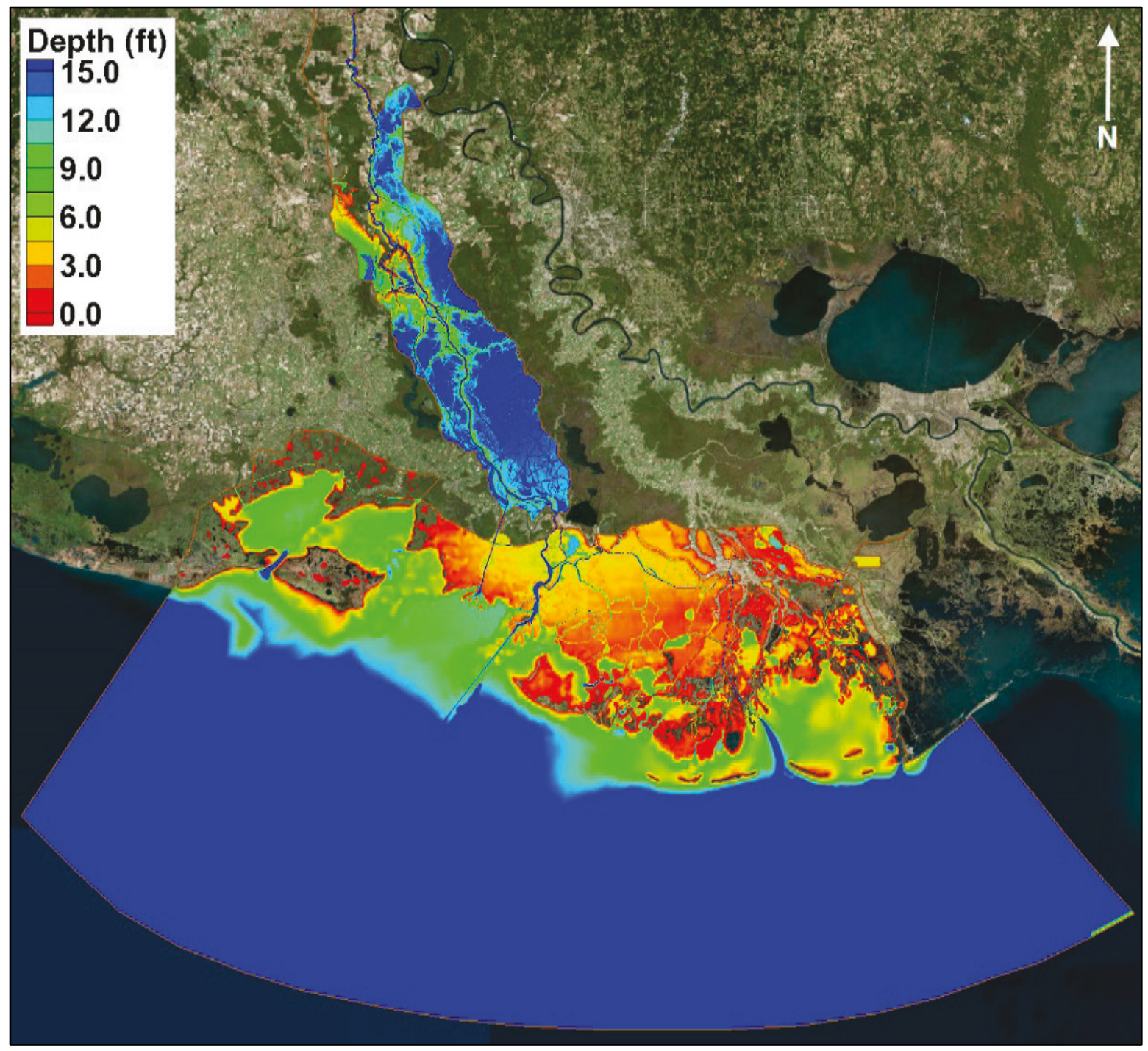

\subsection{Project design flow simulation}

The Morganza Floodway was designed such that it should pass a Project Flood of 600,000 cfs of flow from the Mississippi River through the control structure. For this simulation, the flow was ramped up from an initial value of 9,745 cfs (approximately the value for flow through one 
gate opening) by increments of 2,000 cfs per hour until 600,000 cfs was reached. The flow through the Atchafalaya was kept as the hydrograph recorded during the 2011 flood event (beginning on 14 May 2011, 16:00). When the peak value of $\sim 694,000 \mathrm{cfs}$ was reached on the Atchafalaya River, it was held constant throughout the duration of the simulation. The calibrated model, utilizing the URV parameters for the forested areas was used for this simulation. Cross sections were drawn across the model domain in three locations (Figure 45) just downstream of the MCS (the model boundary is outlined in red). A reference table of flow values per day of the simulation is shown in Table 3 . The results at each of these cross sections can be seen in Figure 46 - Figure 48. Note that the levee overtops well before the design flow of $600,000 \mathrm{cfs}$ is reached on day 12. The blue lines represent the ground elevation of the cross sections. The two peaks left and right are the tops of the levees, which generally fall between 55 and $60 \mathrm{ft}$. The water levels shown for days 8,9 , and 10 may not be the highest water level reached at these locations during this flood event. The simulations were stopped once the water levels overtopped the levees. A contour plot showing the water depth at day 10 of the simulation can be seen in Figure 49.

Figure 45. Locations of cross section arcs to be analyzed.

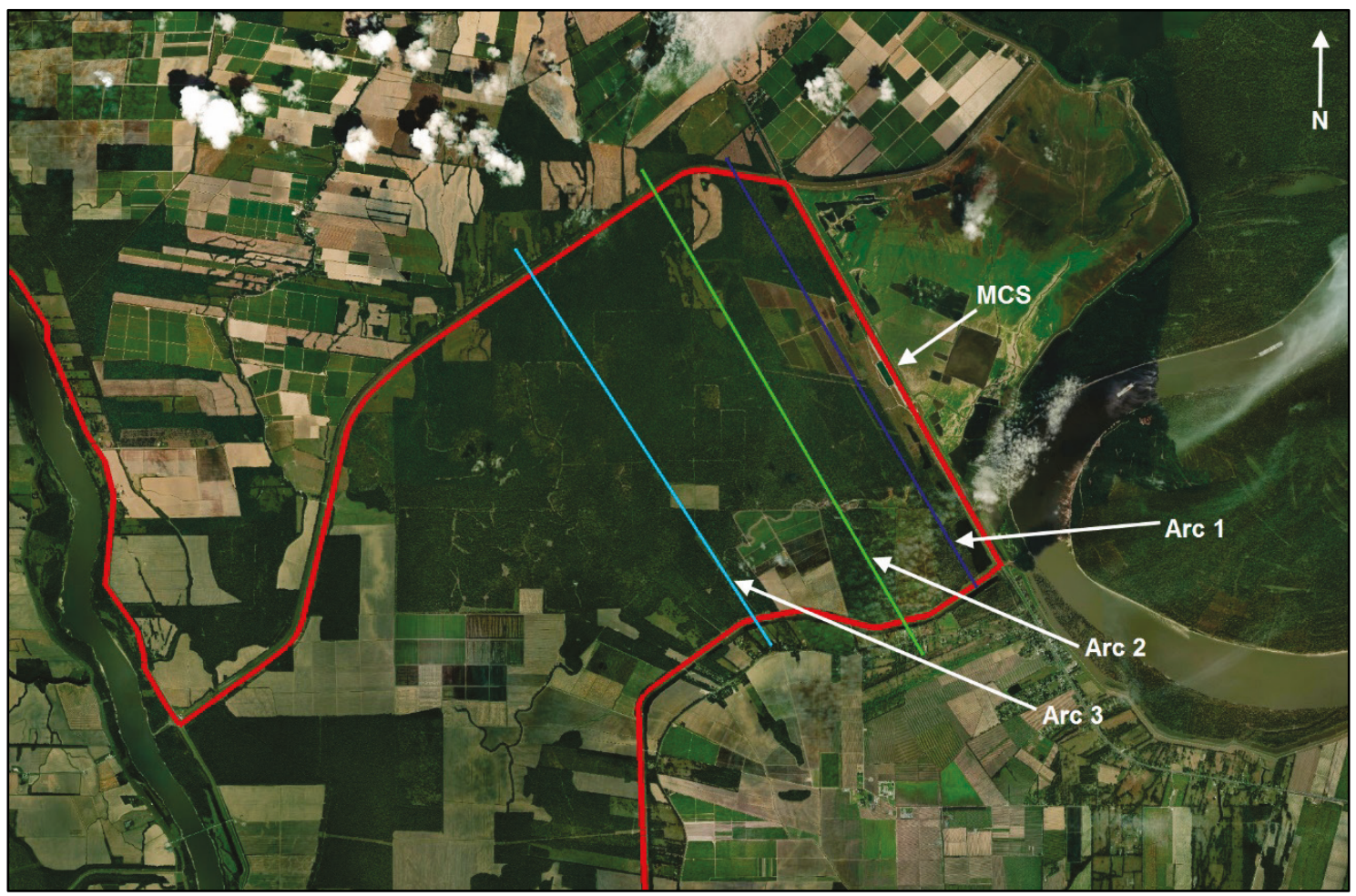


Table 3. Reference table for flow values/days.

\begin{tabular}{|c|c|}
\hline Time & Q (cfs) \\
\hline Day 0 & 9,745 \\
\hline Day 1 & 57,745 \\
\hline Day 2 & 105,745 \\
\hline Day 3 & 153,745 \\
\hline Day 4 & 201,745 \\
\hline Day 5 & 249,745 \\
\hline Day 6 & 297,745 \\
\hline Day 7 & 345,745 \\
\hline Day 8 & 393,745 \\
\hline Day 9 & 441,745 \\
\hline Day 10 & 489,745 \\
\hline Day 11 & 537,745 \\
\hline Day 12 & 600,000 \\
\hline
\end{tabular}

Figure 46. Results at Arc 1 (URV).

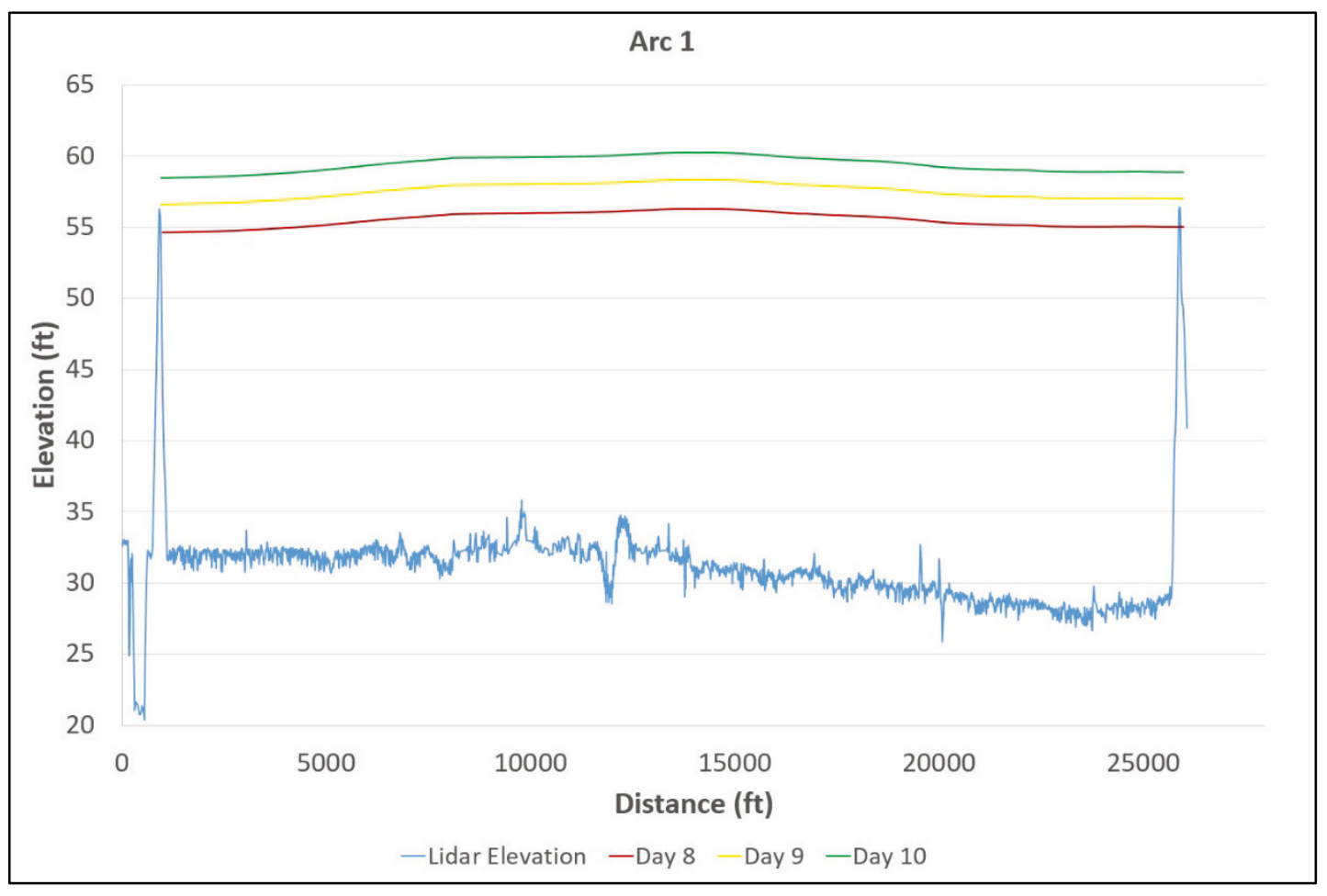


Figure 47. Results at Arc 2 (URV).

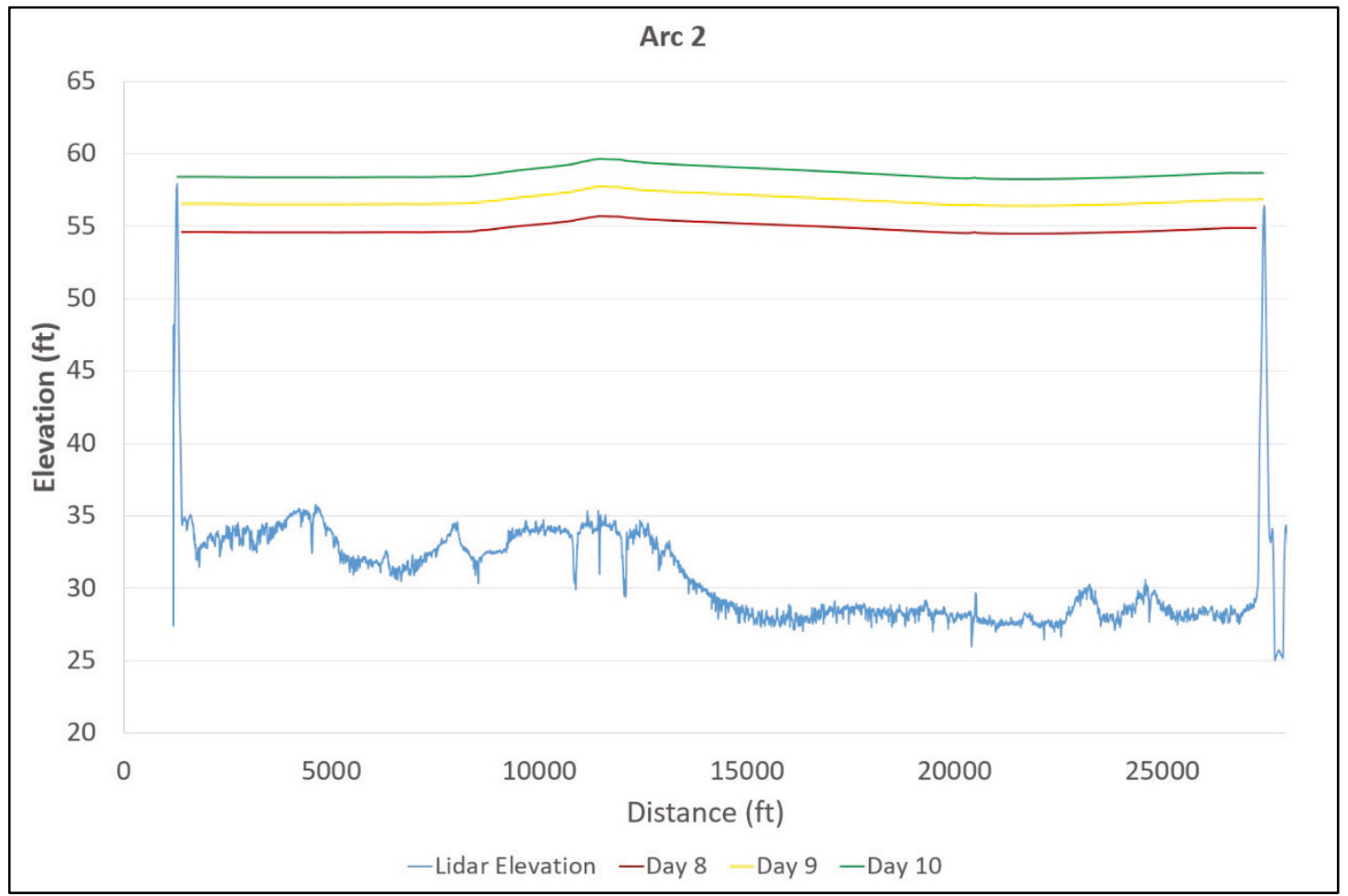

Figure 48. Results at Arc 3 (URV).

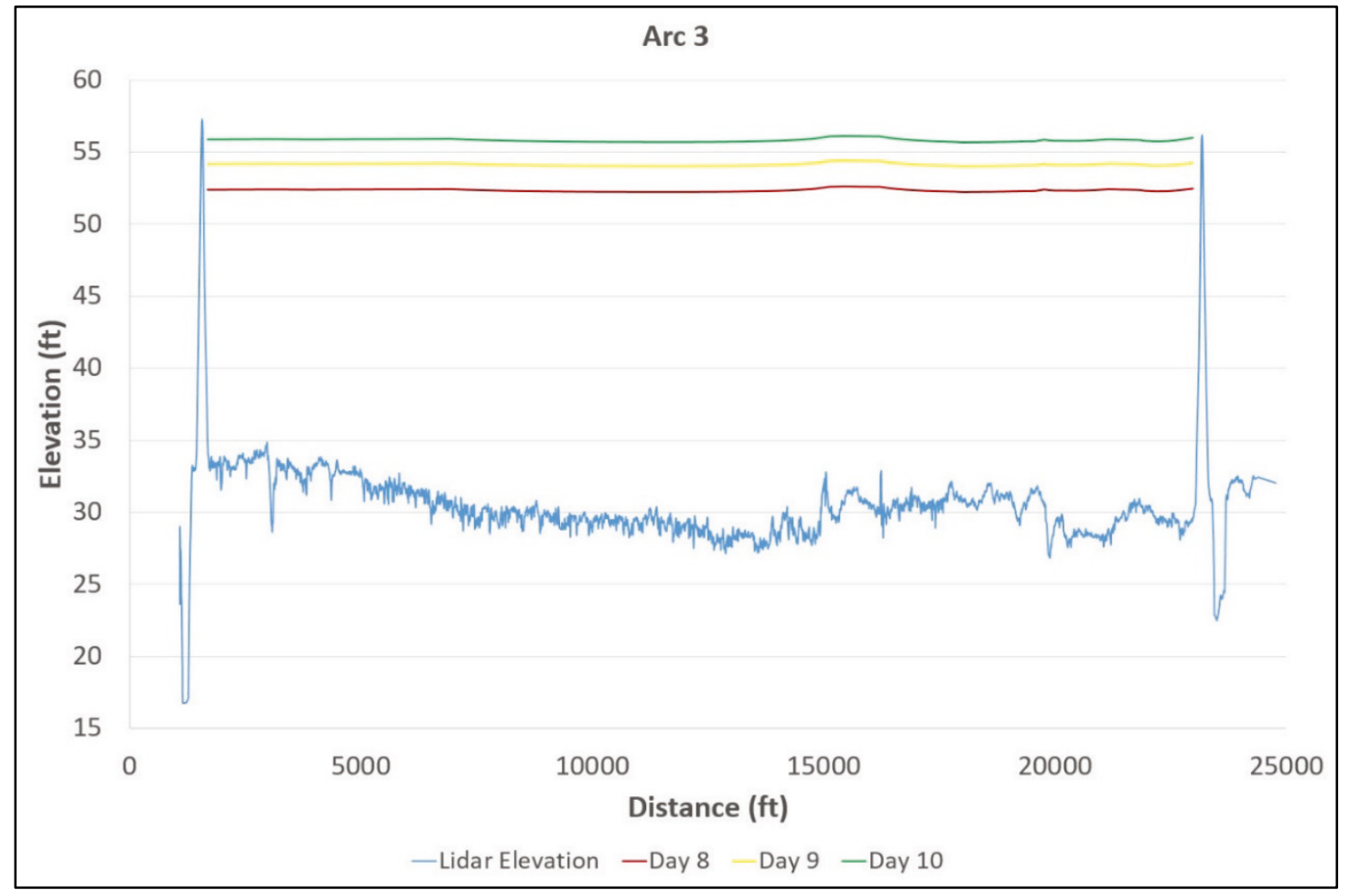


Figure 49. Water depth during the project flood event simulation at day 10.

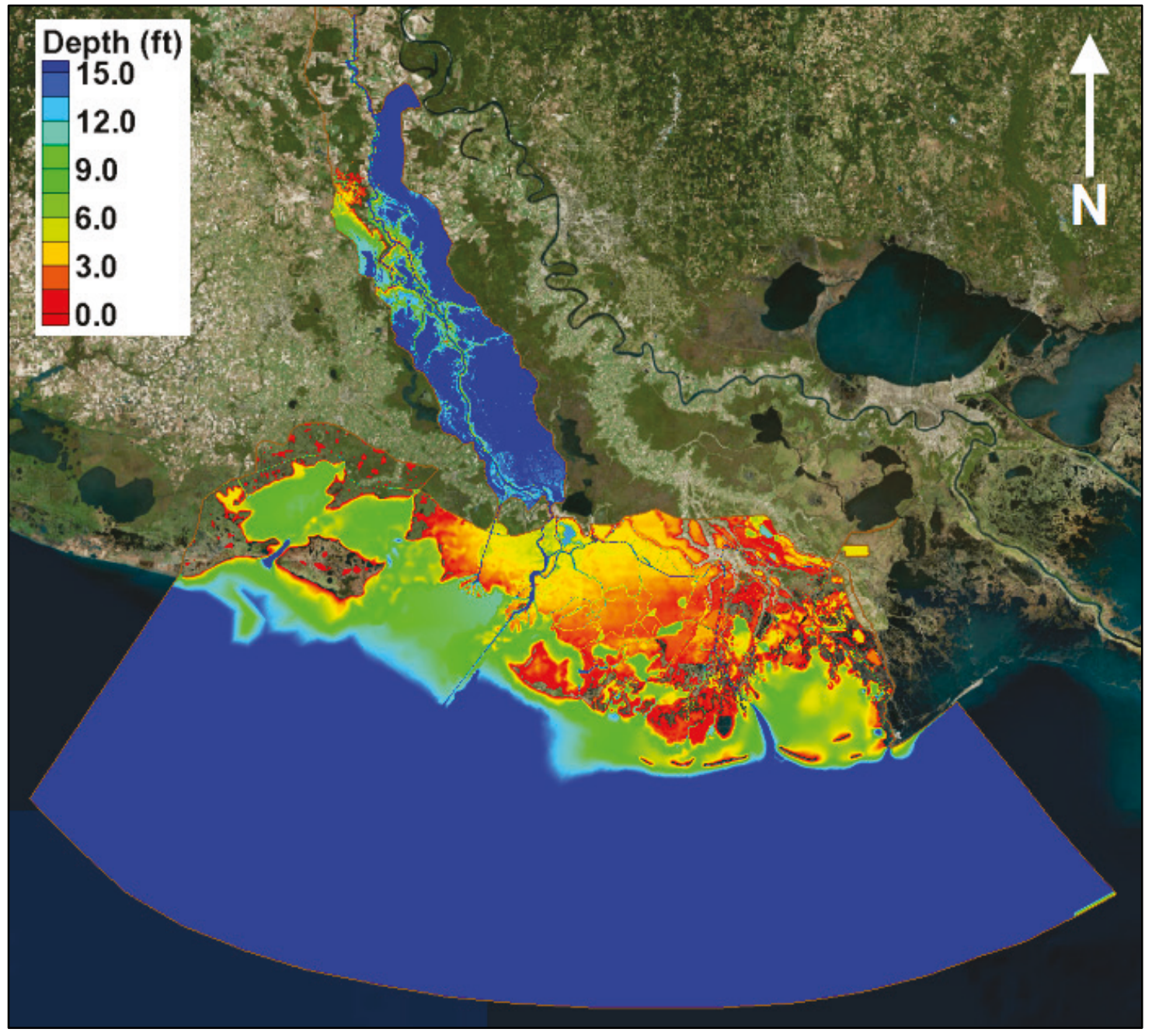

\subsection{Model sensitivity testing}

For reference, the 2011 flood event was plotted at the same cross sections presented previously (Figure 45). It is known that the levees did not overtop in these locations during this flood event. The days captured (8, 9, and 10) represent the time periods during the highest discharges through the MCS ( 170,000 cfs). As can be seen in the figures, the highest water levels attained were approximately elevation $45 \mathrm{ft}$. This is approximately 10 to $12 \mathrm{ft}$ below the top of the levees. The plots showing the results of this simulation are shown in Figure 50 - Figure 52. The AdH model also shows no levee overtopping during this event. 
Figure 50. 2011 flood event results at Arc 1.

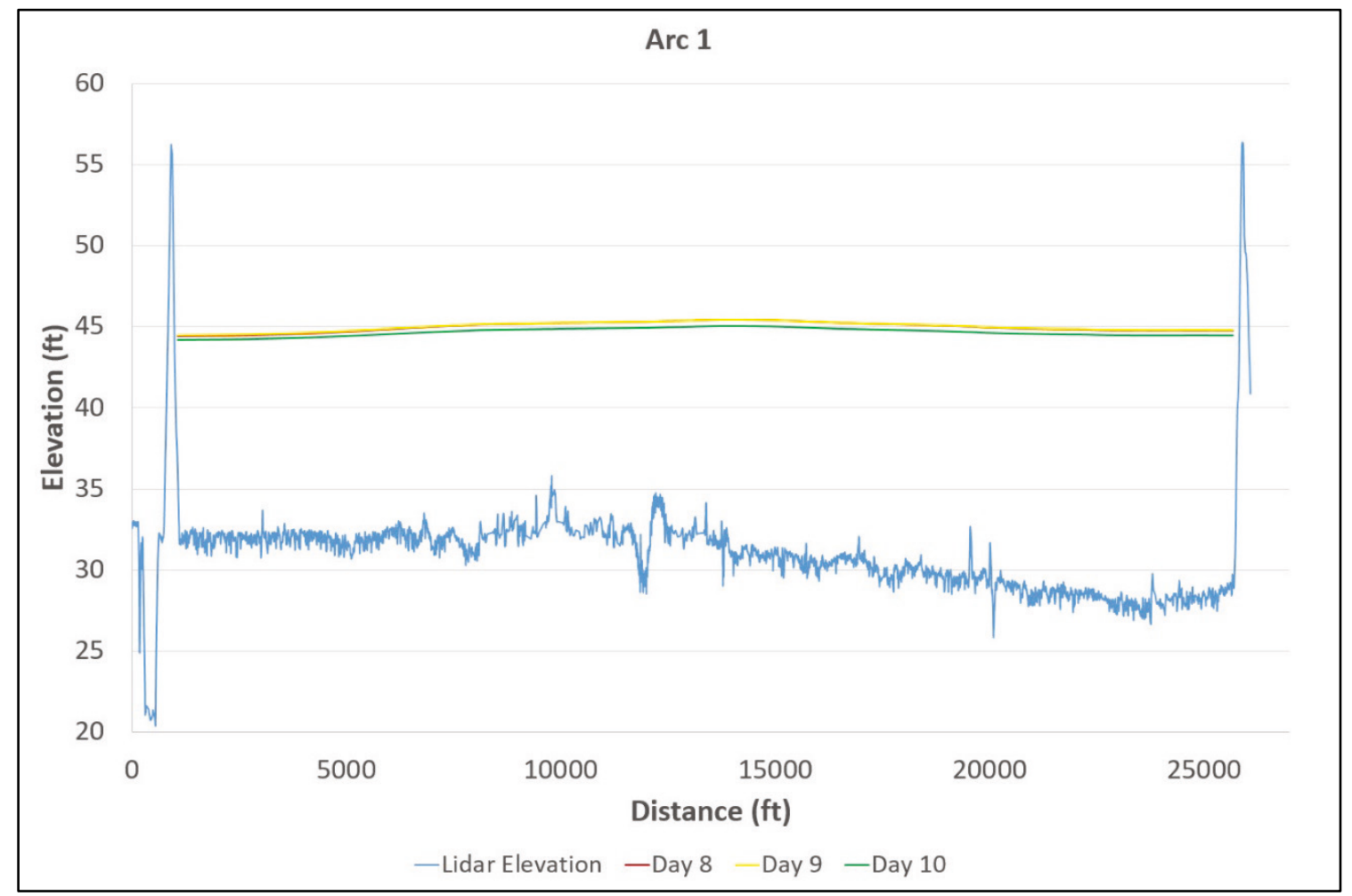

Figure 51. 2011 flood event results at Arc 2.

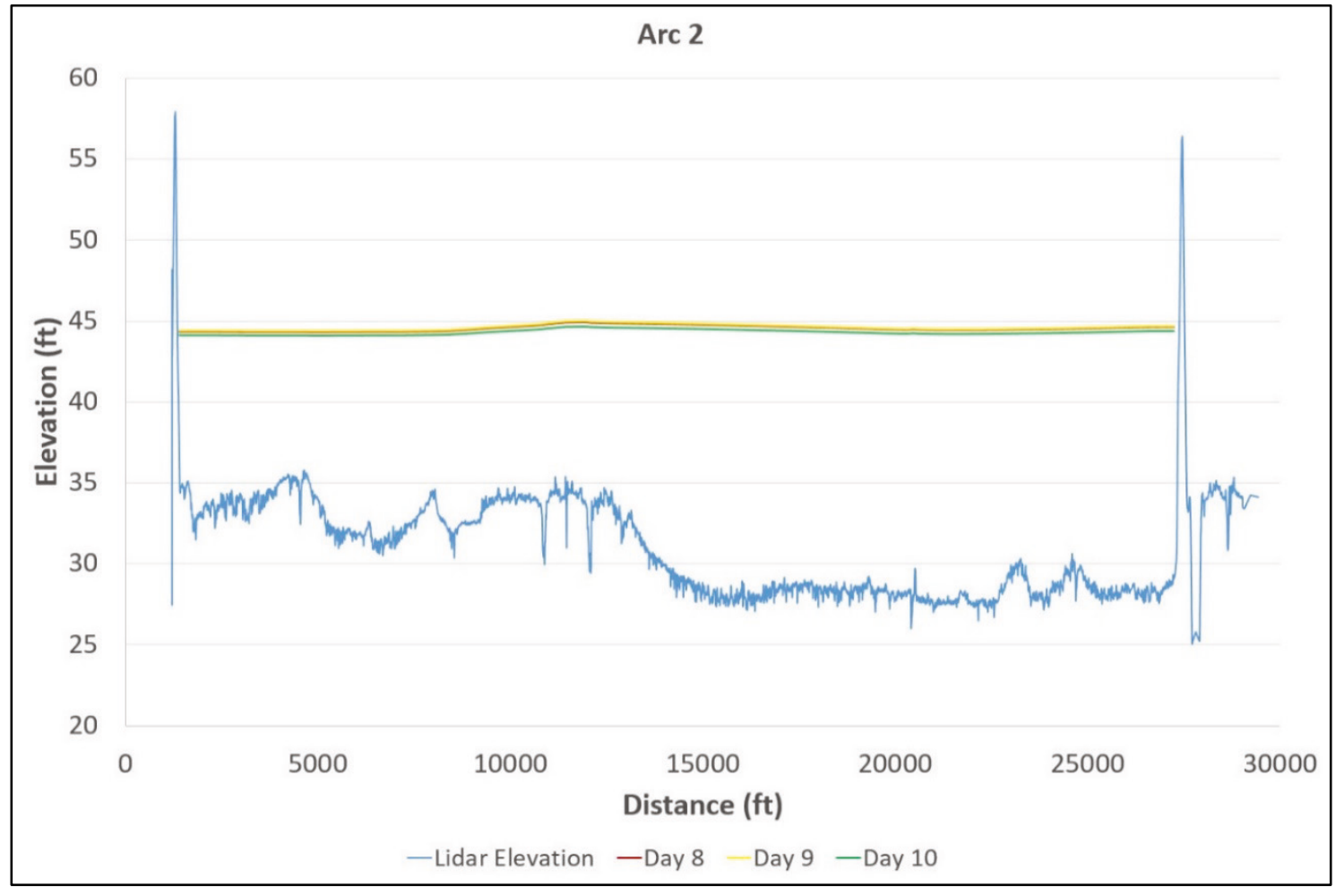


Figure 52. 2011 flood event results at Arc 3.

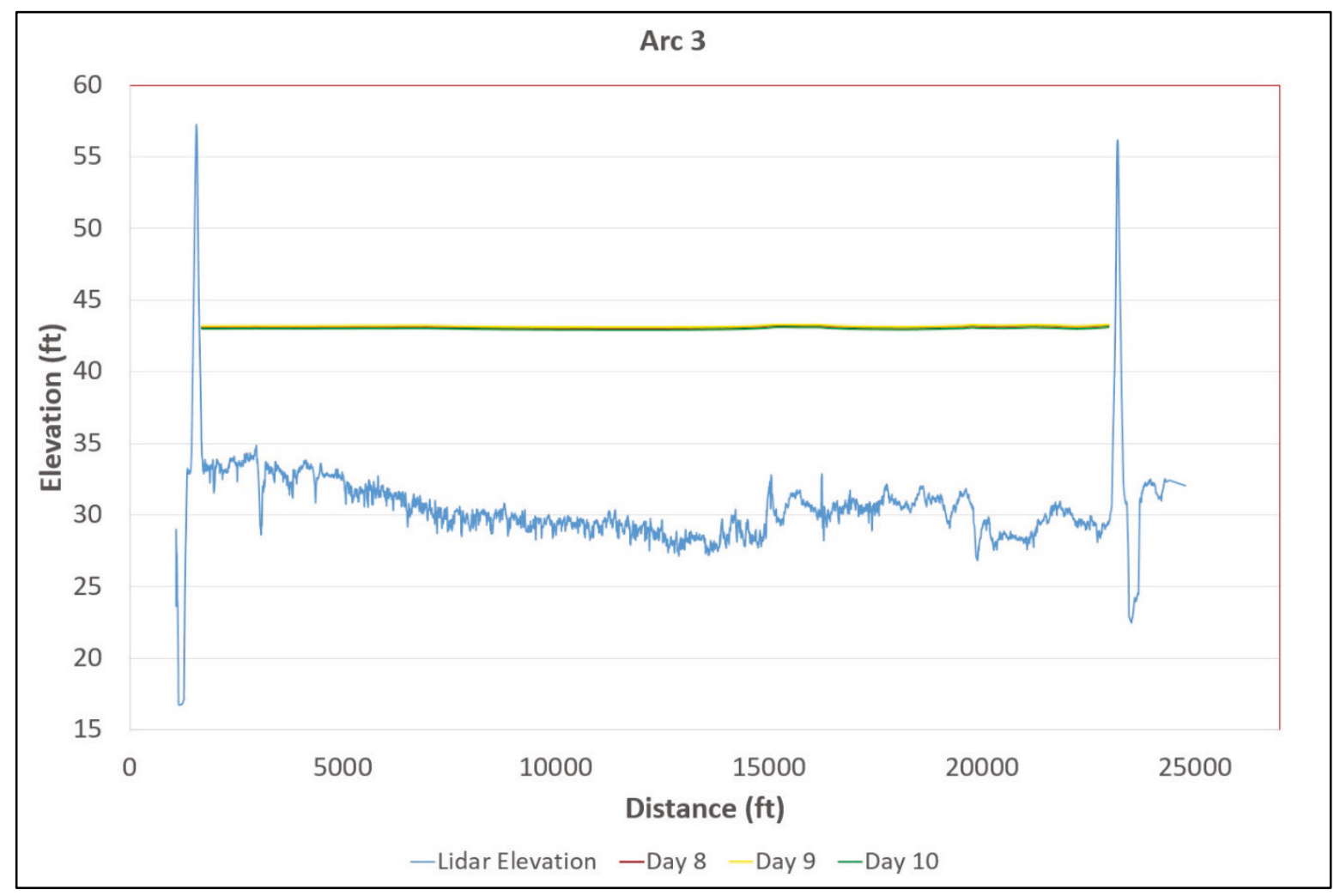

\subsubsection{Friction type sensitivity}

The results in section 4.1 show relatively good agreement between the modeled and measured data. It was decided, however, that a sensitivity test be performed investigating how the model represents the areas that were forested/high vegetation. Up to this point the model parameters treated each forested area as URV. In these areas, values for the roughness height of the bed, stem diameter, and stem density were assigned. This method is used to compute a shear-stress coefficient for use in computing the bottom shear stress from a steady (or quasi-steady) current through rigid, unsubmerged vegetation (ERDC CHL 2017).

Each of the areas that were assigned URV parameters in the model were changed so that they utilized an assigned Manning's roughness value. Model simulation results with these parameters are represented by the letters "MNC" in this report. Selection of the value for these areas was guided by Arcement et al. 1989. These values were then calibrated to the 2011 flood event as were the URV values in section 4.1. Comparison plots are provided in Figures 53-83. 
Figure 53. Gage AO1 model results.

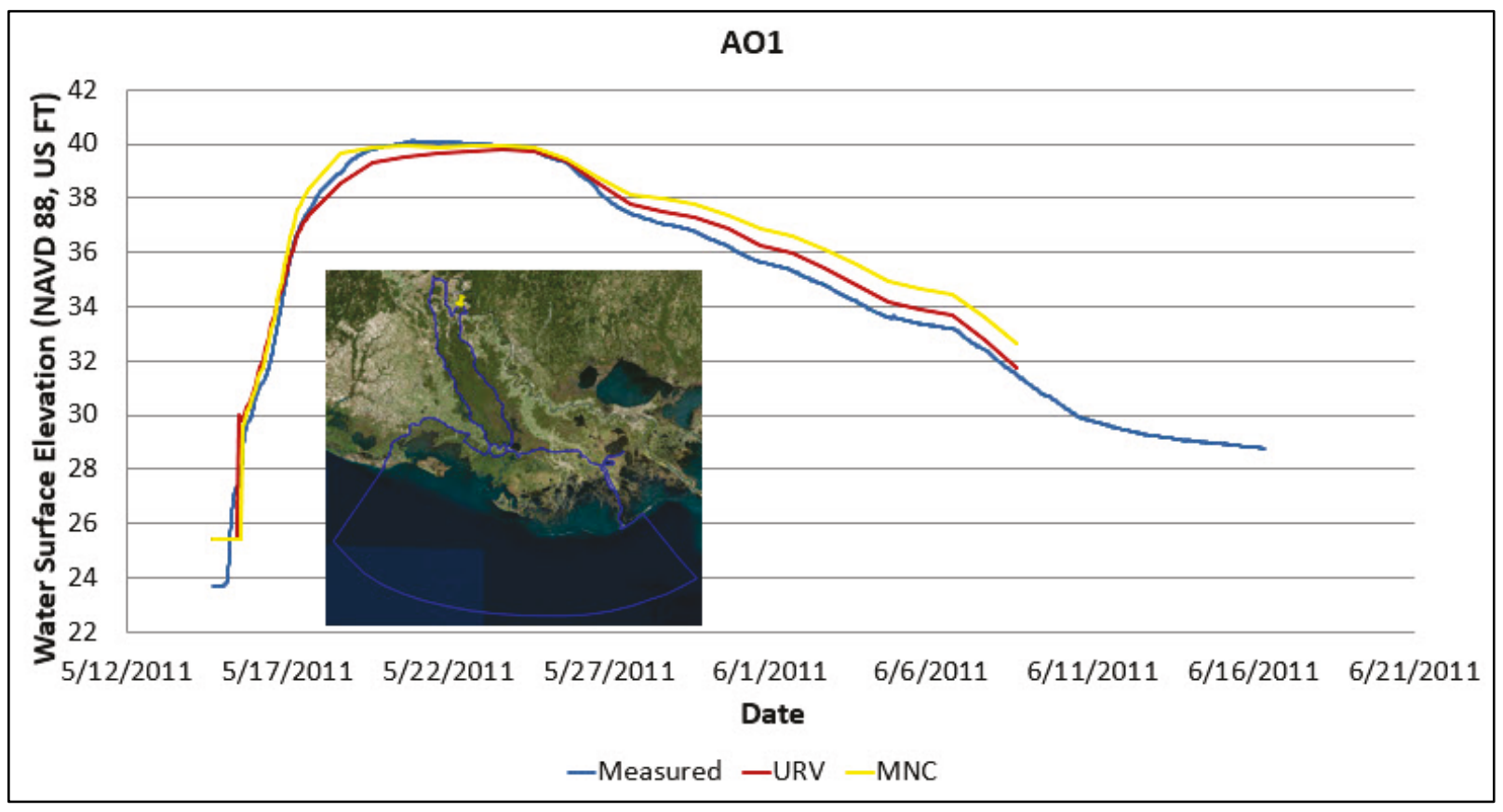

Figure 54. Gage AO2 model results.

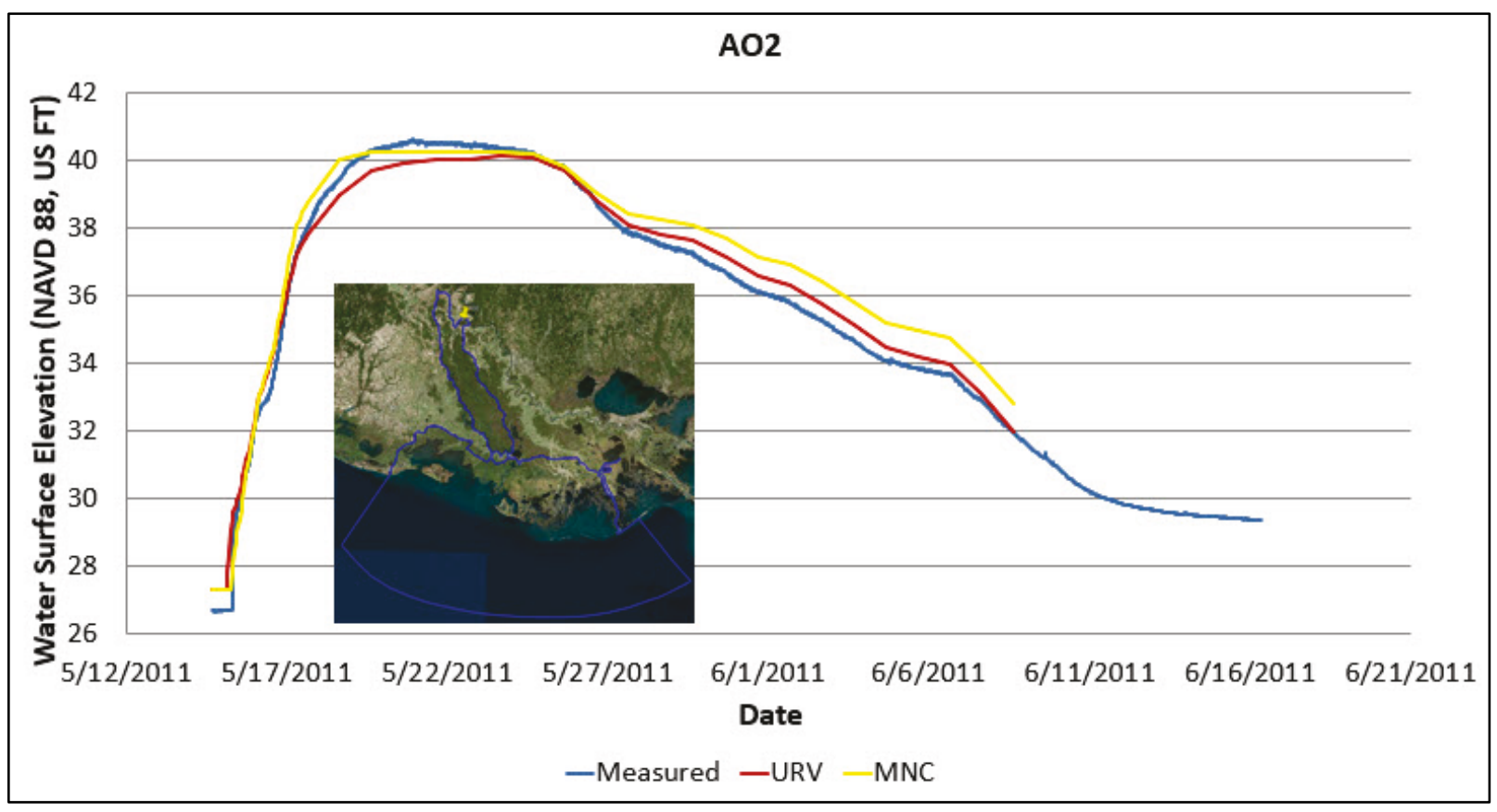


Figure 55. Gage AO3 model results.

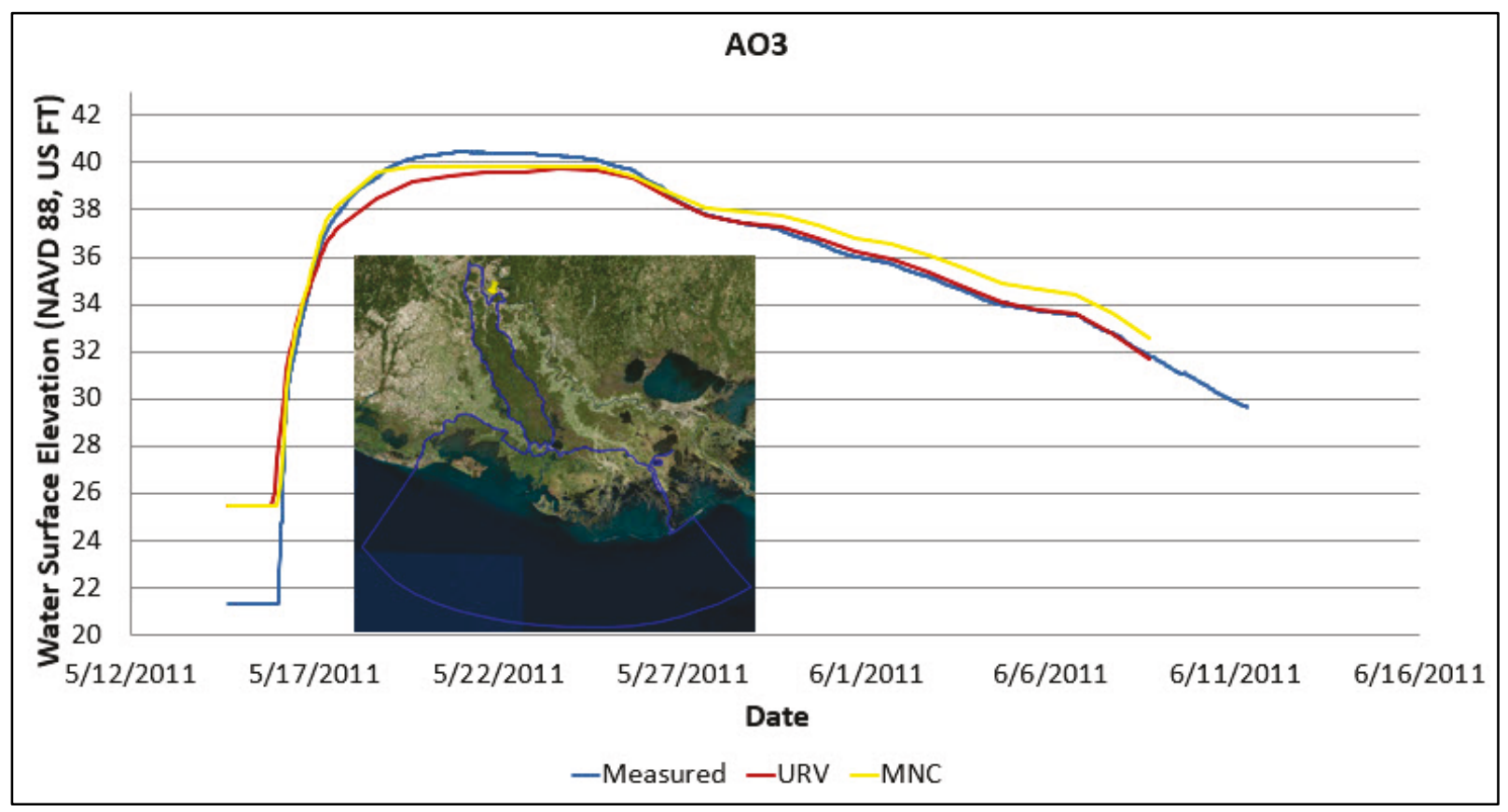

Figure 56. Gage AO4 model results.

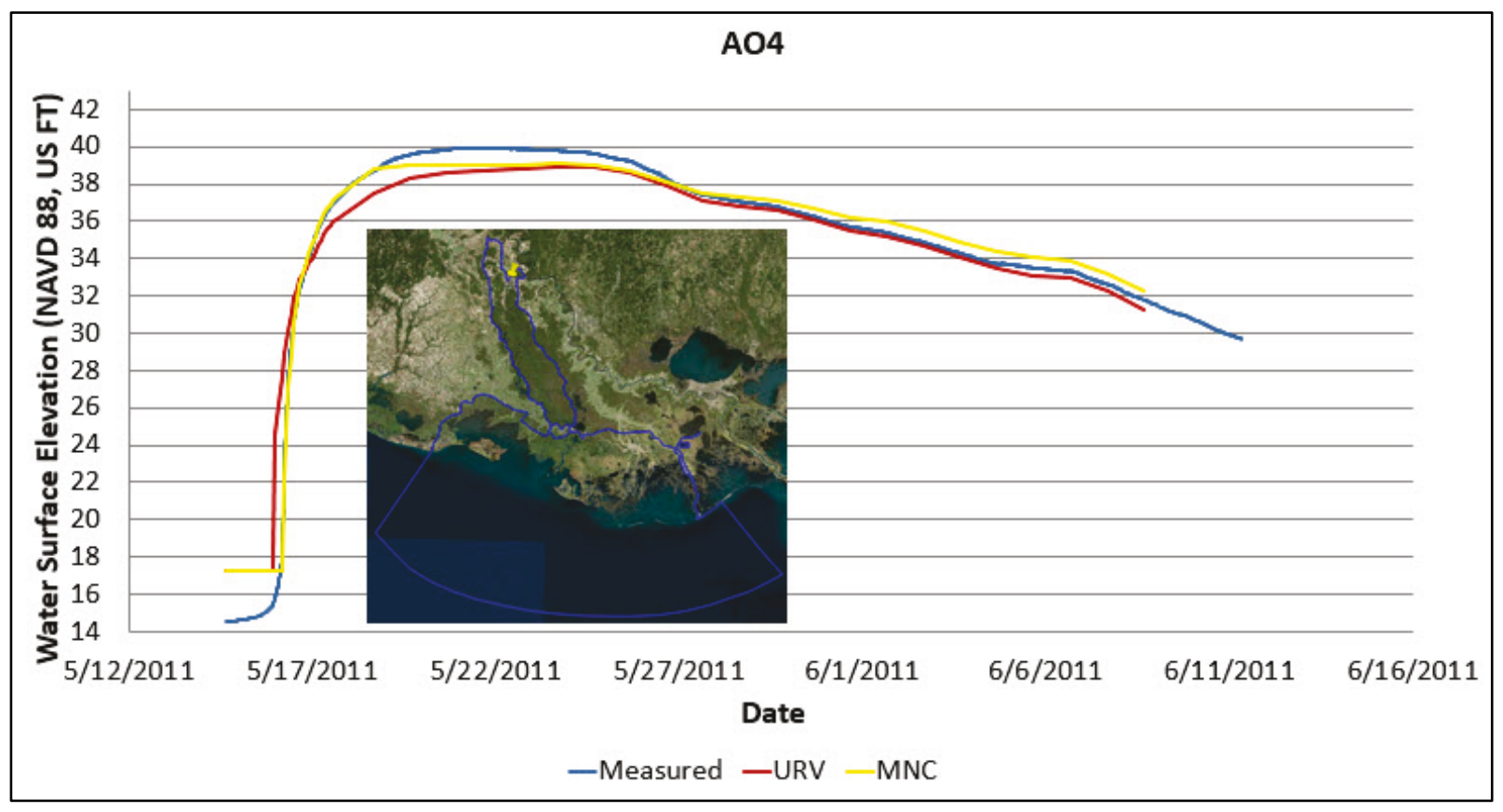


Figure 57. Gage A06 model results.

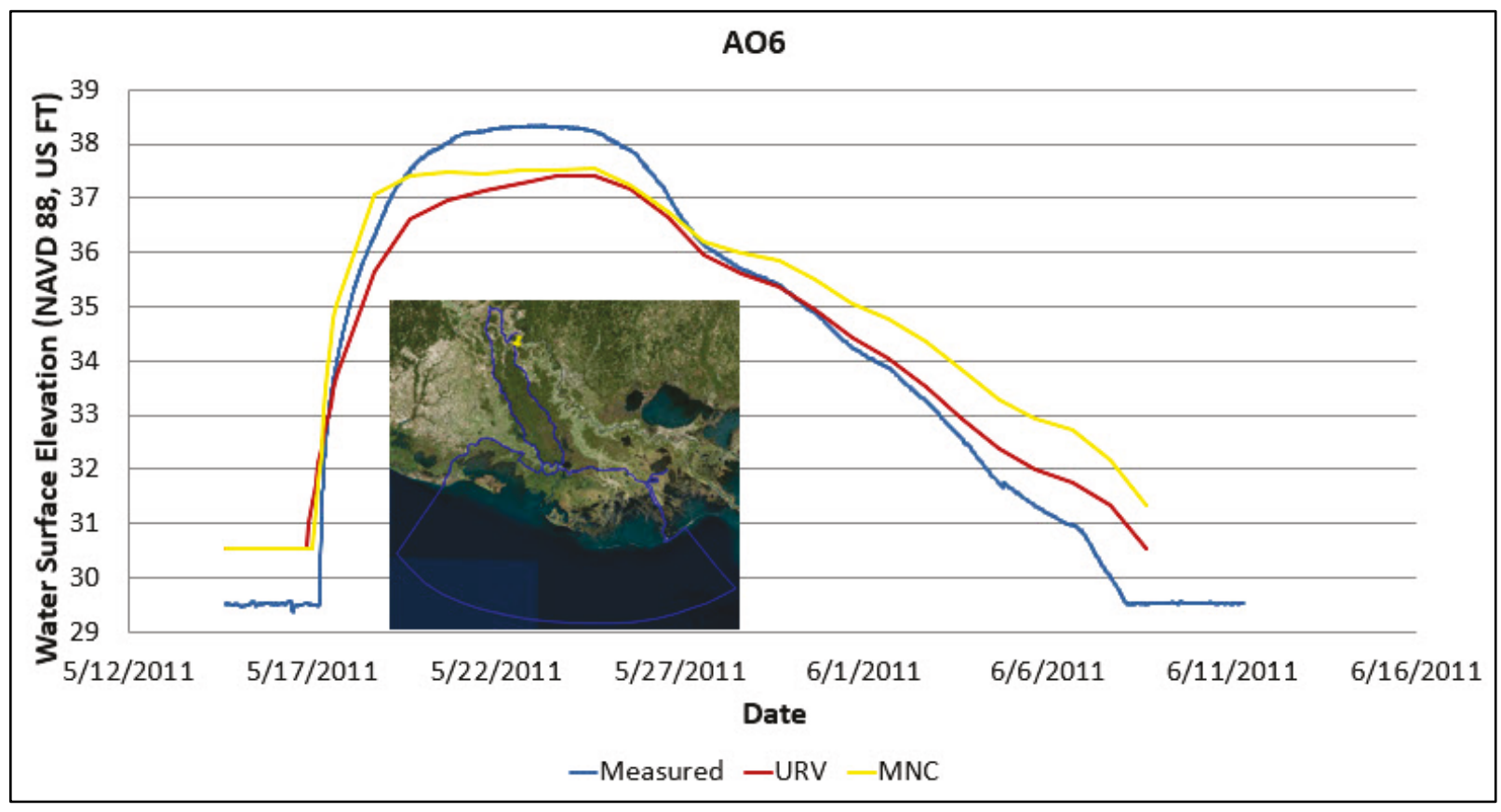

Figure 58. Gage A07 model results.

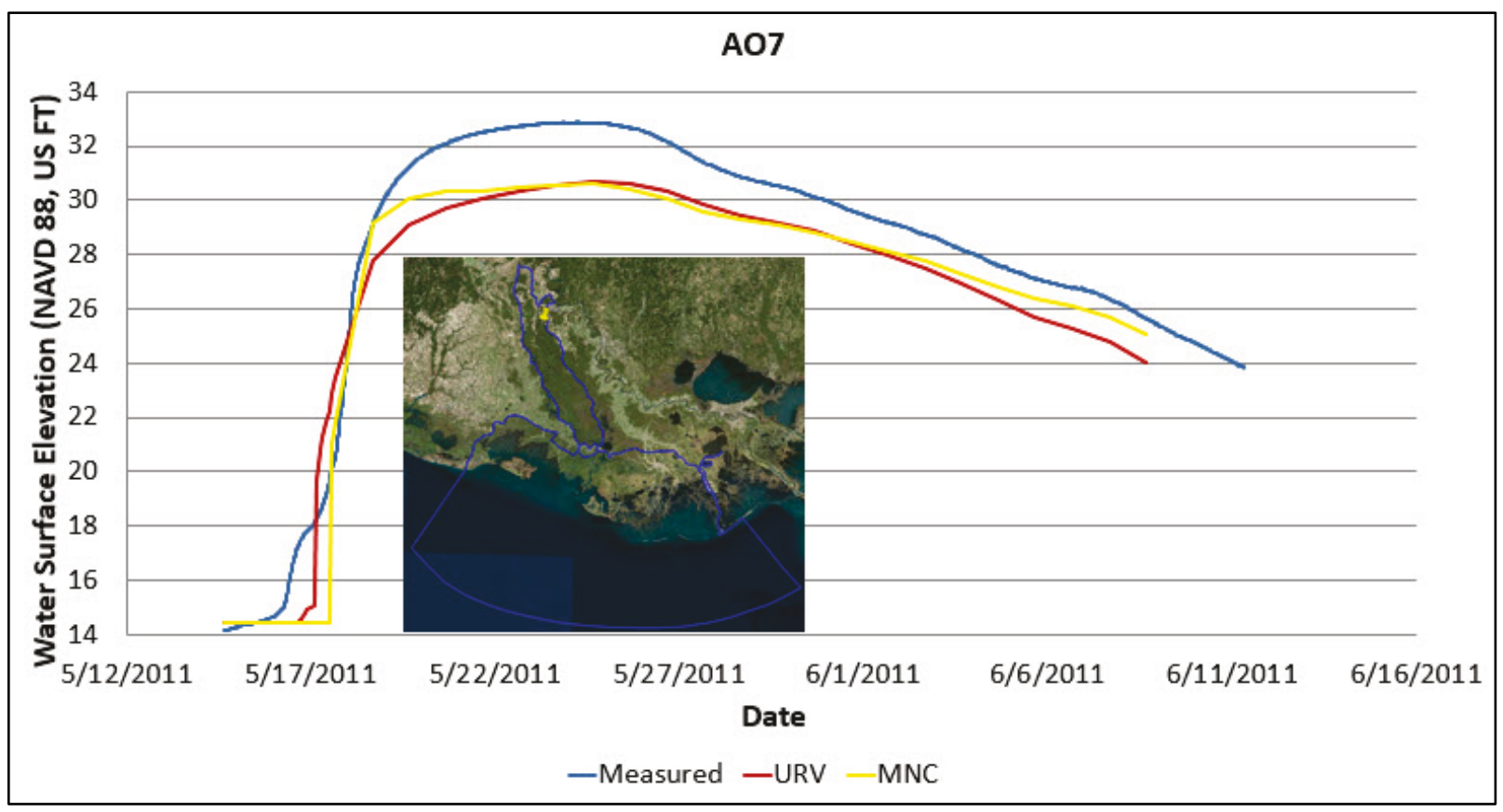


Figure 59. Gage B04 model results.

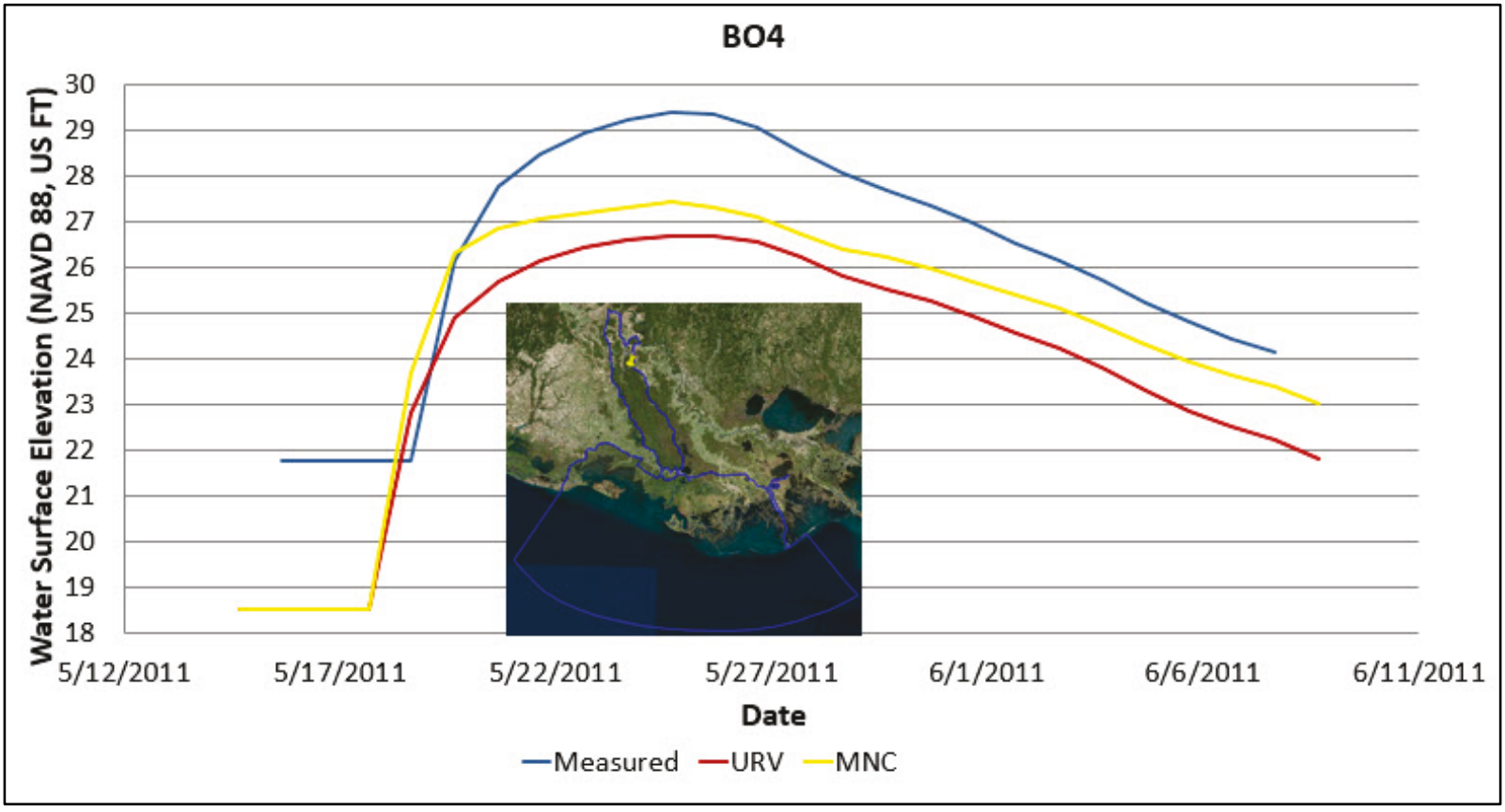

Figure 60. Gage $\mathrm{CO4}$ model results.

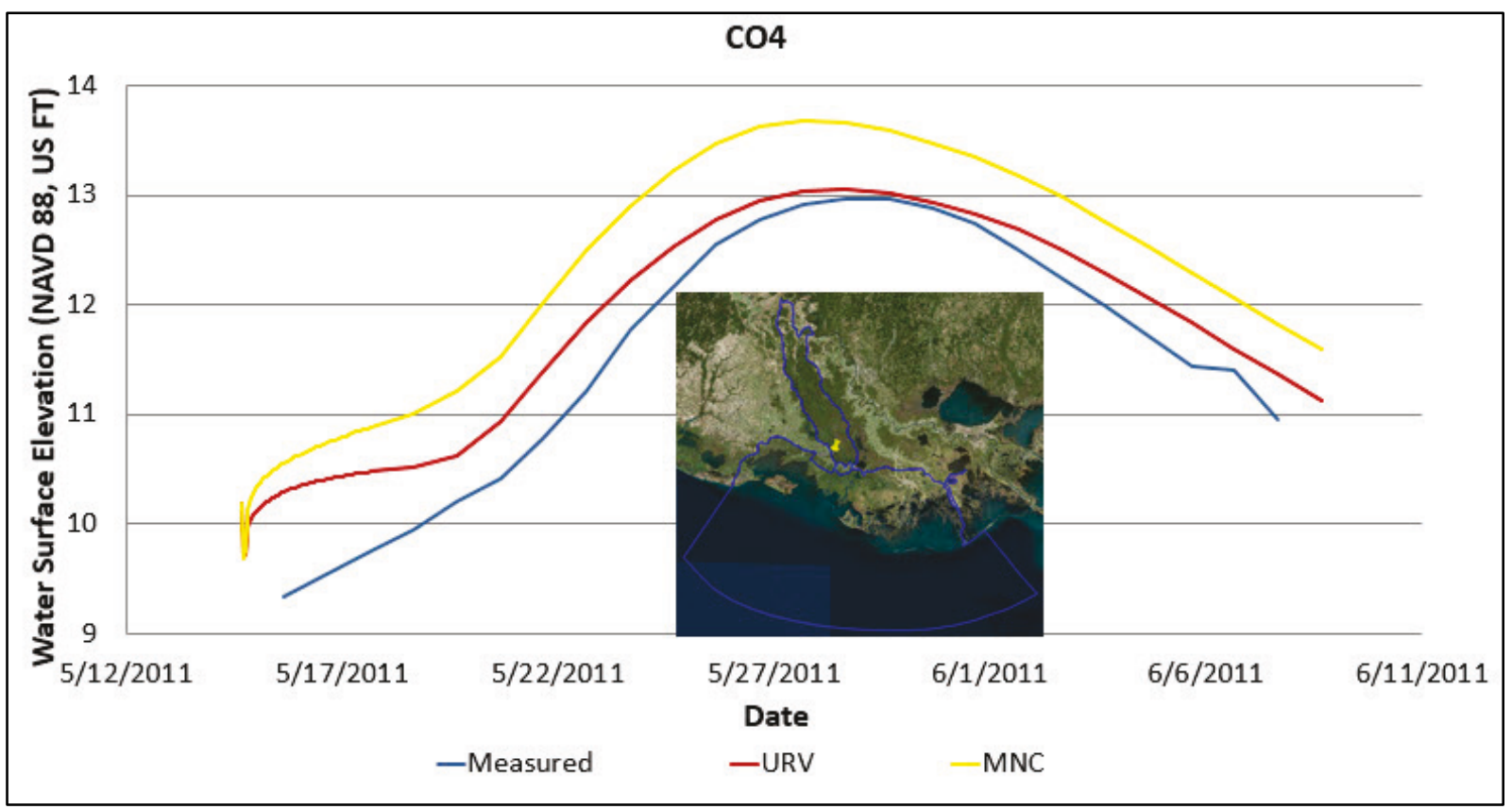


Figure 61. Gage K2 model results.

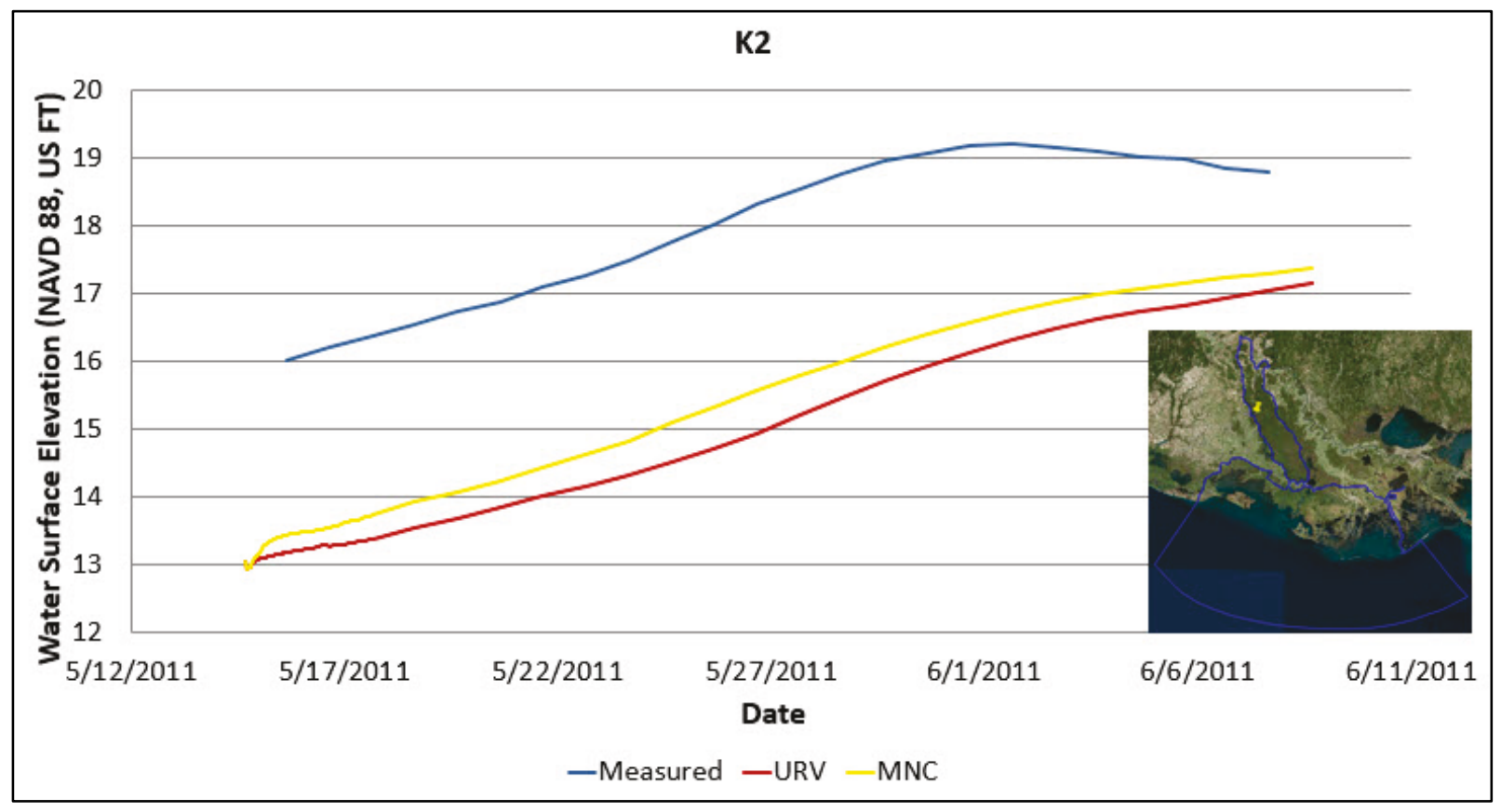

Figure 62. Gage K3 model results.

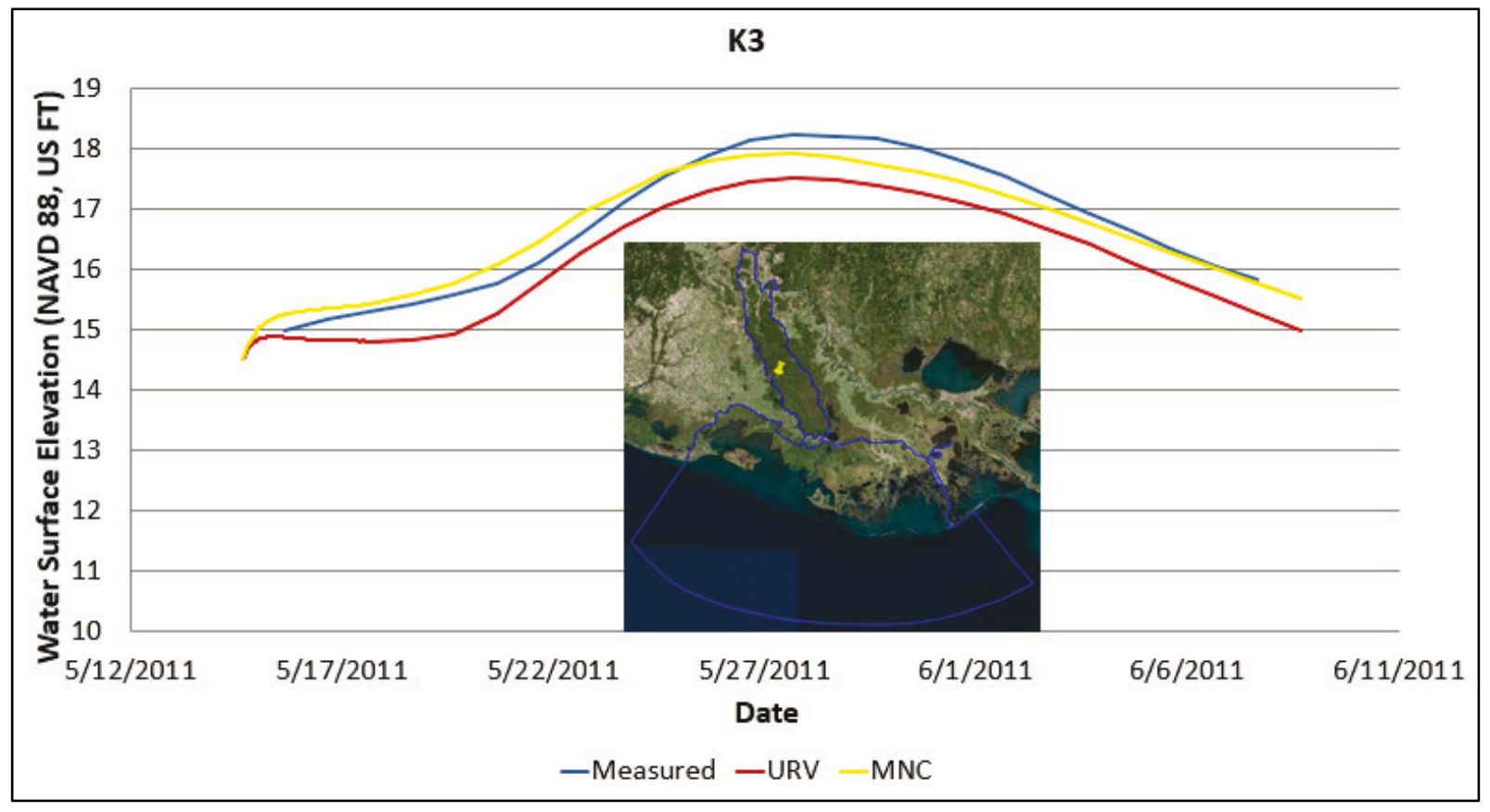


Figure 63. Gage K4 model results.

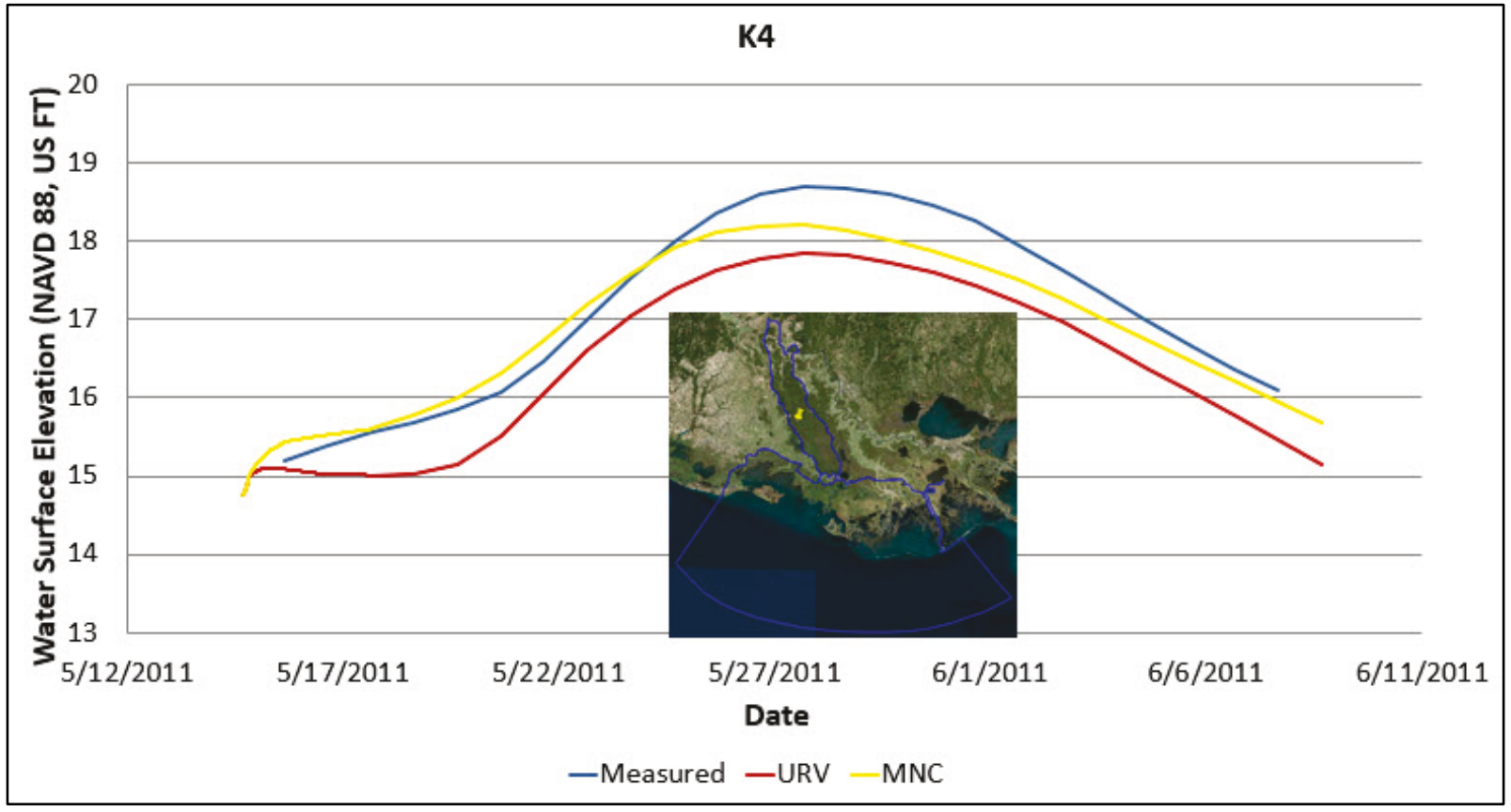

Figure 64. Gage K5 model results.

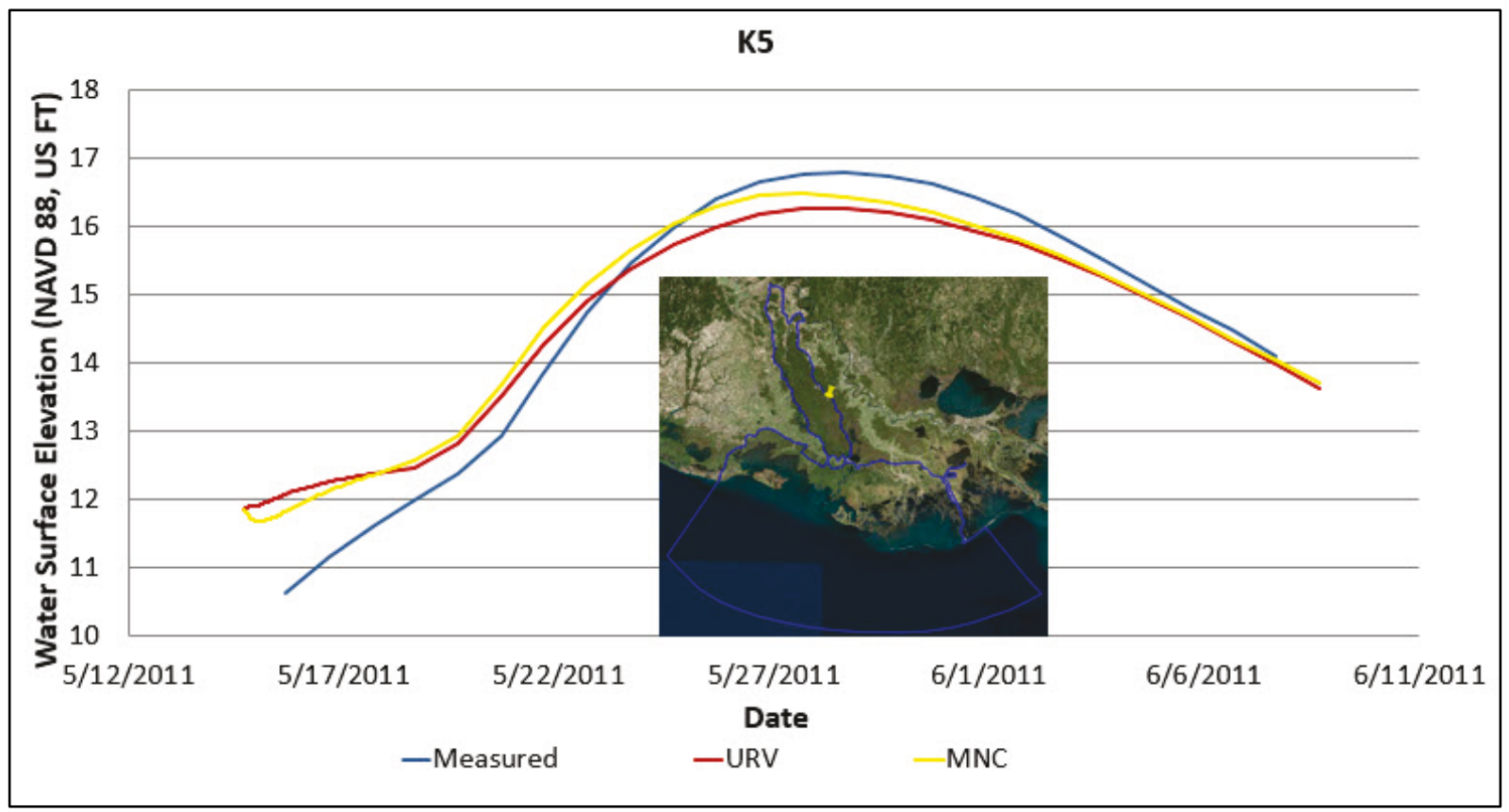


Figure 65. Gage K6 model results.

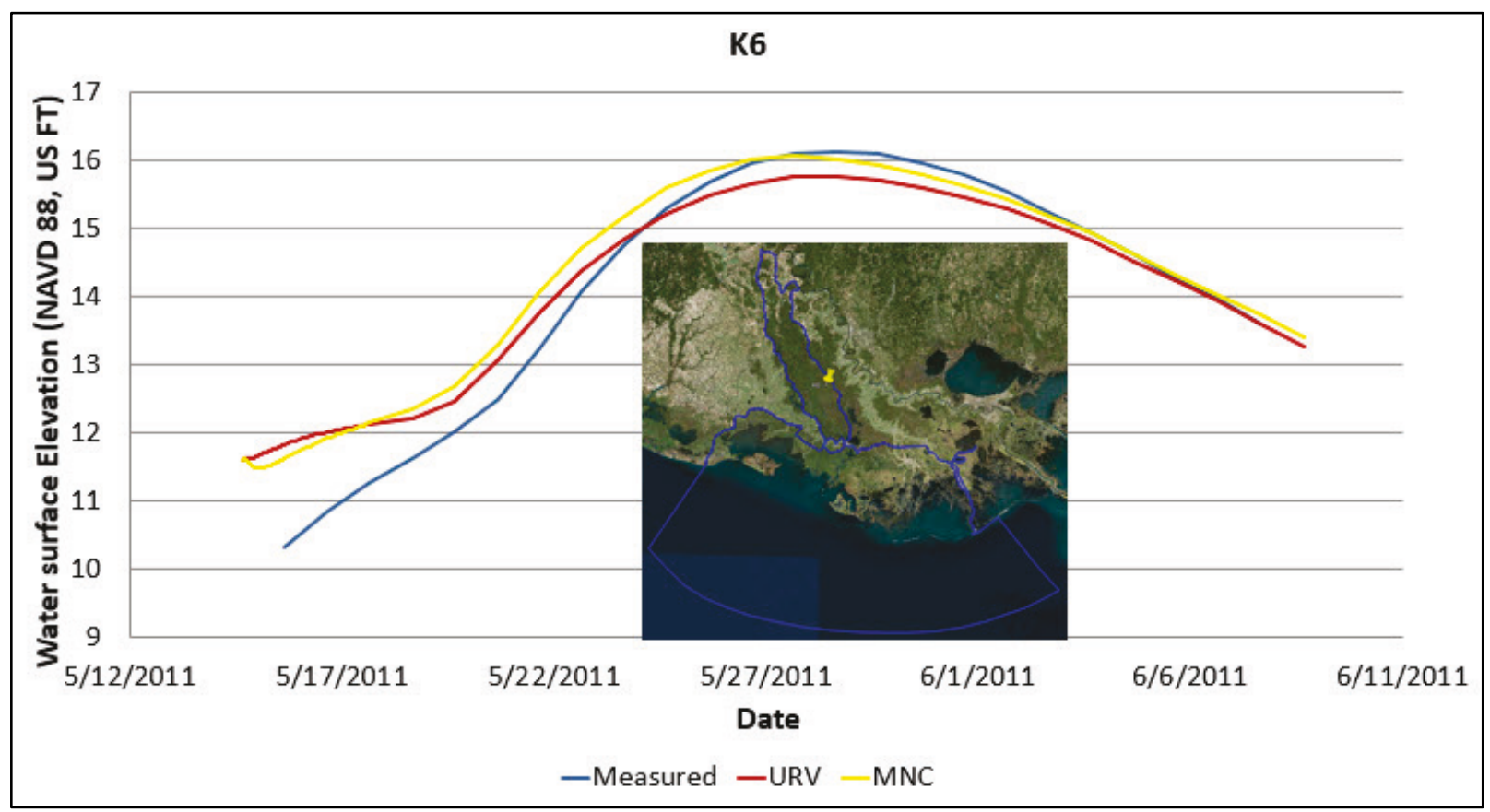

Figure 66. Gage K7 model results.

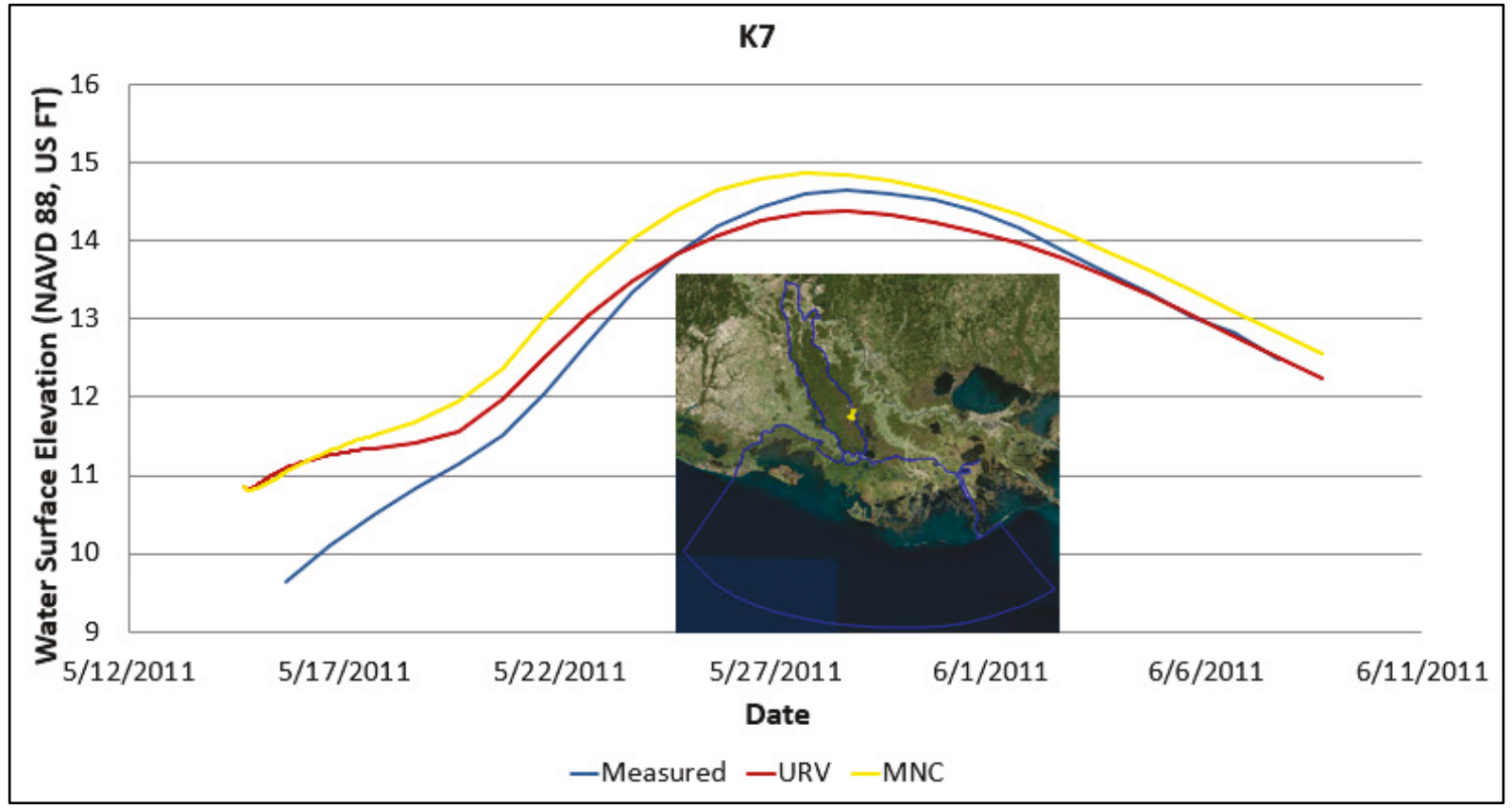


Figure 67. Gage K8 model results.

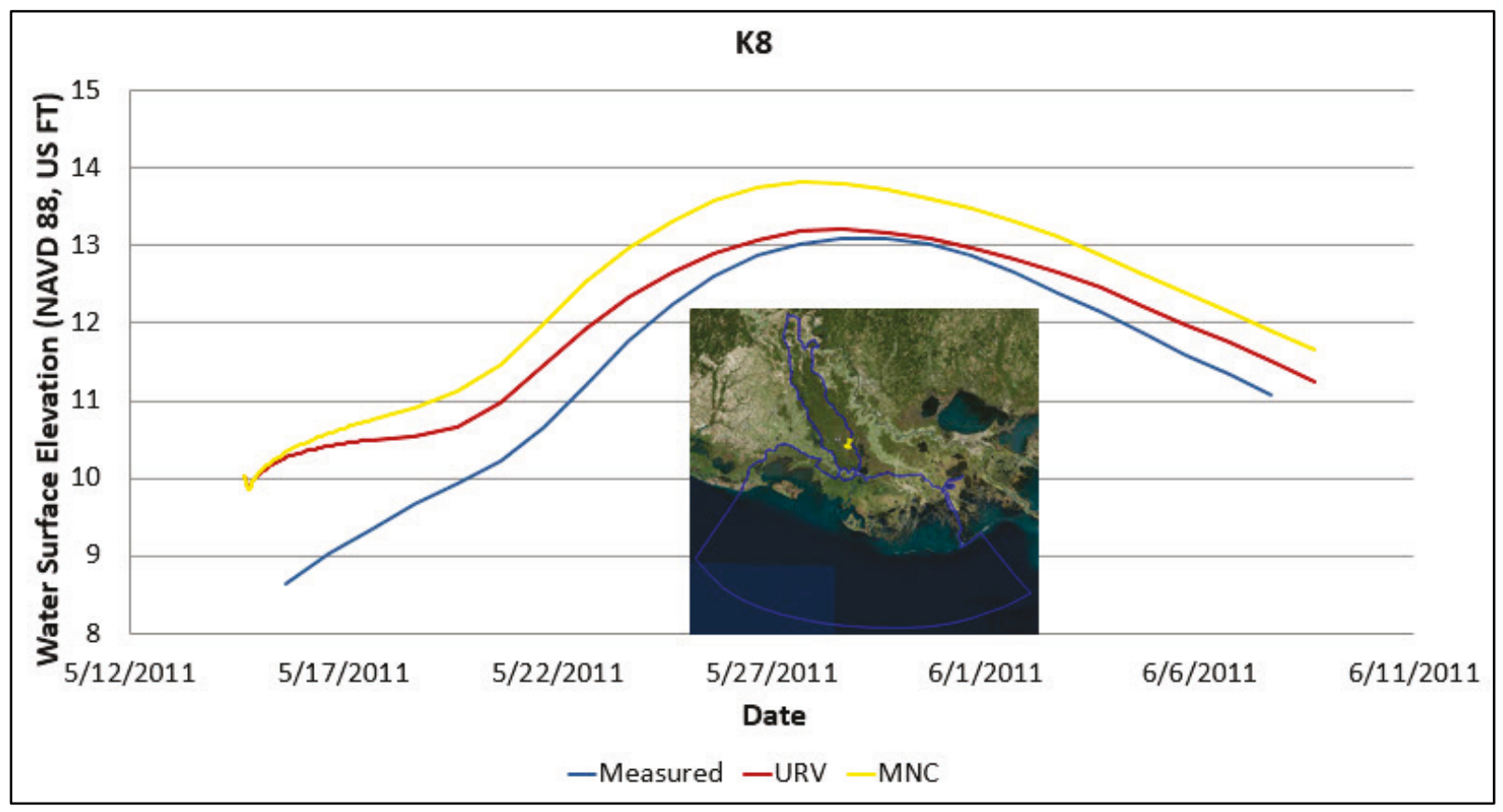

Figure 68. Gage K9 model results.

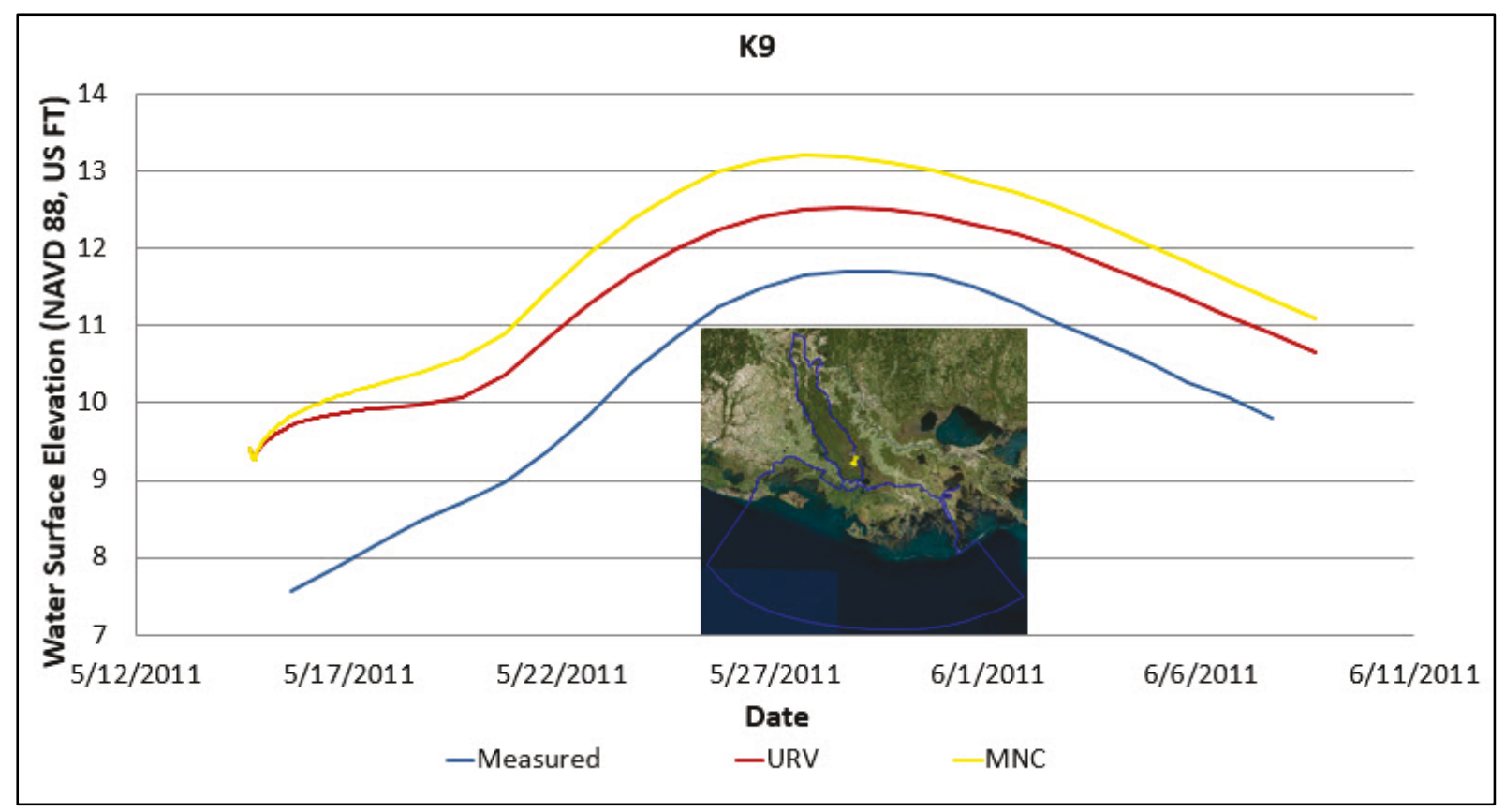


Figure 69. Gage K10 model results.

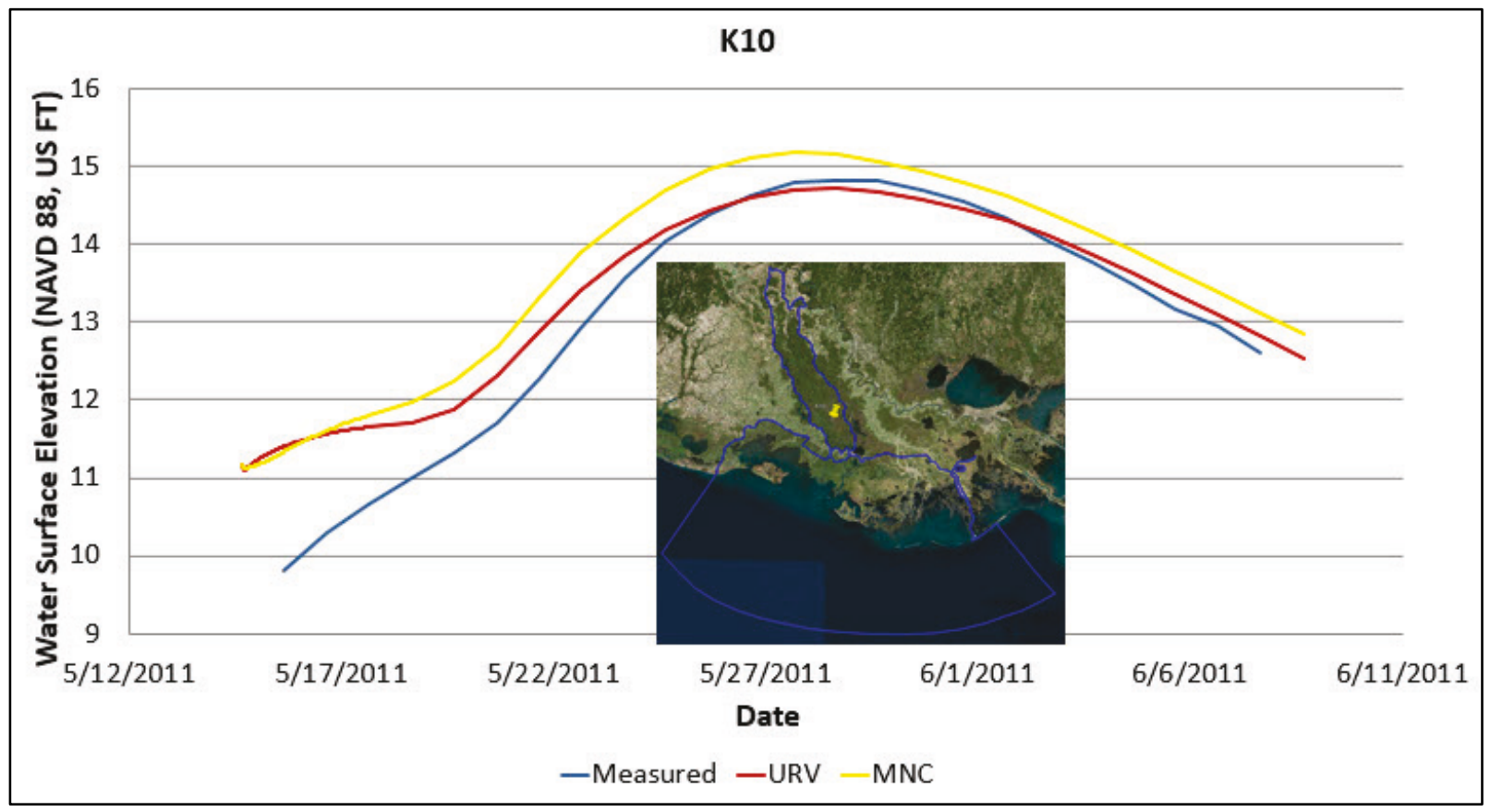

Figure 70. Gage K11 model results.

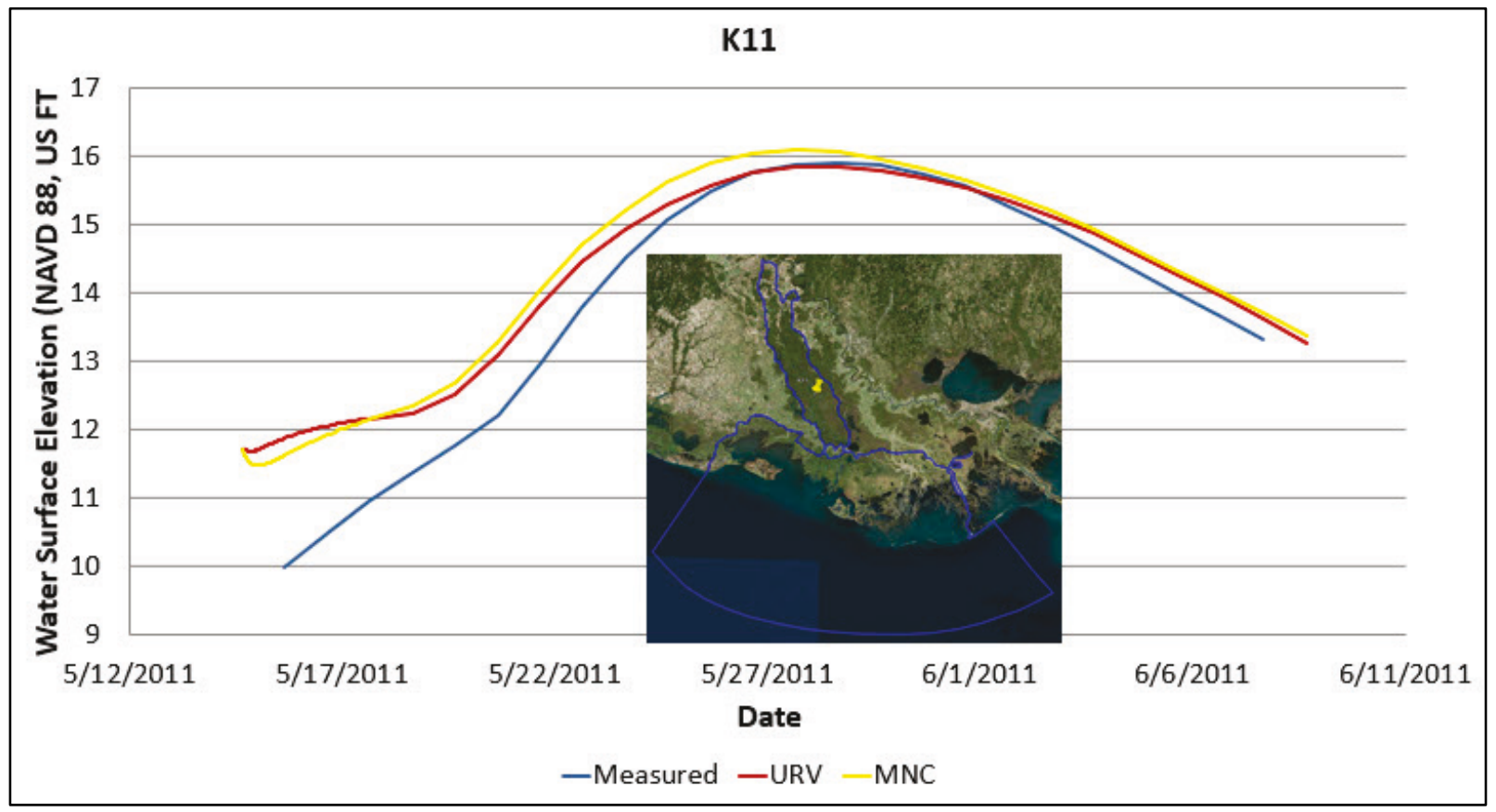


Figure 71. Gage K12 model results.

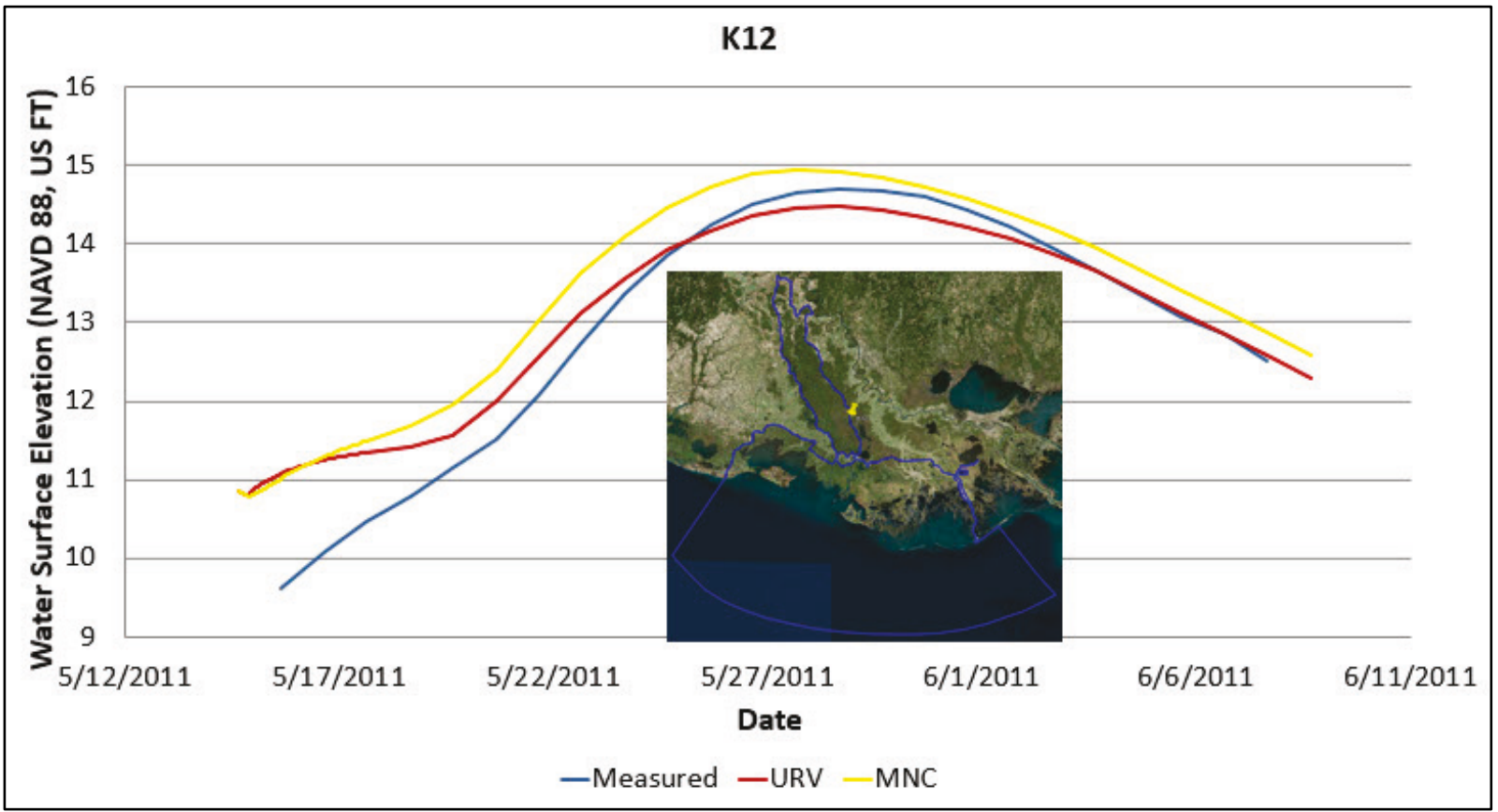

Figure 72. Gage K13 model results.

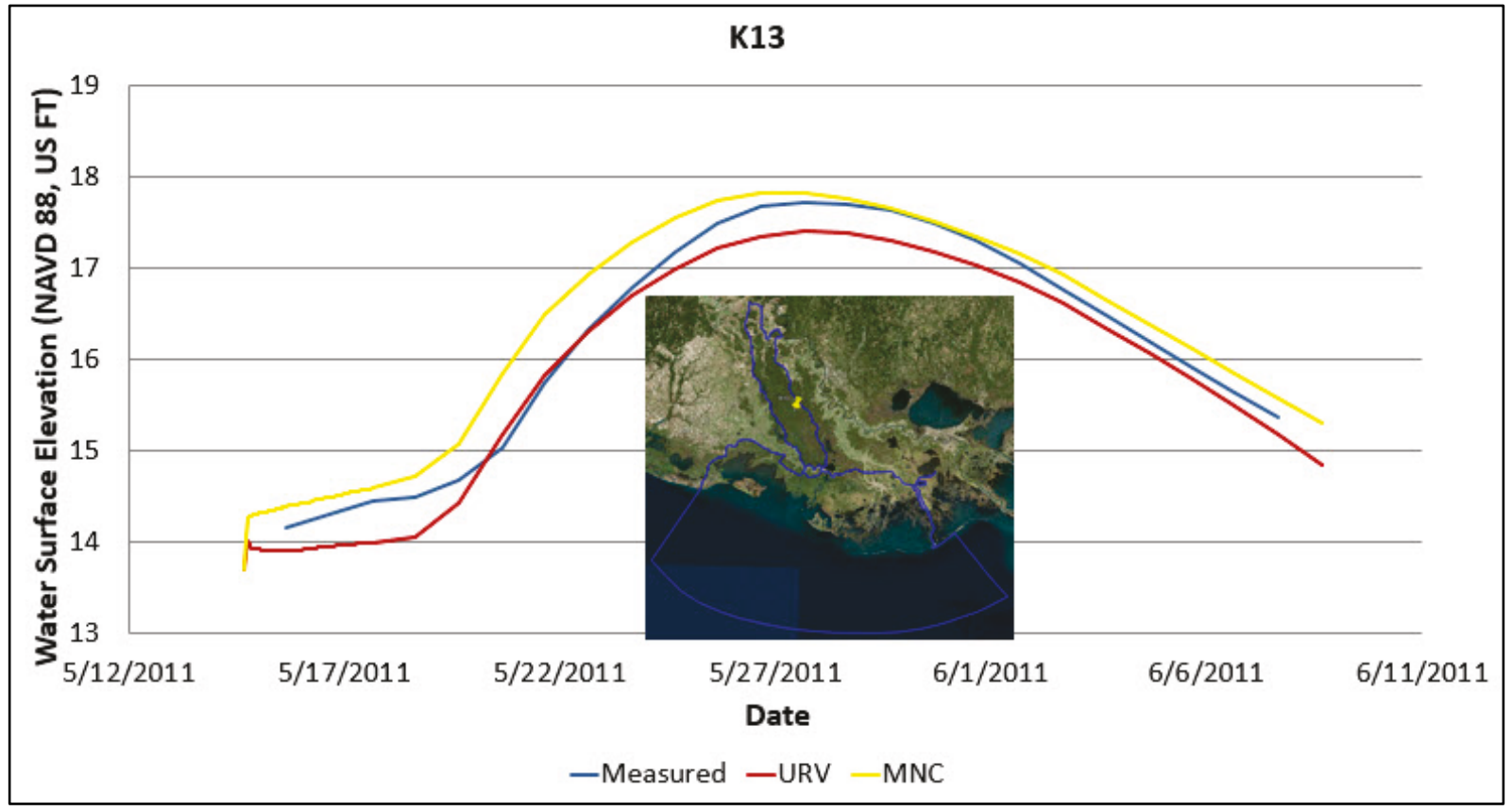


Figure 73. Gage K14 model results.

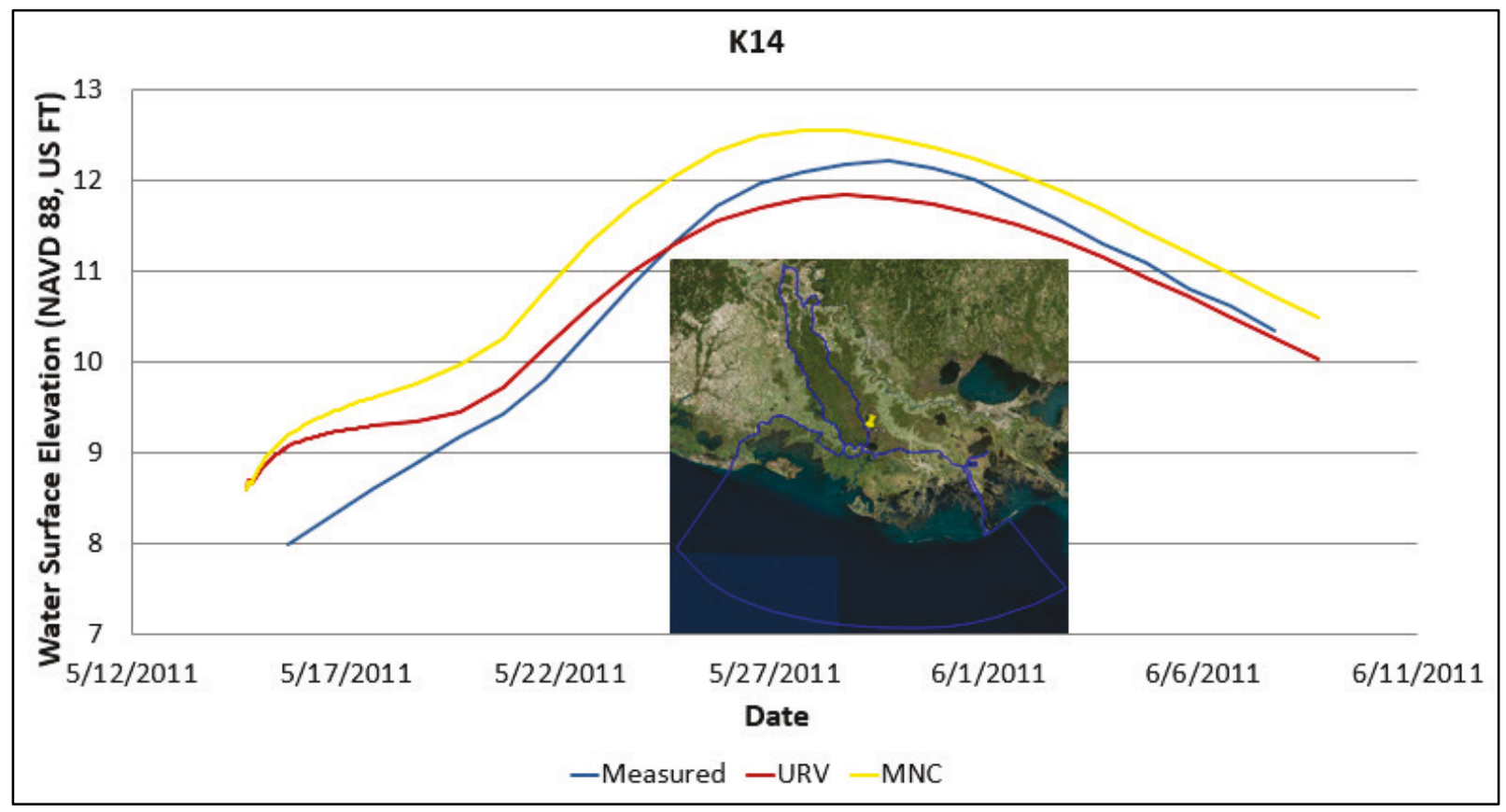

Figure 74. Gage K15 model results.

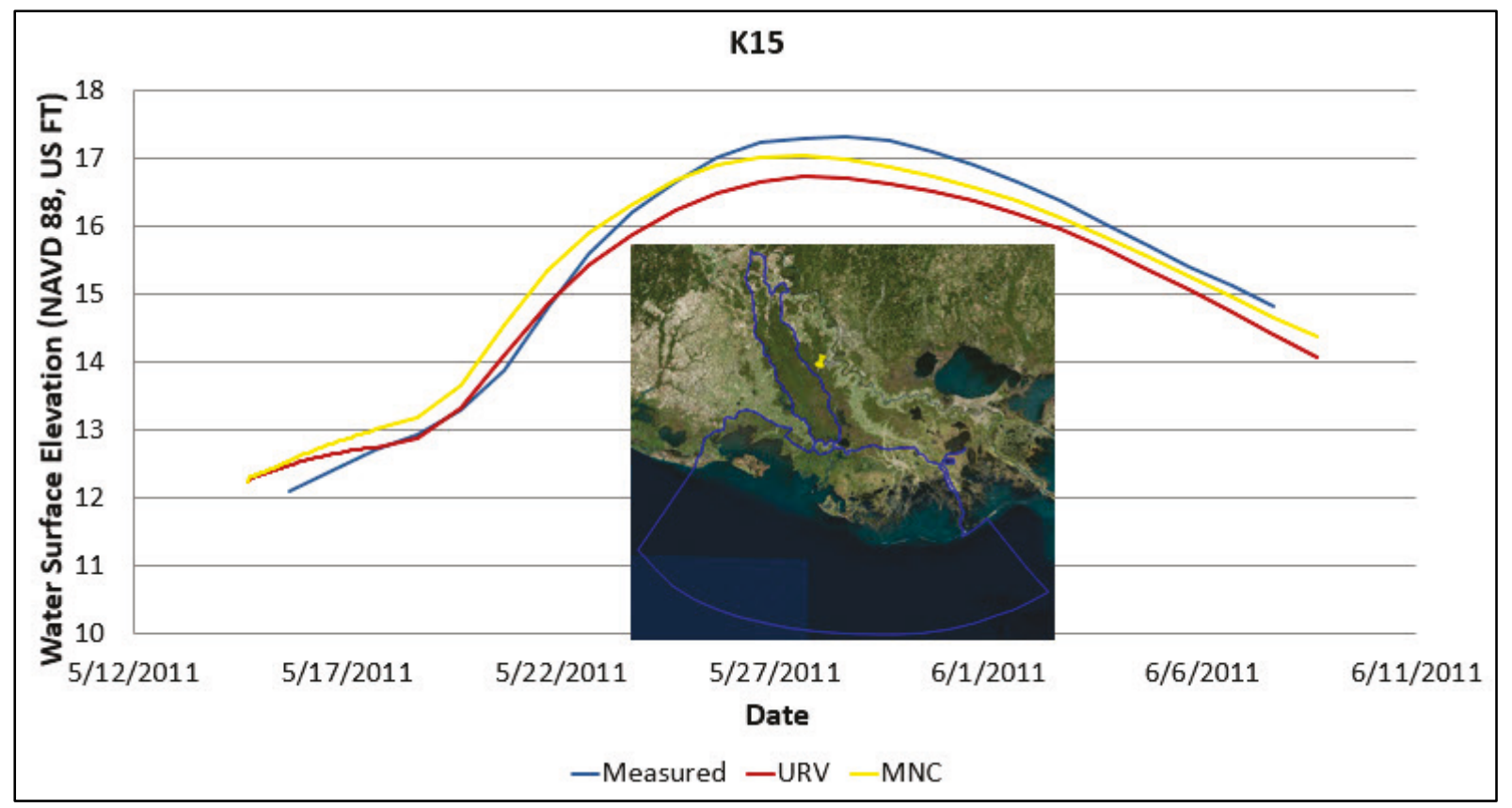


Figure 75. Gage K16 model results.

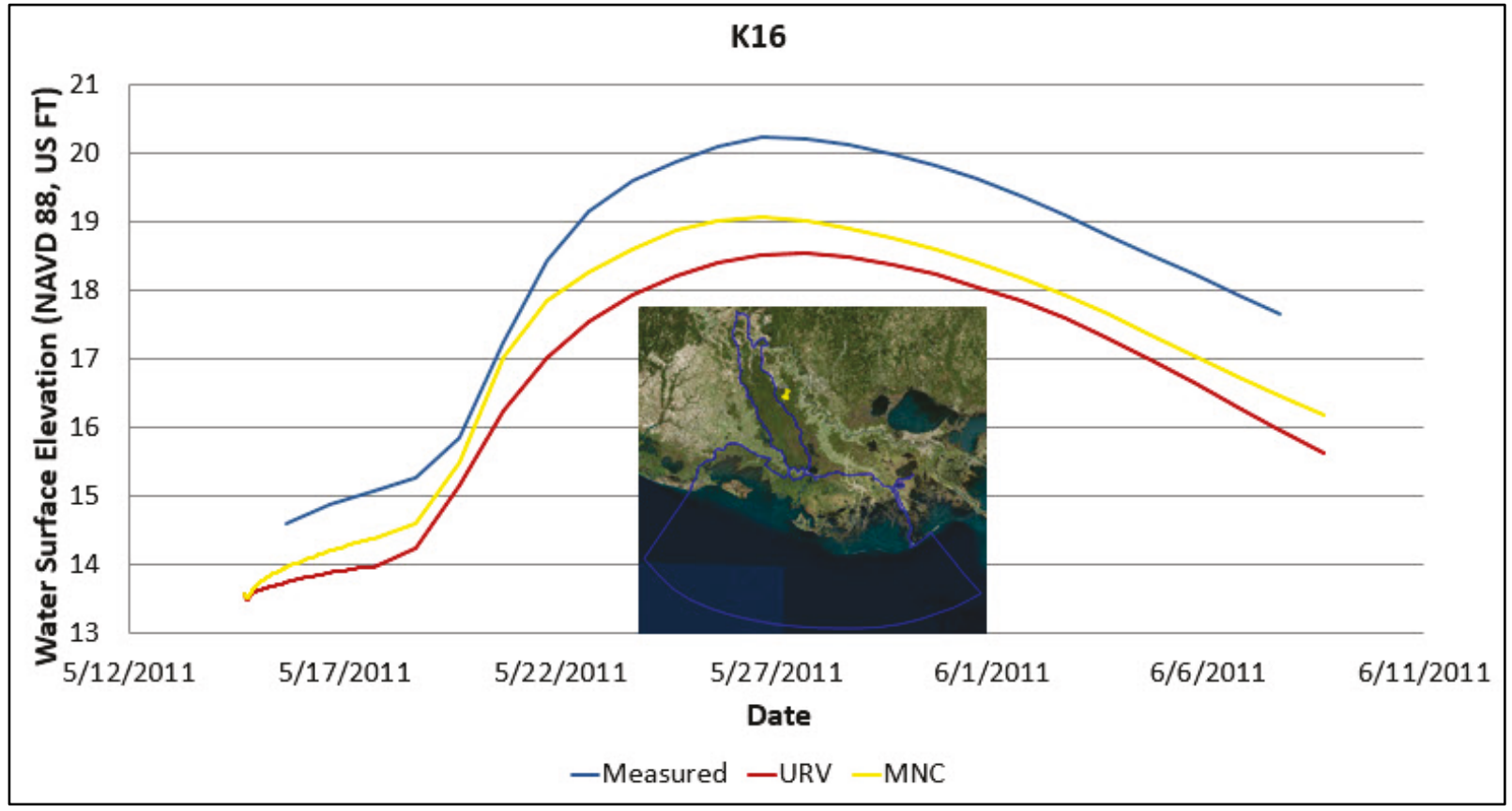

Figure 76. Gage K17 model results.

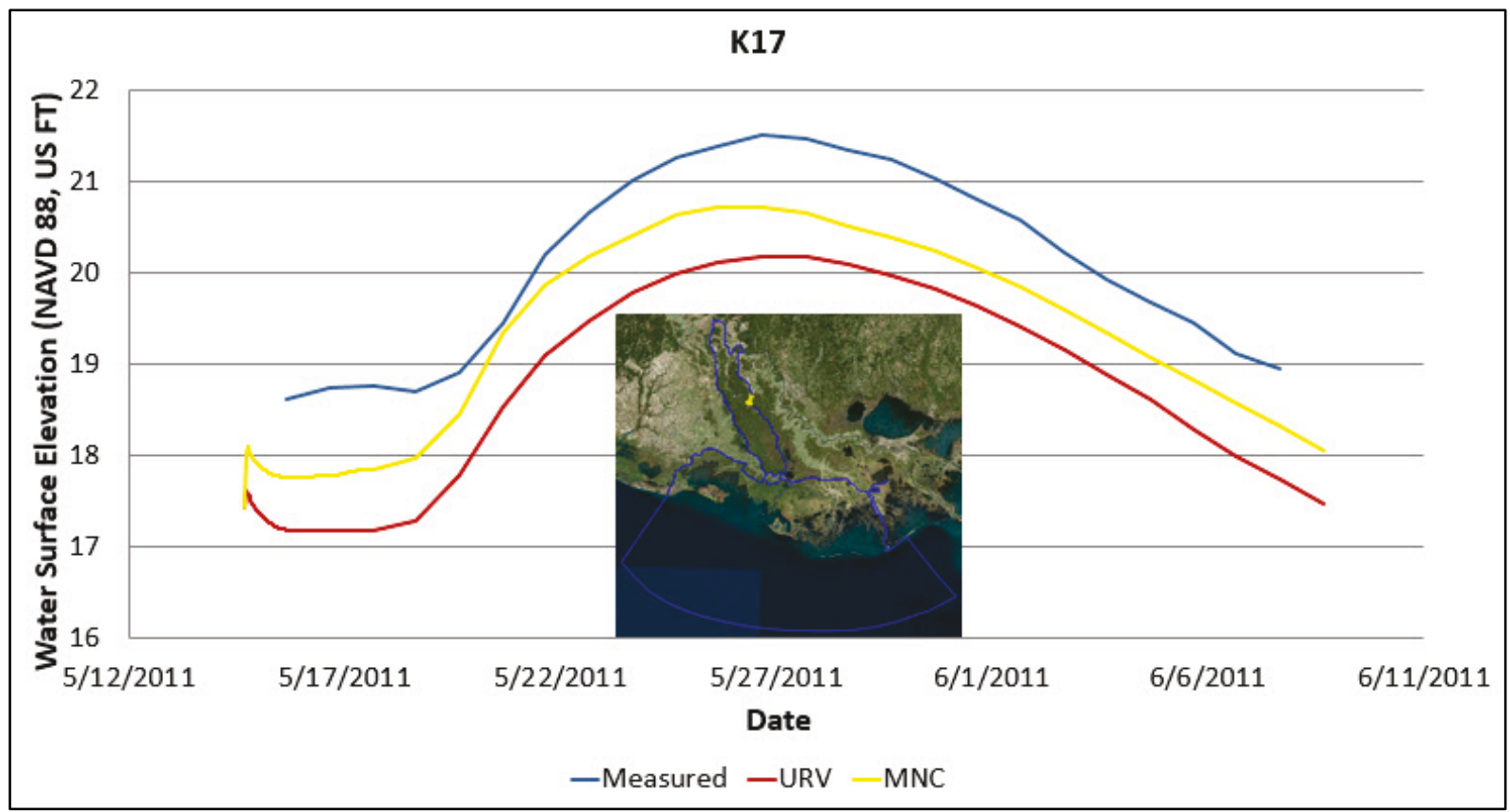


Figure 77. Gage K18 model results.

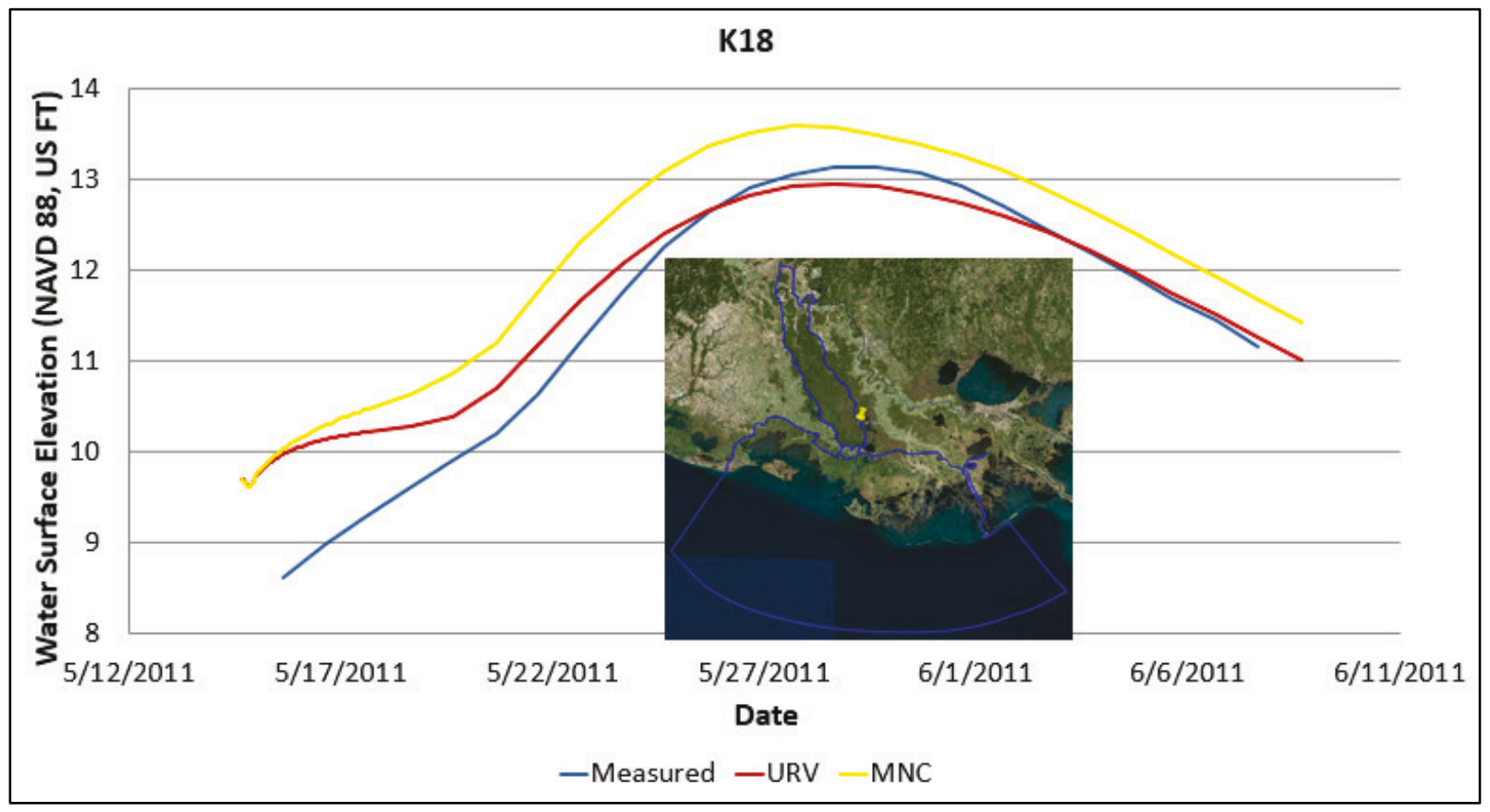

Figure 78. Gage K19 model results.

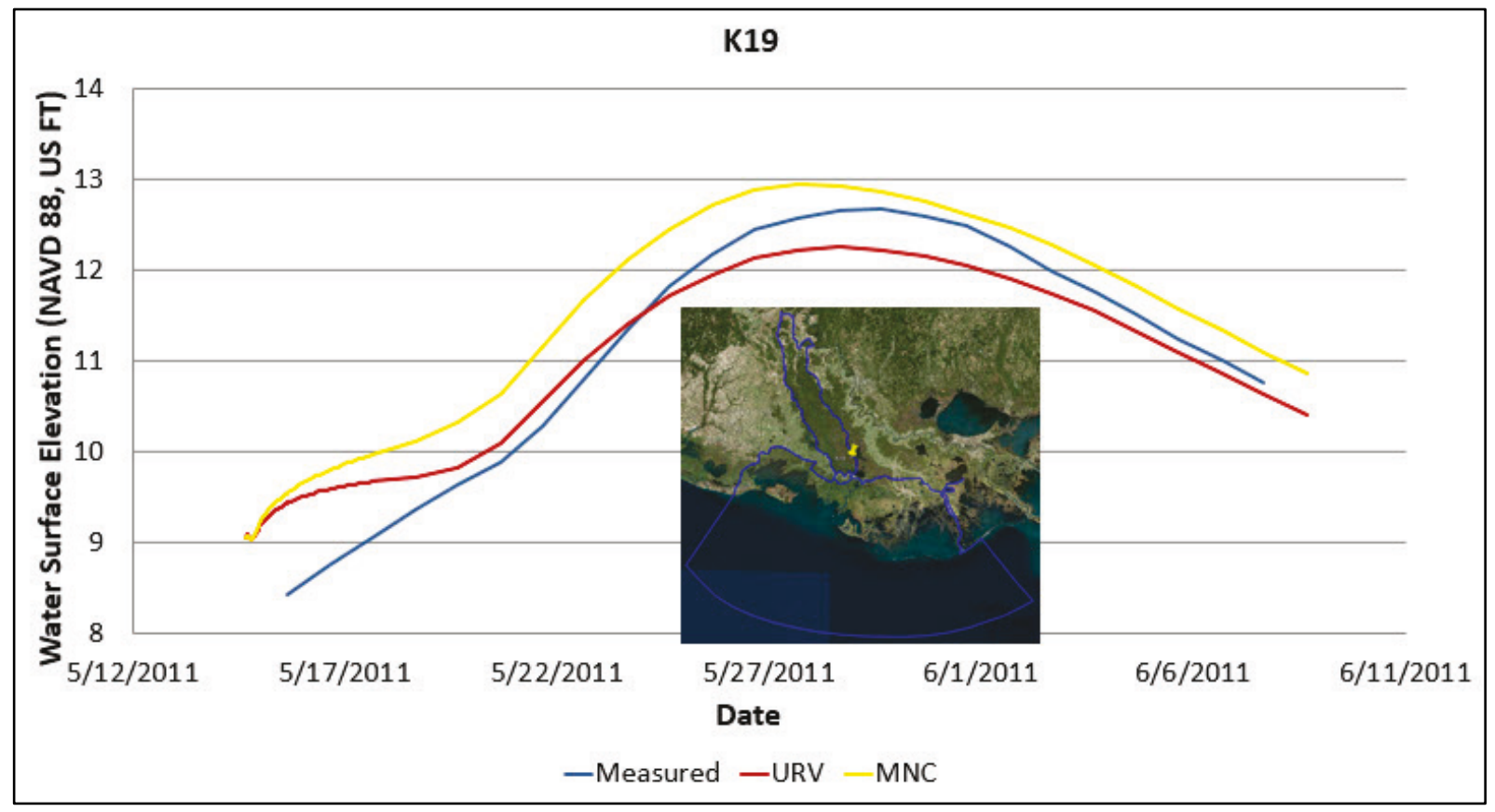


Figure 79. Gage K21 model results.

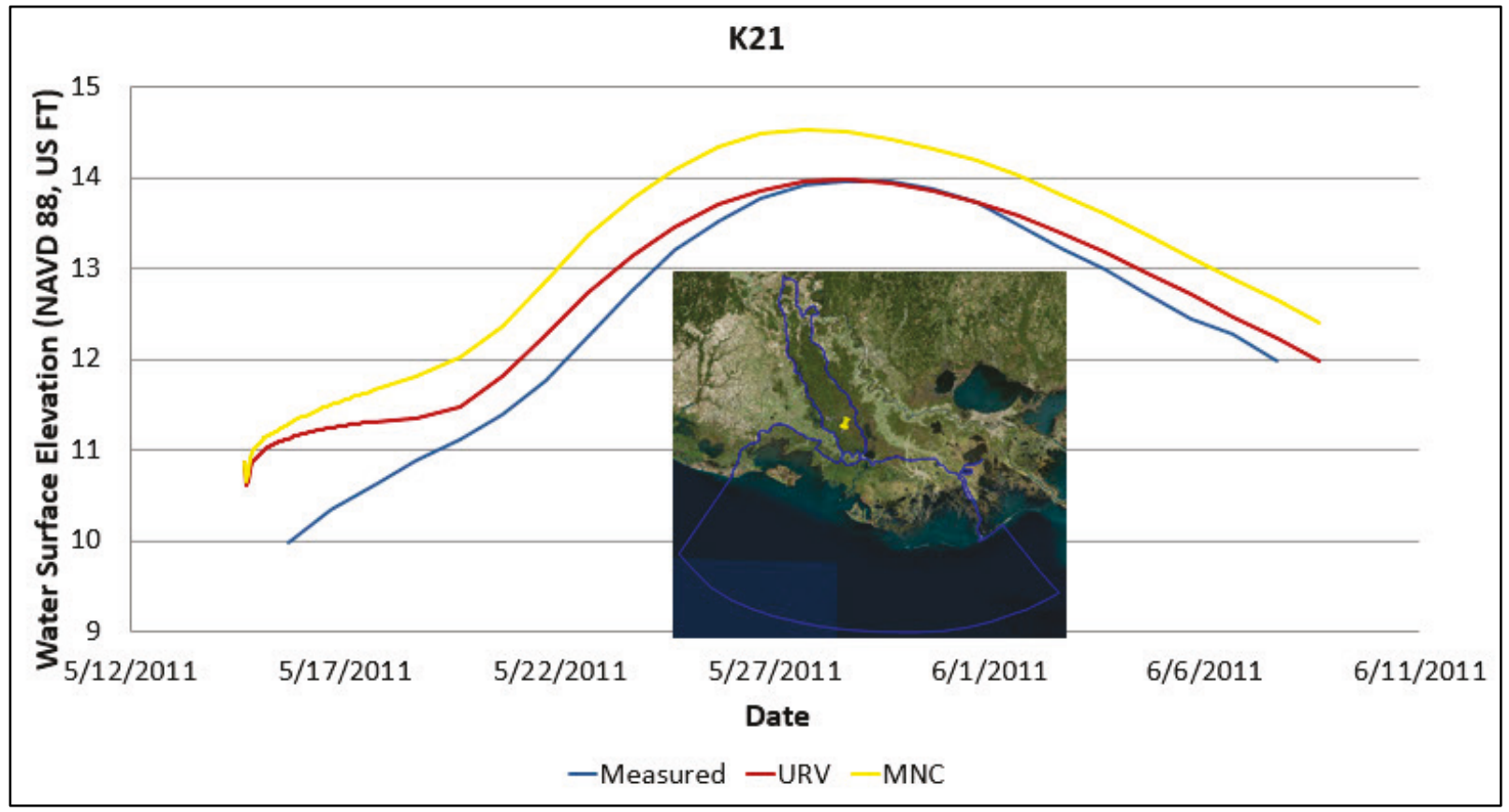

Figure 80. USGS gage at Wax Lake Outlet (water surface elevation).

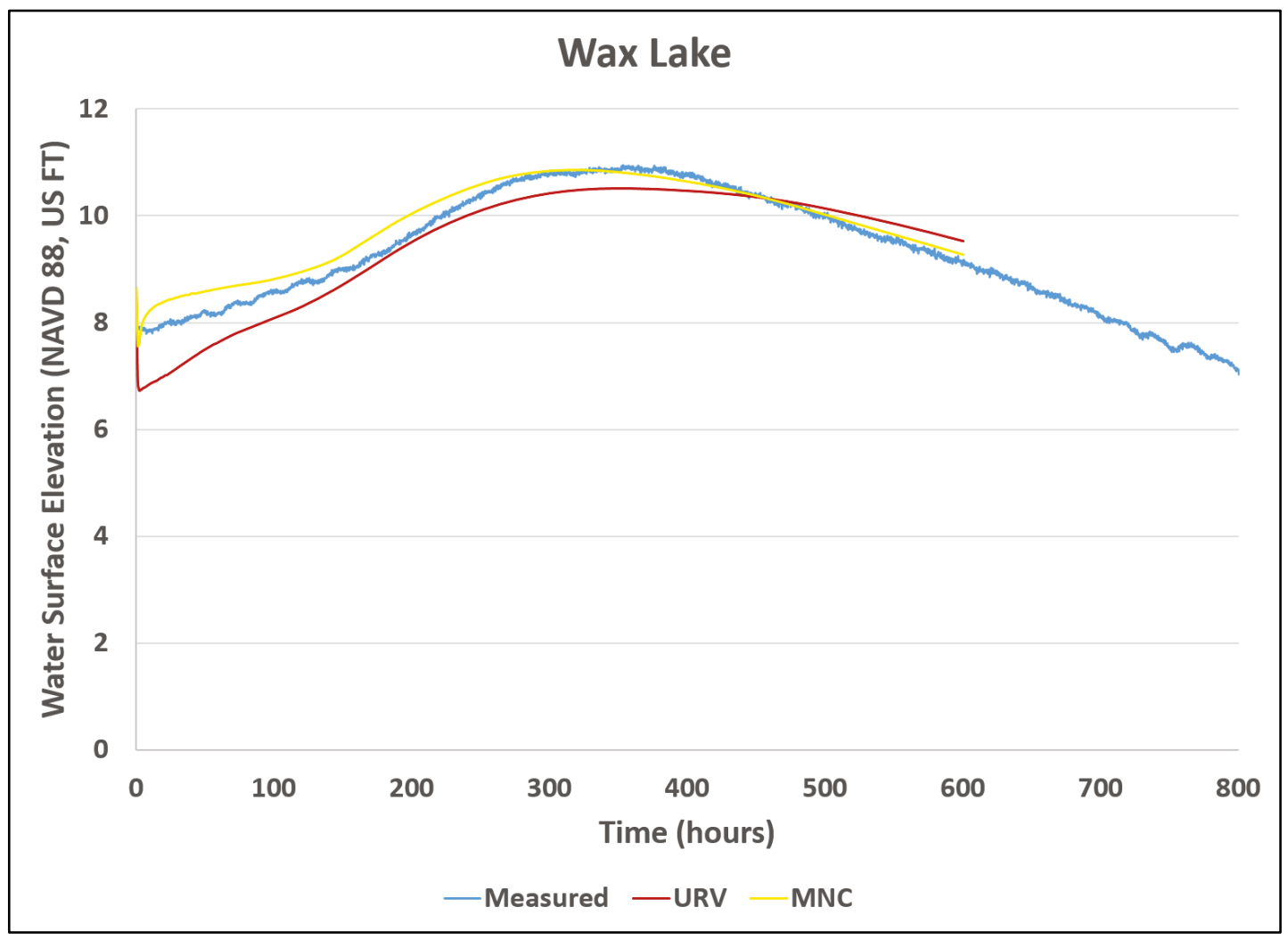


Figure 81. USGS gage at Morgan City Outlet (water surface elevation).

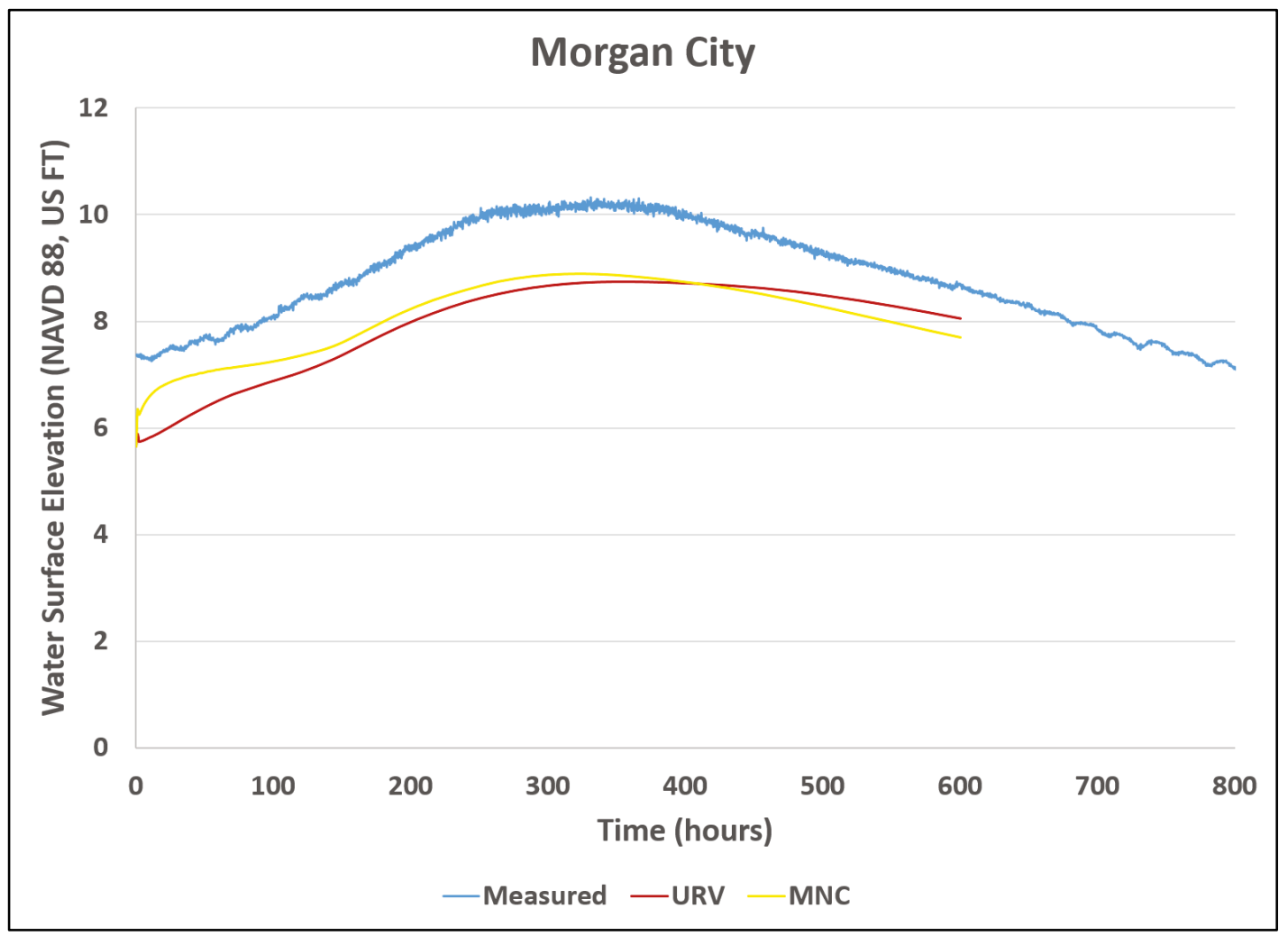

Figure 82. USGS gage at Wax Lake Outlet (discharge).

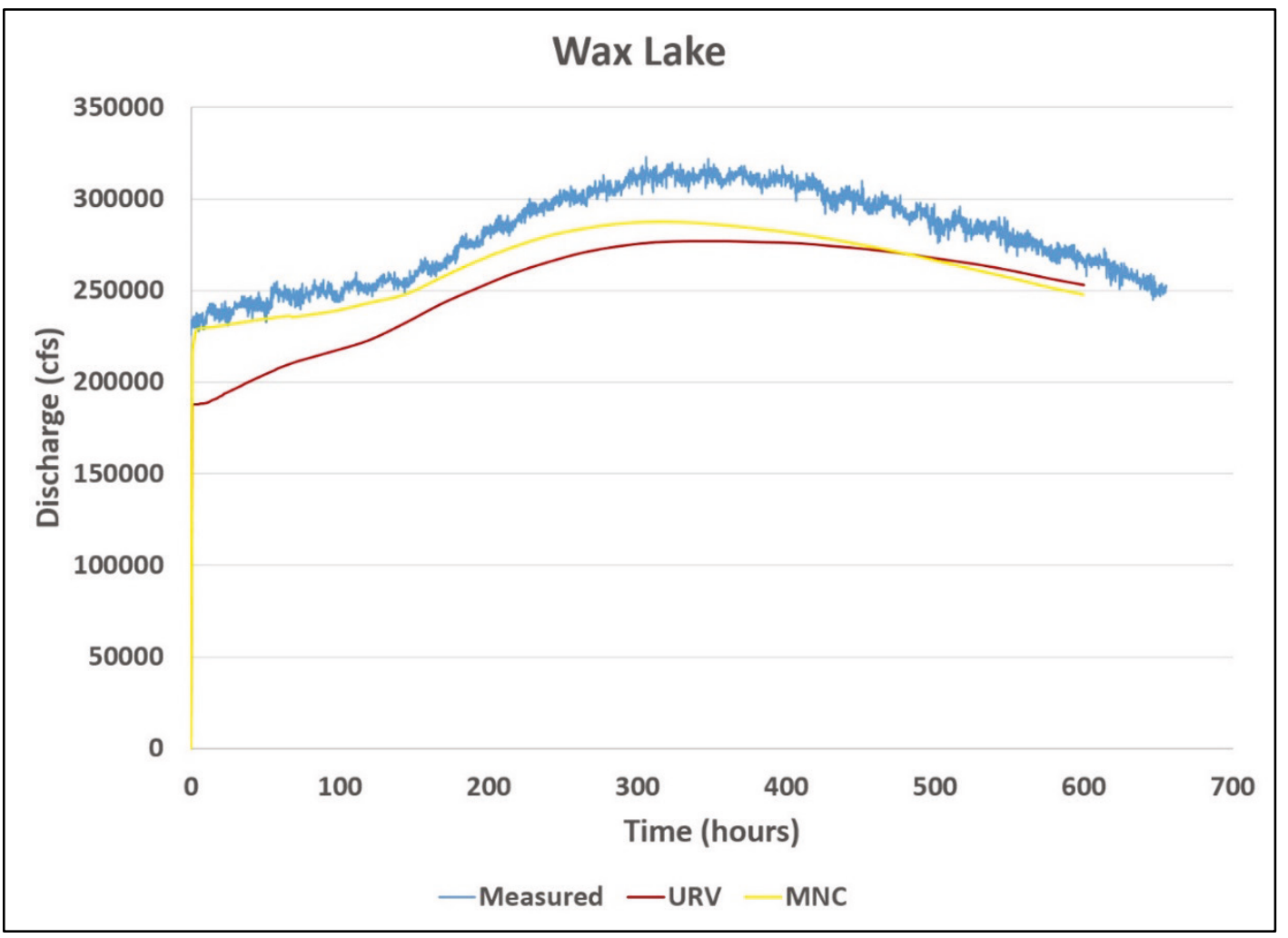


Figure 83. USGS gage at Morgan City Outlet (discharge).

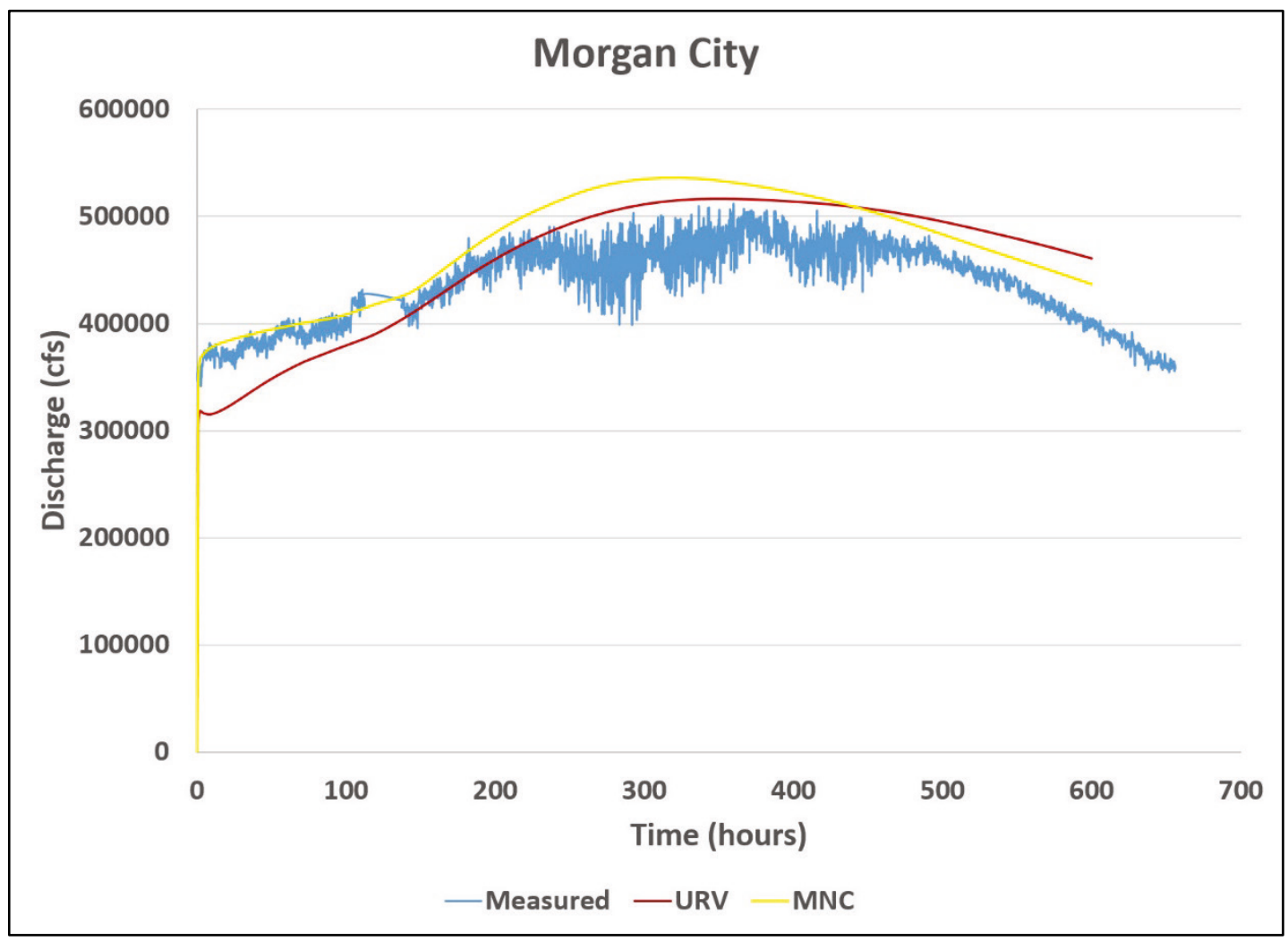

The RMSE was calculated at each gage for the duration of the simulation. The daily summed RMSE (Column A), RMSE for each gage throughout entire simulation (Column B), and the maximum/minimum error for each gage (Column C and Column D, respectively) can be seen for all gages together in Table 4. These results are the best comparisons to measured data for the 2011 flood event model calibration. The spatial variability of error is random throughout the domain of the model as shown in Column B. This means that there was no spatial pattern of the model having more error in one location than another. With regards to temporal error, generally the error decreased as time moved forward throughout the entire simulation as shown in Column A.

It was decided that although there are some differences in comparing the "URV" model with the "MNC" model, the "URV" model produced the most satisfactory results for this modeling effort. The total average value that is located in Column B was slightly better for the "URV" model (0.85) than it was for the "MNC" model (o.88). Note that both of these RMSE values include the initial conditions for each gage. 
Table 4. Summary of RMSE and model error (feet).

\begin{tabular}{|c|c|}
\hline \multicolumn{2}{|c|}{ Column A } \\
\hline \multicolumn{2}{|c|}{ Daily Summed RMSE } \\
\hline 5/15/11 16:00 & 1.62 \\
\hline $5 / 16 / 1116: 00$ & 1.40 \\
\hline $5 / 17 / 1116: 00$ & 1.23 \\
\hline $5 / 18 / 1116: 00$ & 1.00 \\
\hline 5/19/11 16:00 & 0.90 \\
\hline 5/20/11 16:00 & 1.02 \\
\hline 5/21/11 16:00 & 1.13 \\
\hline $5 / 22 / 1116: 00$ & 1.13 \\
\hline $5 / 23 / 1116: 00$ & 1.08 \\
\hline $5 / 24 / 1116: 00$ & 1.02 \\
\hline $5 / 25 / 1116: 00$ & 0.99 \\
\hline $5 / 26 / 1116: 00$ & 0.96 \\
\hline $5 / 27 / 1116: 00$ & 0.92 \\
\hline $5 / 28 / 1116: 00$ & 0.90 \\
\hline $5 / 29 / 1116: 00$ & 0.88 \\
\hline $5 / 30 / 1116: 00$ & 0.86 \\
\hline $5 / 31 / 1116: 00$ & 0.86 \\
\hline $6 / 1 / 1116: 00$ & 0.86 \\
\hline 6/2/11 16:00 & 0.84 \\
\hline $6 / 3 / 1116: 00$ & 0.83 \\
\hline $6 / 4 / 1116: 00$ & 0.83 \\
\hline $6 / 5 / 1116: 00$ & 0.83 \\
\hline 6/6/11 16:00 & 0.80 \\
\hline $6 / 7 / 1116: 00$ & 0.83 \\
\hline
\end{tabular}

\begin{tabular}{|c|c|}
\hline \multirow{2}{*}{\multicolumn{2}{|c|}{$\begin{array}{c}\text { Column B } \\
\text { RMSE for each Gage } \\
\text { throughout Entire Simulation }\end{array}$}} \\
\hline & \\
\hline A01 & 0.96 \\
\hline $\mathrm{AO2}$ & 0.78 \\
\hline $\mathrm{AO3}$ & 1.30 \\
\hline $\mathrm{AO4}$ & 0.88 \\
\hline A06 & 1.06 \\
\hline A07 & 1.51 \\
\hline K5 & 0.55 \\
\hline K7 & 0.49 \\
\hline K4 & 0.66 \\
\hline K2 & 2.92 \\
\hline BO4 & 2.31 \\
\hline $\mathrm{CO} 4$ & 0.45 \\
\hline К9 & 1.25 \\
\hline K14 & 0.41 \\
\hline K13 & 0.25 \\
\hline K17 & 1.24 \\
\hline K16 & 1.47 \\
\hline K15 & 0.41 \\
\hline $\mathrm{K3}$ & 0.56 \\
\hline K18 & 0.49 \\
\hline K19 & 0.40 \\
\hline K21 & 0.42 \\
\hline K10 & 0.55 \\
\hline K11 & 0.69 \\
\hline K12 & 0.49 \\
\hline K6 & 0.52 \\
\hline K8 & 0.66 \\
\hline Total Average & 0.88 \\
\hline
\end{tabular}

\begin{tabular}{|c|c|}
\hline \multicolumn{2}{|c|}{ Column C } \\
\hline \multicolumn{2}{|c|}{ Maximum Error for each Gage } \\
\hline A01 & 0.17 \\
\hline $\mathrm{AO} 2$ & 0.29 \\
\hline $\mathrm{AO3}$ & 0.60 \\
\hline AO4 & 0.89 \\
\hline AO6 & 0.80 \\
\hline AO7 & 2.84 \\
\hline K5 & 0.54 \\
\hline K7 & 0.28 \\
\hline K4 & 0.88 \\
\hline K2 & 3.40 \\
\hline BO4 & 3.26 \\
\hline $\mathrm{co4}$ & -0.06 \\
\hline K9 & -0.78 \\
\hline K14 & 0.41 \\
\hline K13 & 0.45 \\
\hline K17 & 1.59 \\
\hline K16 & 1.71 \\
\hline K15 & 0.62 \\
\hline K3 & 0.75 \\
\hline K18 & 0.23 \\
\hline K19 & 0.45 \\
\hline K21 & 0.03 \\
\hline K10 & 0.14 \\
\hline K11 & 0.08 \\
\hline K12 & 0.25 \\
\hline K6 & 0.38 \\
\hline K8 & -0.07 \\
\hline
\end{tabular}

\begin{tabular}{|c|c|}
\hline \multicolumn{2}{|c|}{ Column D } \\
\hline \multicolumn{2}{|c|}{ Minimum Error for each Gage } \\
\hline A01 & -1.77 \\
\hline $\mathrm{AO2}$ & -1.17 \\
\hline $\mathrm{AO3}$ & -4.13 \\
\hline $\mathrm{AO4}$ & -2.80 \\
\hline A06 & -2.11 \\
\hline A07 & -1.24 \\
\hline K5 & -1.45 \\
\hline K7 & -1.45 \\
\hline K4 & 0.11 \\
\hline K2 & 1.73 \\
\hline BO4 & -1.05 \\
\hline $\mathrm{CO} 4$ & -0.95 \\
\hline K9 & -2.14 \\
\hline K14 & -1.09 \\
\hline K13 & -0.15 \\
\hline K17 & 0.91 \\
\hline K16 & 0.69 \\
\hline K15 & -0.40 \\
\hline K3 & 0.11 \\
\hline K18 & -1.36 \\
\hline K19 & -1.01 \\
\hline K21 & -1.15 \\
\hline K10 & -1.60 \\
\hline K11 & -1.88 \\
\hline K12 & -1.46 \\
\hline K6 & -1.51 \\
\hline К8 & -1.63 \\
\hline
\end{tabular}




\subsubsection{Project design flow - friction sensitivity testing}

The project design flow was then simulated for the model that utilized Manning's roughness values for the forested areas instead of the URV characterization. The results from this sensitivity analysis can be seen below in Figure 84 - Figure 86. Note that this simulation also overtops the levee before the project design flow value is reached, as seen with the URV friction specification.

Figure 84. Arc 1 results (MNC).

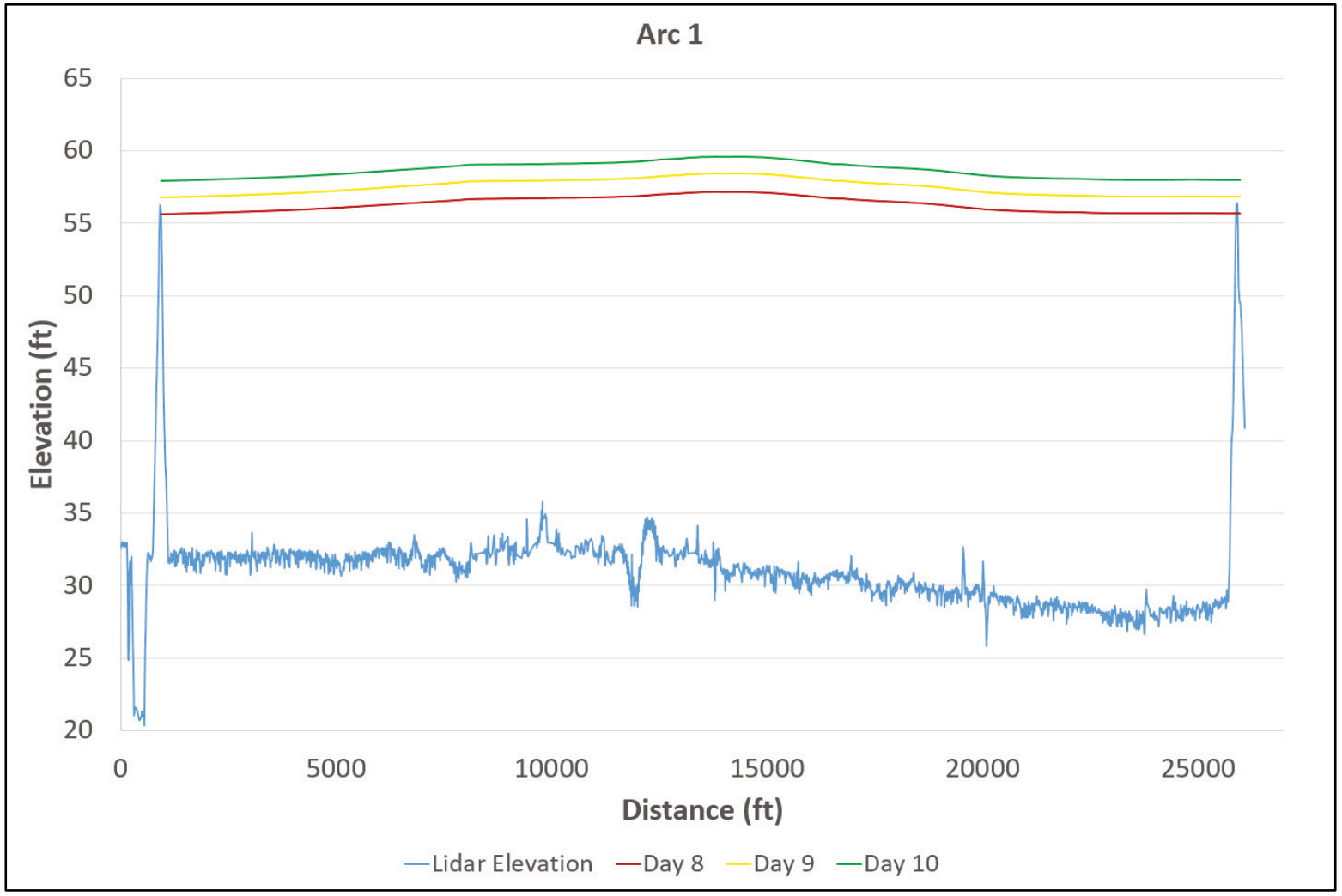


Figure 85. Arc 2 results (MNC).

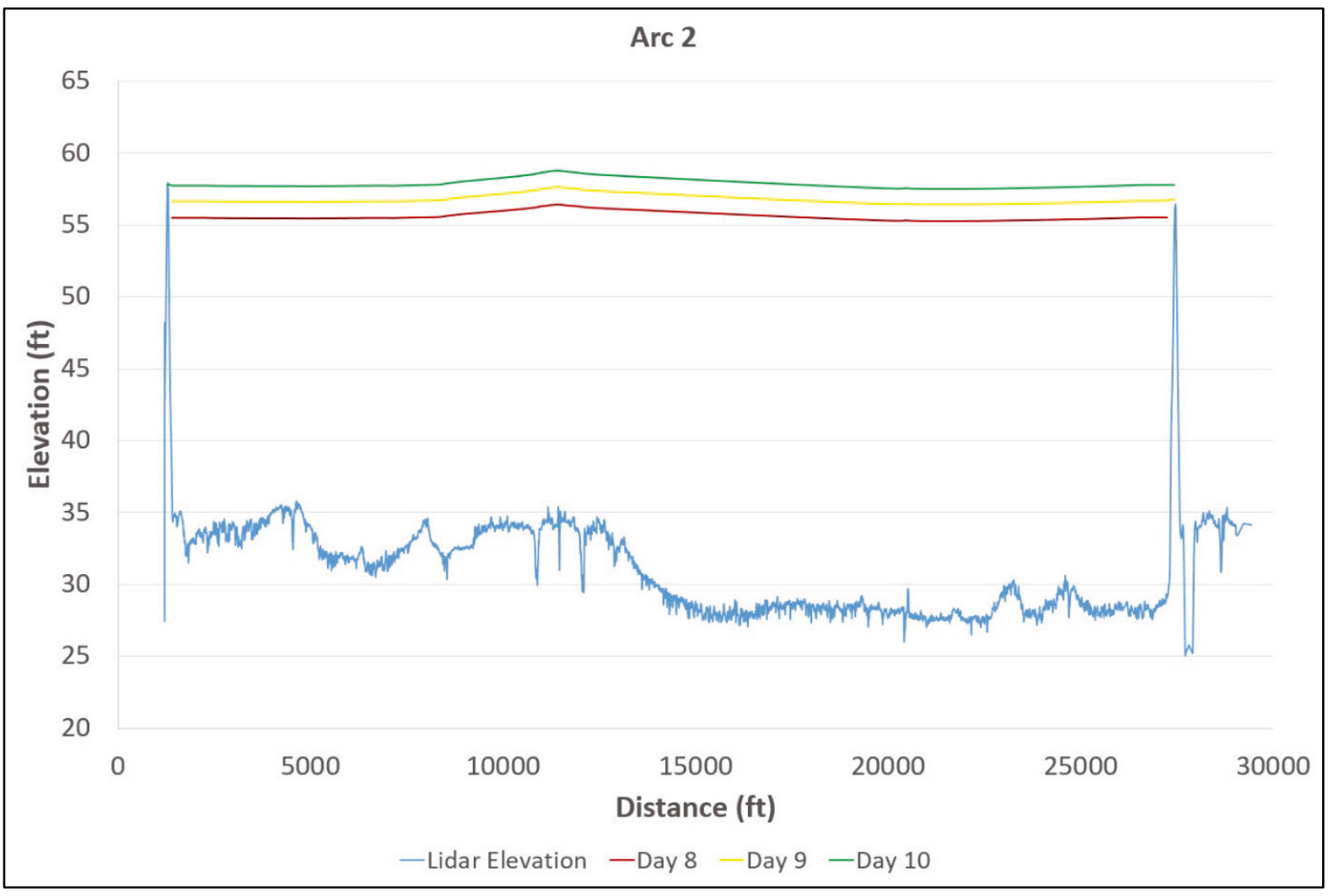

Figure 86. Arc 3 results (MNC).

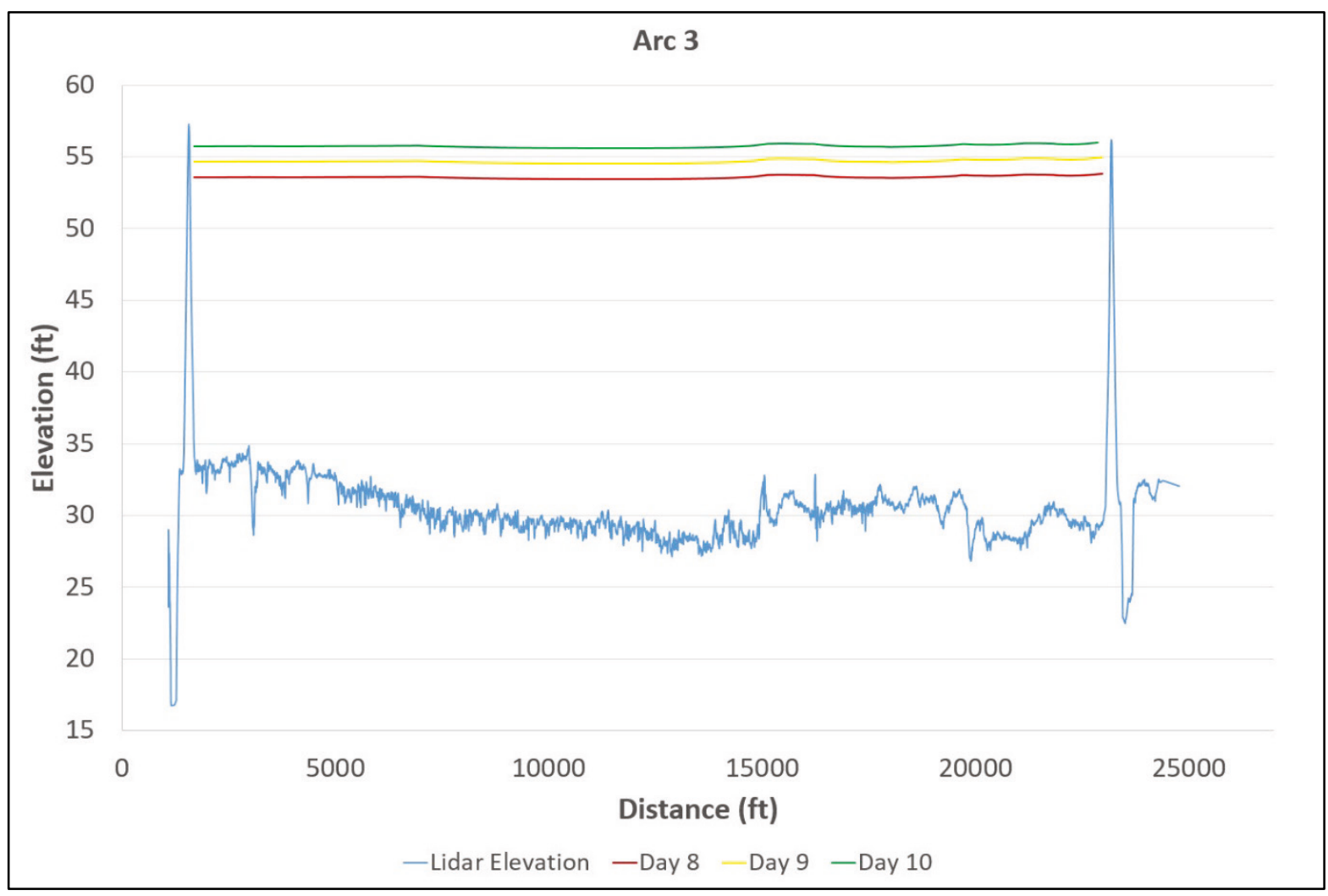




\subsubsection{De-forestation simulation}

An additional sensitivity simulation was made to emulate a scenario in which the Morganza Floodway between the MCS and Highway 190 was cleared of its forested areas. To do this, the material types in the region that were previously forested areas were now assigned Manning's roughness values equal to that of the "open land" type $(n=0.038)$. Figure 87 displays the approximate location of the areas that were cleared in the model. Figure 88 - Figure 90 show the results from the model at Arc 1, 2, and 3. Although day 12.3 is not plotted, it can be seen that the levees would not be overtopped at the arc locations with the increase of flow to 600,000 cfs. Note that after the flood water leaves the Morganza Floodway (south of Highway 190), the water can now spread out much more and is not as constricted. The water depths throughout the domain of the model can be seen in Figure 91. 
Figure 87. Location of simulated cleared out trees areas.

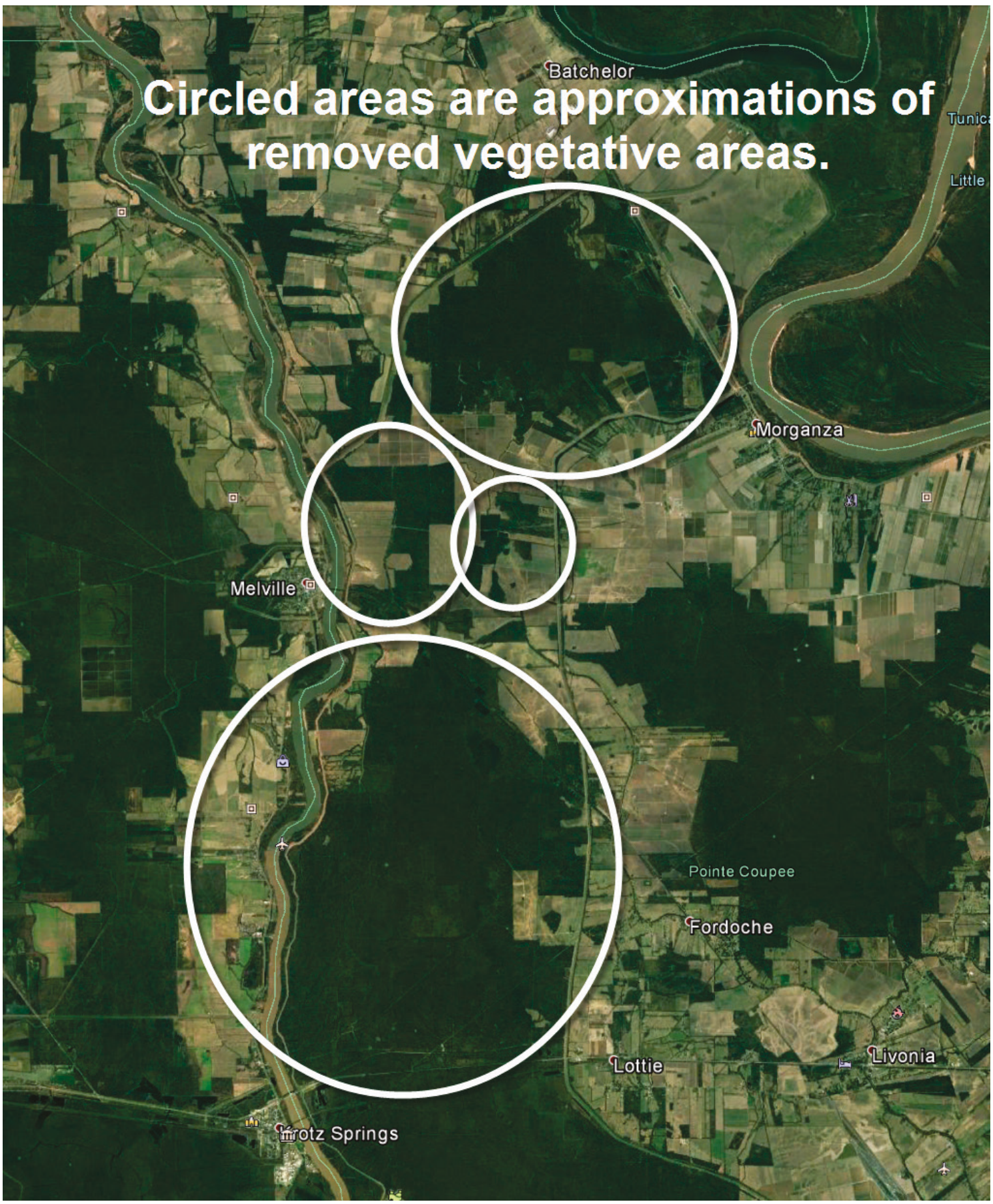


Figure 88. Results from cleared out trees simulation at Arc 1.

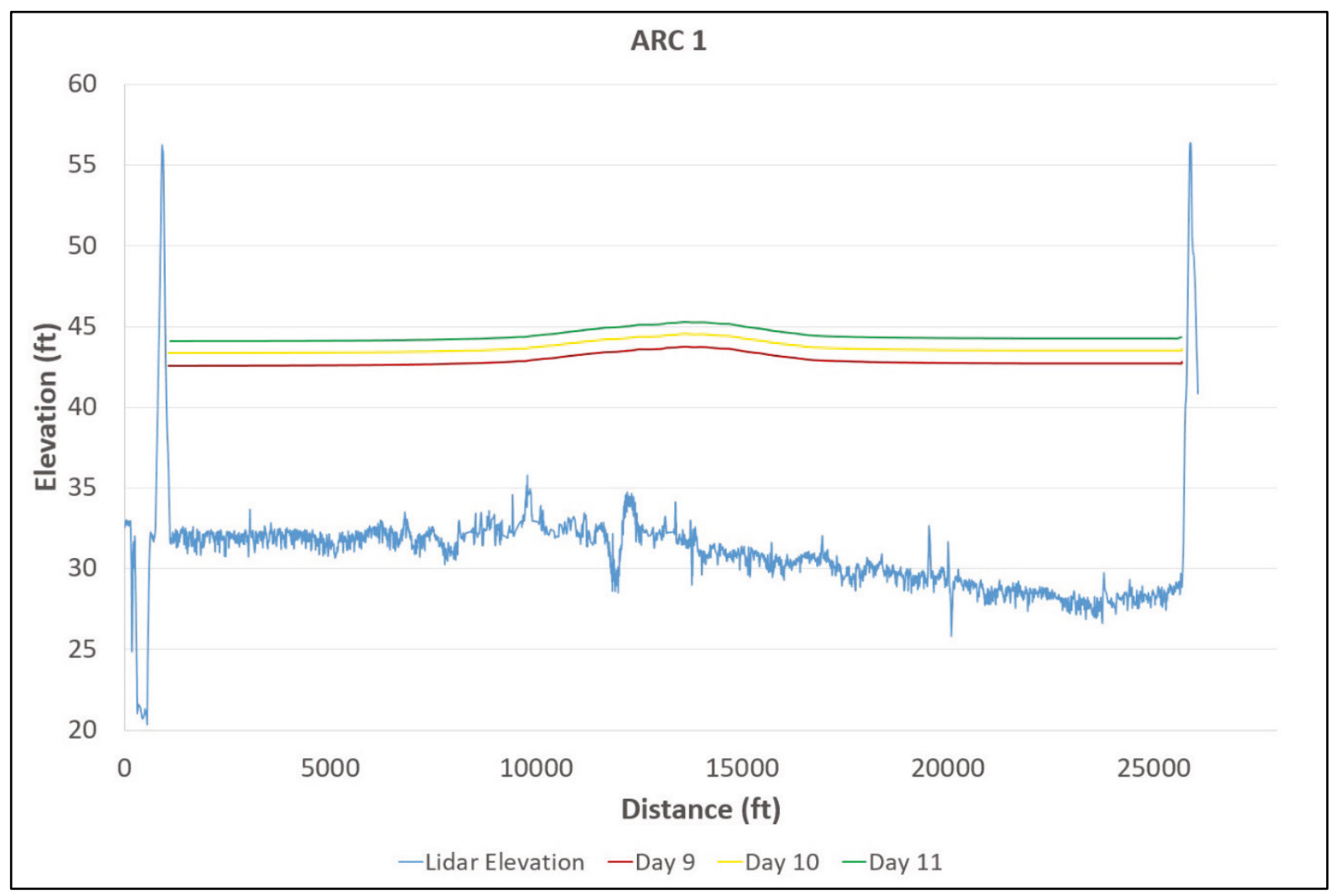

Figure 89. Results from cleared out trees simulation at Arc 2.

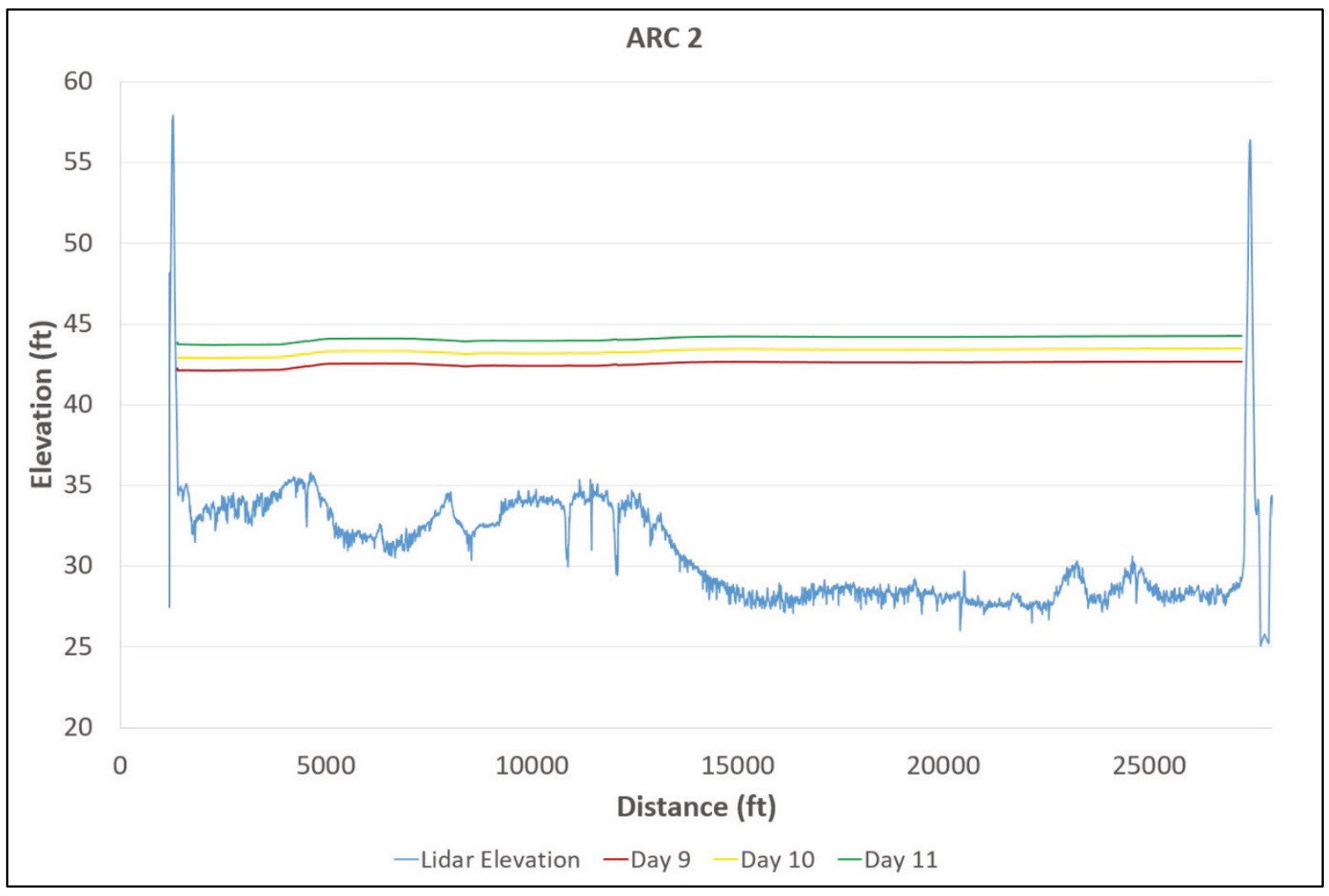


Figure 90. Results from cleared out trees simulation at Arc 3.

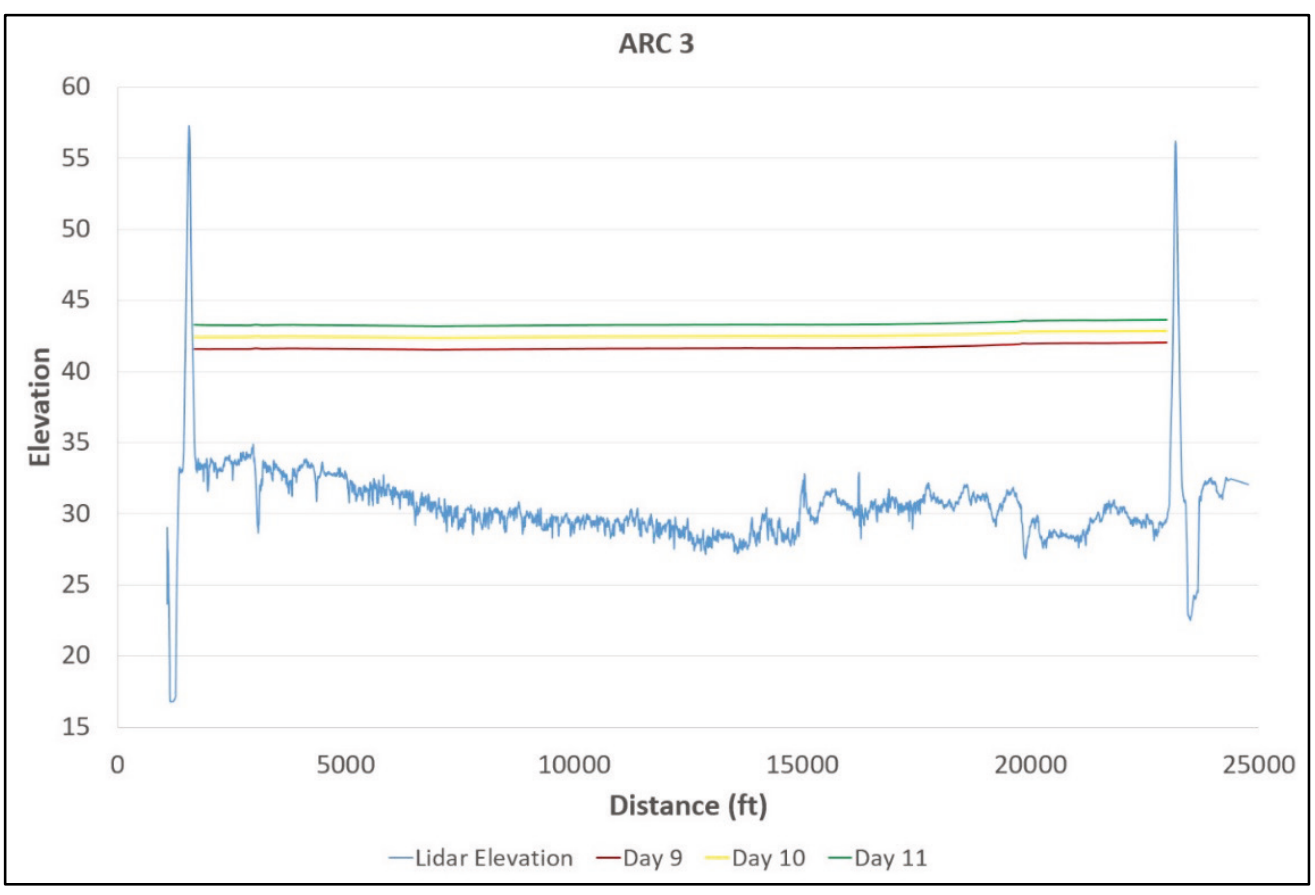

Figure 91. Project flood event water depth at day 11 of the simulation.

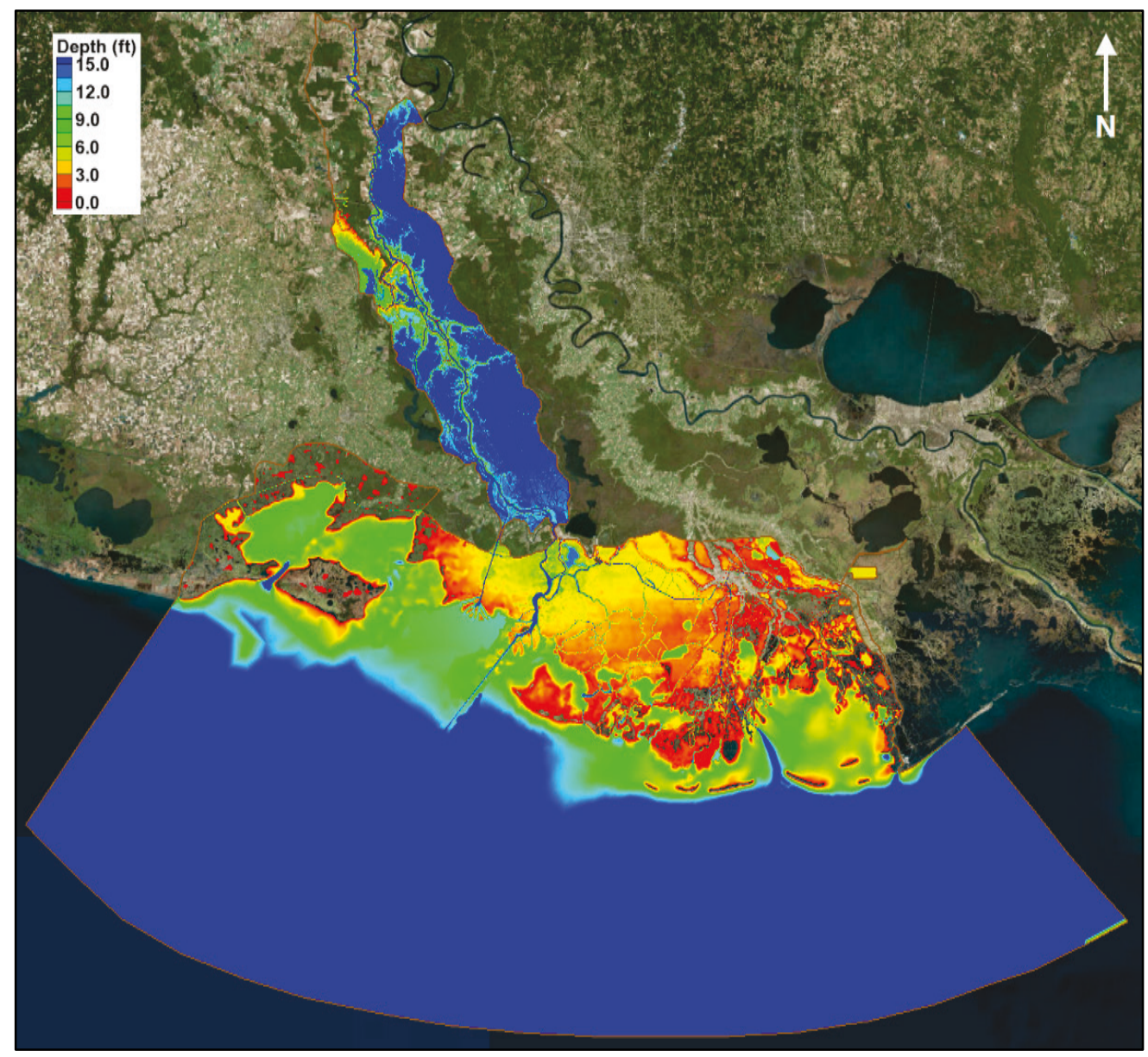




\section{Conclusion and Discussion}

A 2D hydrodynamic model was developed for the Morganza Floodway and Atchafalaya Basin beginning immediately downstream of the MCS to the Gulf of Mexico. Various steps were made to ensure the model was adequate to reproduce the field conditions as discussed in Appendix A Appendix $\mathrm{C}$ and Chapter 3. The final calibrated model, as discussed in Chapter 4, indicates good overall agreement to field water surface elevations and known discharges. The model results in Chapter 4 show that the final calibrated model results match up well with the measured 2011 flood event data. The overall combined average RMSE value for all gages throughout the simulation was 0.85 (note that this includes the initial conditions for each gage). The value would be lower if the initial conditions where the flood water has not reached yet (for several days in some cases) were ignored in the RMSE calculations (total average RMSE for each gage throughout entire simulation would be closer to 0.79).

The project design flow event of $600 \mathrm{kcfs}$ through the MCS was simulated to analyze if the floodway(s) could handle the capacity. The model results indicate that the levees will be overtopped just downstream of the MCS well before the design flow of 600 kcfs is reached. Both the "URV" and "MNC" models produced good calibrated results compared to the measured data. Both of these models produced overtopping of the levees in the floodway.

When the forested areas south of the MCS and north of Highway 190 were cleared of vegetation, the analyzed cross-section locations were not overtopped. More testing/analysis should be performed on the model to determine the following (not limited to):

- Does the model overtop in other locations with or without cleared vegetation in the area described previously?

- What flow can be passed through the floodways before possible overtopping occurs?

- Are there measures that can be taken to modify the floodway(s) so that the design flow of $600 \mathrm{kcfs}$ can be successfully passed through the floodway without overtopping of the levees?

- How much of the forest in the Morganza Floodway should be removed to allow the flood water to pass through without overtopping? (Run a simulation in which only a portion in the upper Morganza Floodway is stripped of the trees). 


\section{References}

Arcement, G. J., and V. R. Schneider. 1989. Guide for Selecting Manning's Roughness Coefficients for Natural Channels and Flood Plains. U.S. Geological Survey Water-Supply Paper 2339. Reston, VA: U.S. Geological Survey.

Bell, G. L., N. D. Clifton, and D. D. Abraham. 2017. Hydrodynamics in the Morganza Floodway. Report 1: Phase 1-Model Development and Calibration. MRG\&P Report No. 13. Vicksburg, MS: U.S. Army Engineer Research and Development Center.

Maynord, S. T. 2014. Scour Protection Downstream of Morganza Control Structure, Morganza, Louisiana. ERDC/CHL TR-14-1. Vicksburg, MS: U.S. Army Engineer Research and Development Center.

McAlpin, T. O., J. V. Letter Jr., G. Savant, and F. C. Carson. 2013. Hydrodynamic and Salinity Transport Modeling of the Morganza to the Gulf of Mexico Study Area. ERDC/CHL TR-13-7. Vicksburg, MS: U.S. Army Engineer Research and Development Center.

U.S. Army Engineer Research and Development Center, Coastal and Hydraulics Laboratory (ERDC CHL). 2017. Adaptive Hydraulics 2D Shallow Water (AdH$S W 2 D)$ User Manual (Version 4.6). Vicksburg, MS: U.S. Army Engineer Research and Development Center. https://chl.erdc.dren.mil/adh/documentation/AdH_Manual_Hydrodynamic-Version4.6.pdf 


\section{Appendix A: Initial Model Results}

The southern boundaries of the model during the initial modeling stages were set at Morgan City and Wax Lake outlets (refer to Section 3.1 "Initial model results"). This was chosen due to the convenience of USGS gages being located at these sites for boundary condition information (tail water). This boundary is different than the extended boundary presented in the results Section 4.1 "2011 Flood event model calibration results of this report." For completeness, Figures A-2 - A-32 show the results of the model compared to the measured data at this early modeling stage. 
Figure A-1. Initial Model domain.

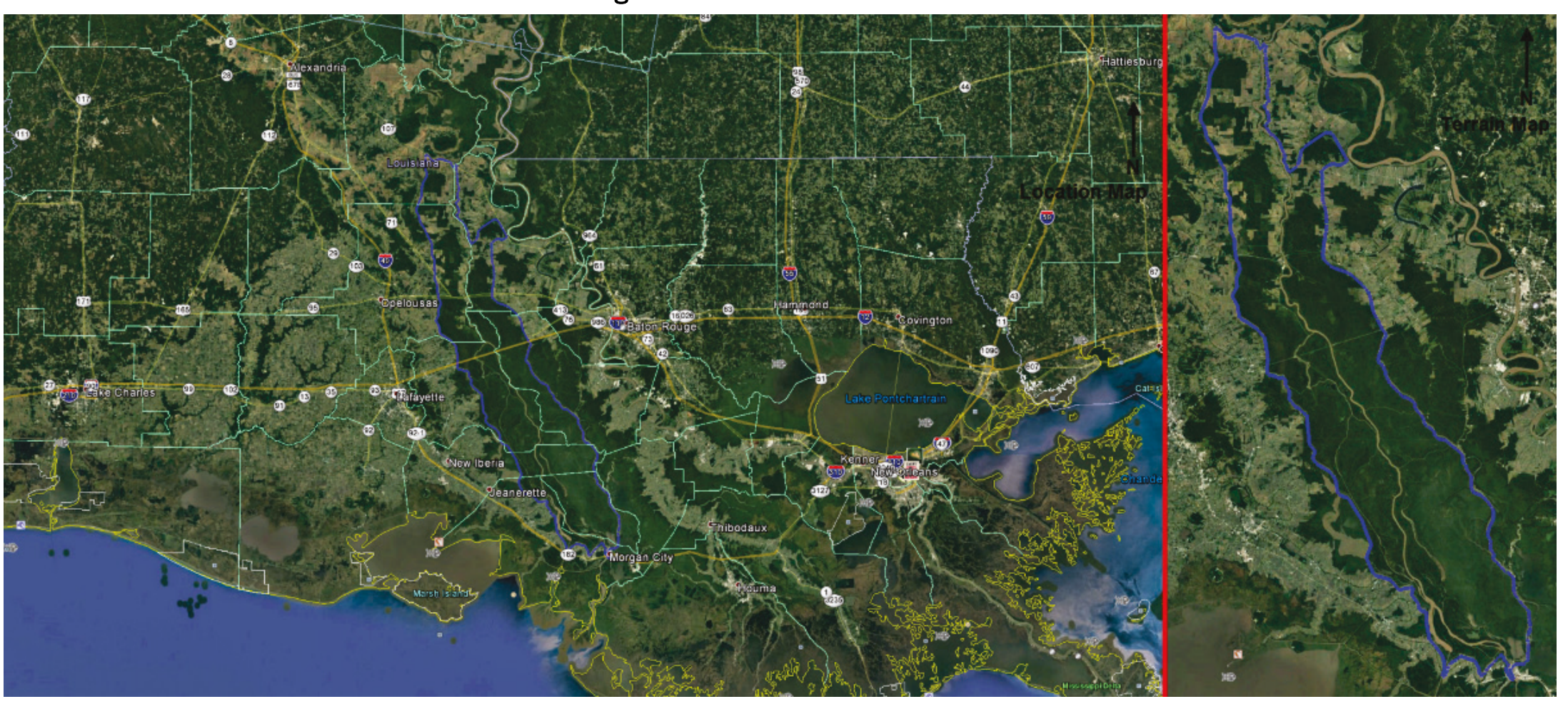


Figure A-2. Gage A01 Initial Model results.

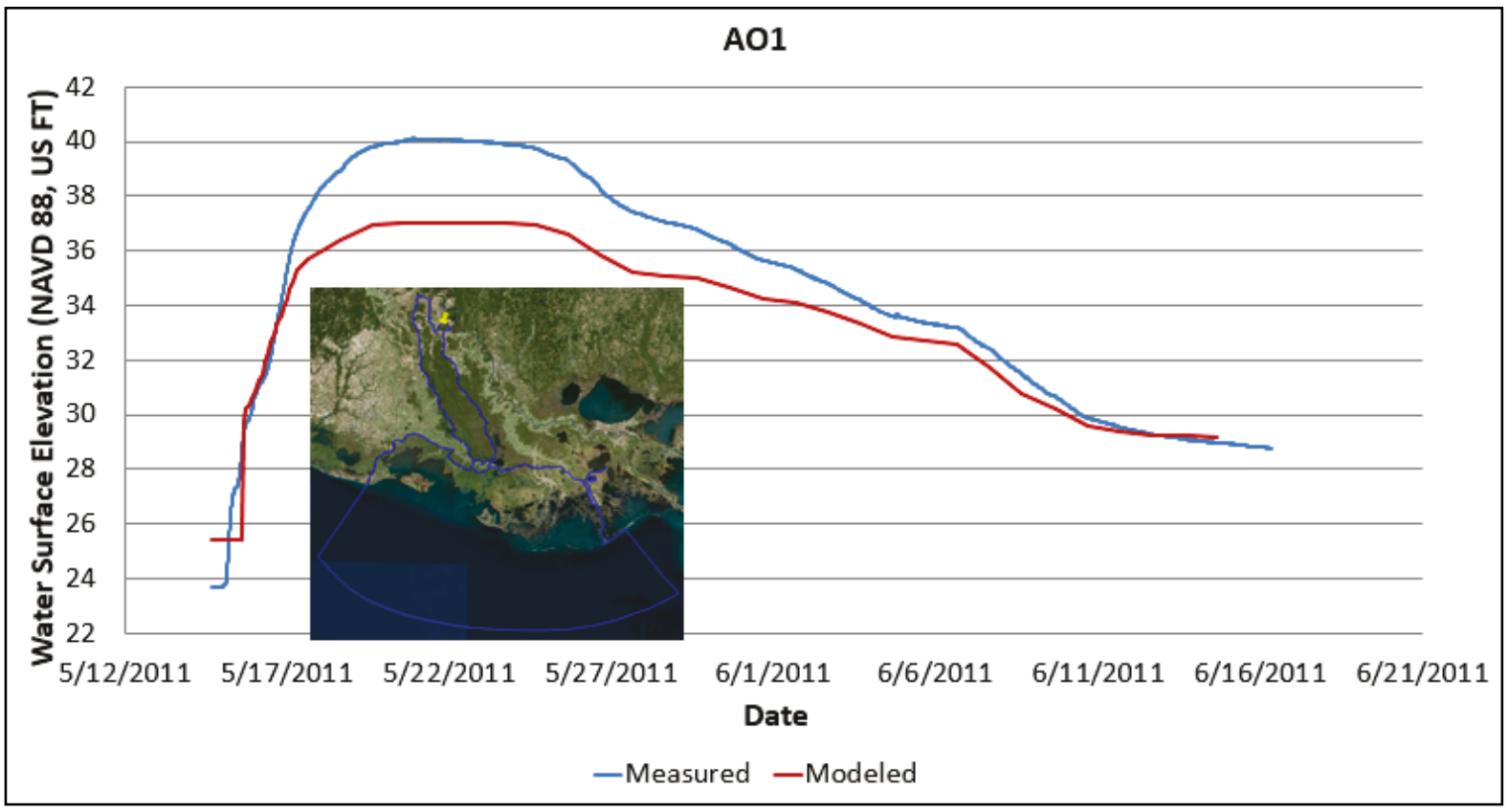

Figure A-3. Gage AO2 Initial Model results.

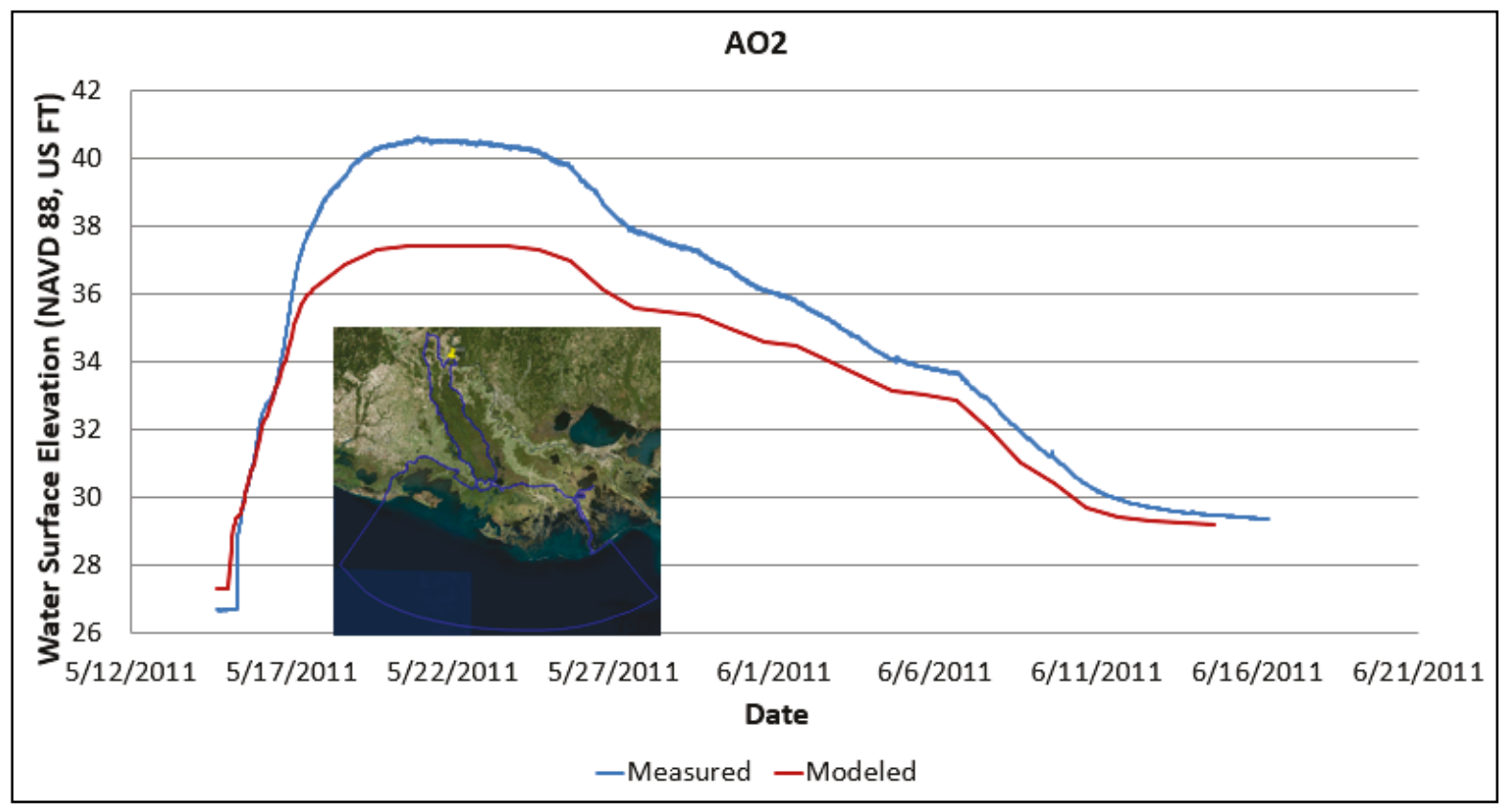


Figure A-4. Gage AO3 Initial Model results.

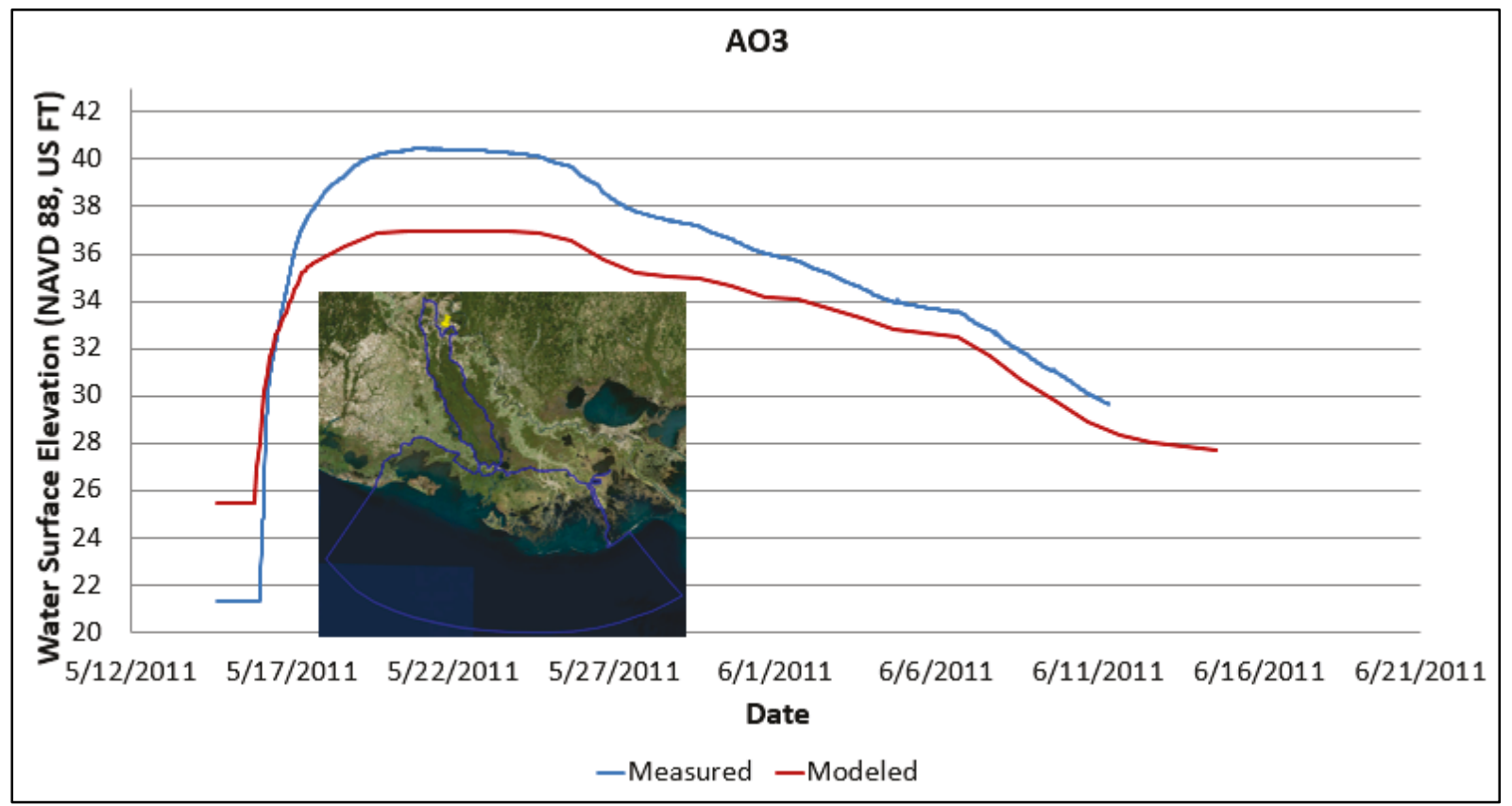

Figure A-5. Gage AO4 Initial Model results.

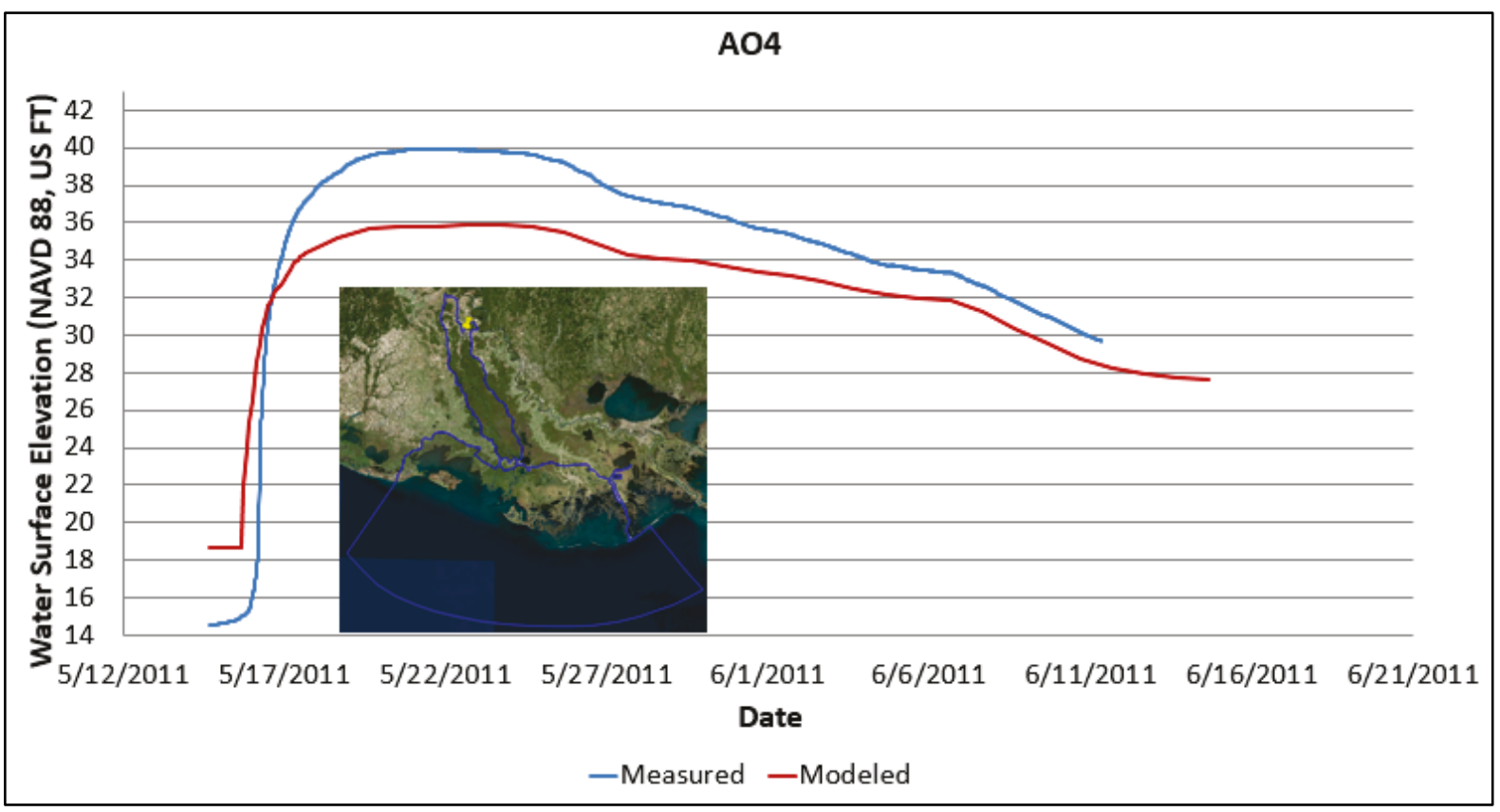


Figure A-6. Gage A06 Initial Model results.

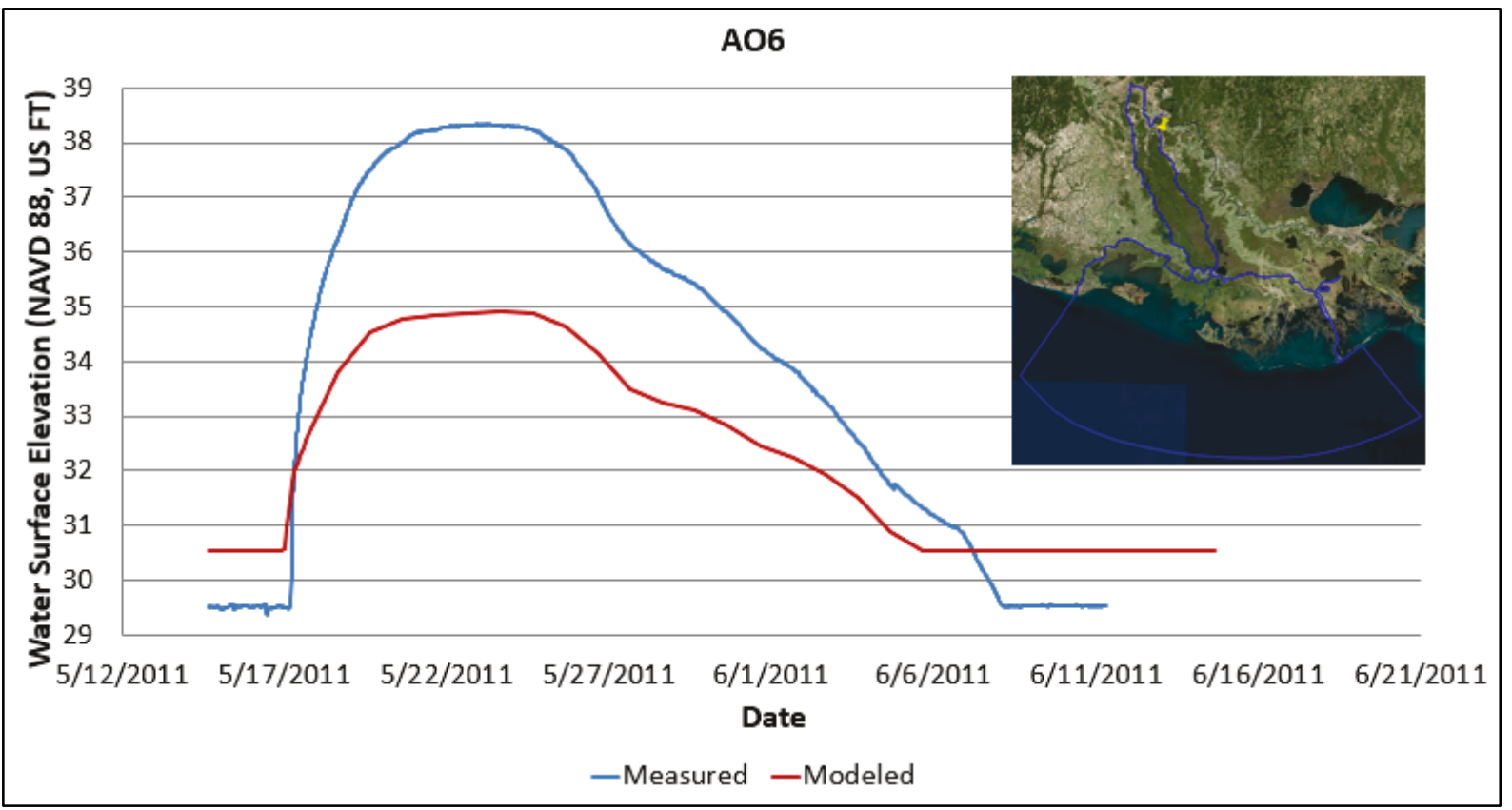

Figure A-7. Gage A07 Initial Model results.

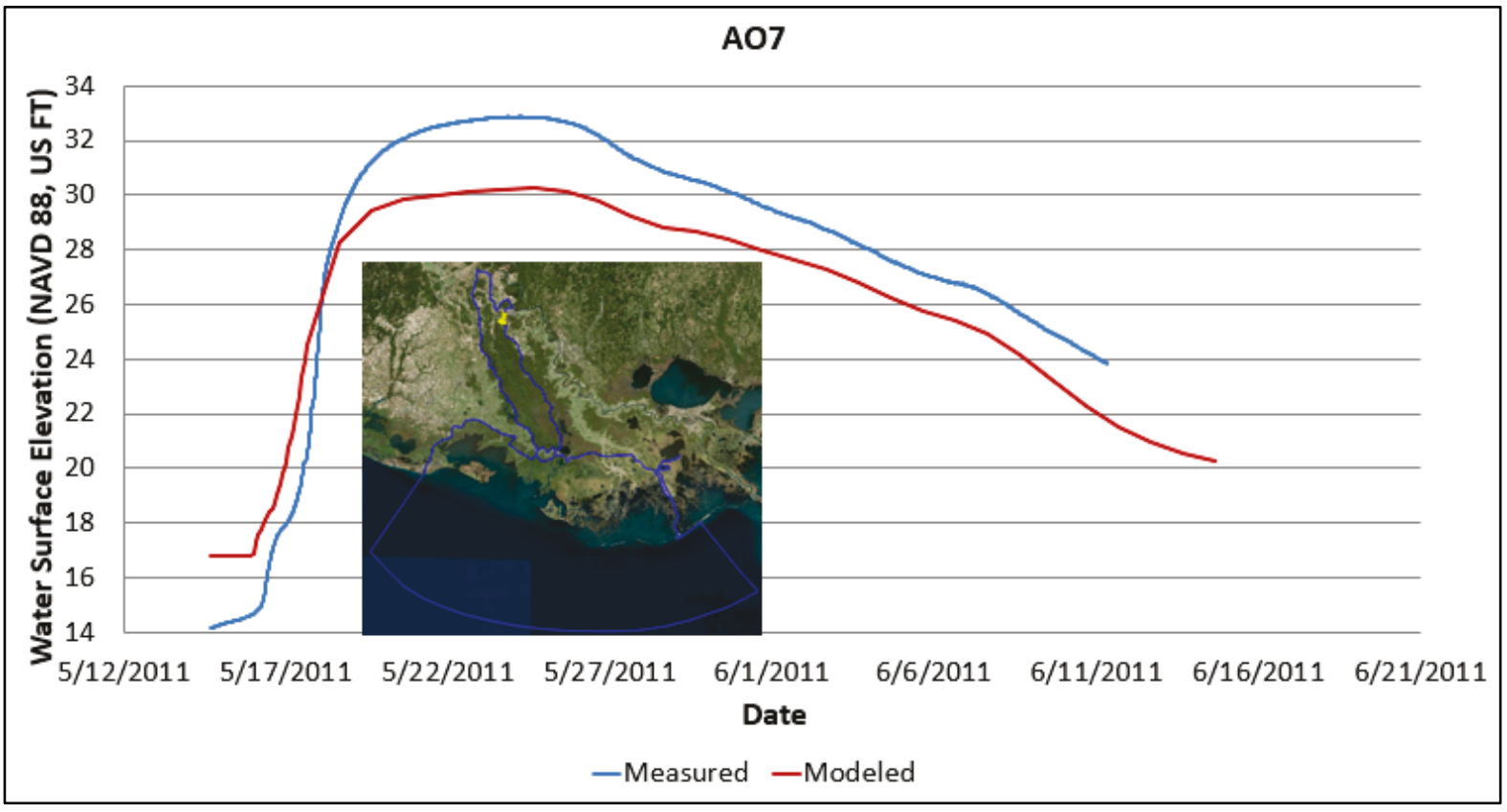


Figure A-8. Gage B04 Initial Model results.

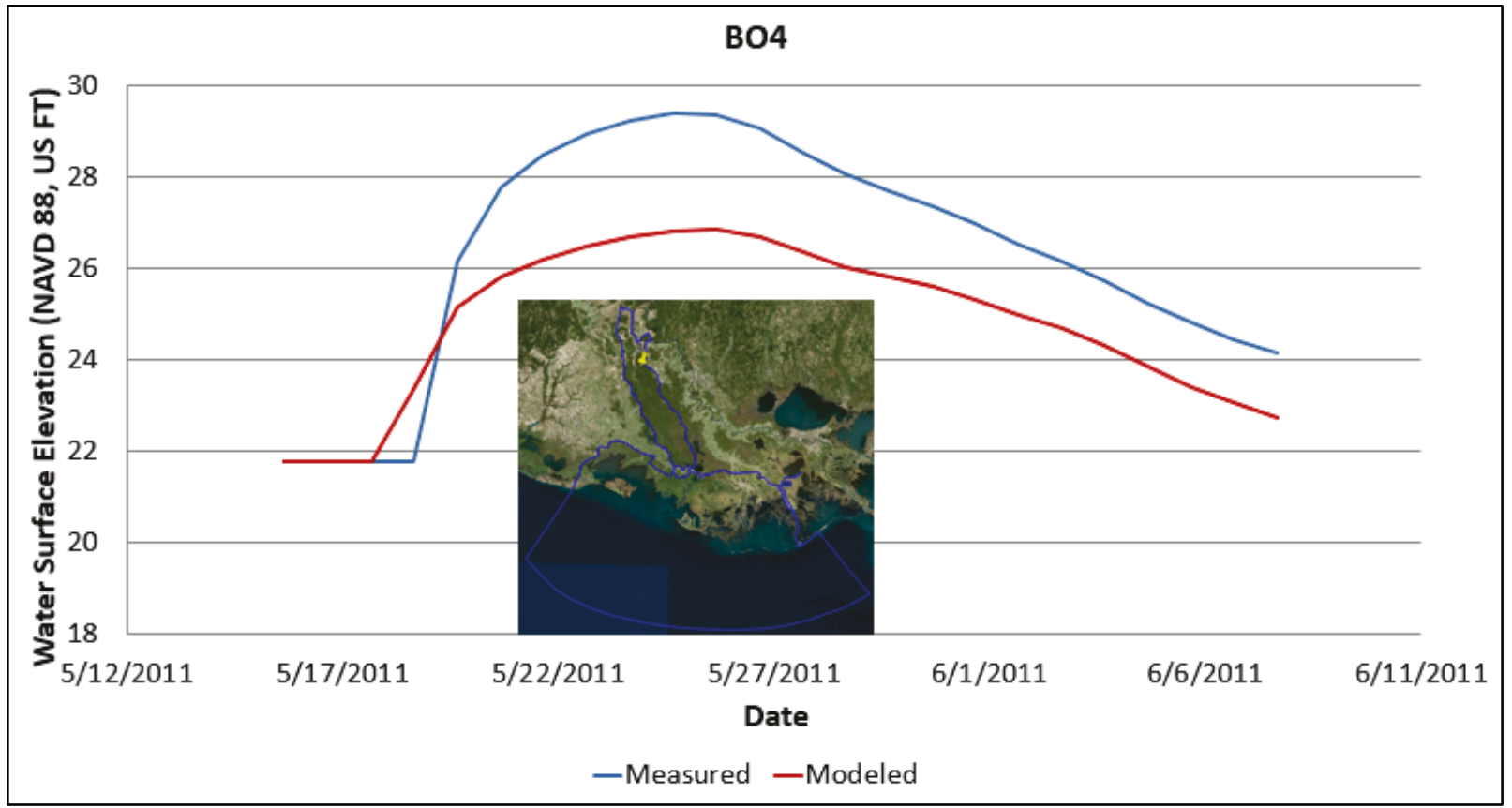

Figure A-9. Gage CO4 Initial Model results.

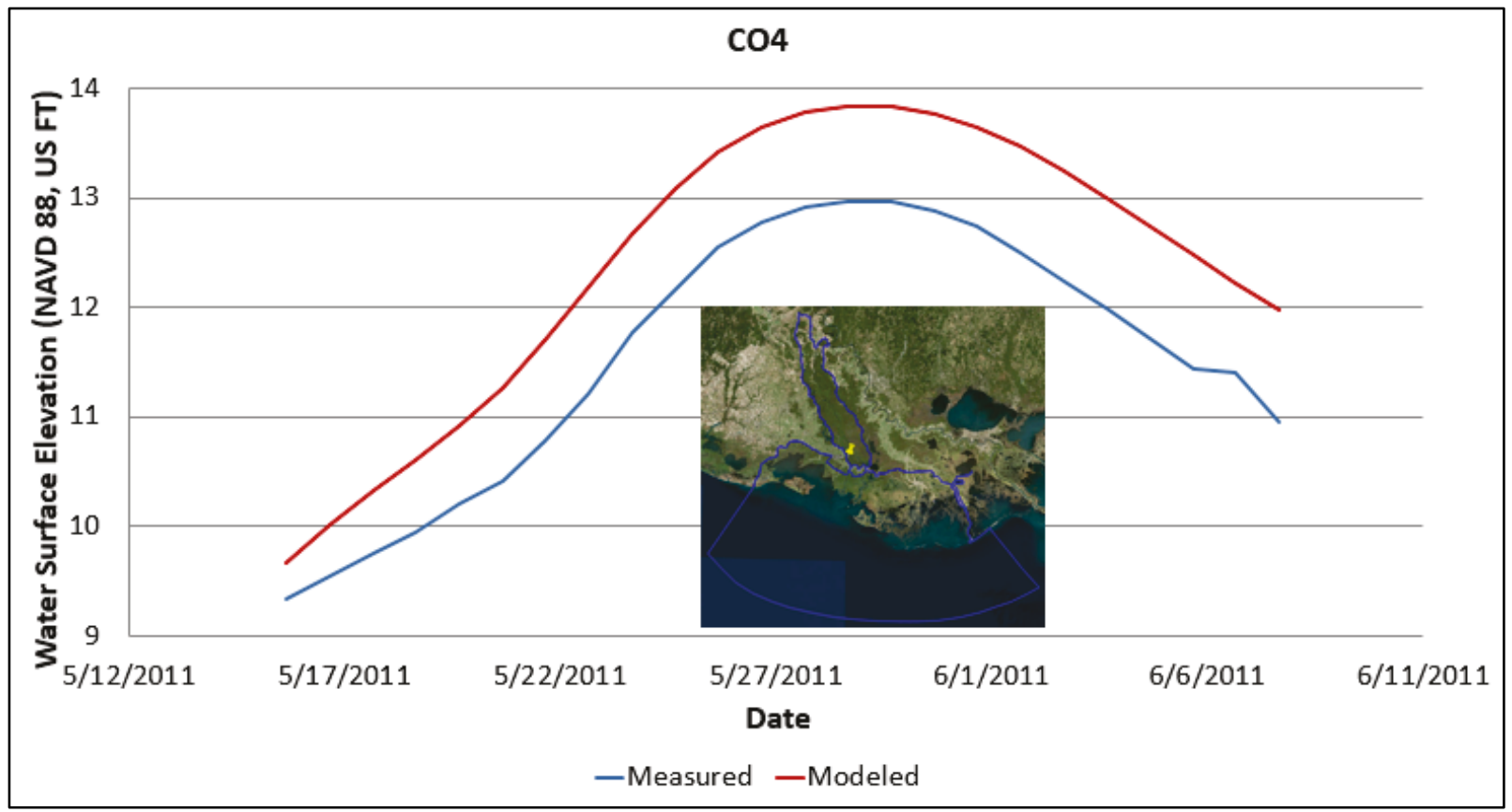


Figure A-10. Gage K2 Initial Model results.

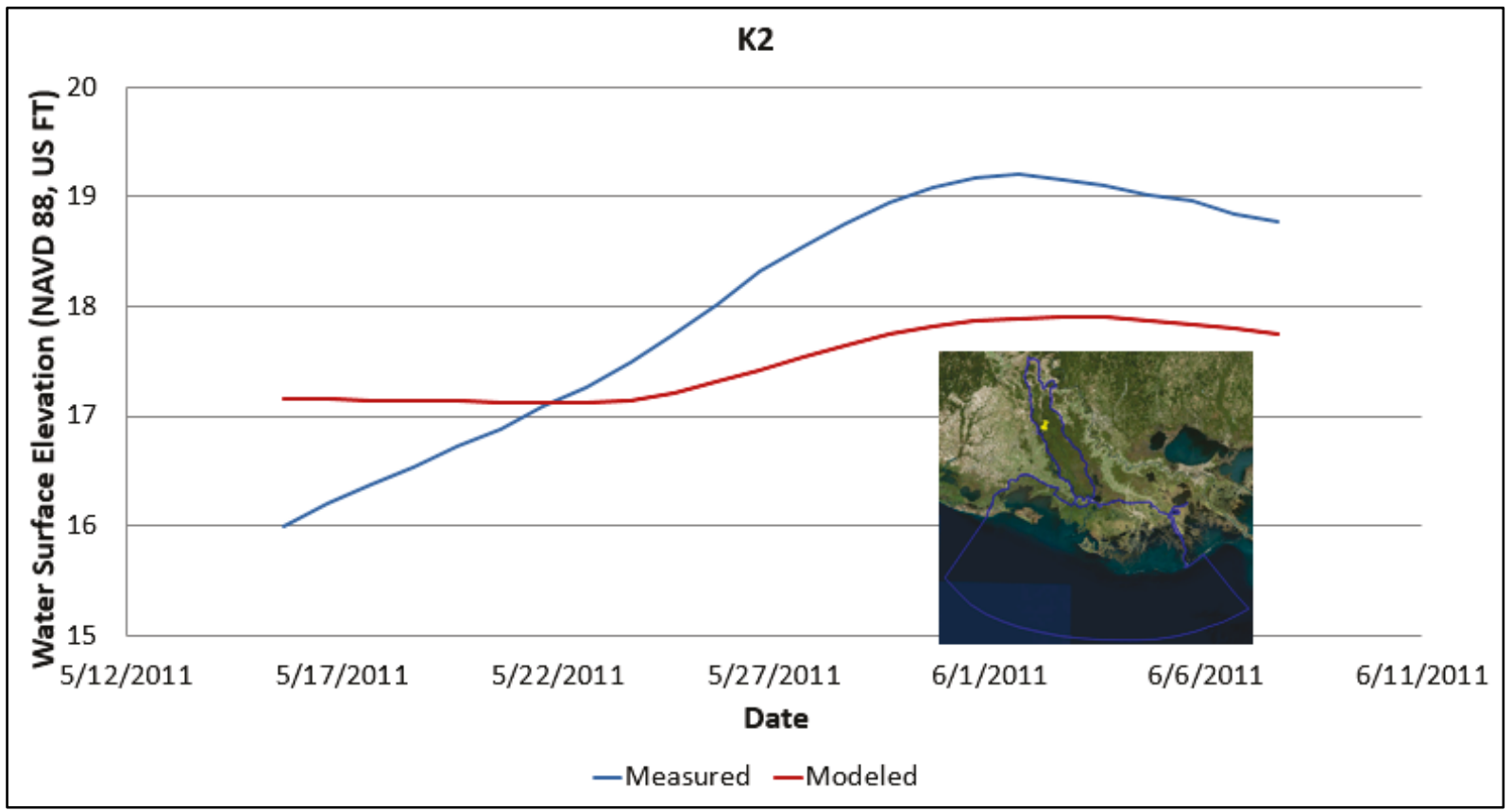

Figure A-11. Gage K3 Initial Model results.

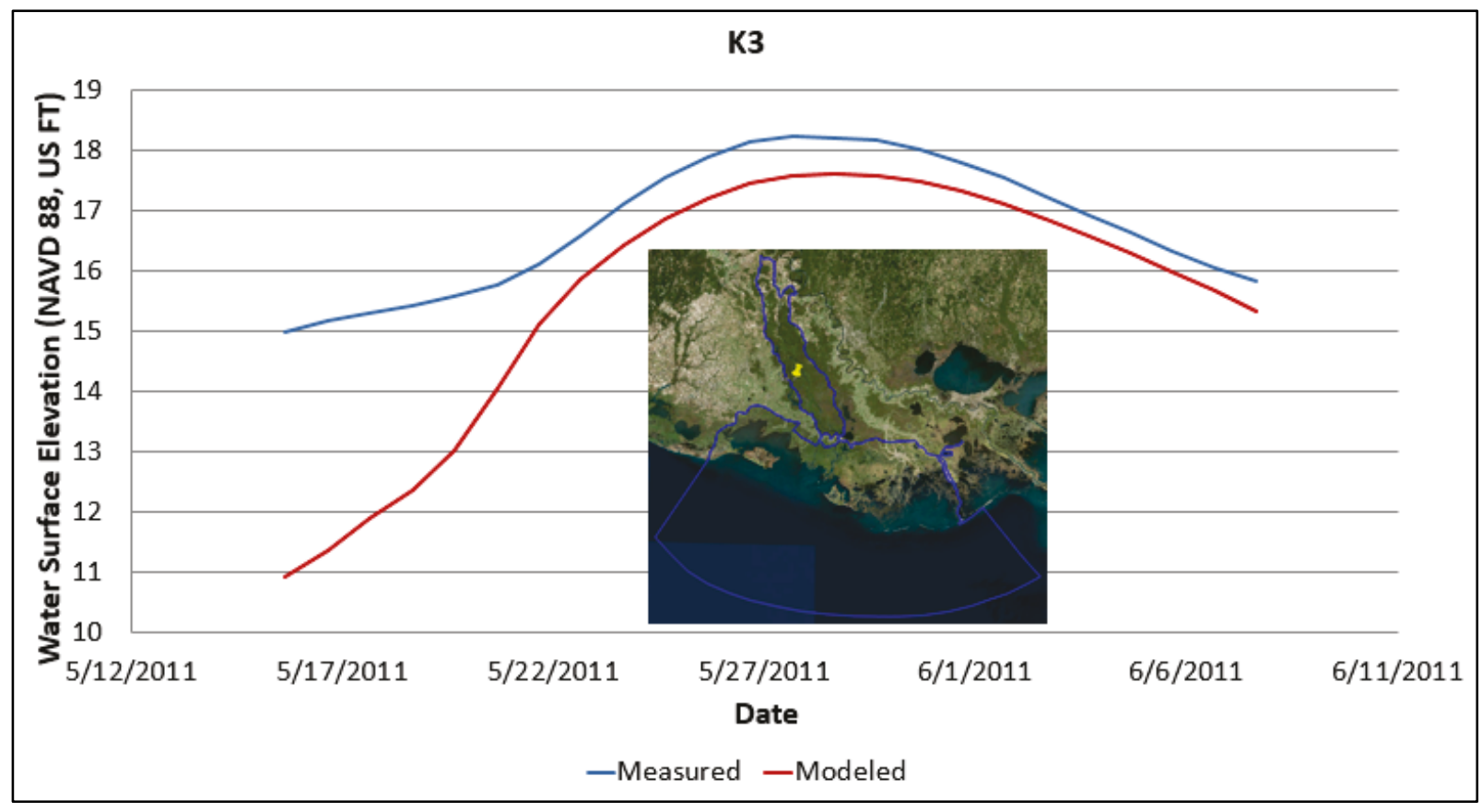


Figure A-12. Gage K4 Initial Model results.

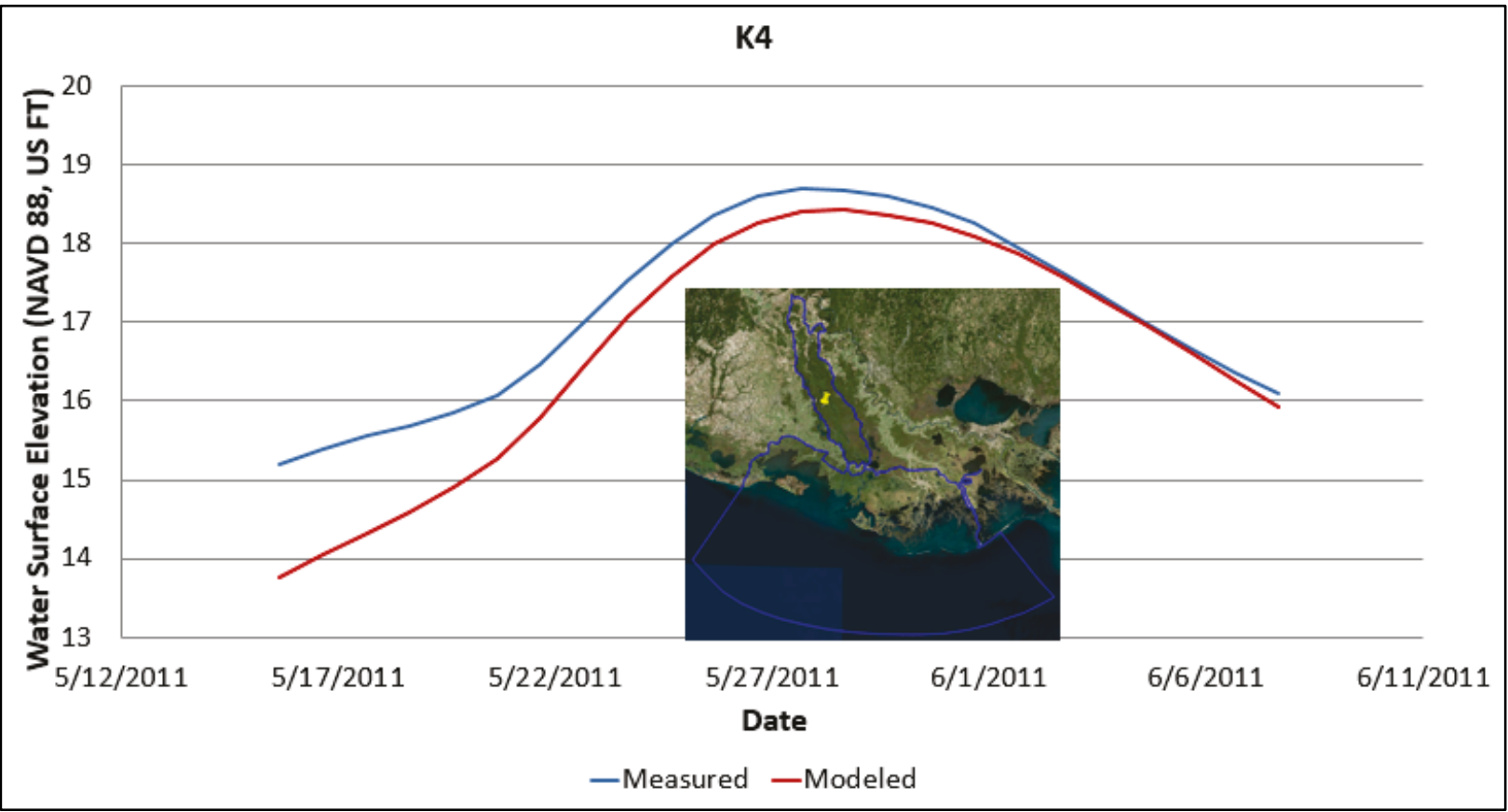

Figure A-13. Gage K5 Initial Model results.

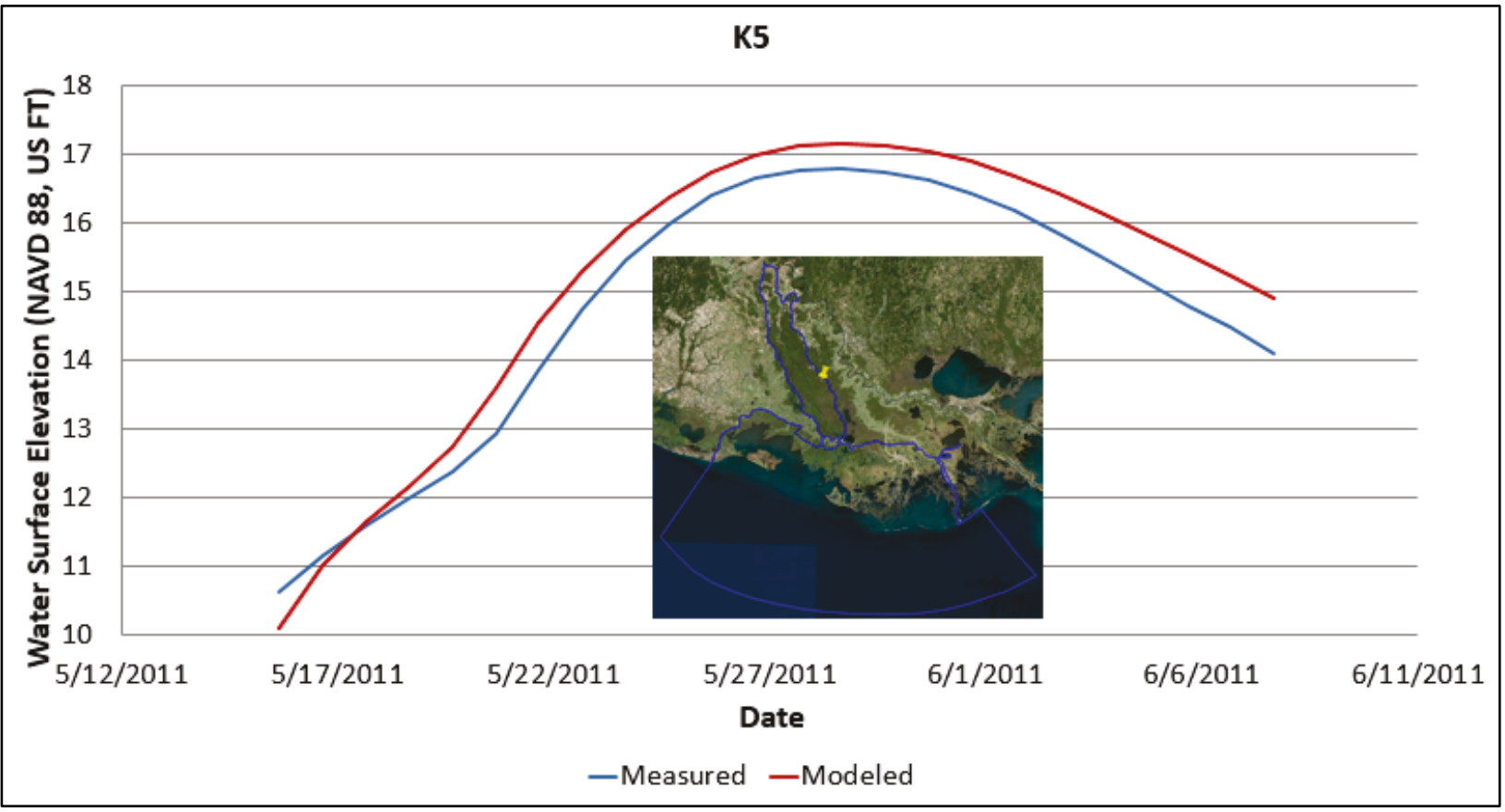


Figure A-14. Gage K6 Initial Model results.

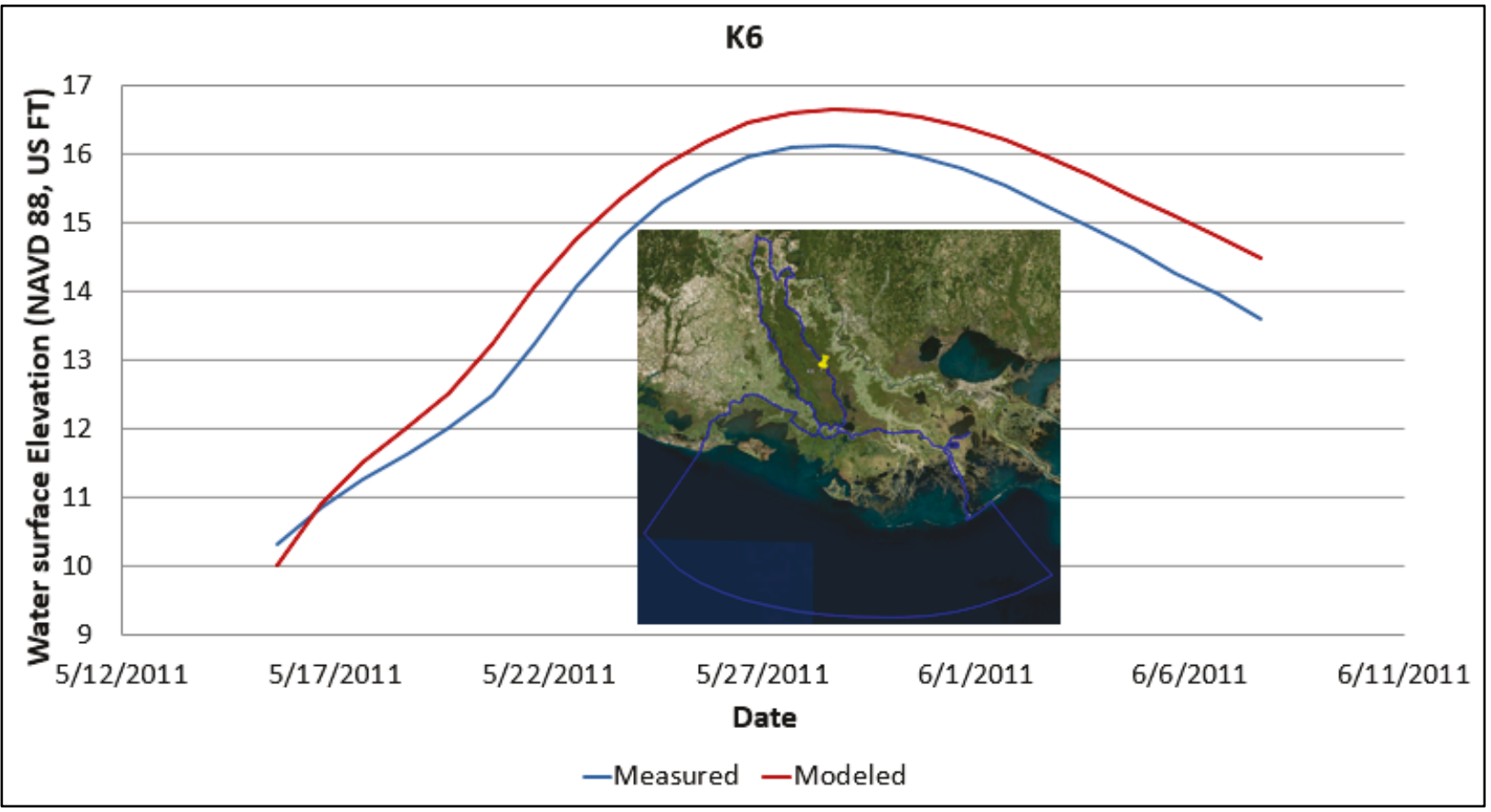

Figure A-15. Gage K7 Initial Model results.

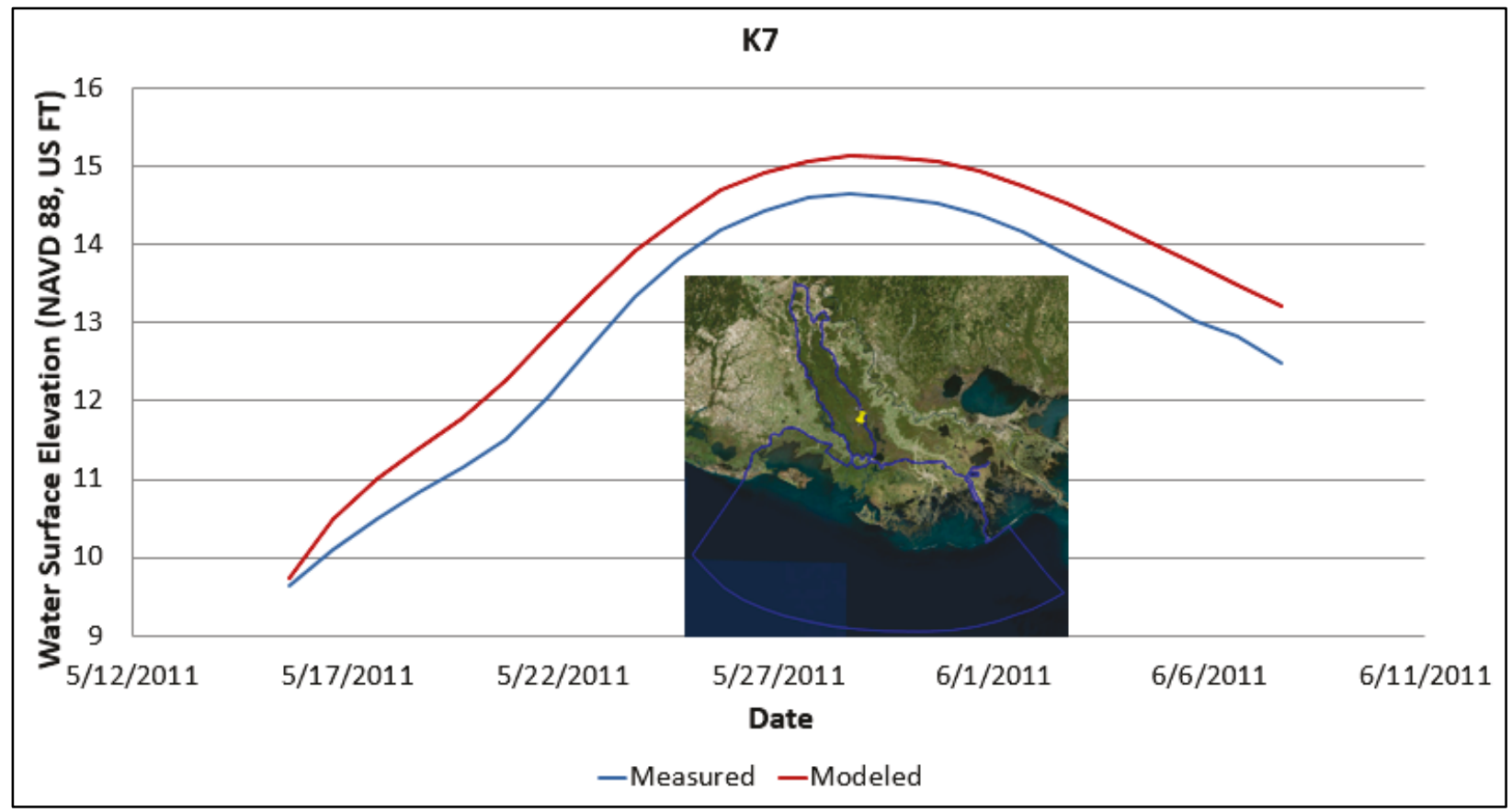


Figure A-16. Gage K8 Initial Model results.

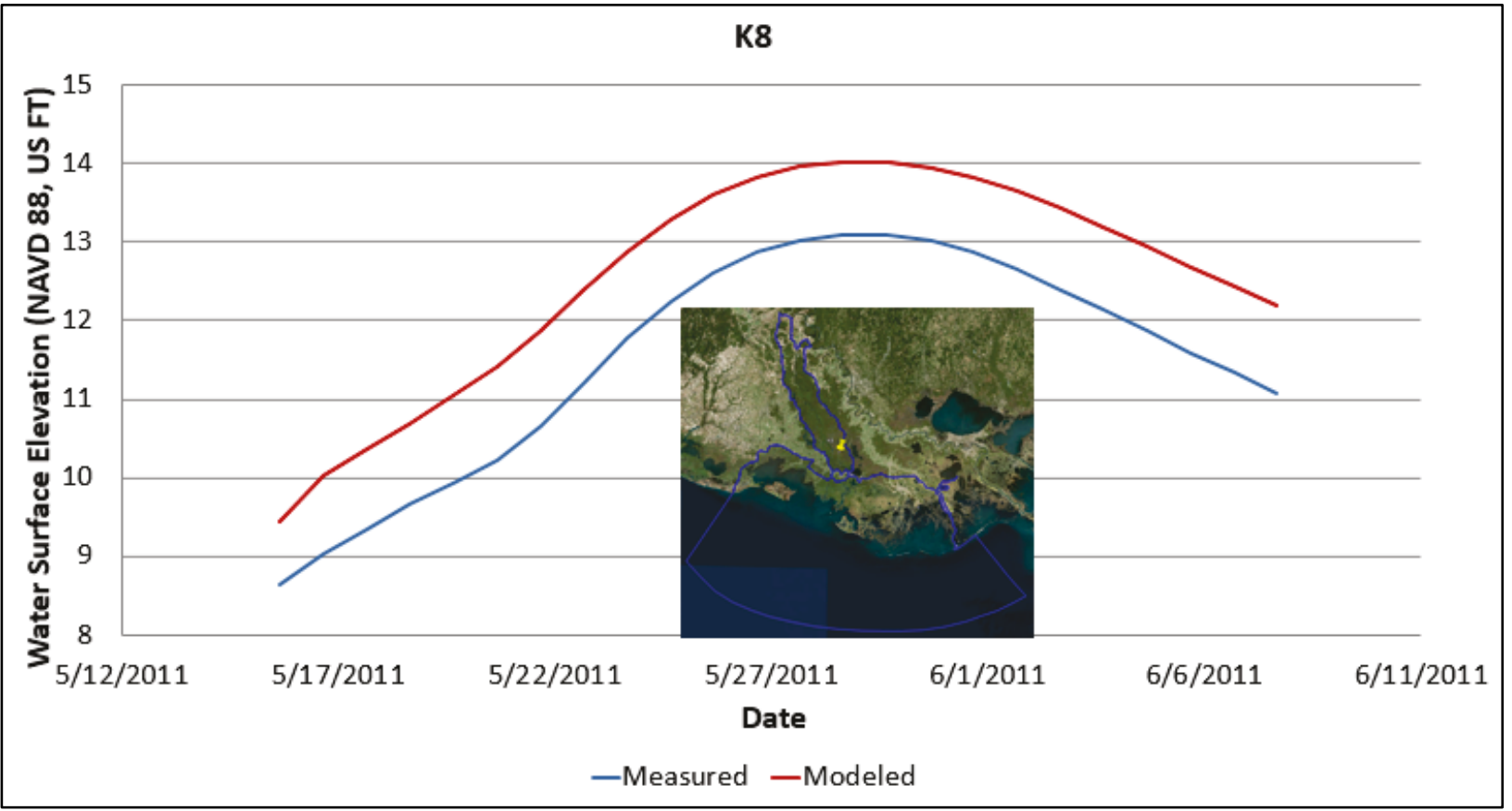

Figure A-17. Gage K9 Initial Model results.

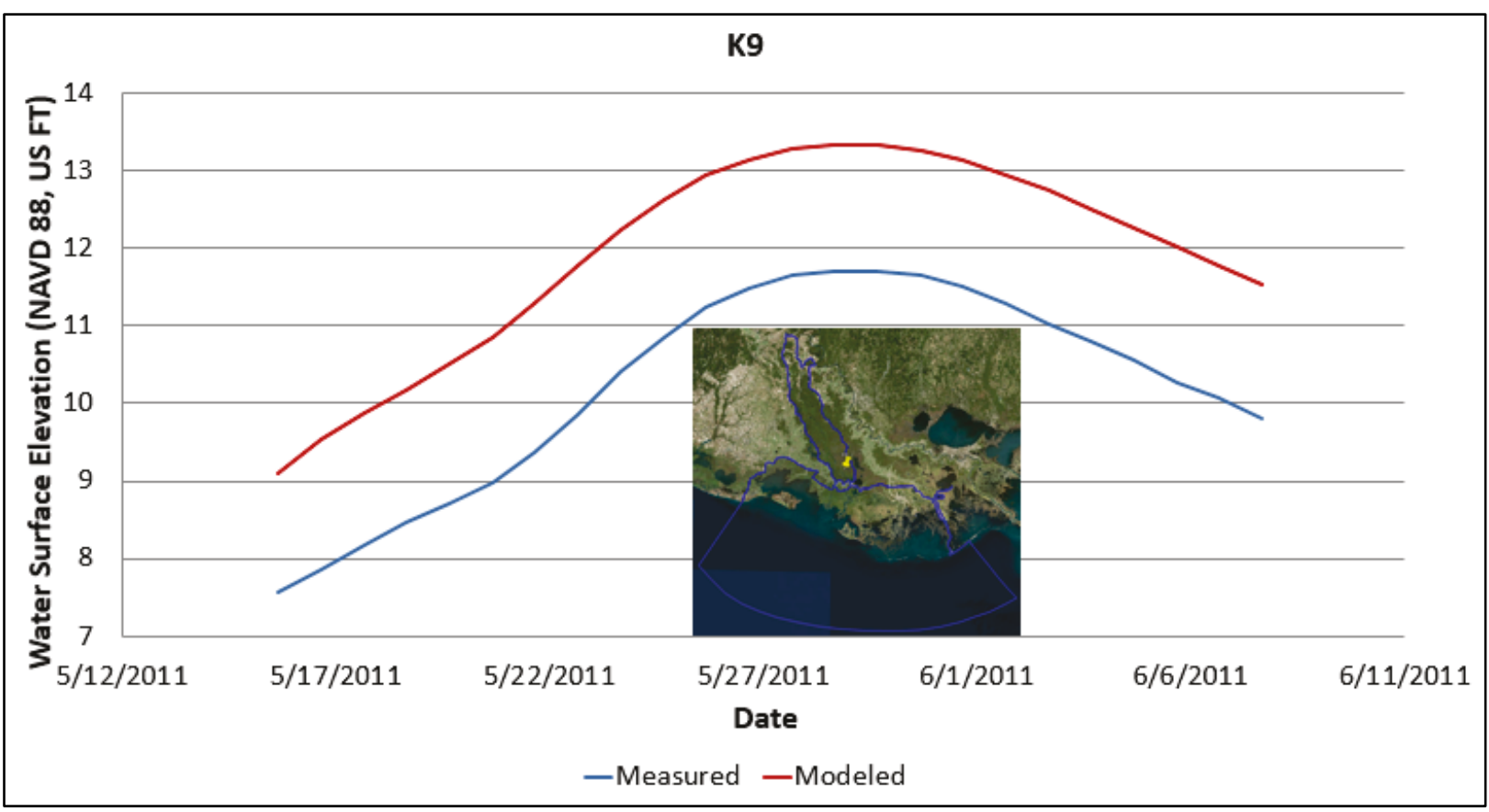


Figure A-18. Gage K10 Initial Model results.

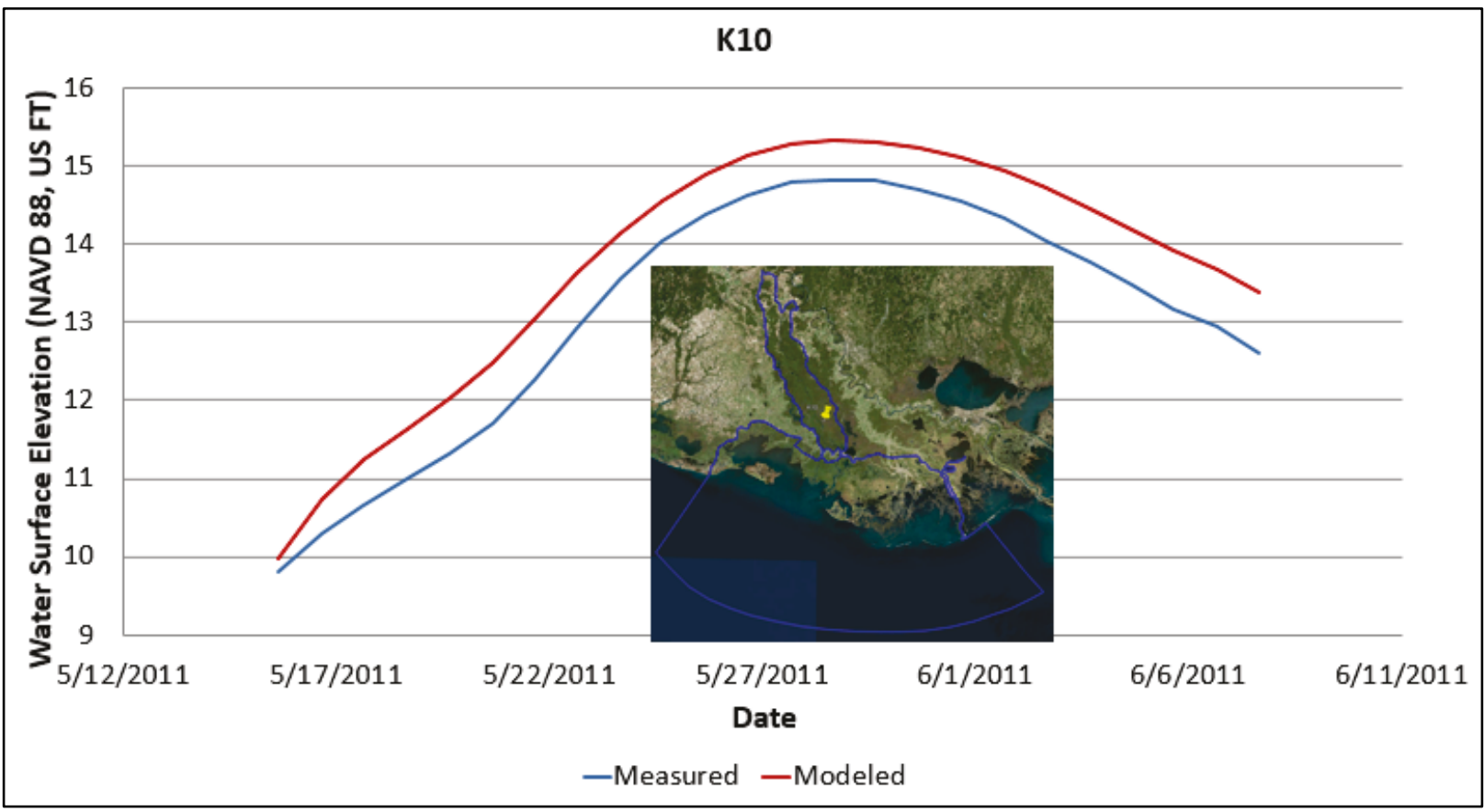

Figure A-19. Gage K11 Initial Model results.

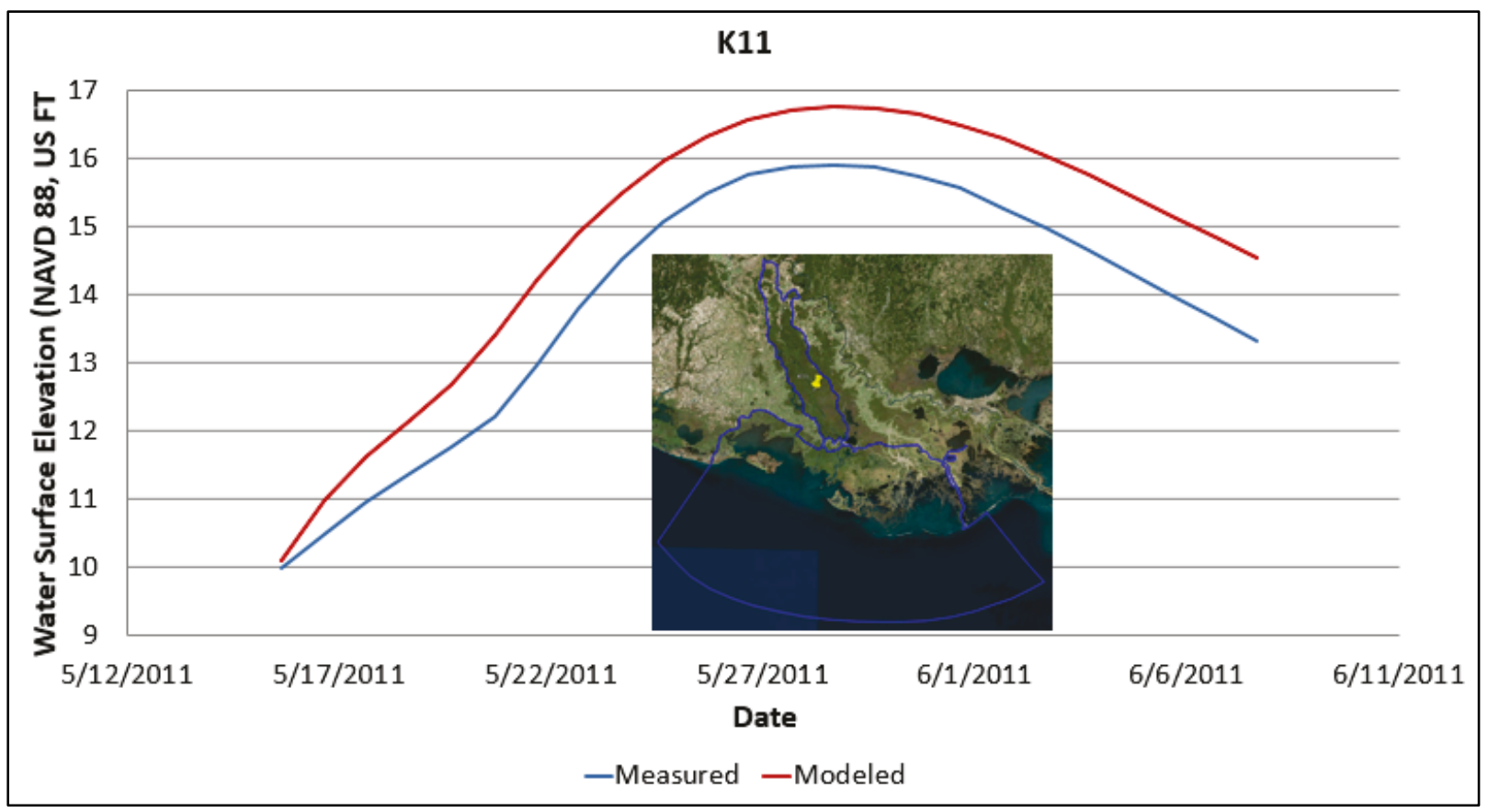


Figure A-20. Gage K12 Initial Model results.

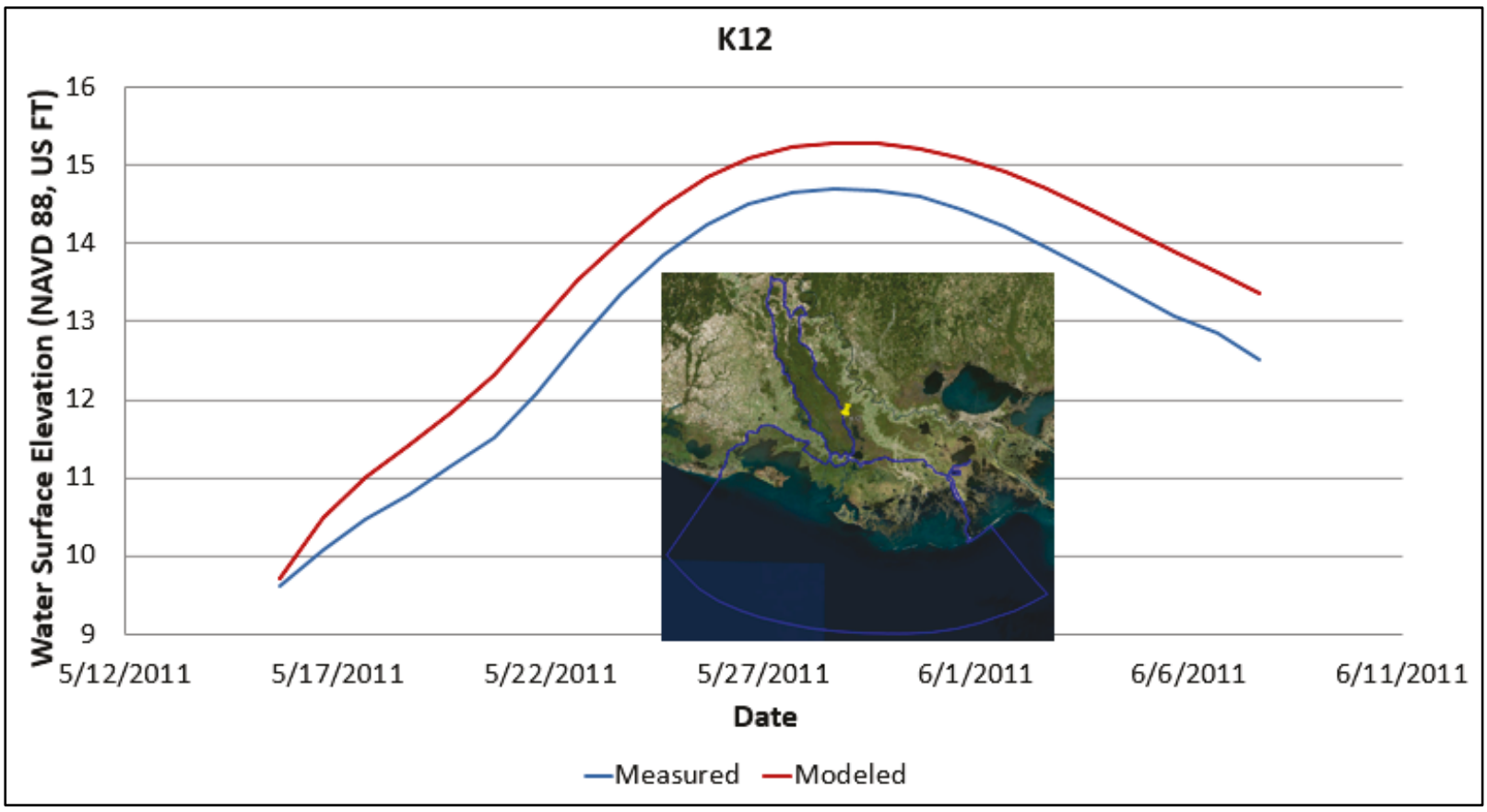

Figure A-21. Gage K13 Initial Model results.

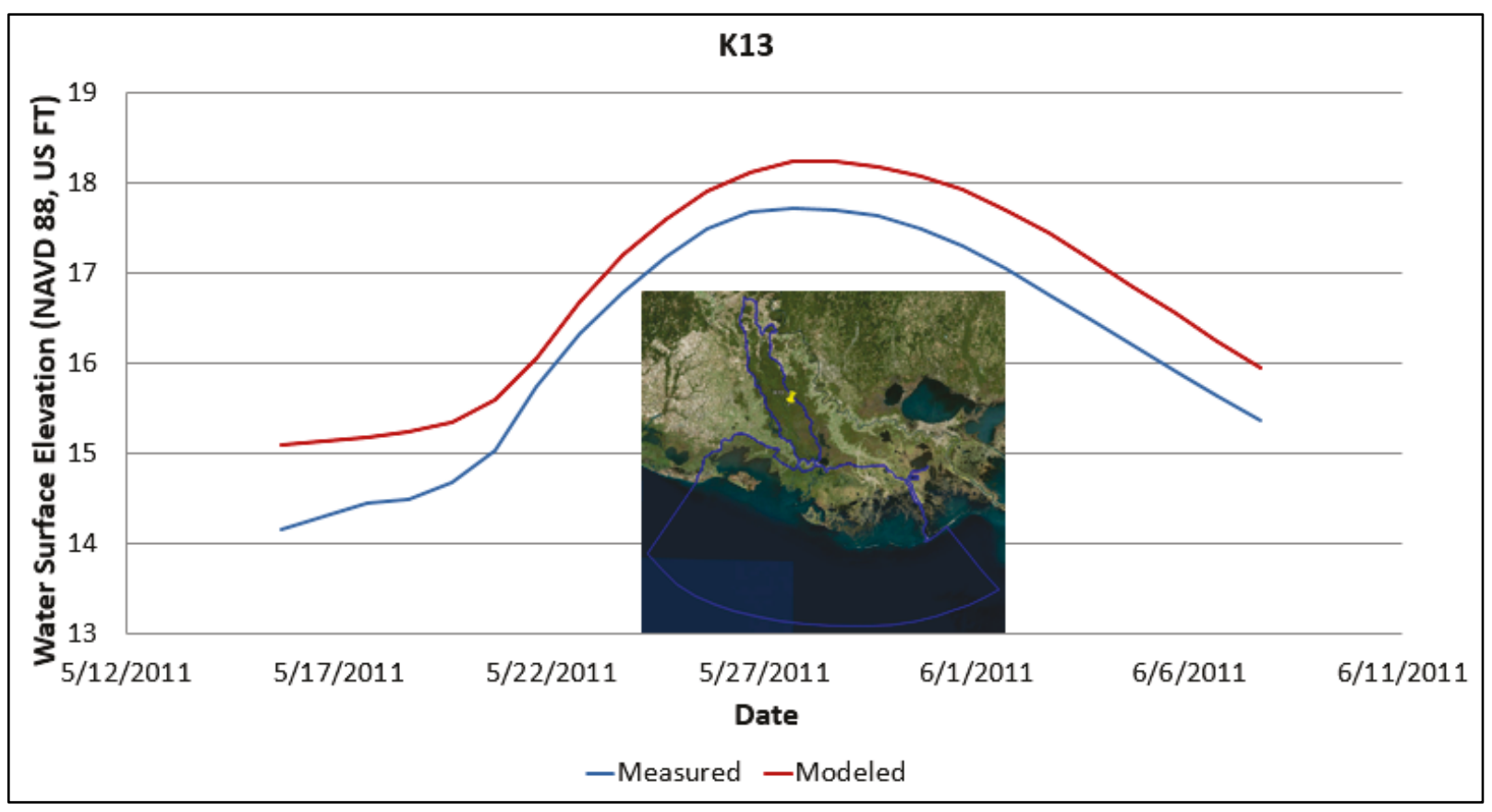


Figure A-22. Gage K14 Initial Model results.

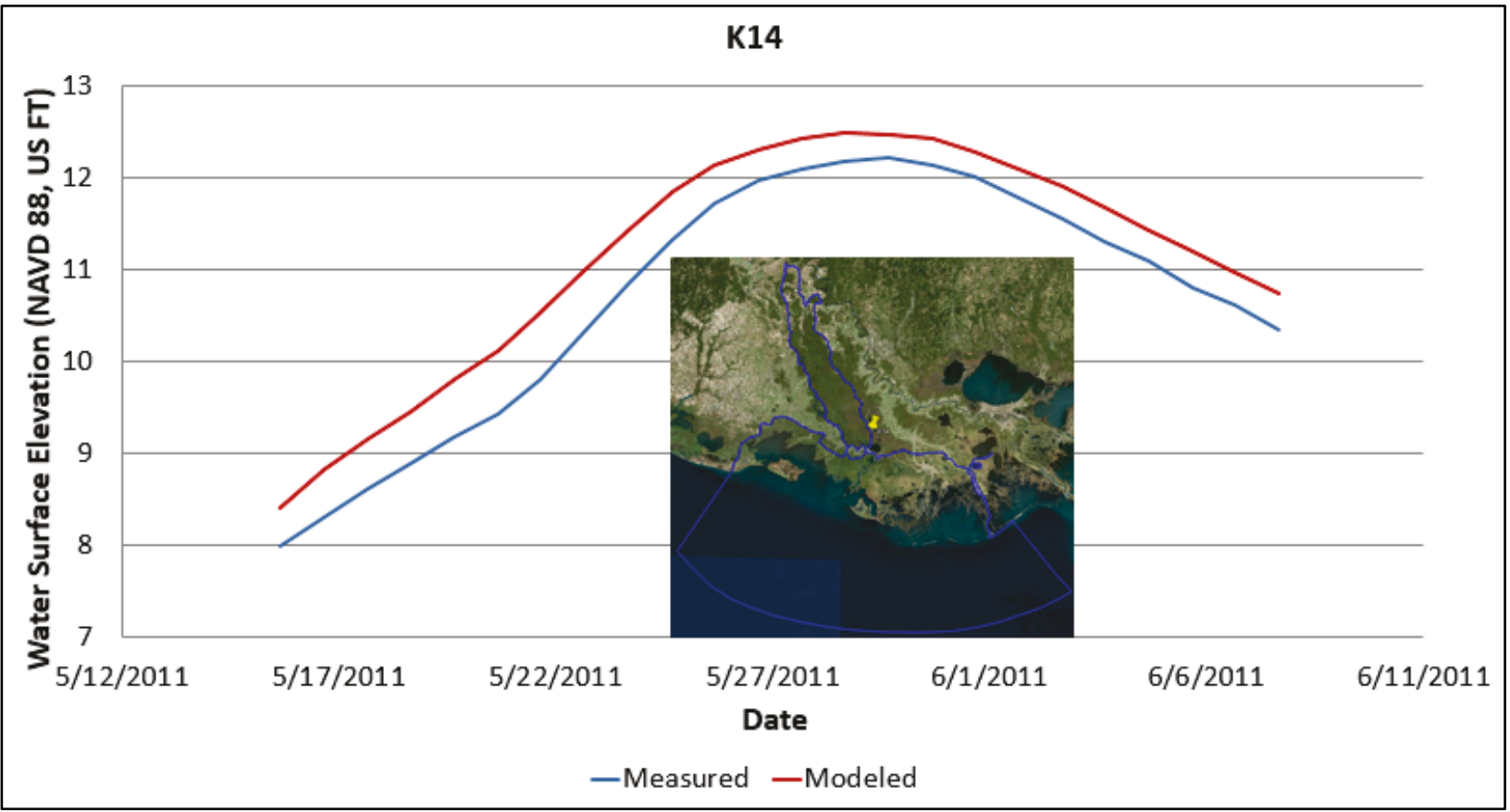

Figure A-23. Gage K15 Initial Model results.

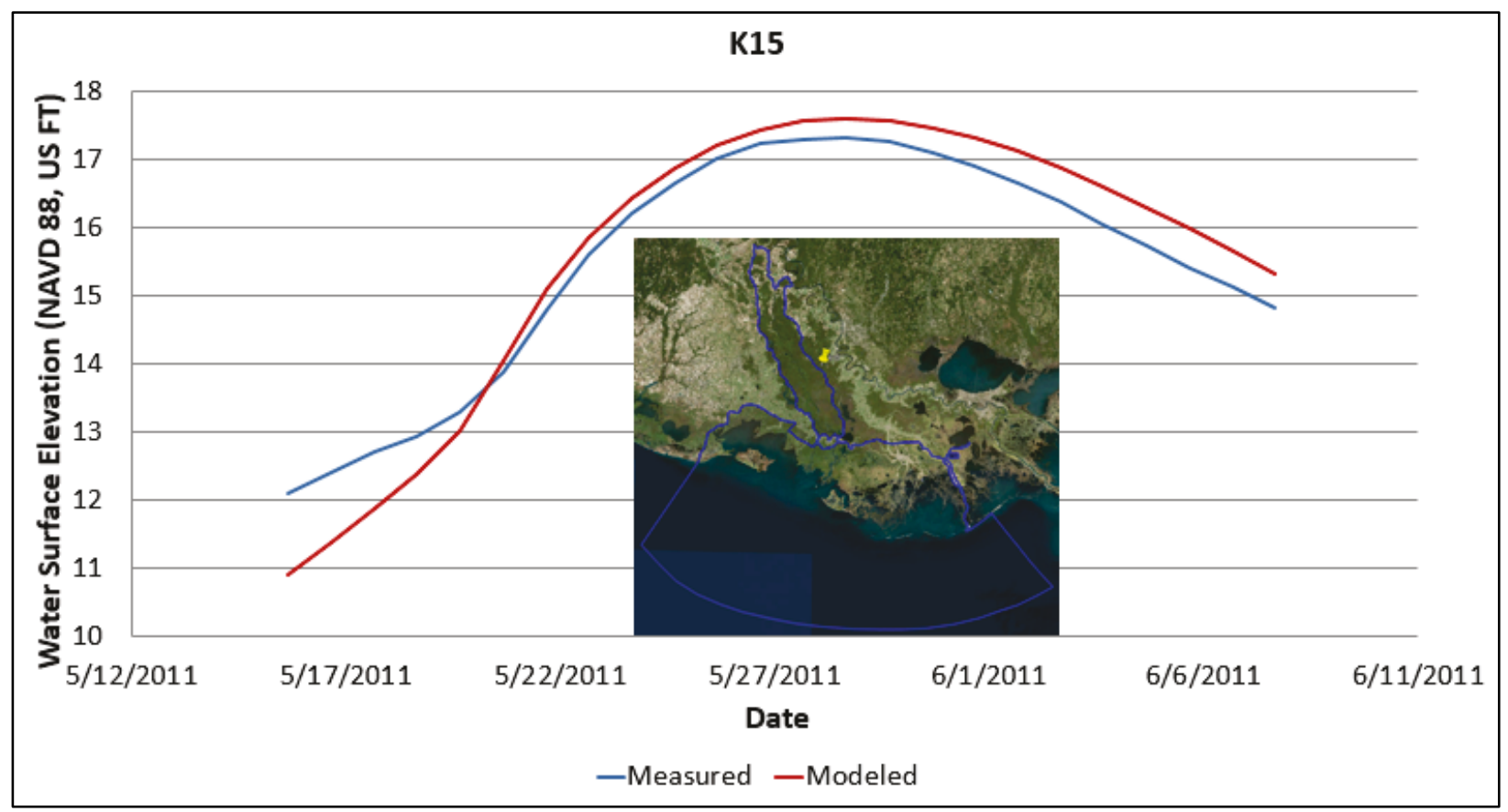


Figure A-24. Gage K16 Initial Model results.

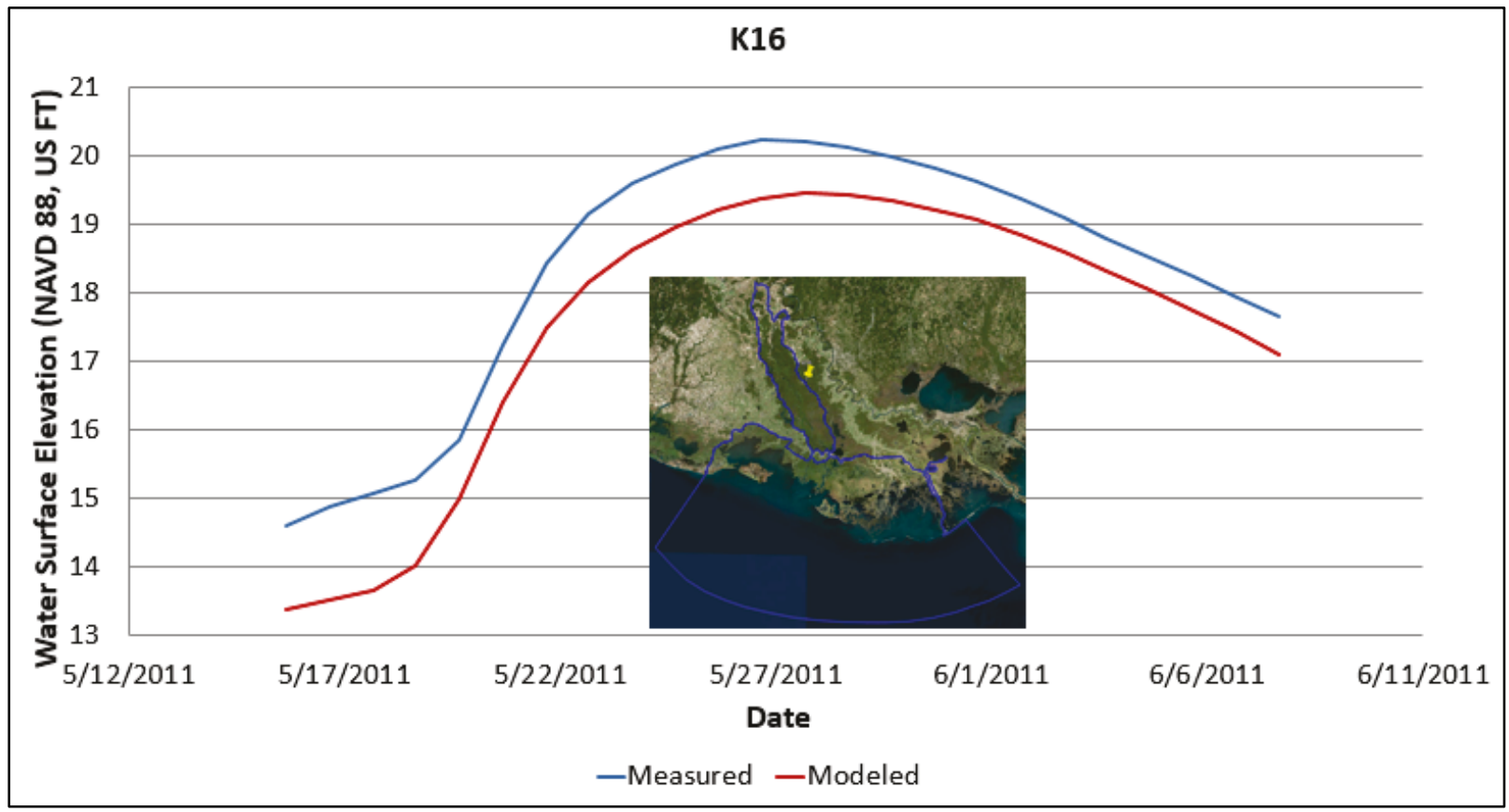

Figure A-25. Gage K17 Initial Model results.

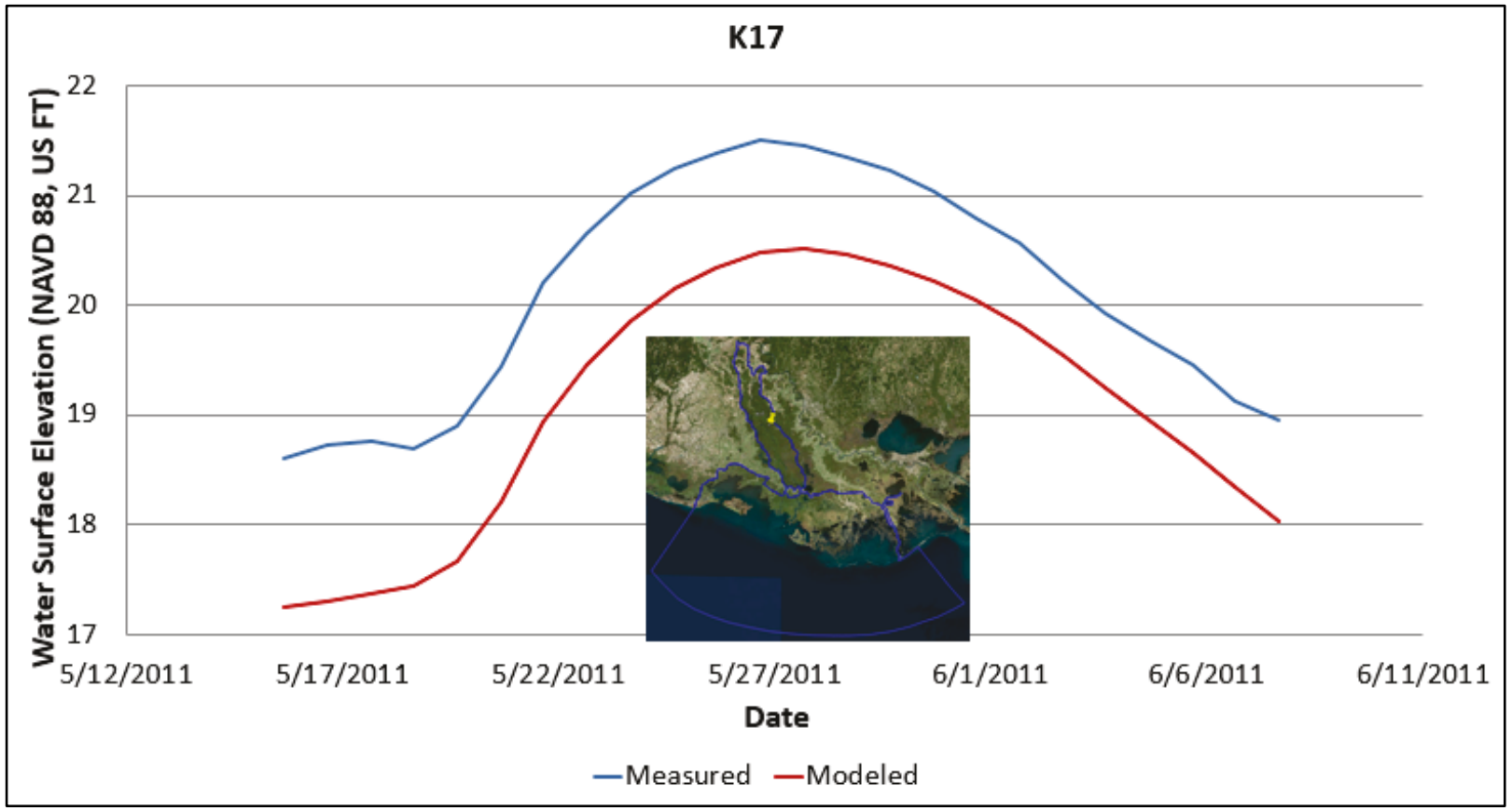


Figure A-26. Gage K18 Initial Model results.

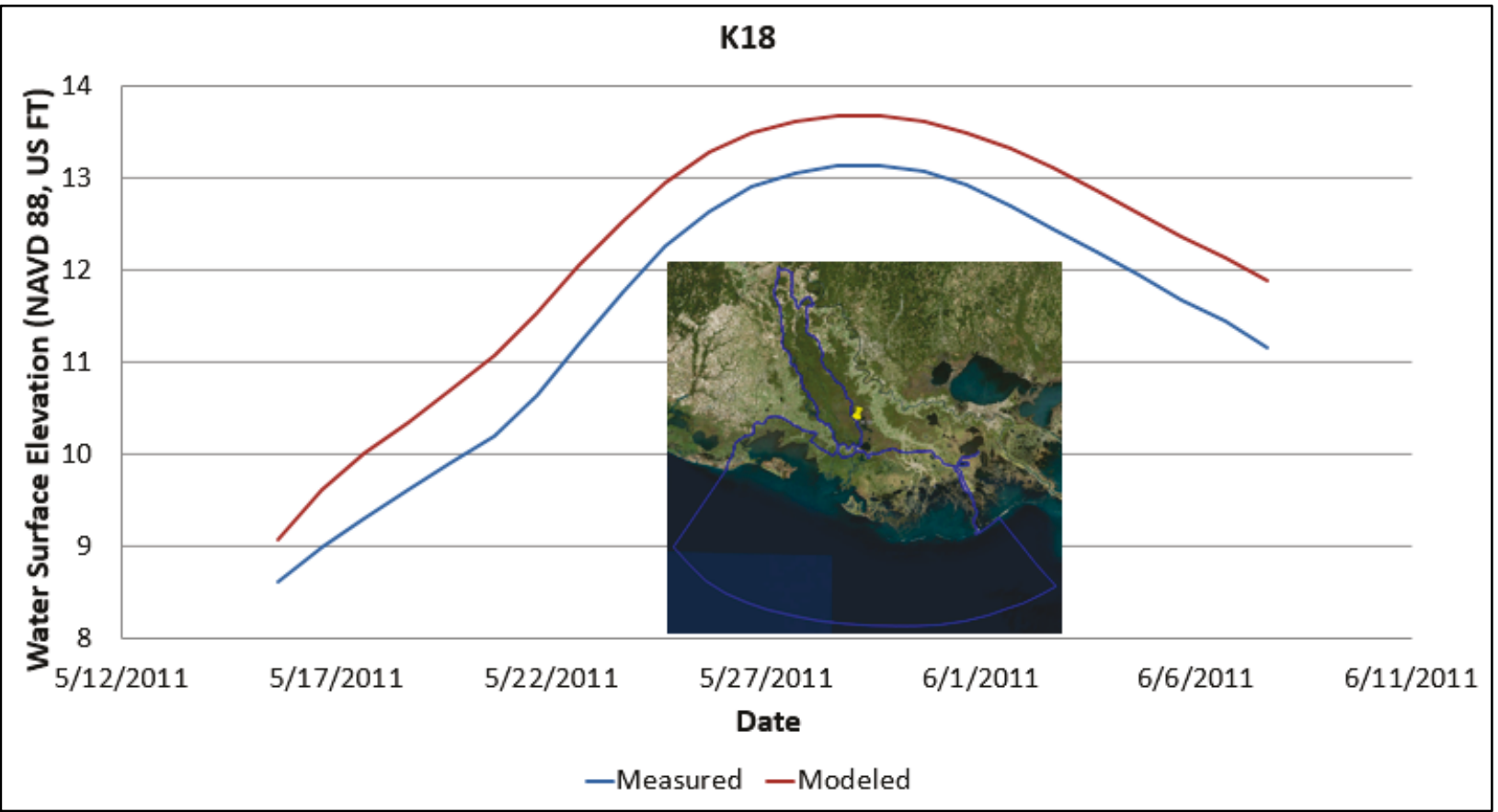

Figure A-27. Gage K19 Initial Model results.

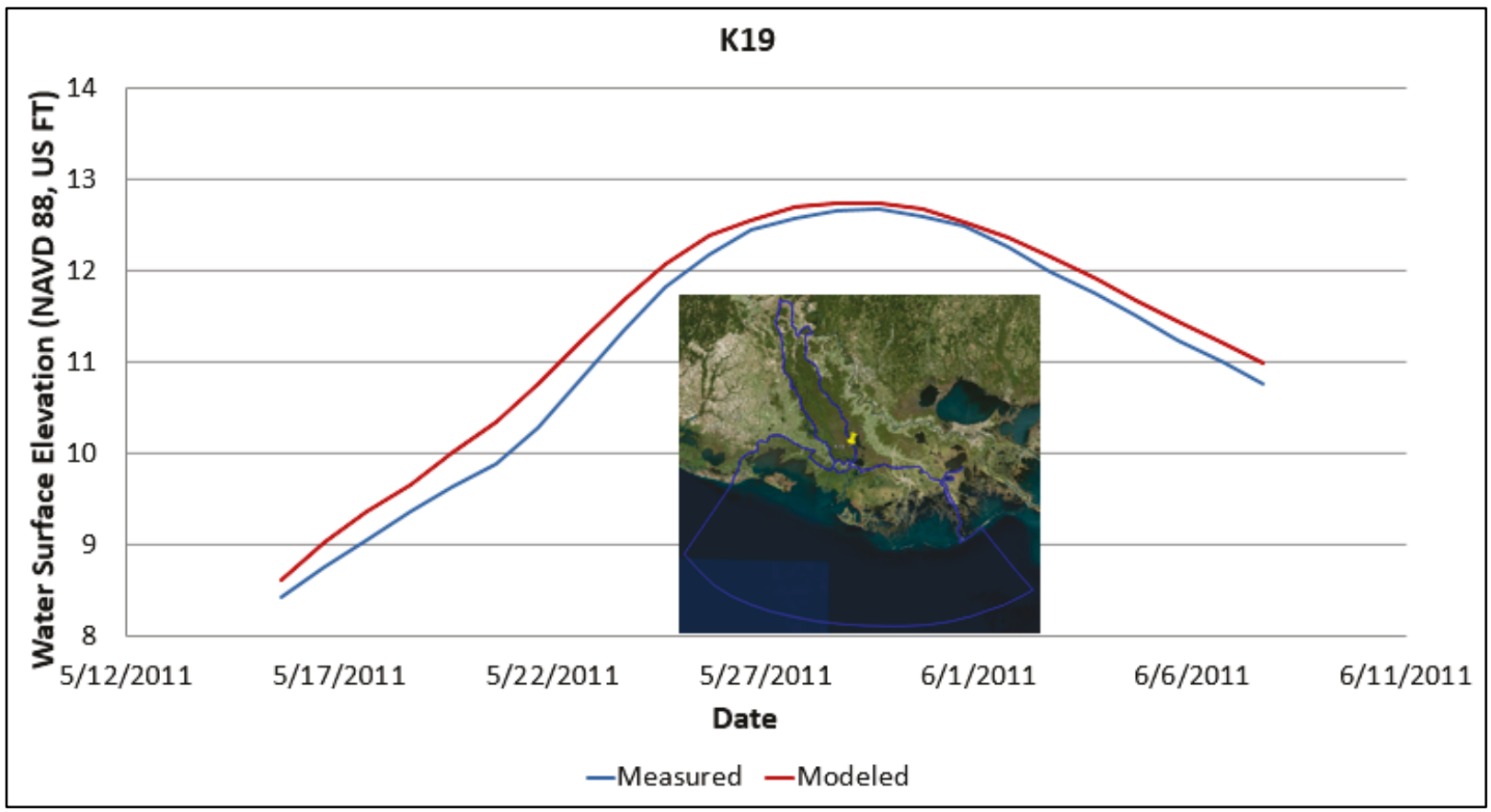


Figure A-28. Gage K21 initial model results.

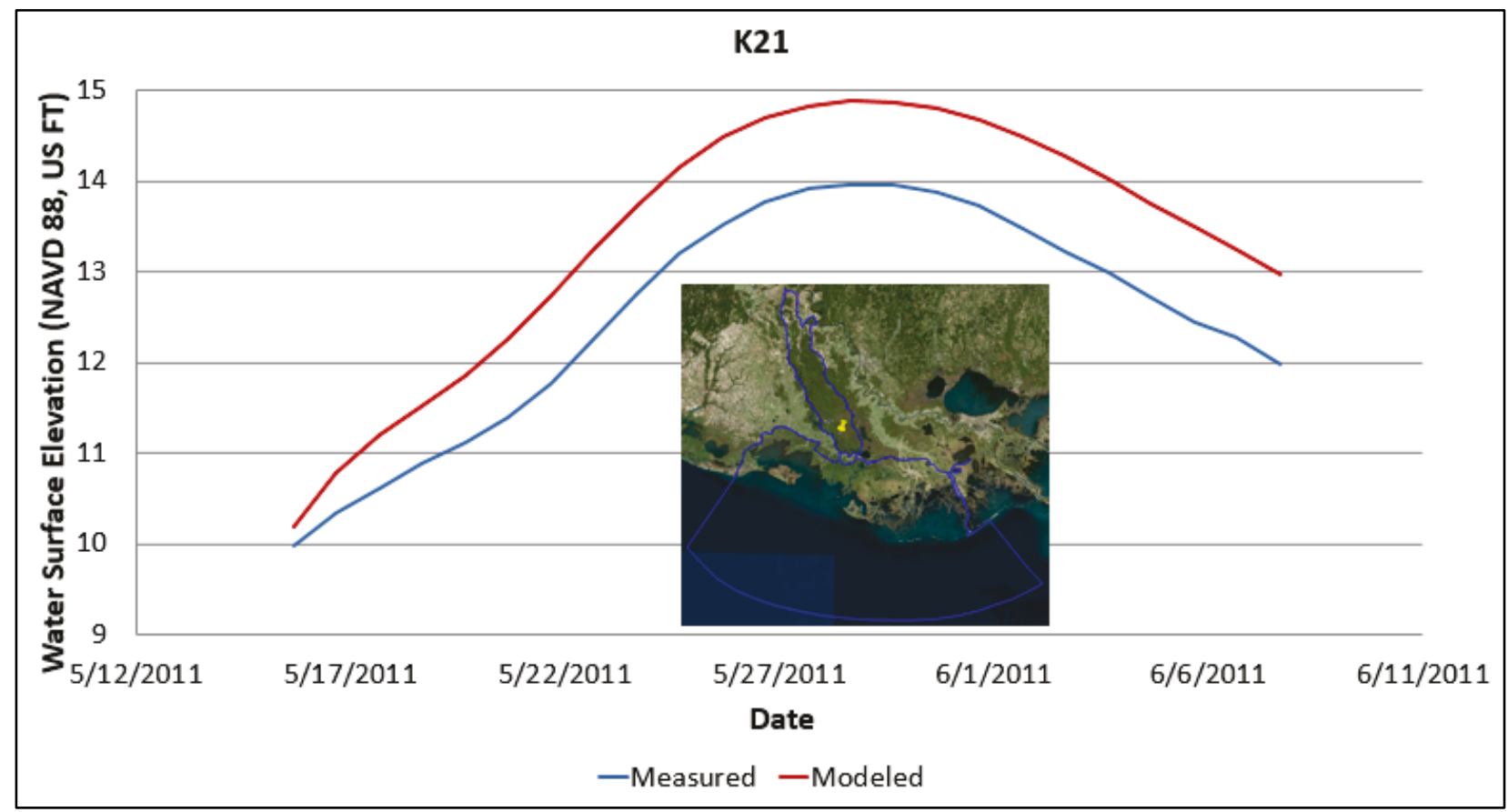

Figure A-29. USGS gage at Wax Lake Outlet (water surface elevation).

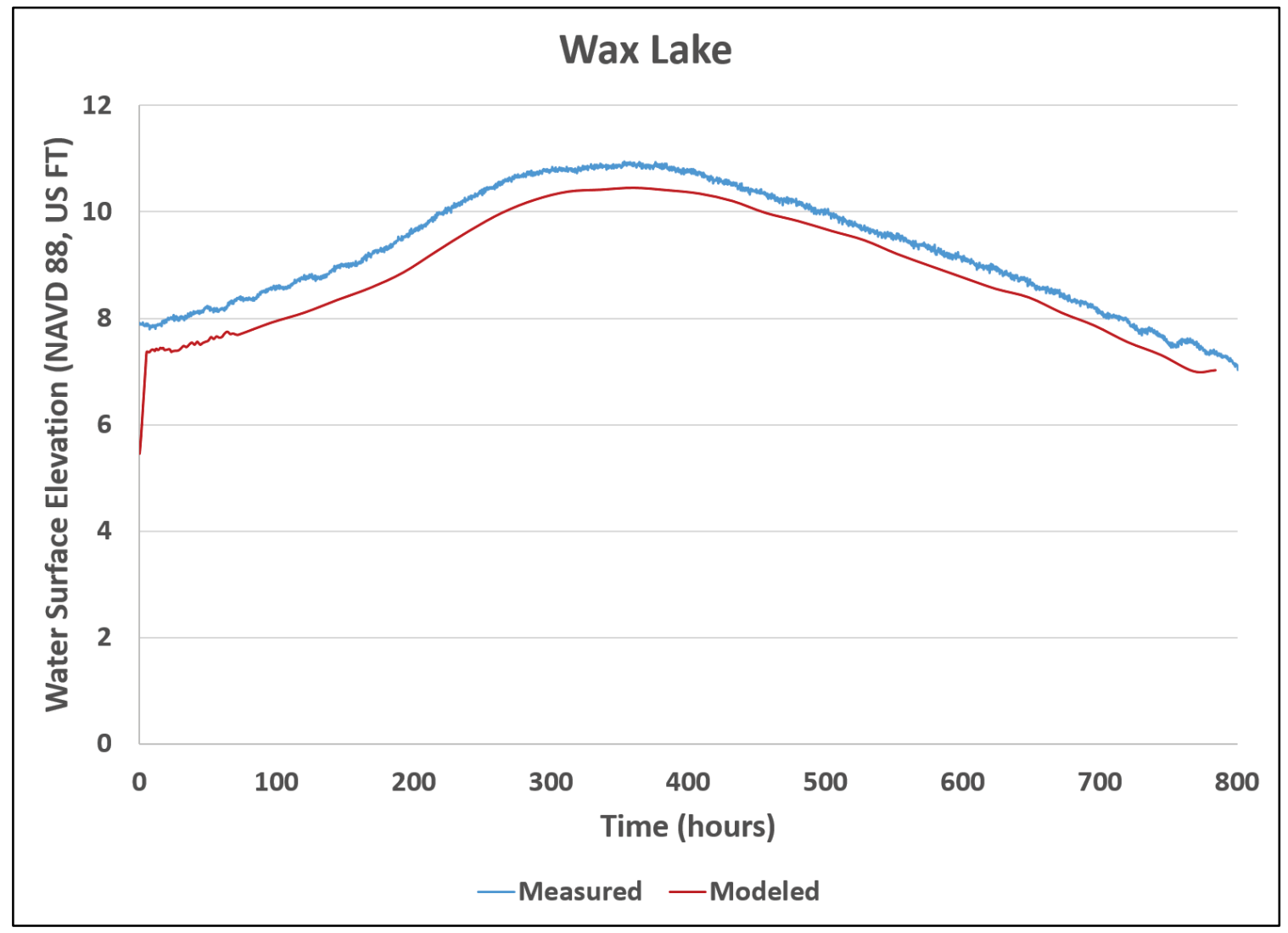


Figure A-30. USGS gage at Morgan City Outlet (water surface elevation).

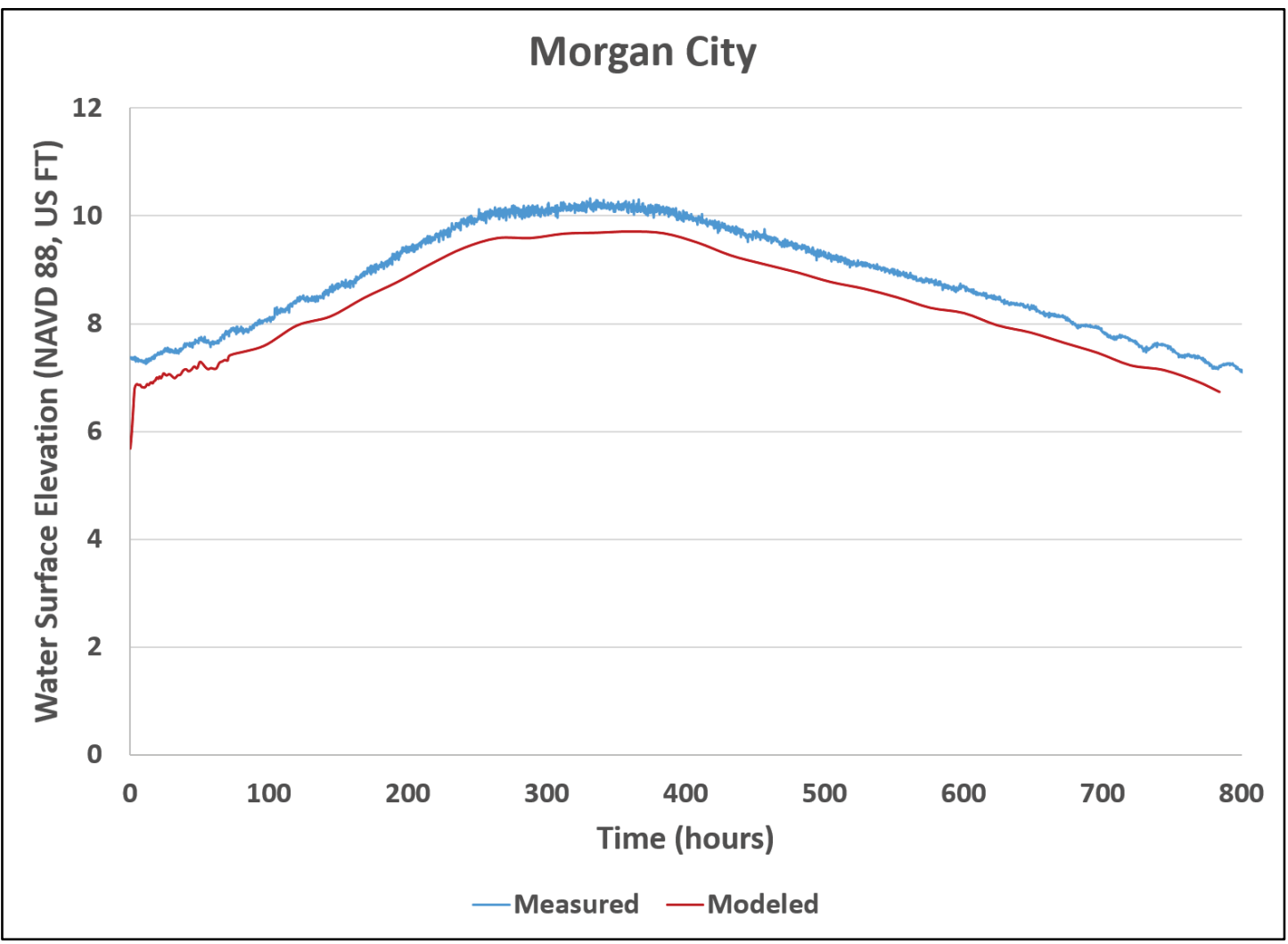

Figure A-31. USGS gage at Wax Lake Outlet (discharge).

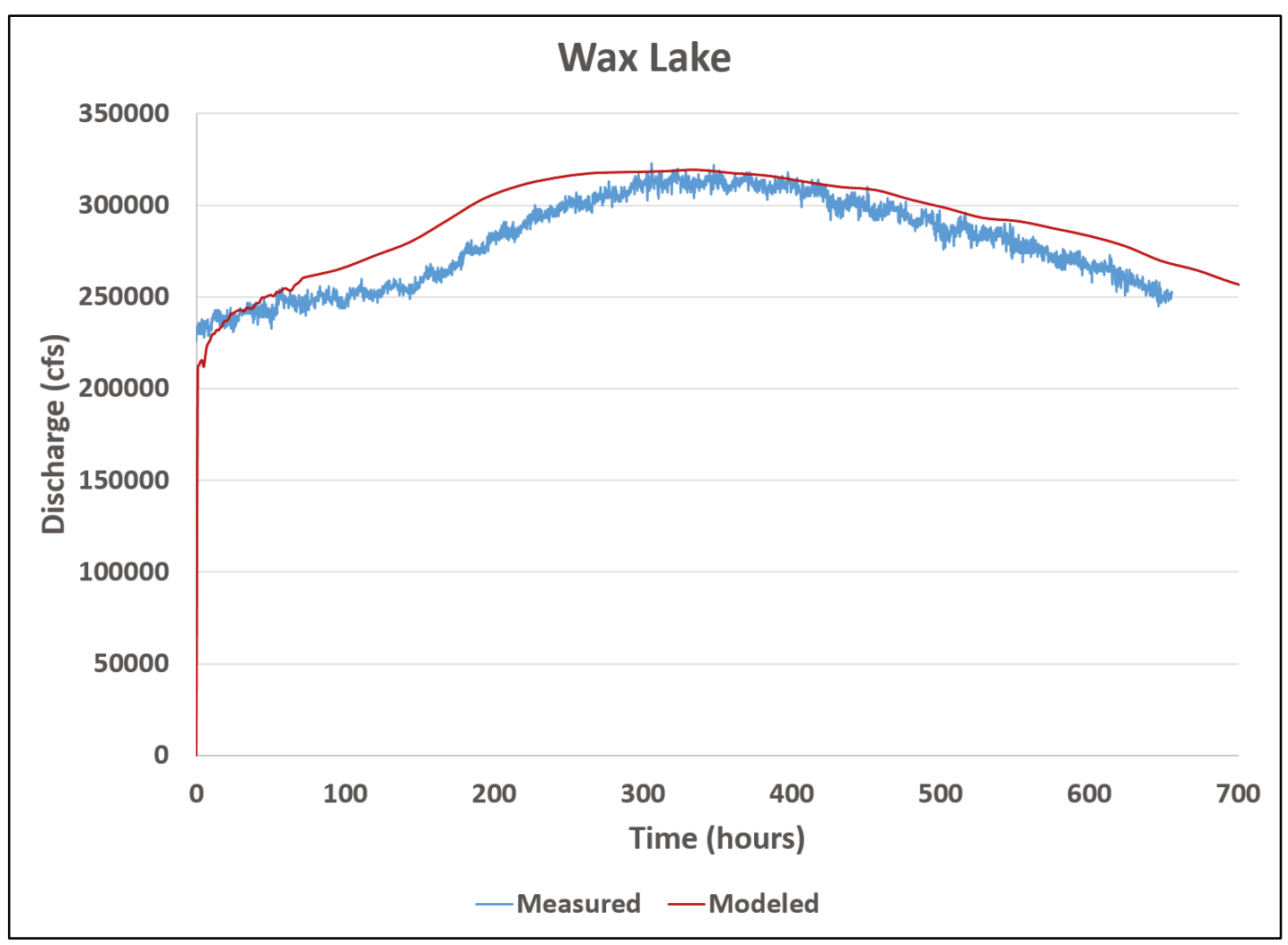


Figure A-32. USGS gage at Morgan City Outlet (discharge).

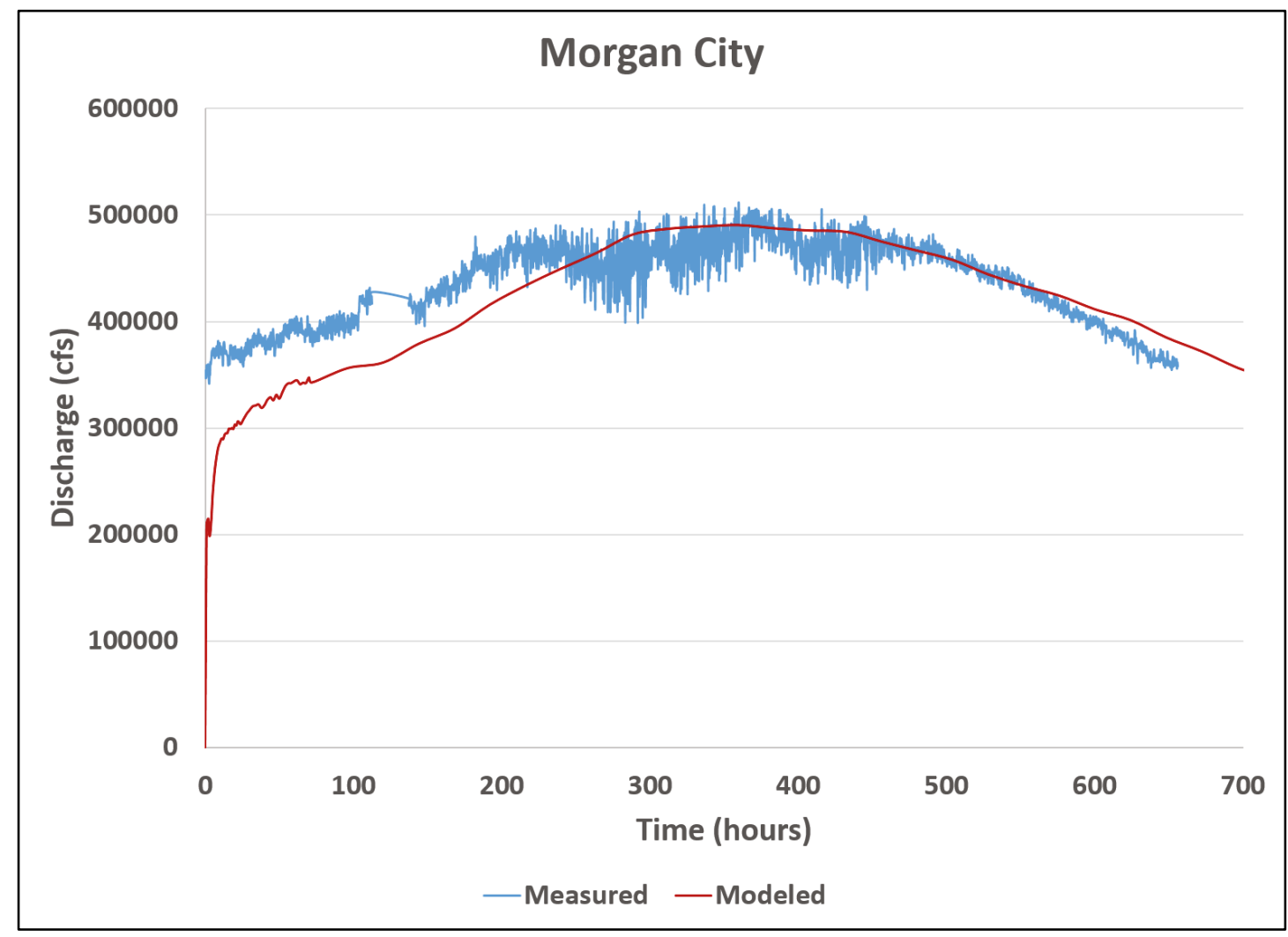




\section{Appendix B: Bathymetric Adjustment Model Results}

The Bathymetric Adjustment Model results have the same mesh domain as the Initial Model results in Appendix A (see Figure A-1). The difference between the two models is the locations in the model where the elevations were lowered by 5 and $15 \mathrm{ft}$ (refer to Figure 7 and Figure 8, respectively in Section 3.2 "Bathymetric adjustments"). This adjustment was done to account for locations where lidar elevation values were representative of the water surface elevation and not the bathymetric/topographic elevation. The results of this modeling effort can be seen in Figures B-1 B-31.

Figure B-1. Gage A01 Bathymetric Adjustment Model results.

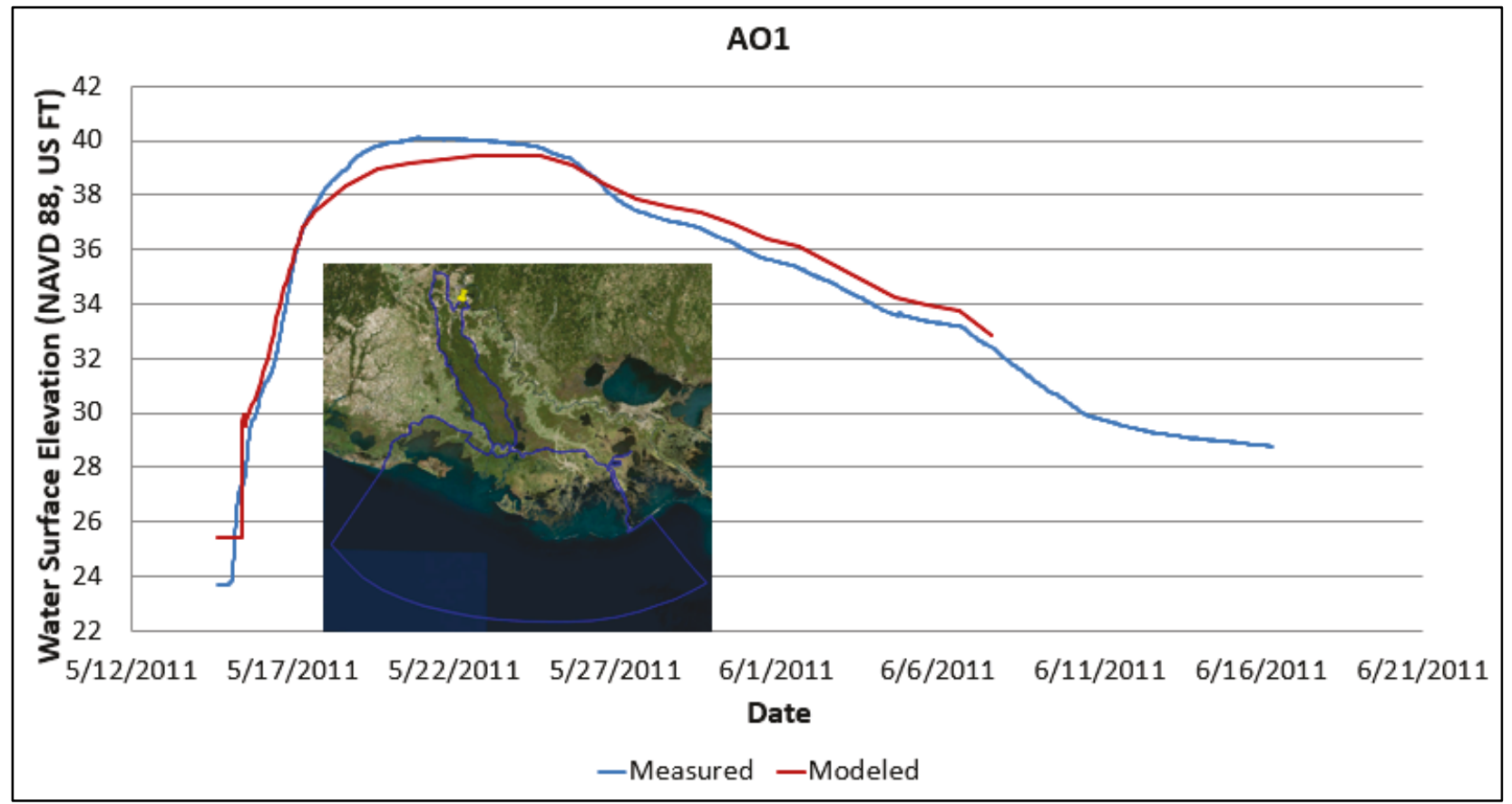


Figure B-2. Gage AO2 Bathymetric Adjustment Model results.

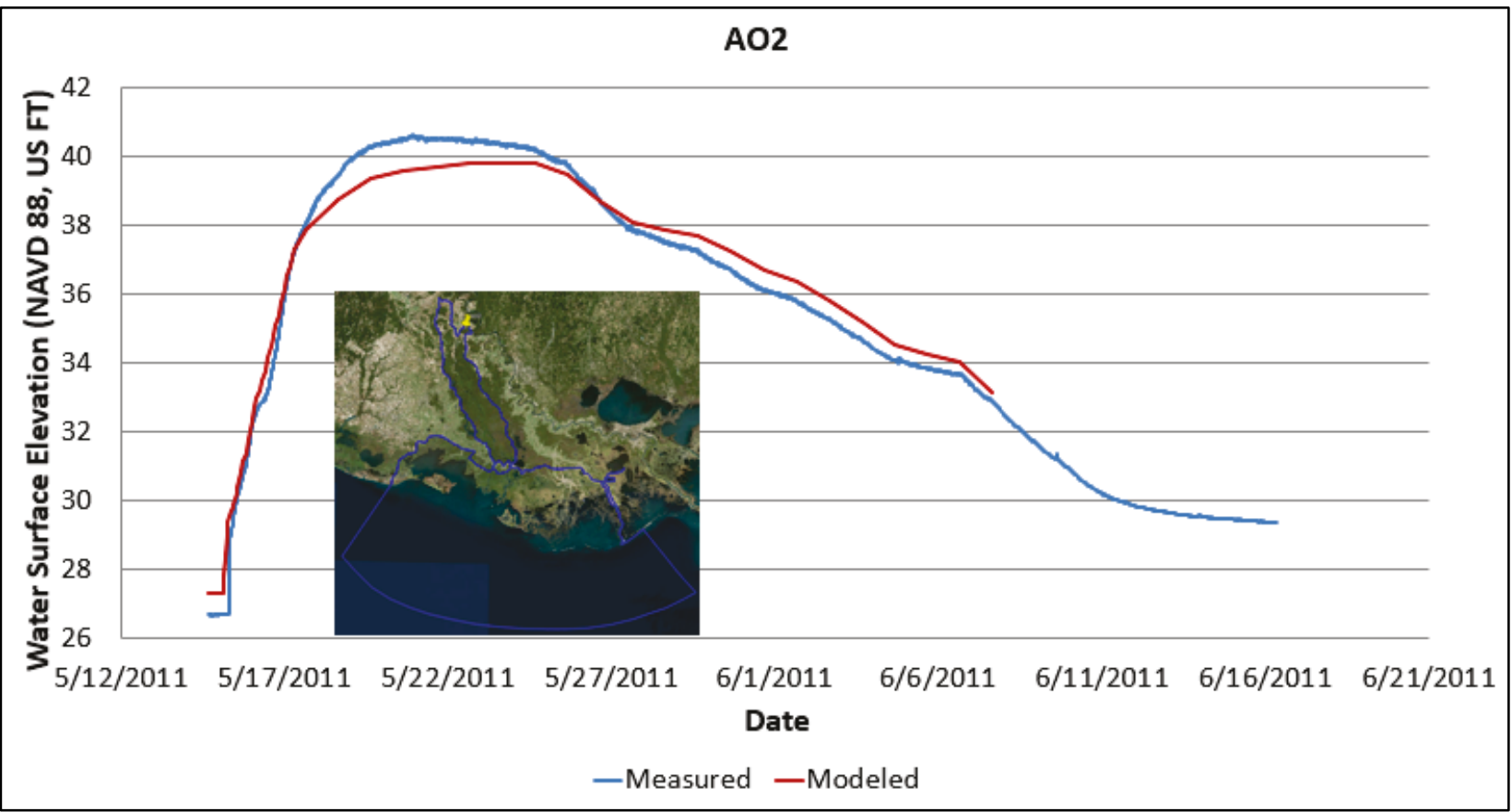

Figure B-3. Gage AO3 Bathymetric Adjustment Model results.

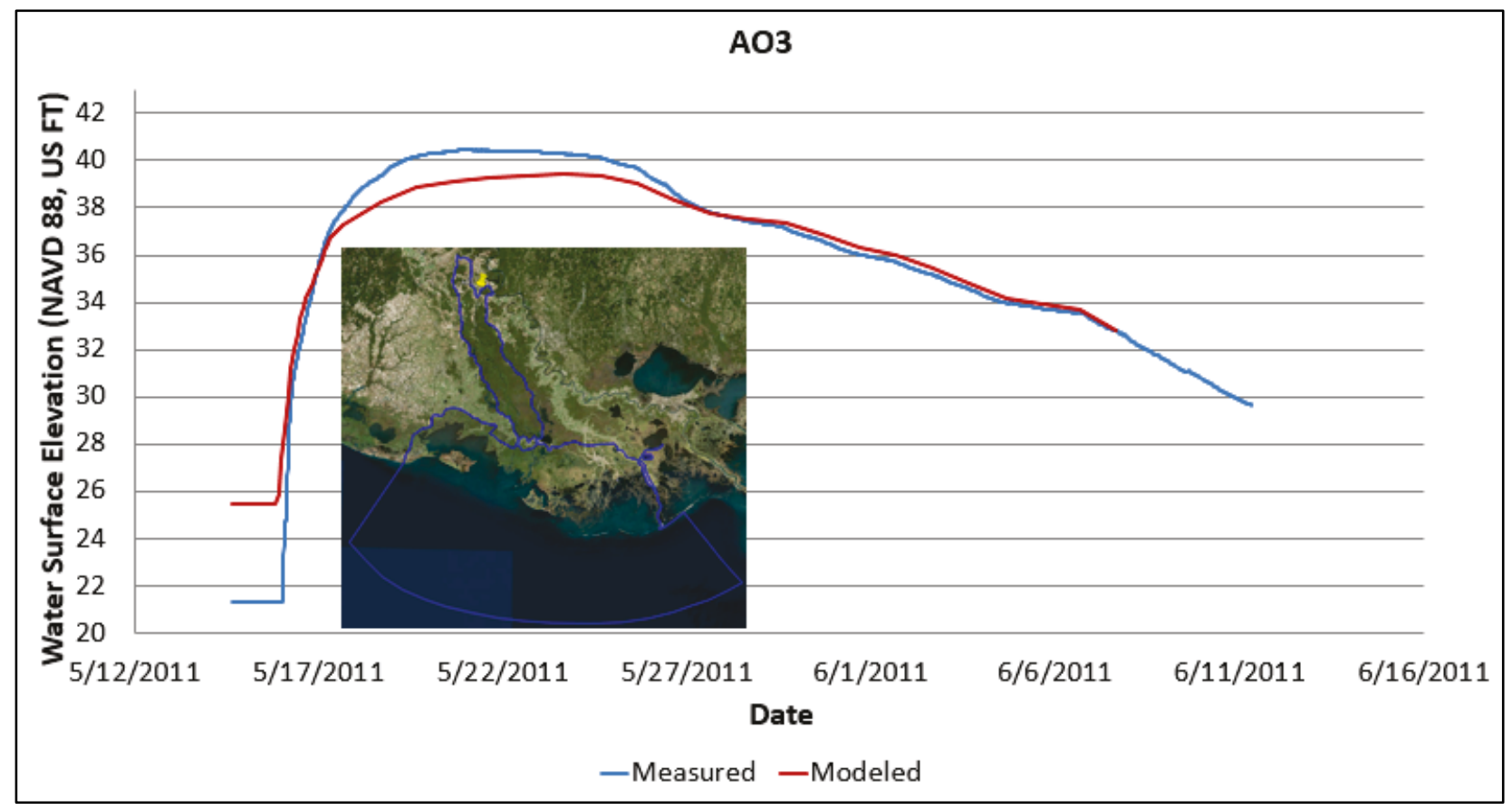


Figure B-4. Gage AO4 Bathymetric Adjustment Model results.

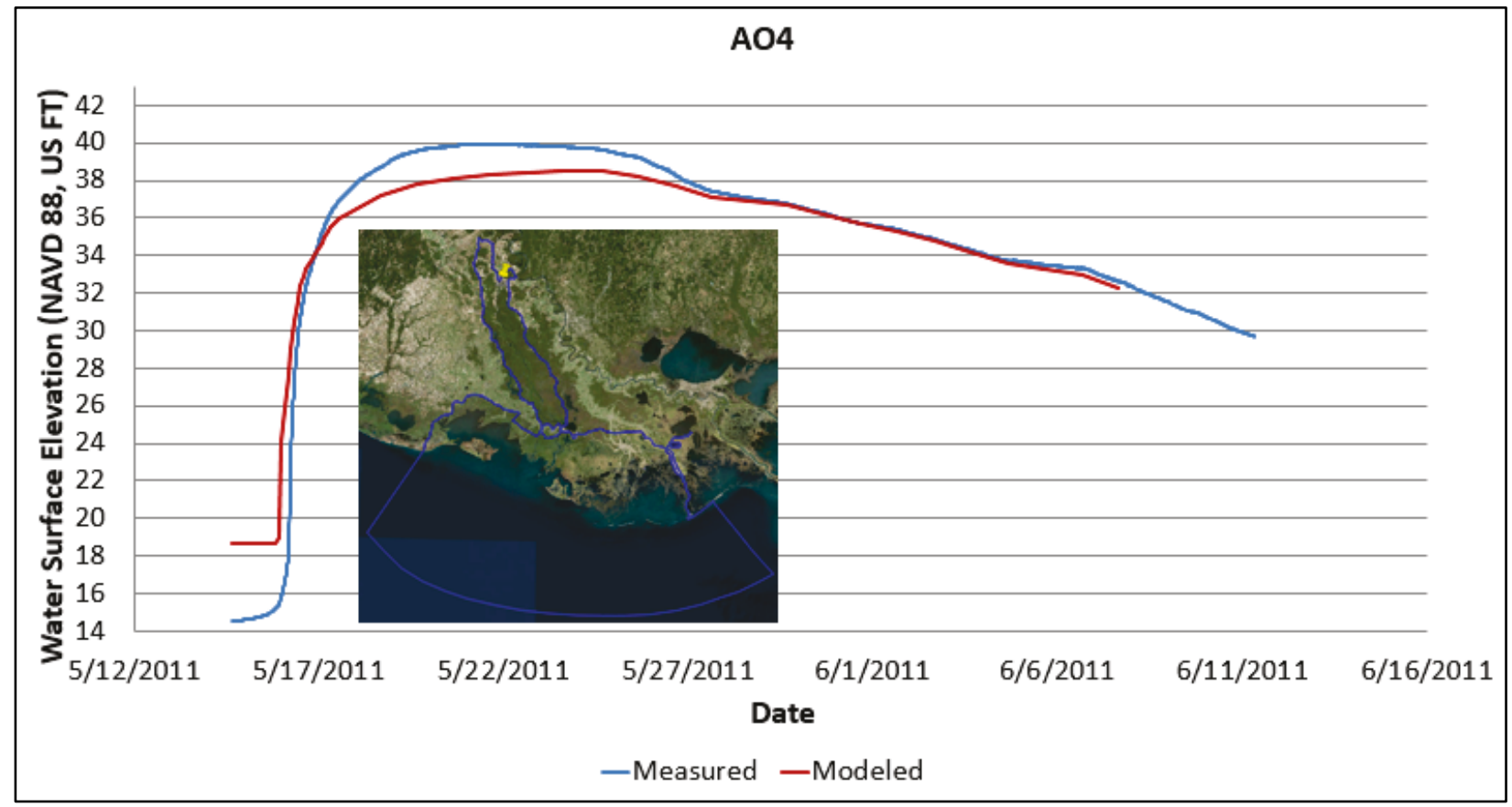

Figure B-5. Gage A06 Bathymetric Adjustment Model results.

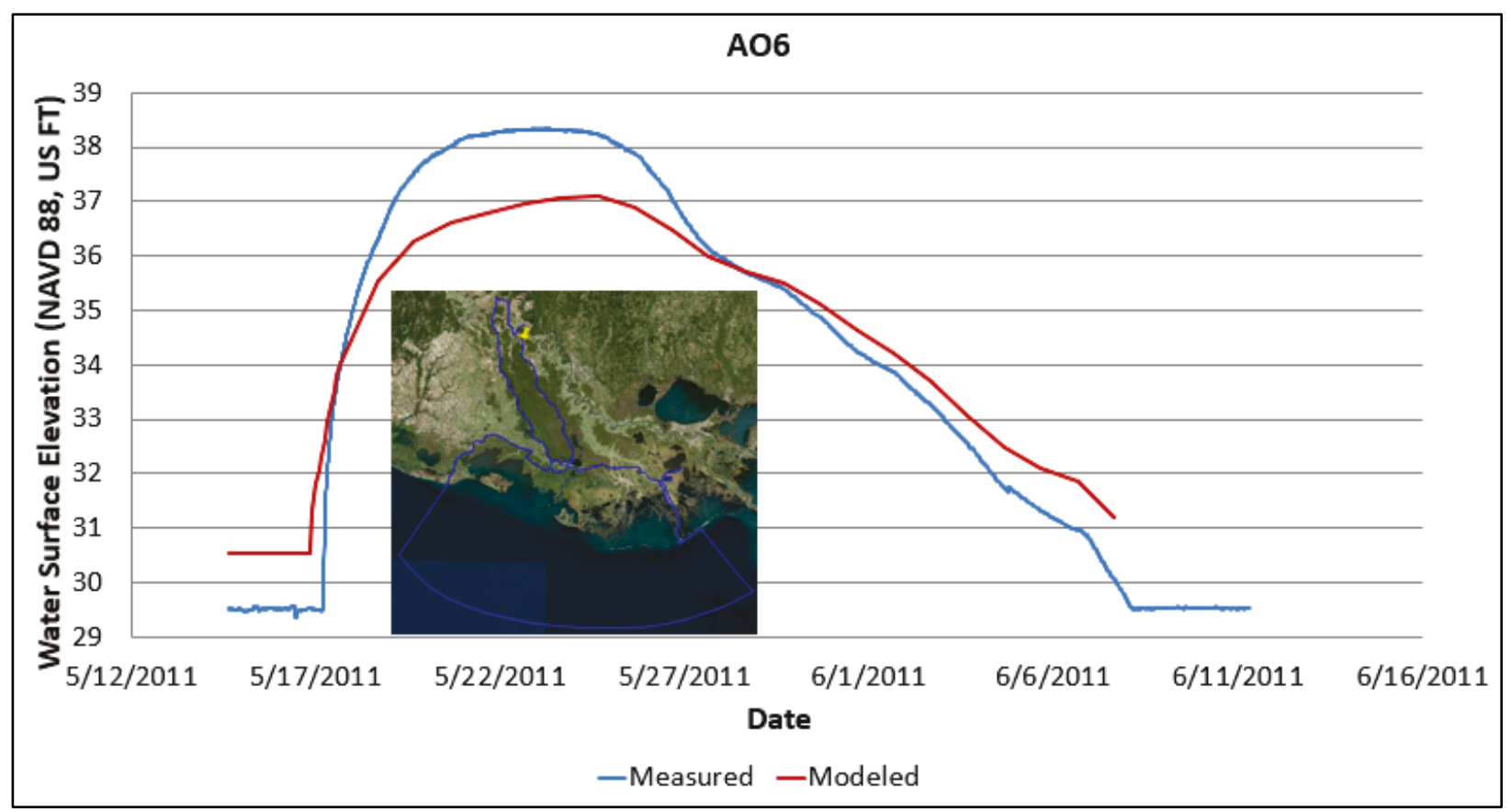


Figure B-6. Gage A07 Bathymetric Adjustment Model results.

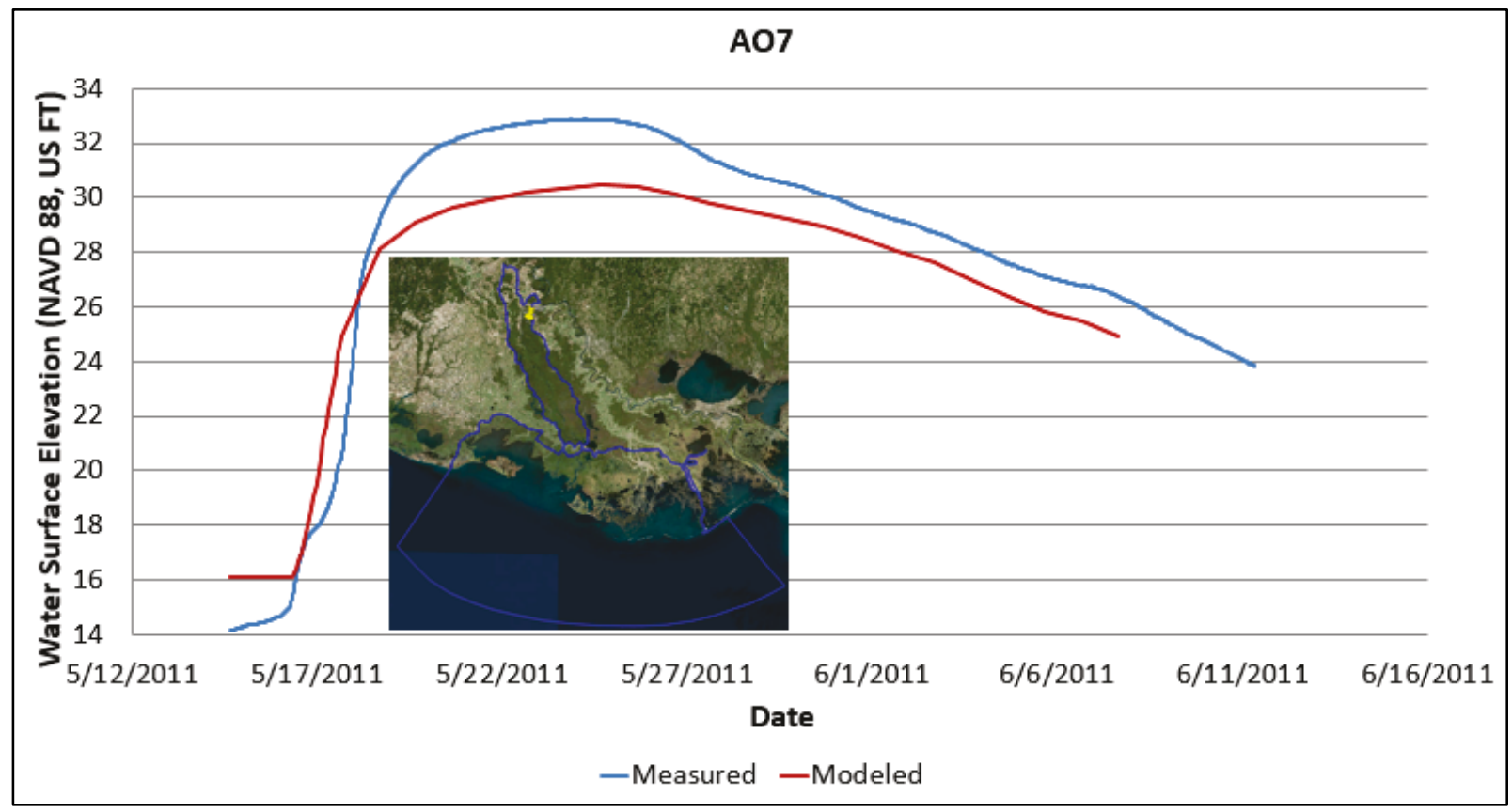

Figure B-7. Gage B04 Bathymetric Adjustment Model results.

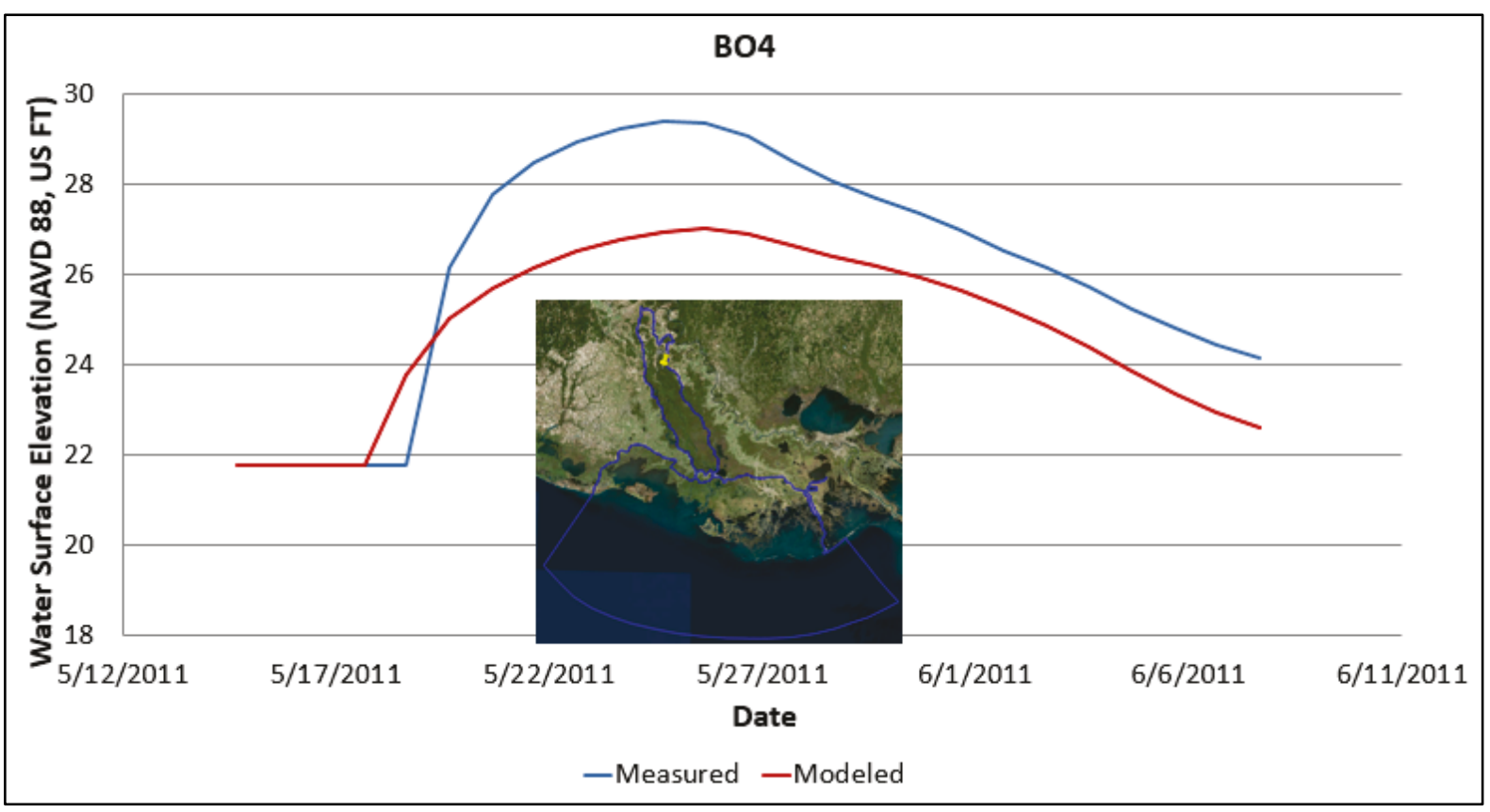


Figure B-8. Gage C04 Bathymetric Adjustment Model results.

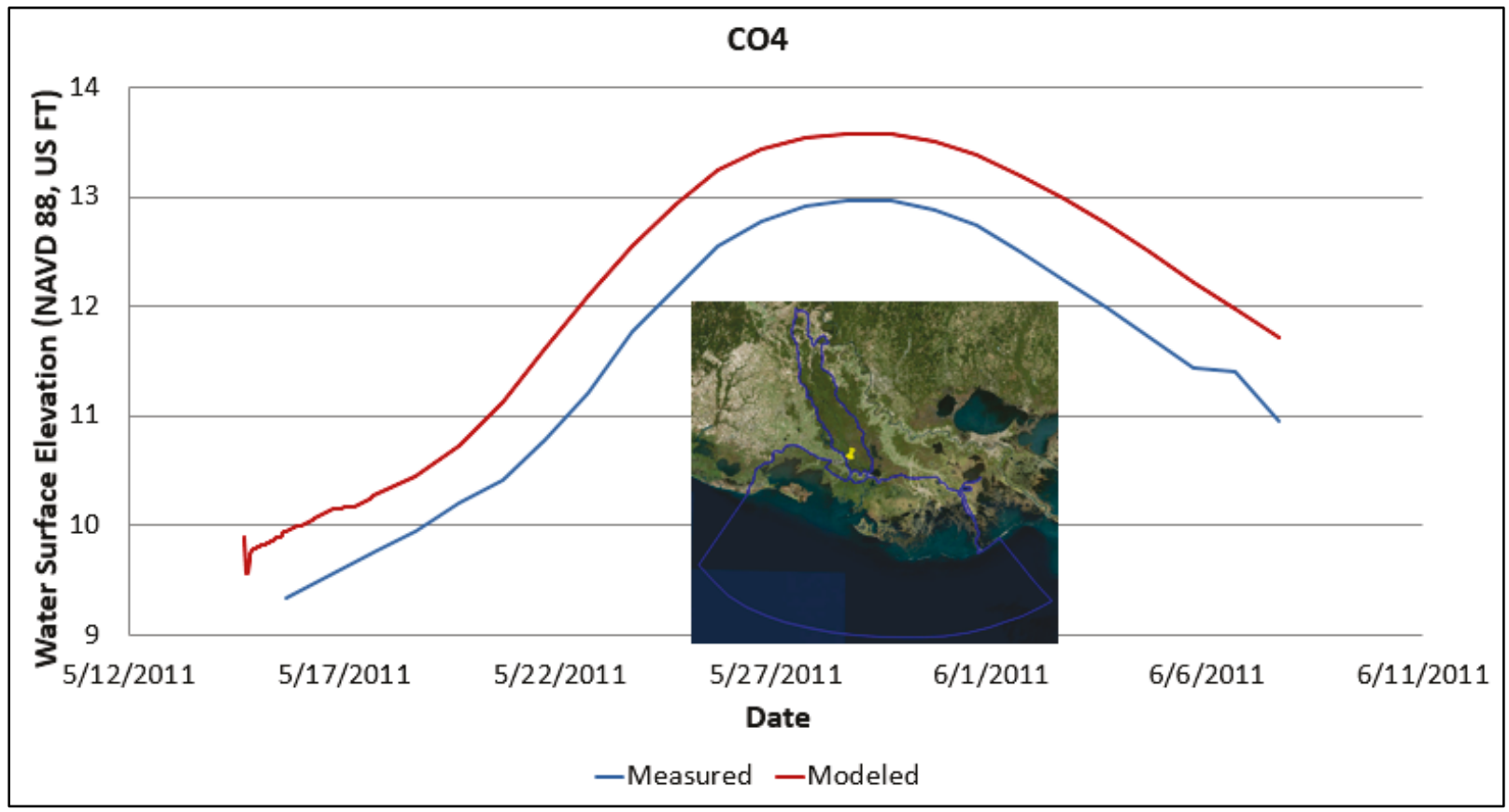

Figure B-9. Gage K2 Bathymetric Adjustment Model results.

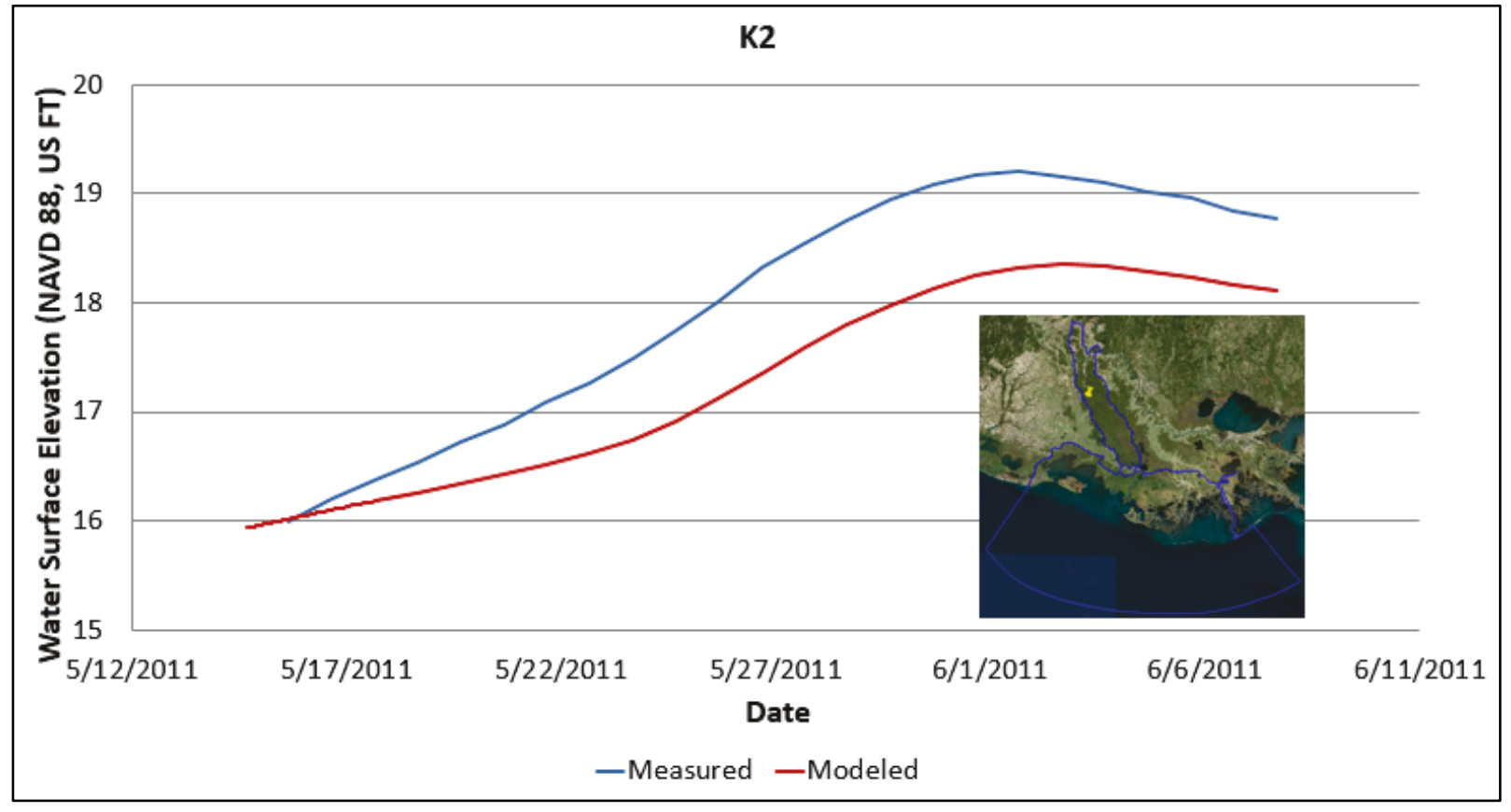


Figure B-10. Gage K3 Bathymetric Adjustment Model results.

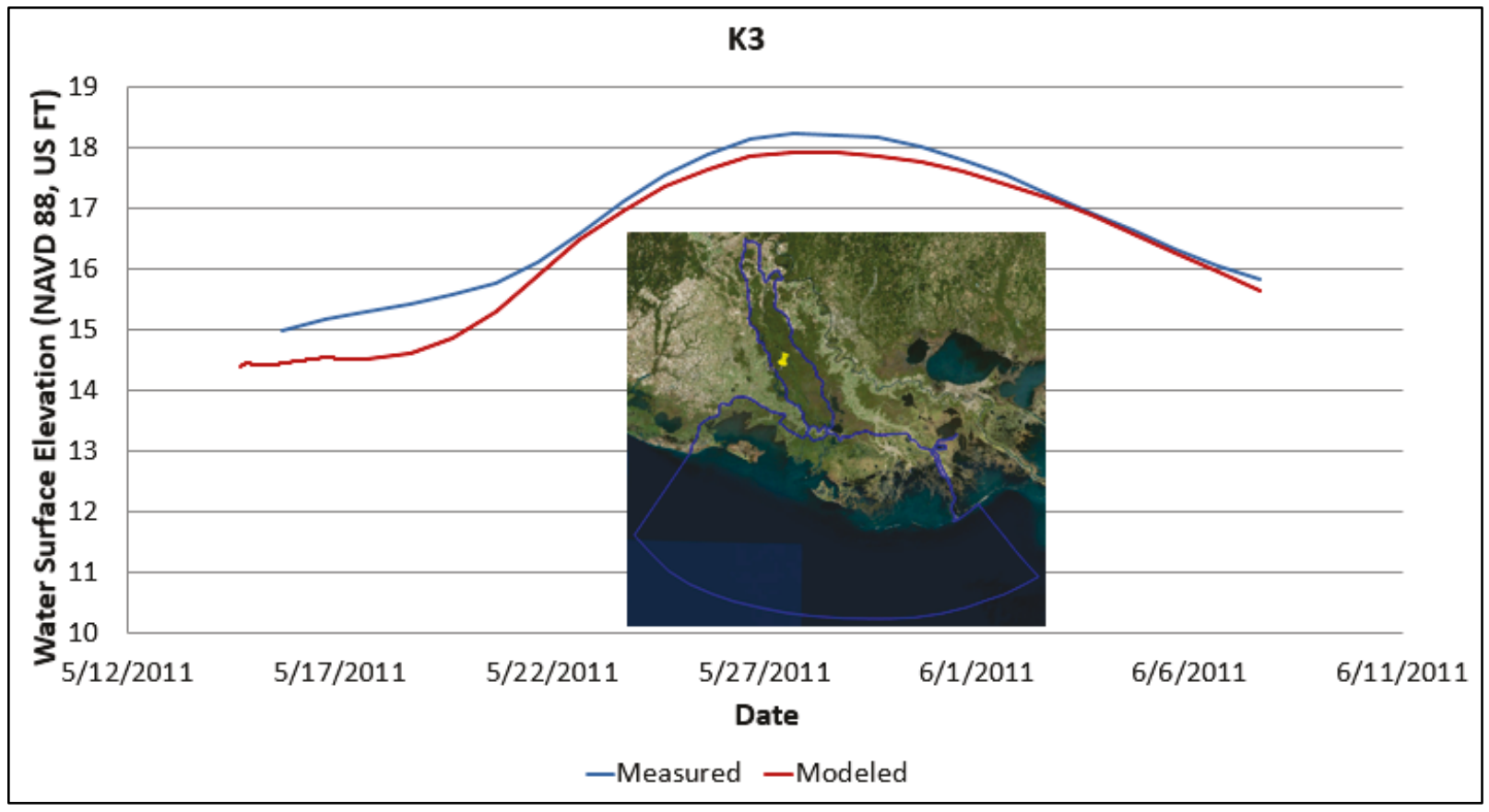

Figure B-11. Gage K4 Bathymetric Adjustment Model results.

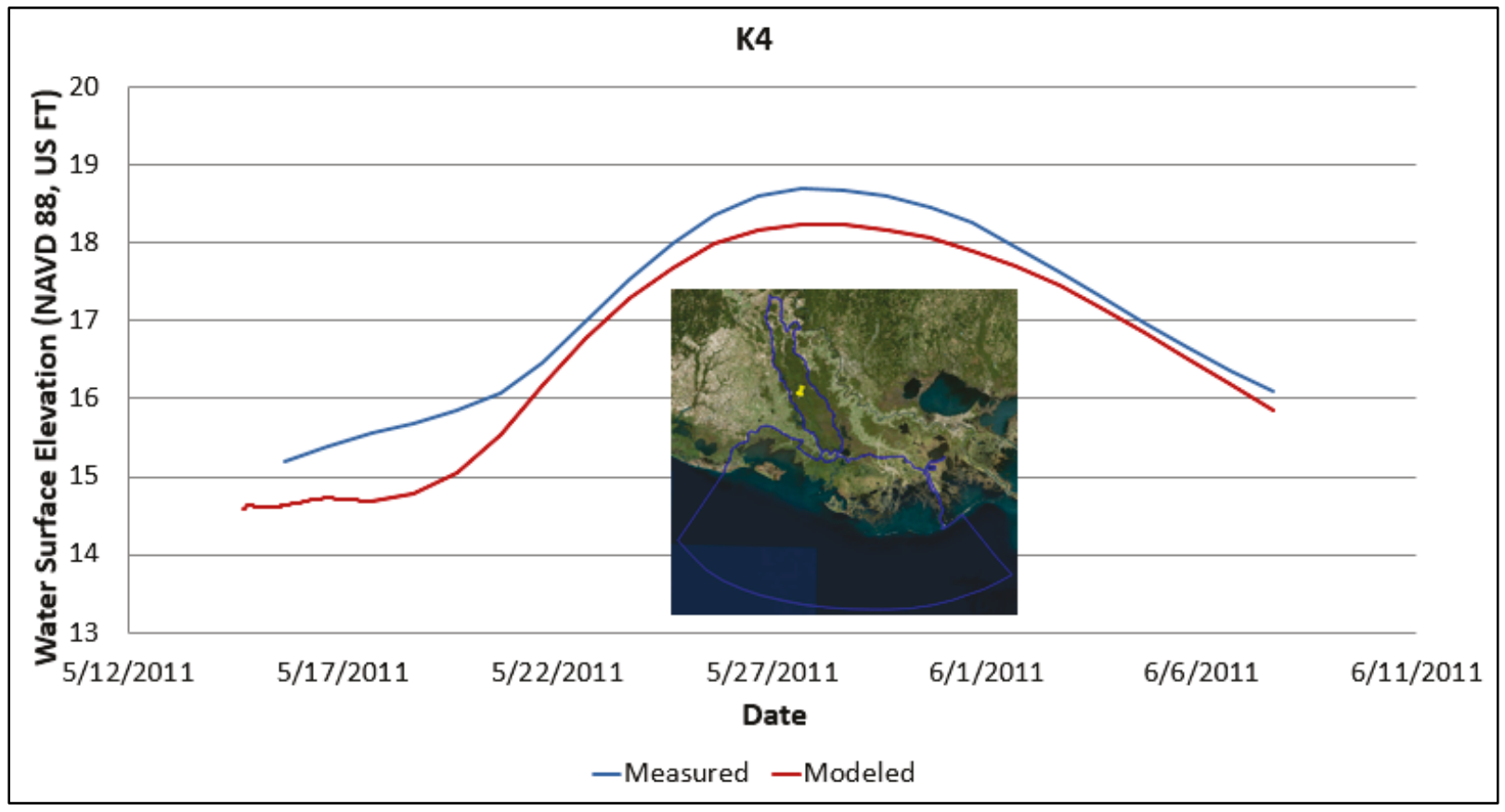


Figure B-12. Gage K5 Bathymetric Adjustment Model results.

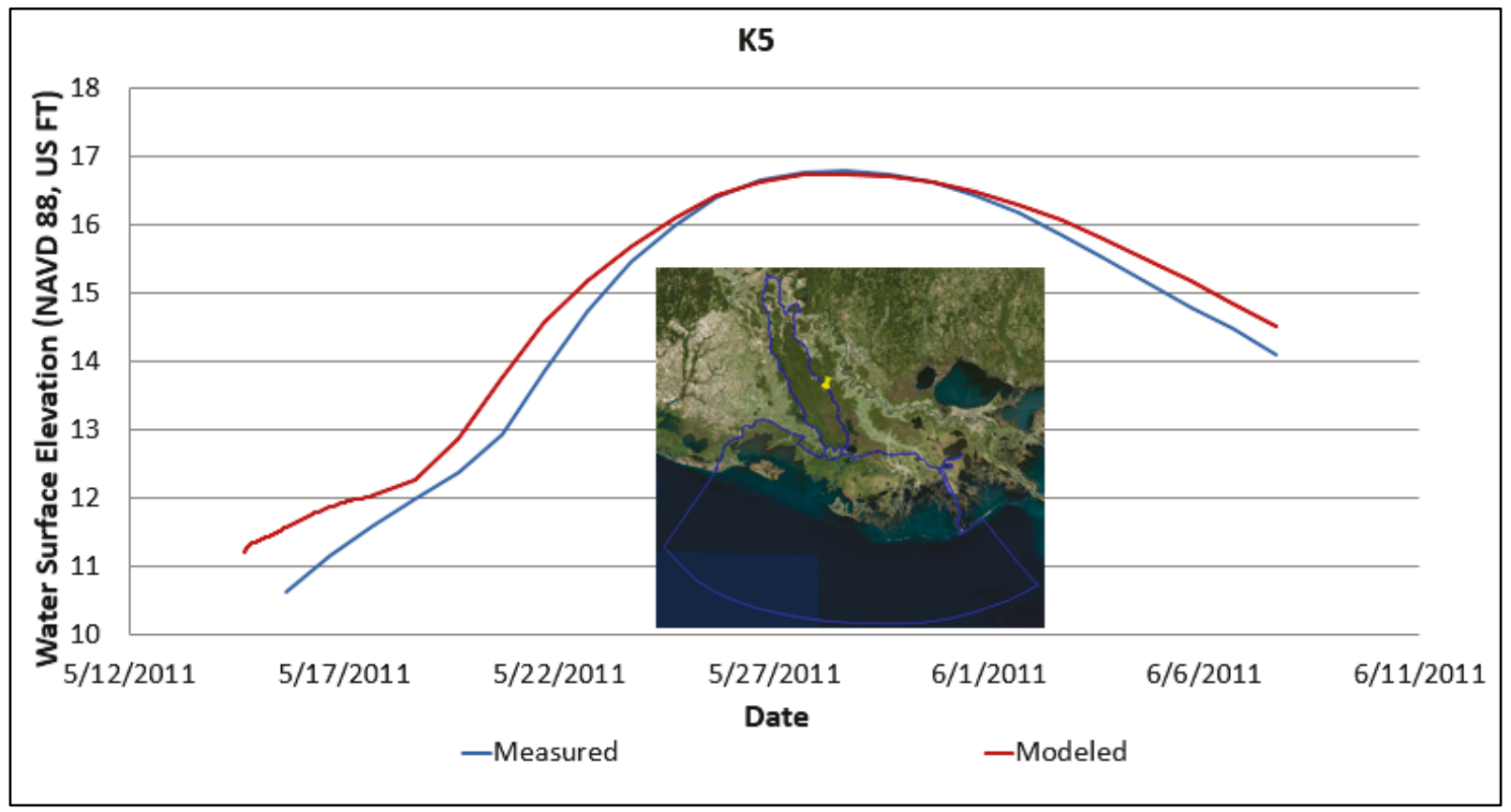

Figure B-13. Gage K6 Bathymetric Adjustment Model results.

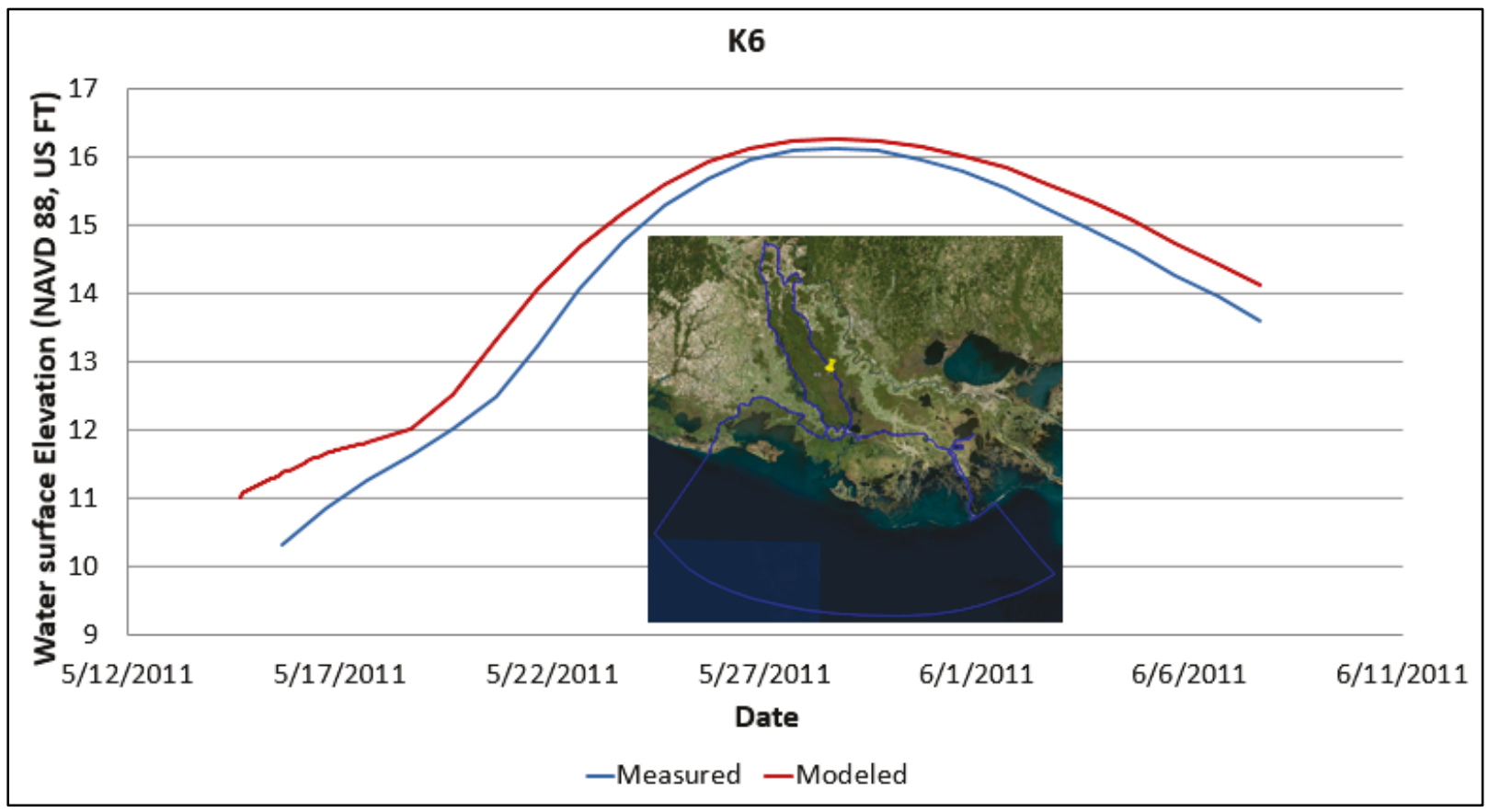


Figure B-14. Gage K7 Bathymetric Adjustment Model results.

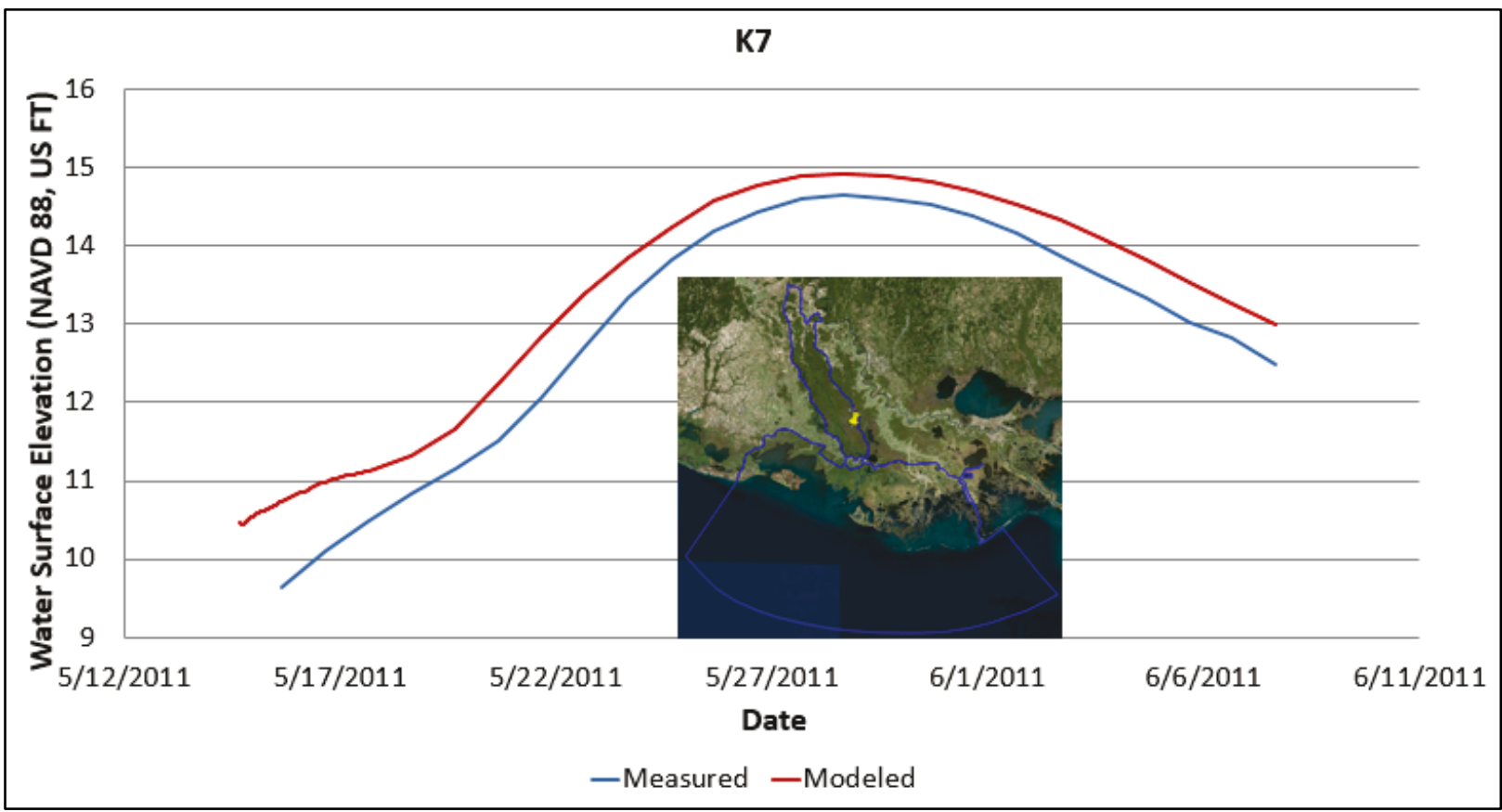

Figure B-15. Gage K8 Bathymetric Adjustment Model results.

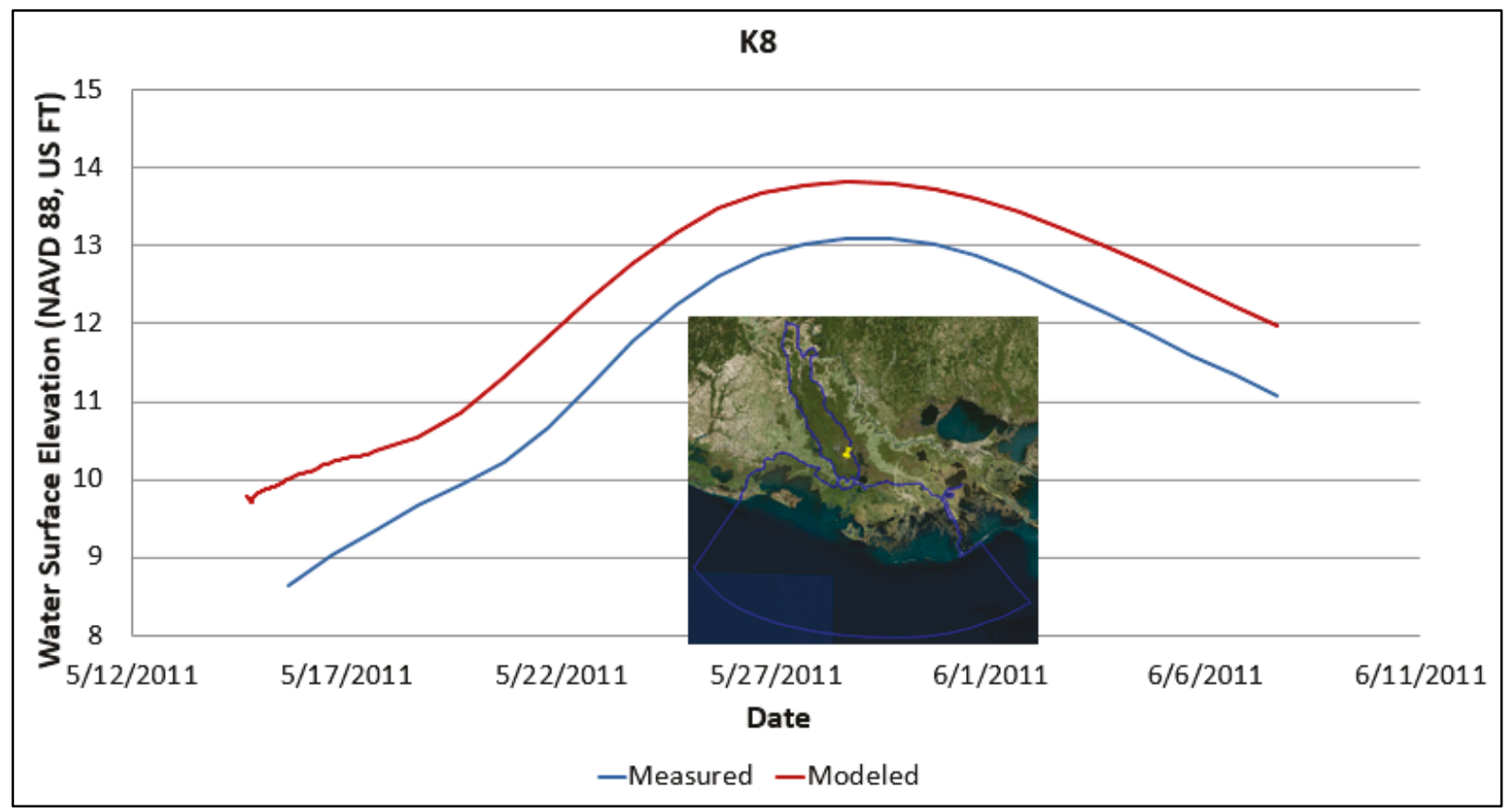


Figure B-16. Gage K9 Bathymetric Adjustment Model results.

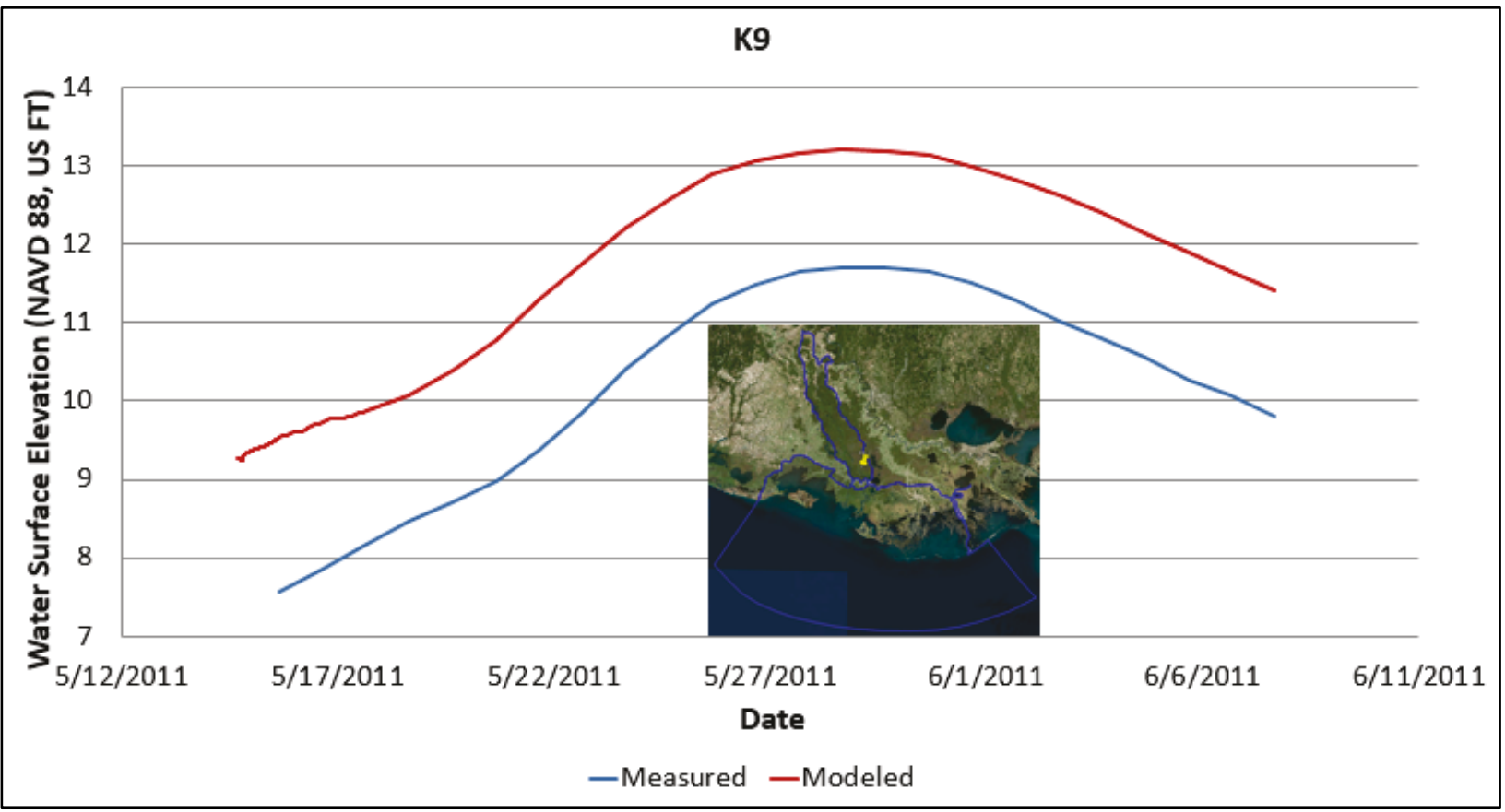

Figure B-17. Gage K10 Bathymetric Adjustment Model results.

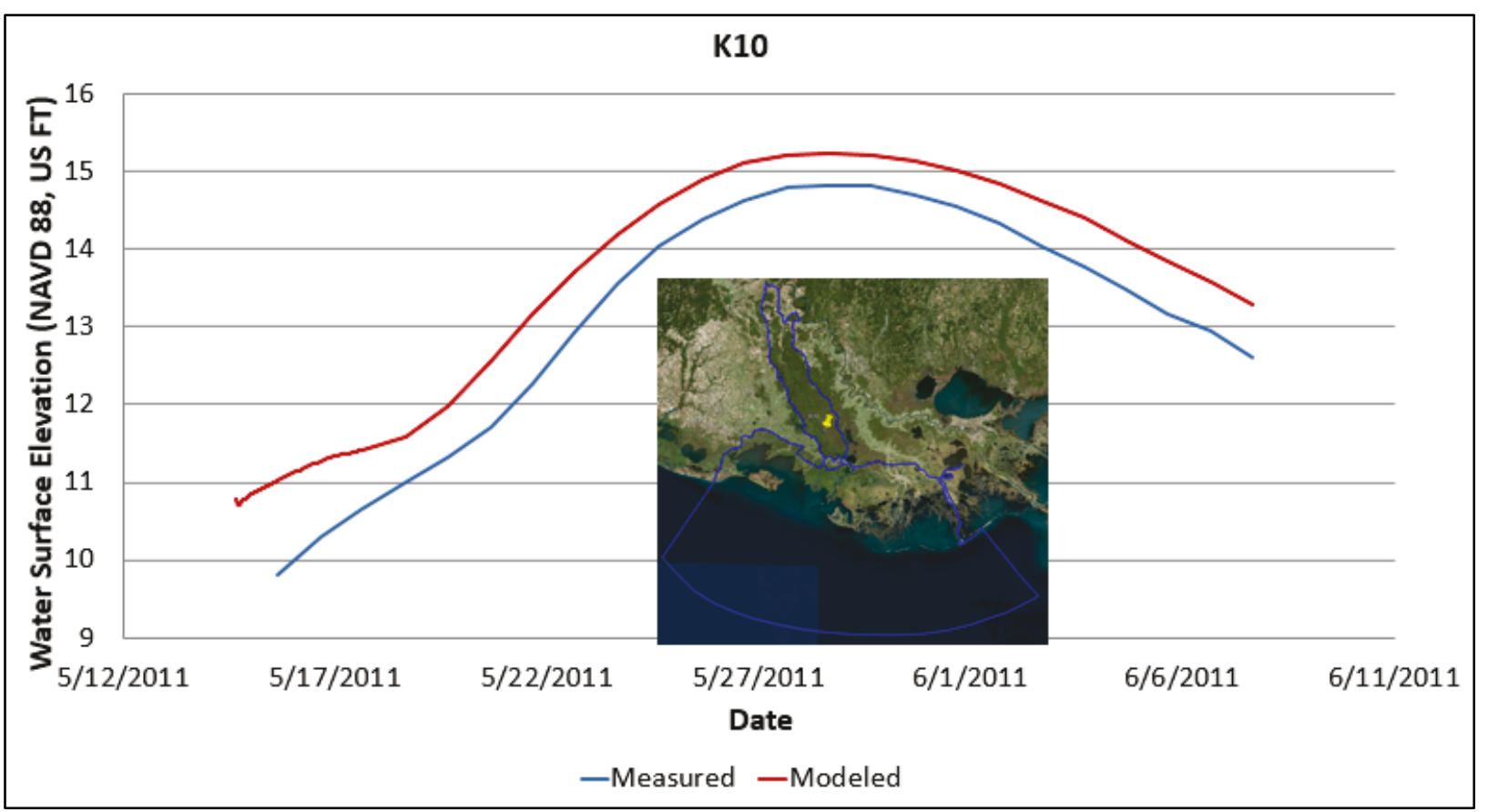


Figure B-18. Gage K11 Bathymetric Adjustment Model results.

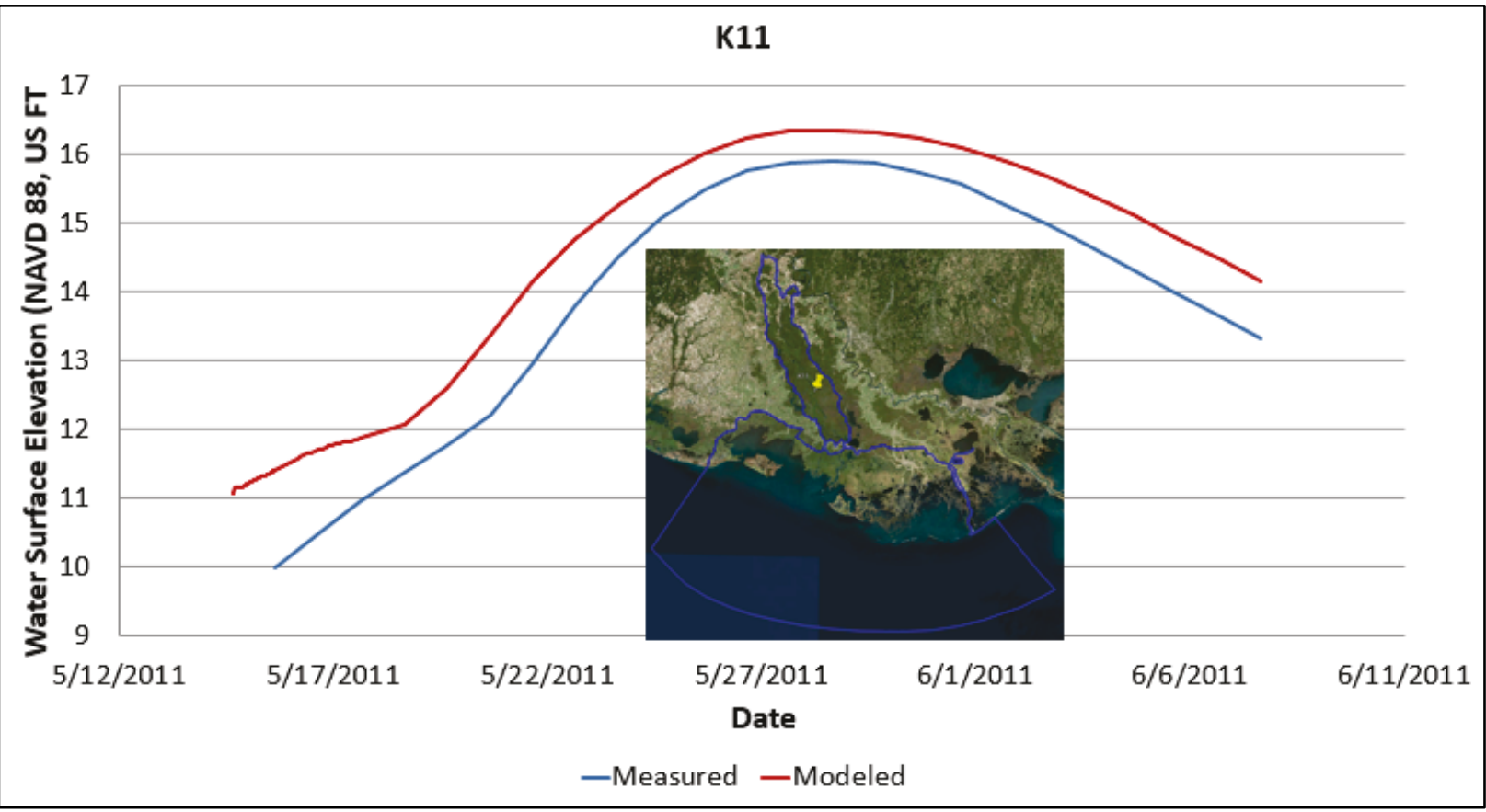

Figure B-19. Gage K12 Bathymetric Adjustment Model results.

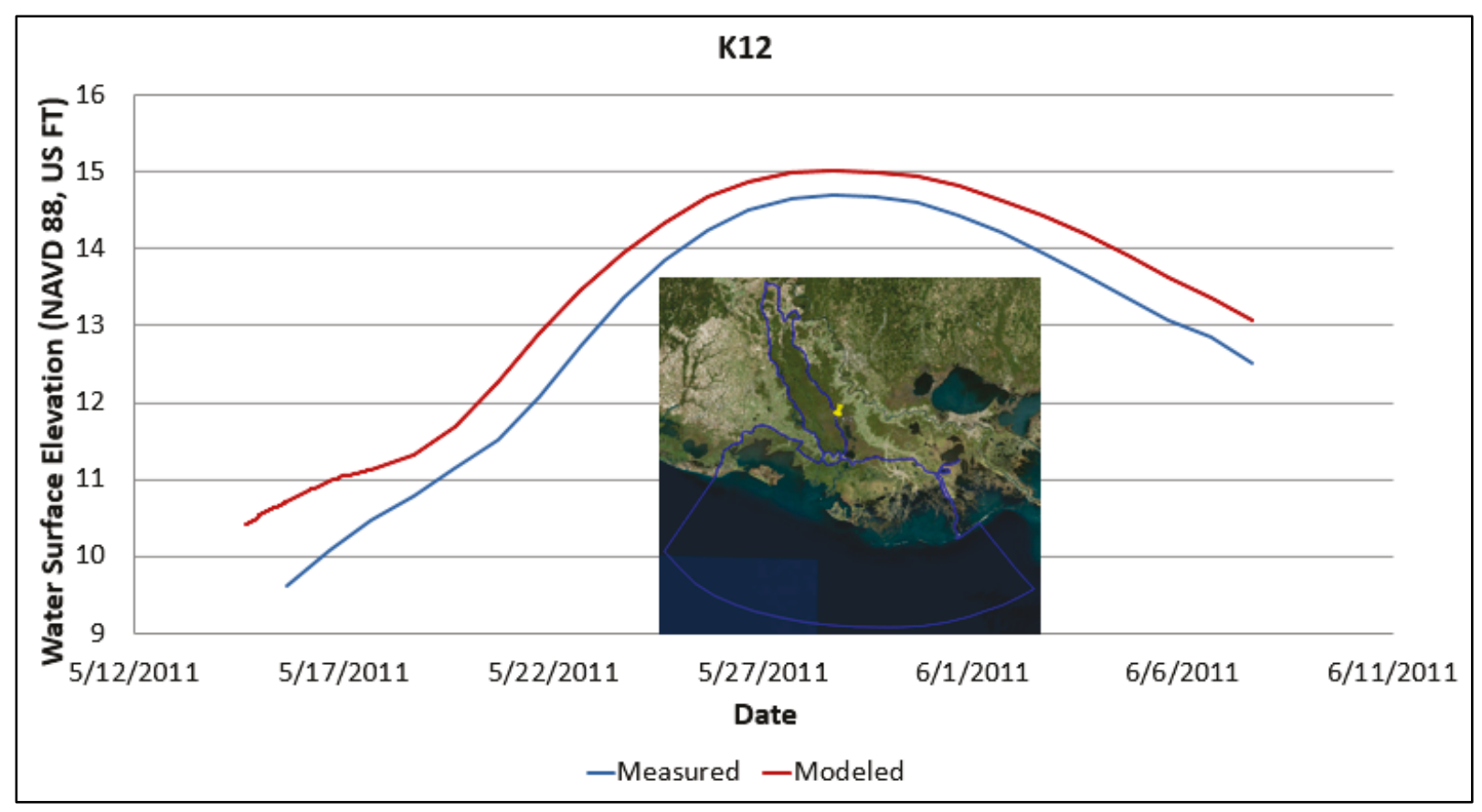


Figure B-20. Gage K13 Bathymetric Adjustment model results.

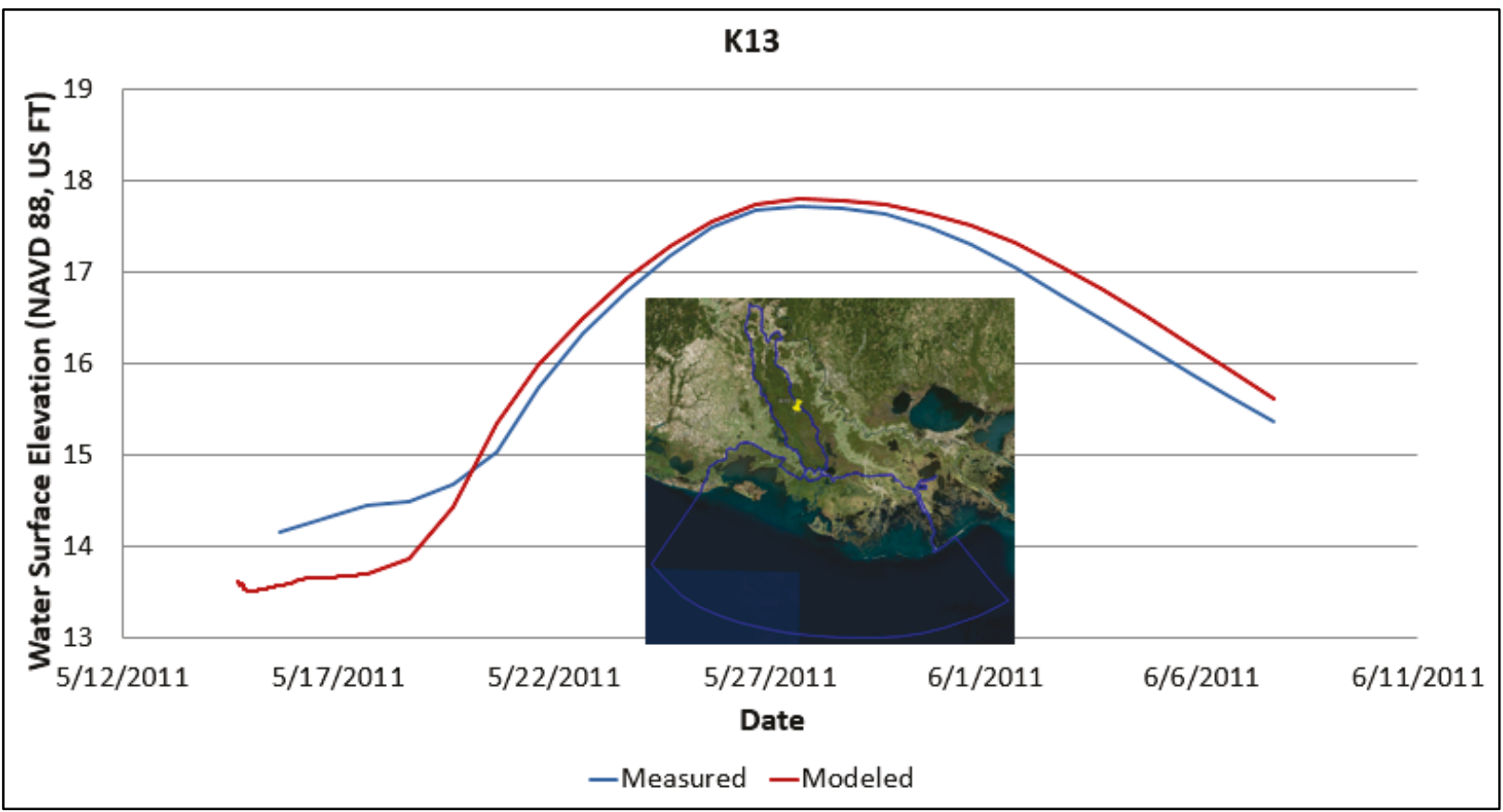

Figure B-21. Gage K14 Bathymetric Adjustment Model results.

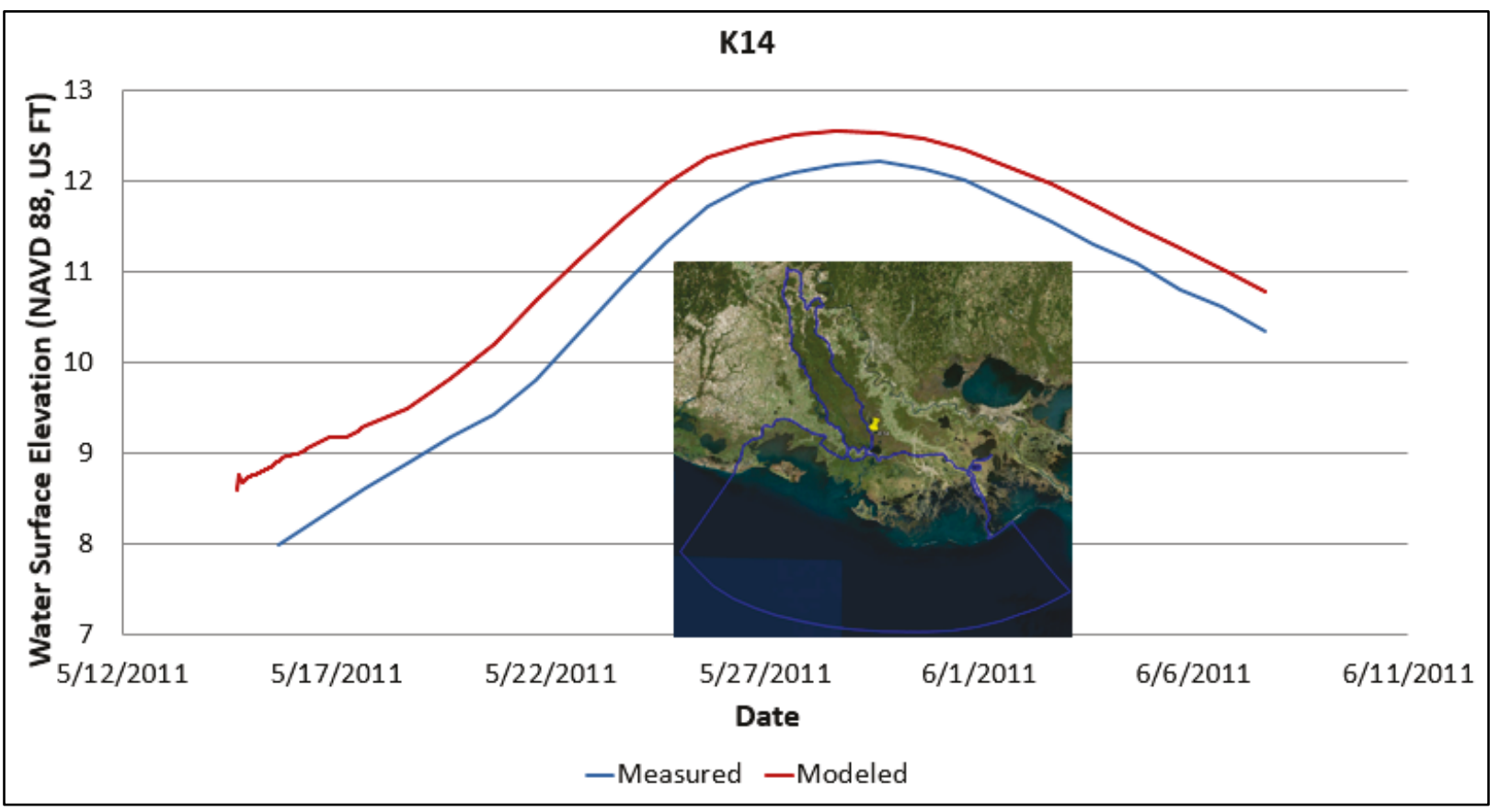


Figure B-22. Gage K15 Bathymetric Adjustment Model results.

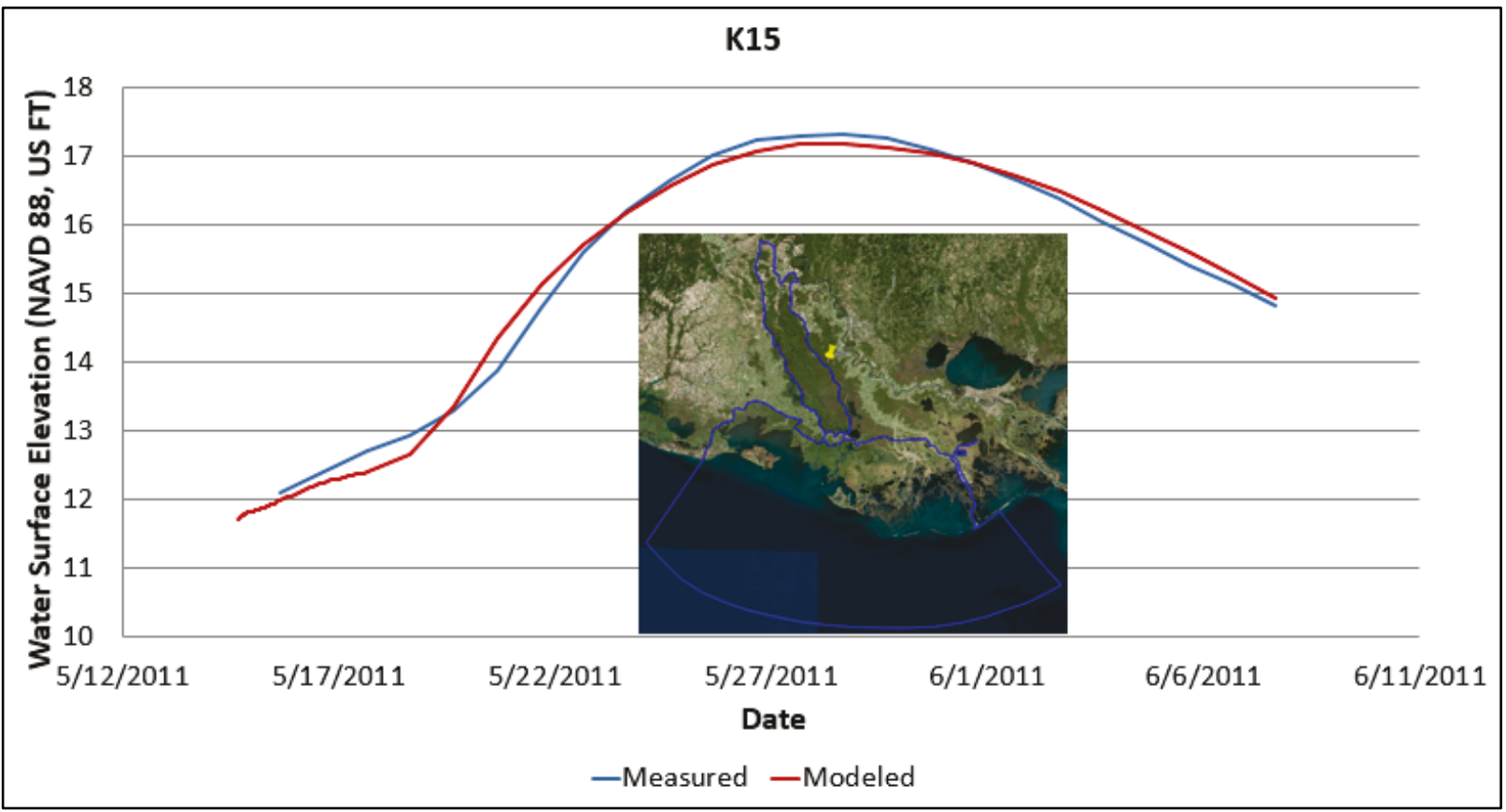

Figure B-23. Gage K16 Bathymetric Adjustment Model results.

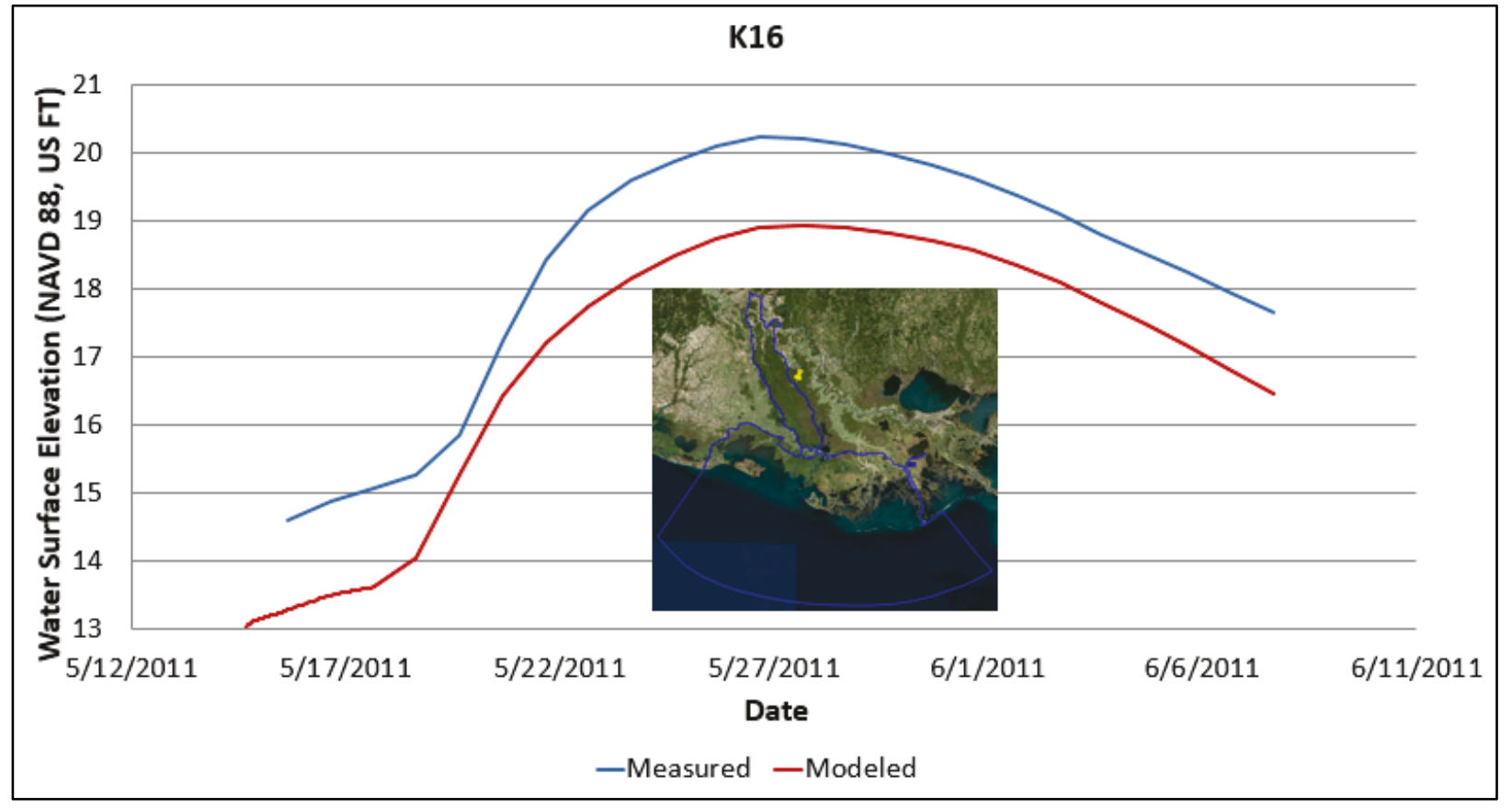


Figure B-24. Gage K17 Bathymetric Adjustment Model results.

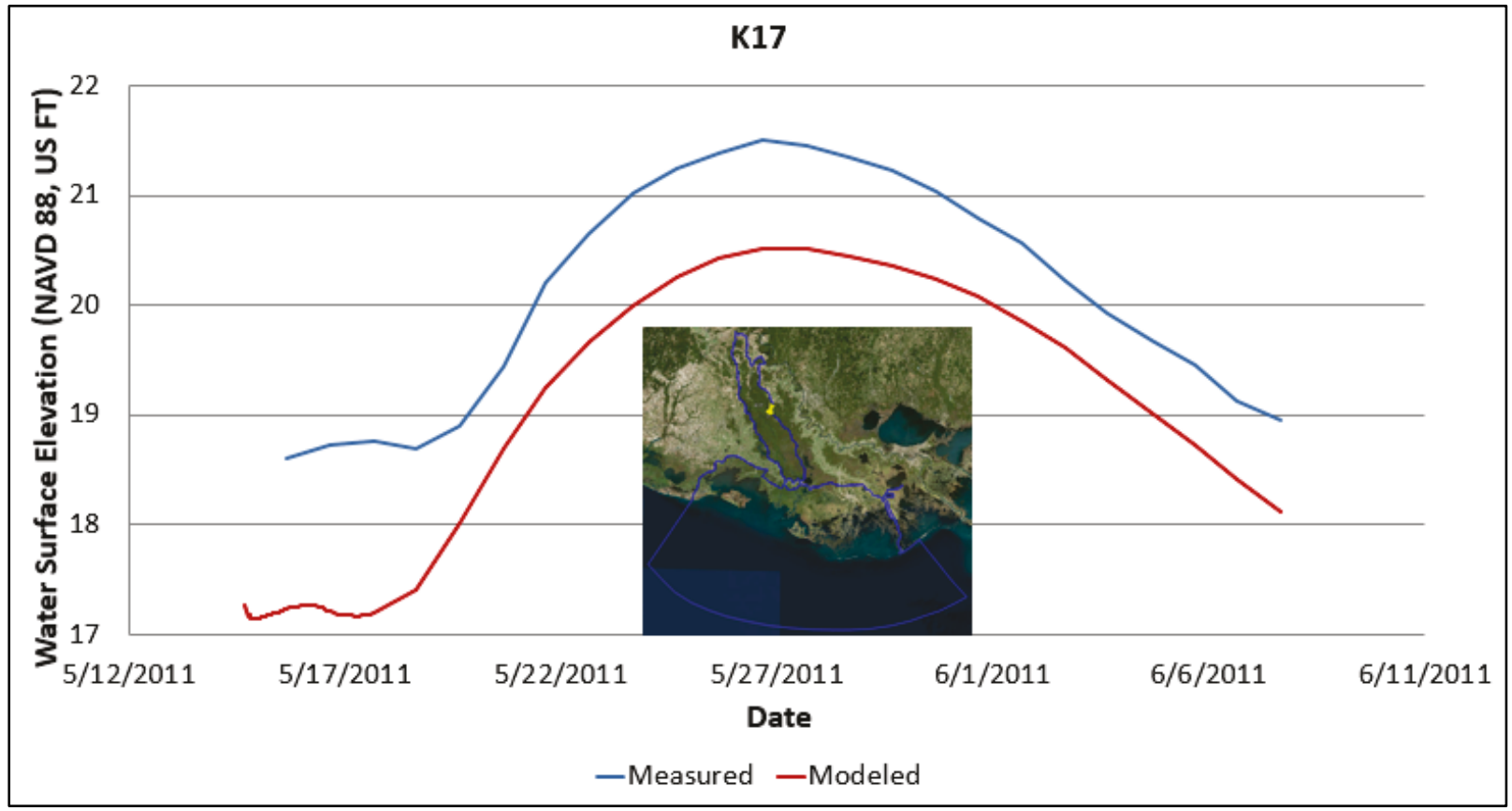

Figure B-25. Gage K18 Bathymetric Adjustment Model results.

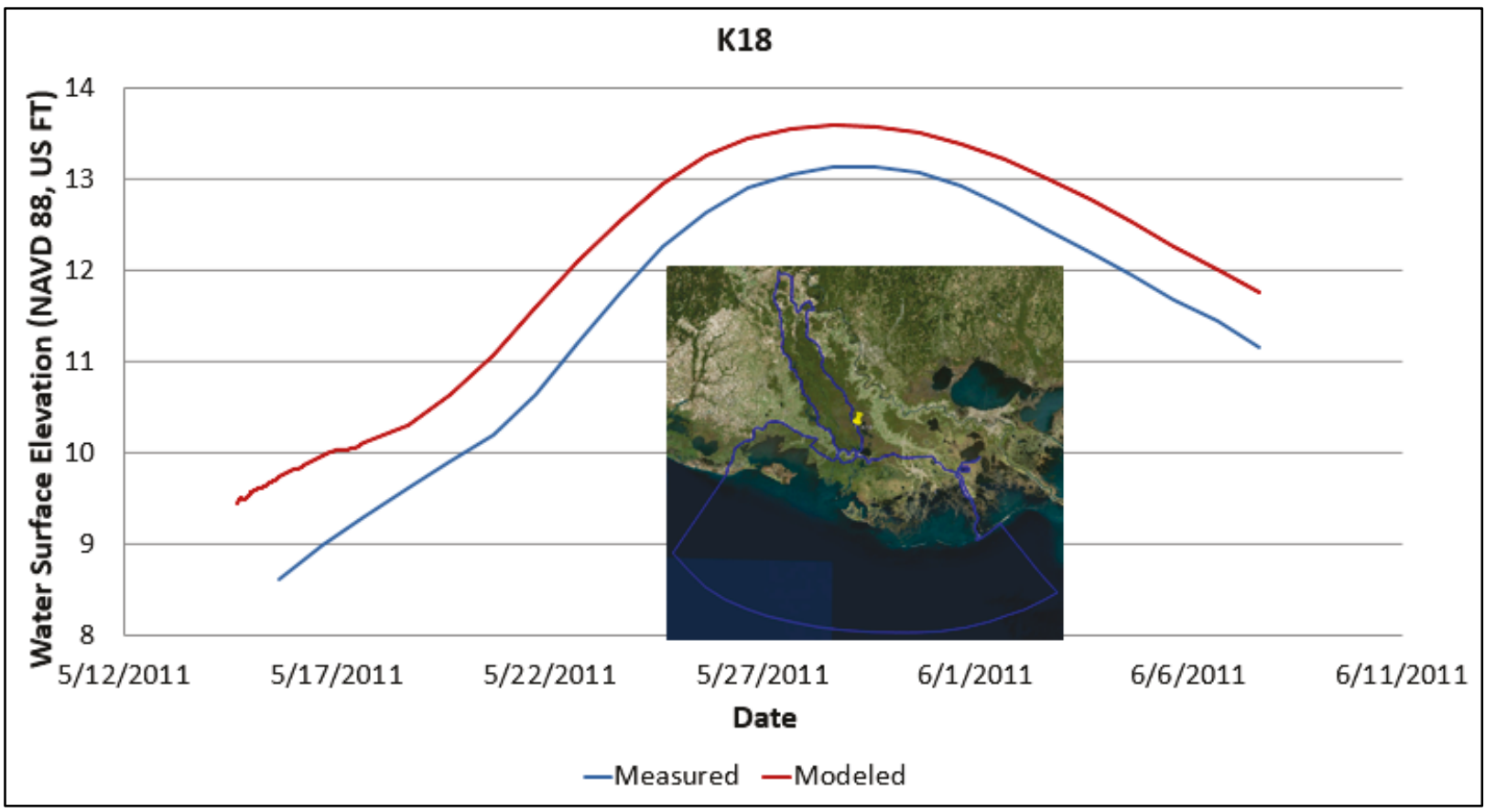


Figure B-26. Gage K19 Bathymetric Adjustment Model results.

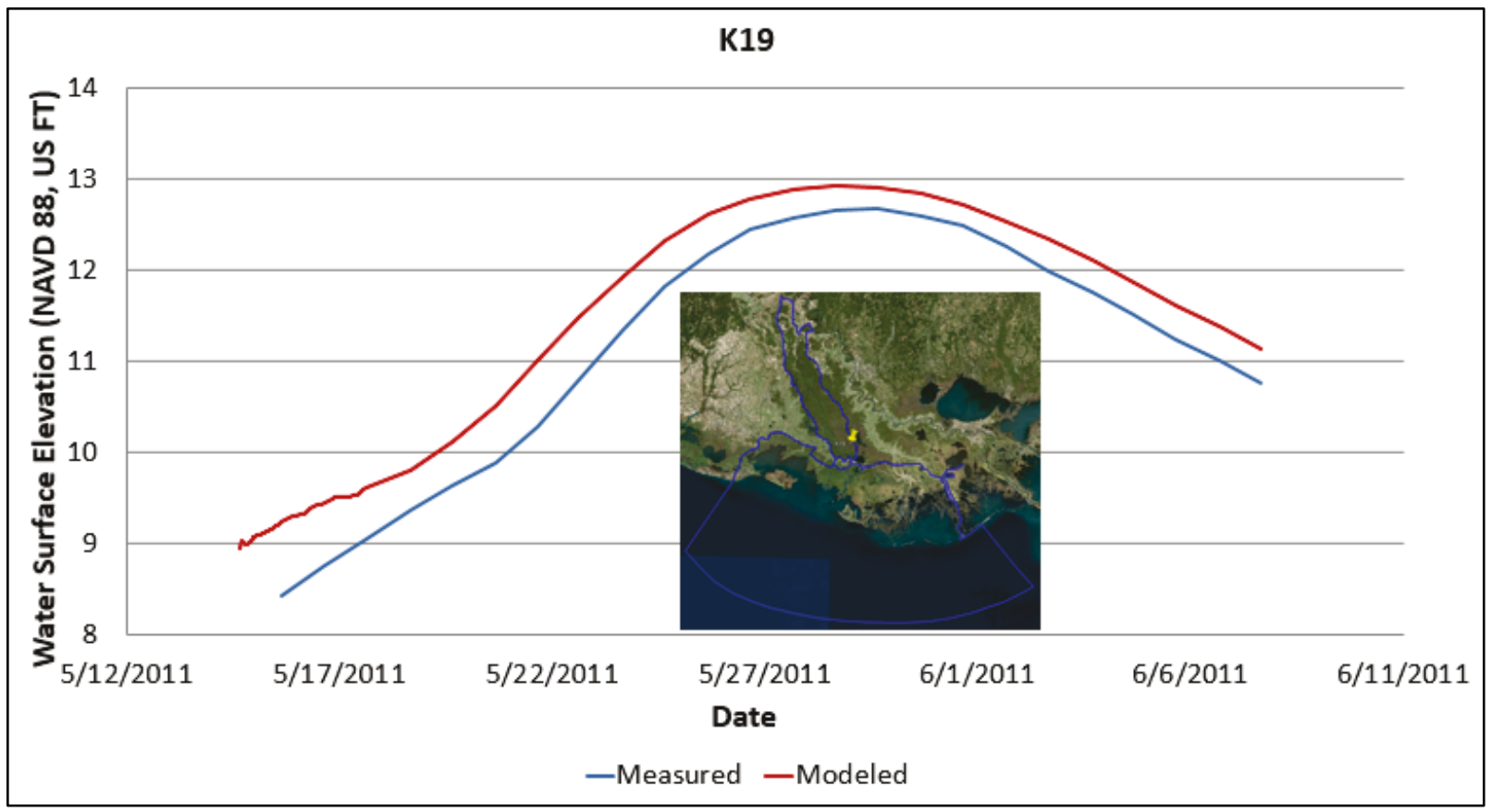

Figure B-27. Gage K21 Bathymetric Adjustment Model results.

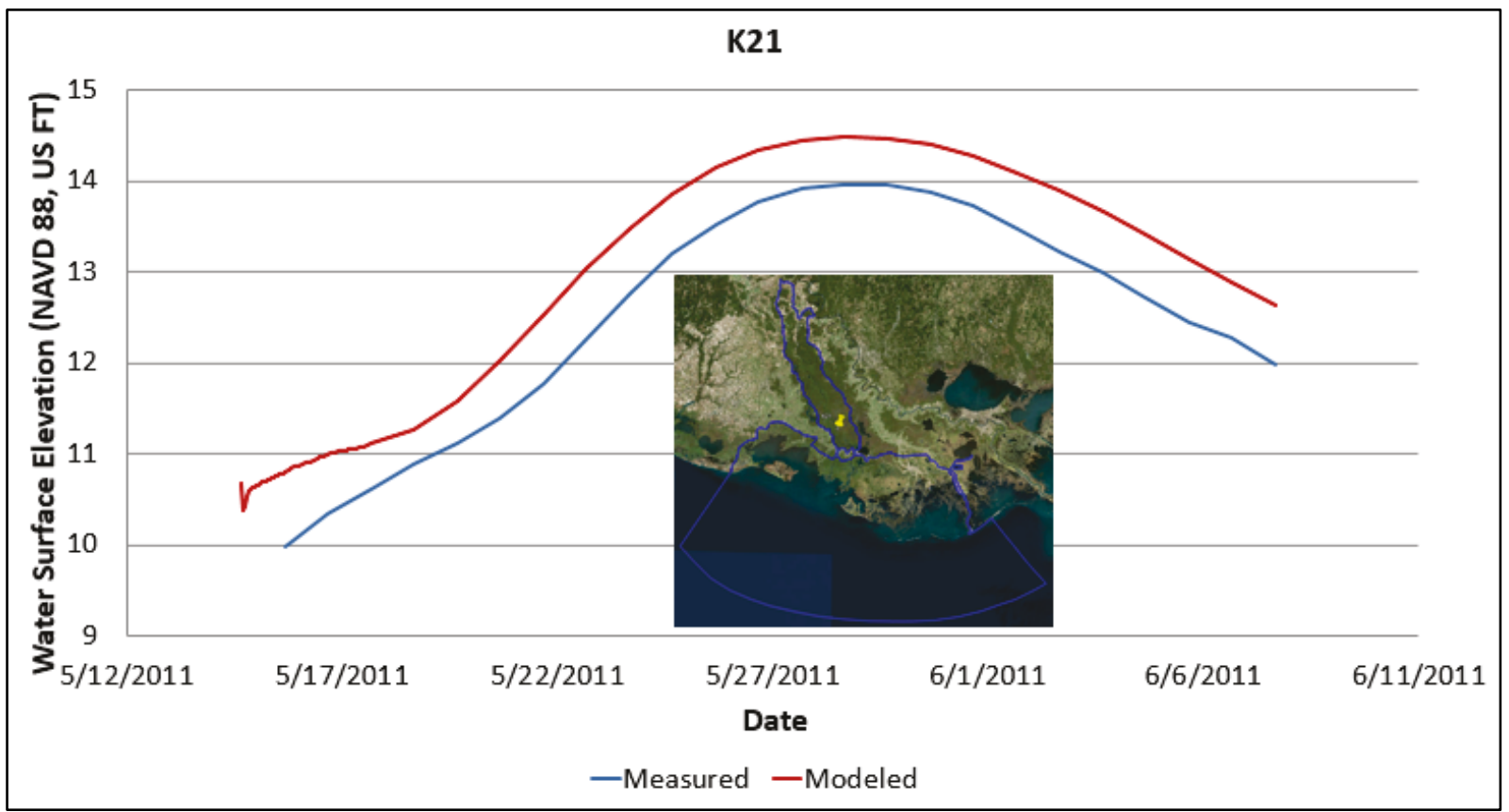


Figure B-28. USGS Gage at Wax Lake Outlet (water surface elevation).

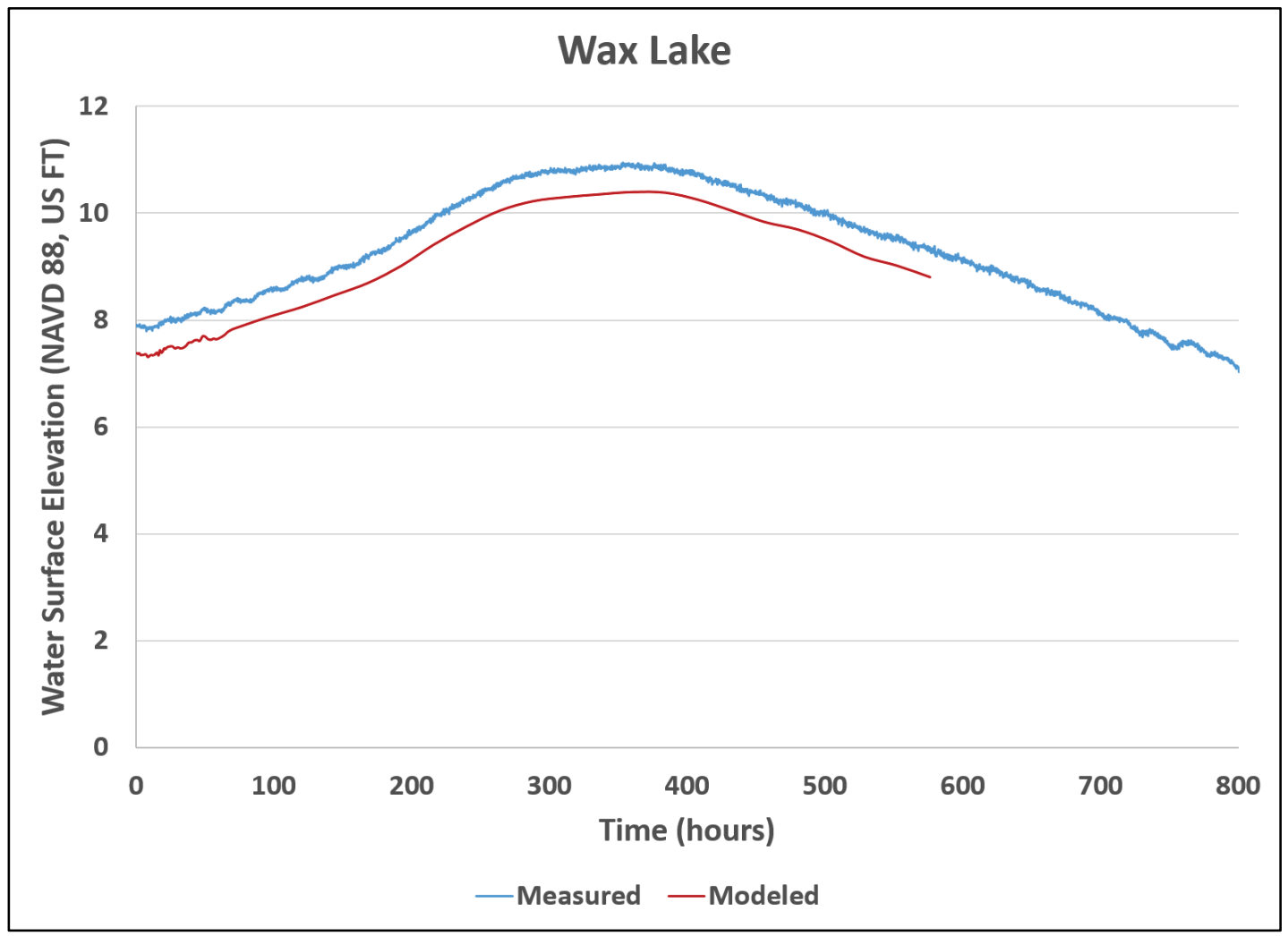

Figure B-29. USGS Gage at Morgan City Outlet (water surface elevation).

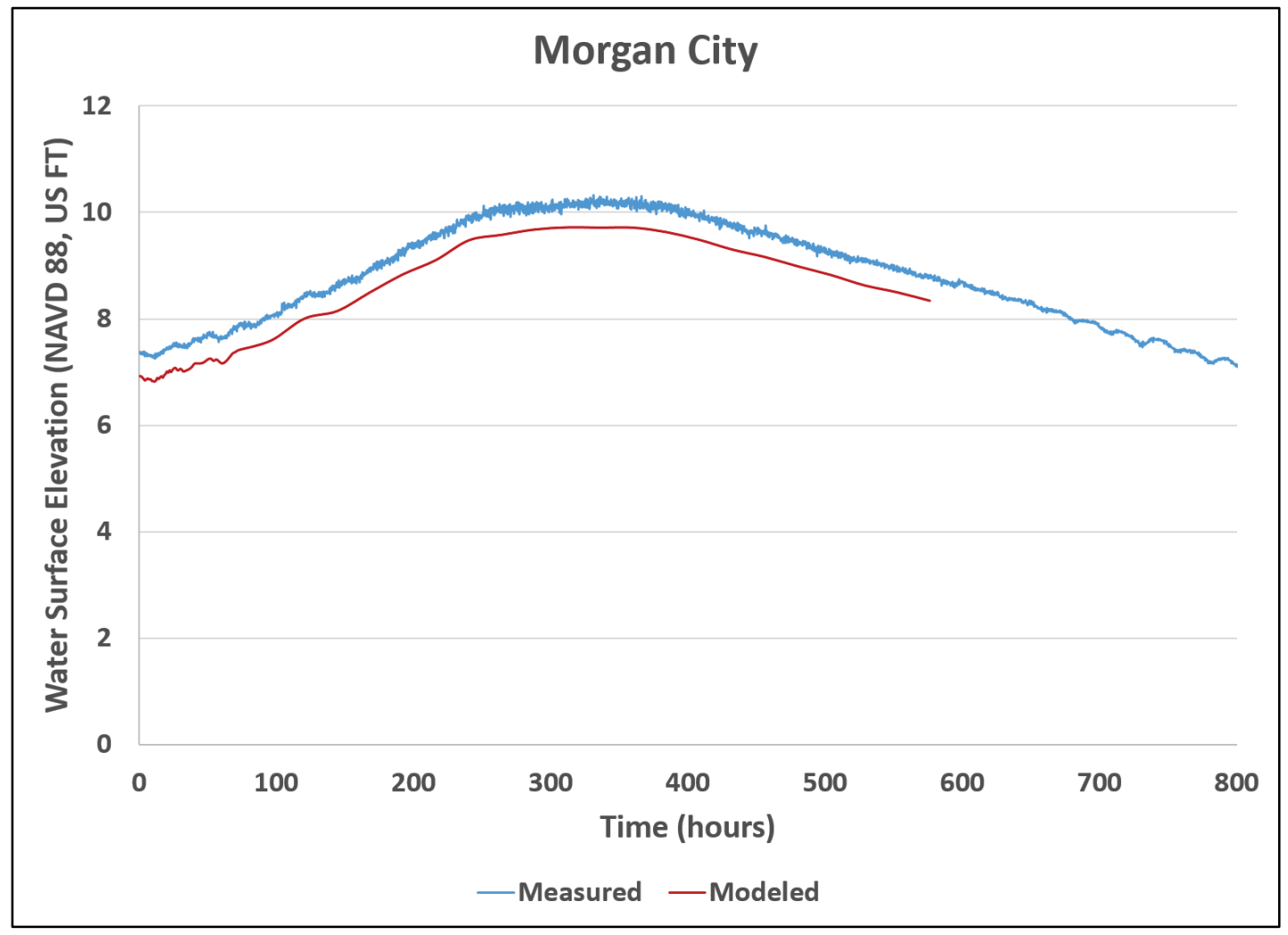


Figure B-30. USGS Gage at Wax Lake Outlet (discharge).

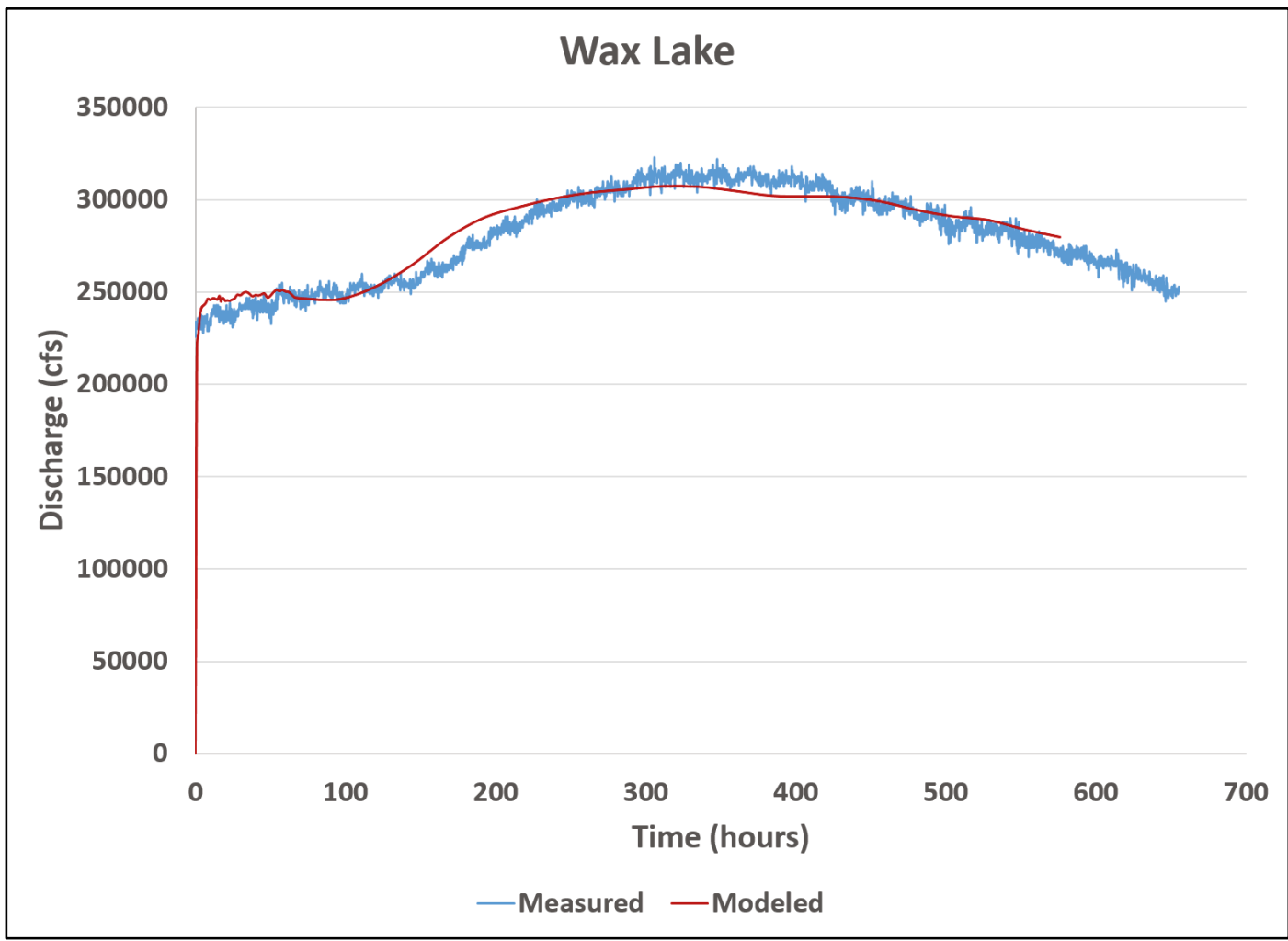

Figure B-31. USGS Gage at Morgan City Outlet (discharge).

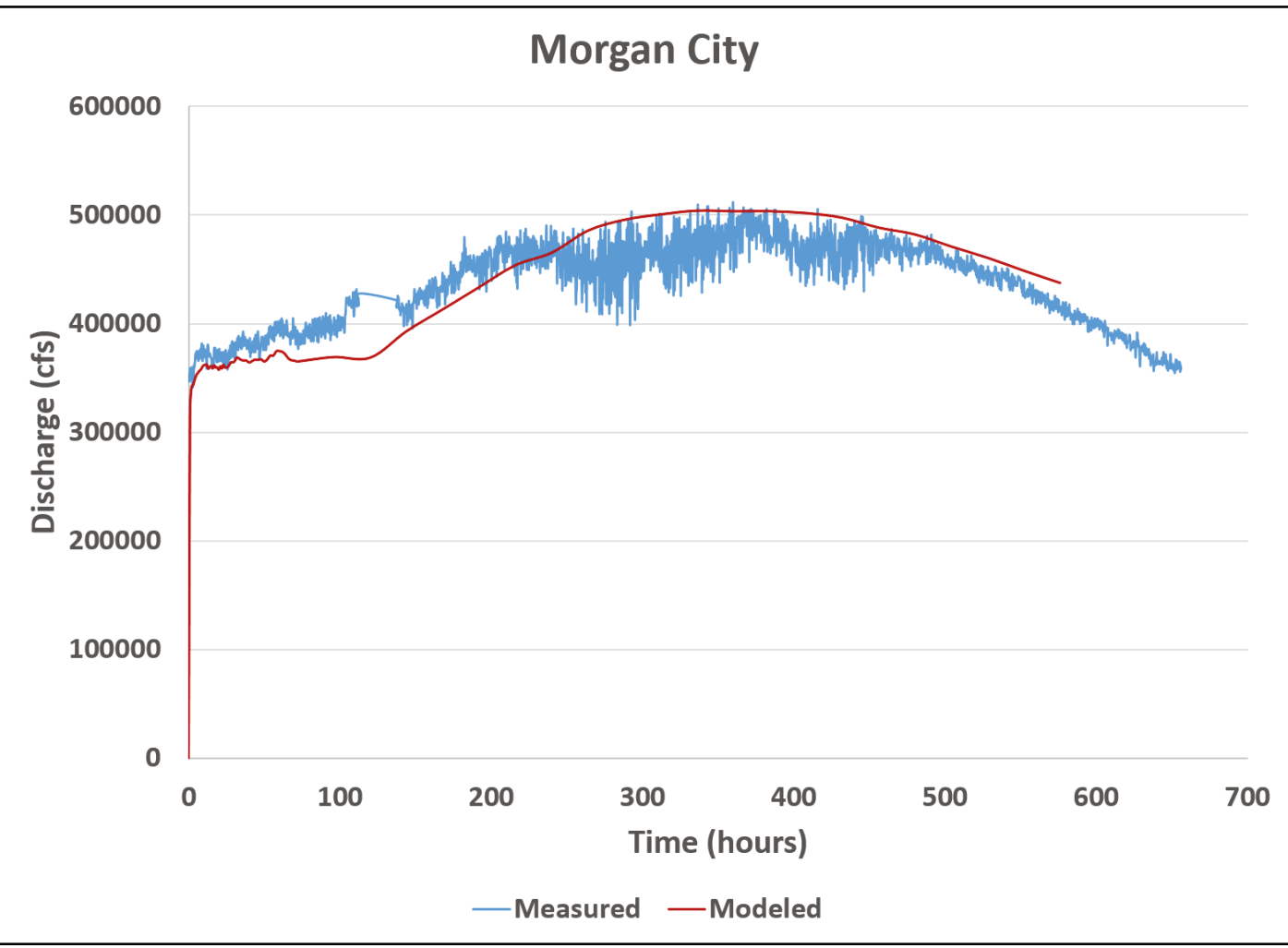




\section{Appendix C: Mesh Convergence Sensitivity Model Results}

The model results in this section have the same downstream boundary locations as in Appendix A as well as the bathymetric adjustments represented in Appendix B. The purpose of this modeling phase was to determine if the mesh refinement was greatly increased (roughly quadrupled) would the modeled versus measured comparisons be better than the previous model (Appendix B results). This refinement was applied to the entire domain of the model as discussed in Section 3.3 "Mesh convergence sensitivity test." These results can be seen in Figures C-1 - C-31.

Figure C-1. Gage A01 Mesh Convergence Sensitivity Model results.

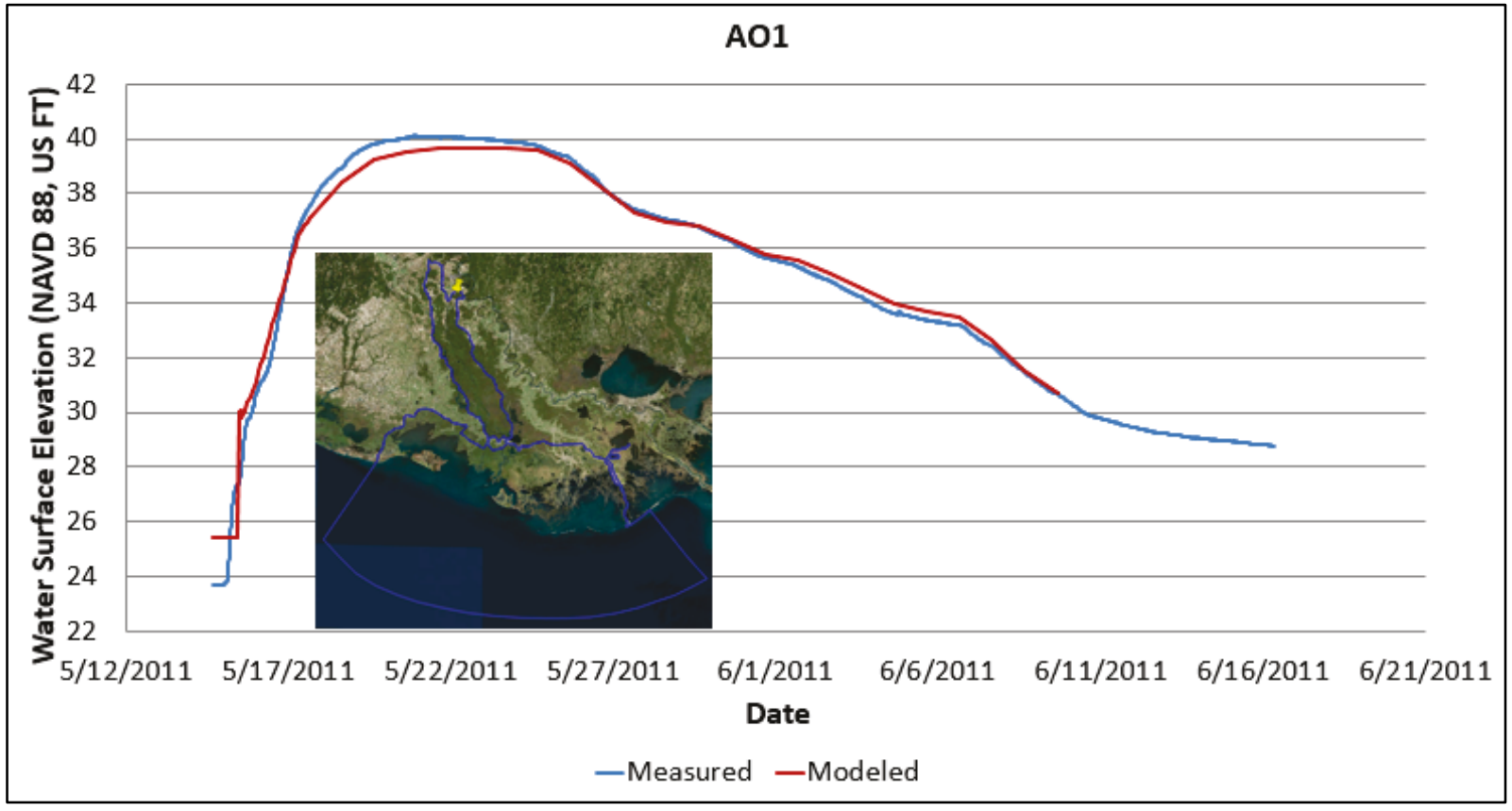


Figure C-2. Gage A02 Mesh Convergence Sensitivity Model results.

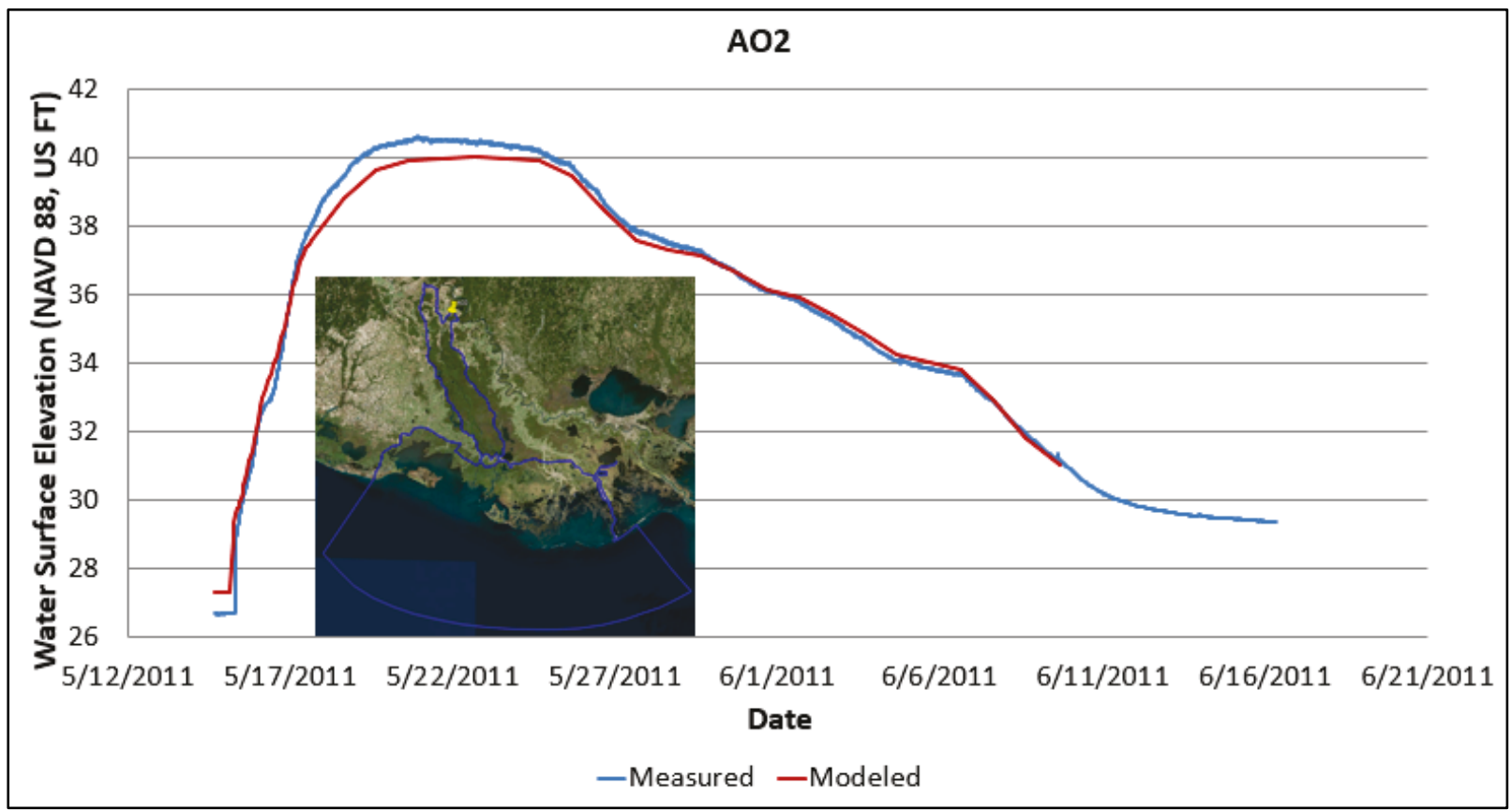

Figure C-3. Gage A03 Mesh Convergence Sensitivity Model results.

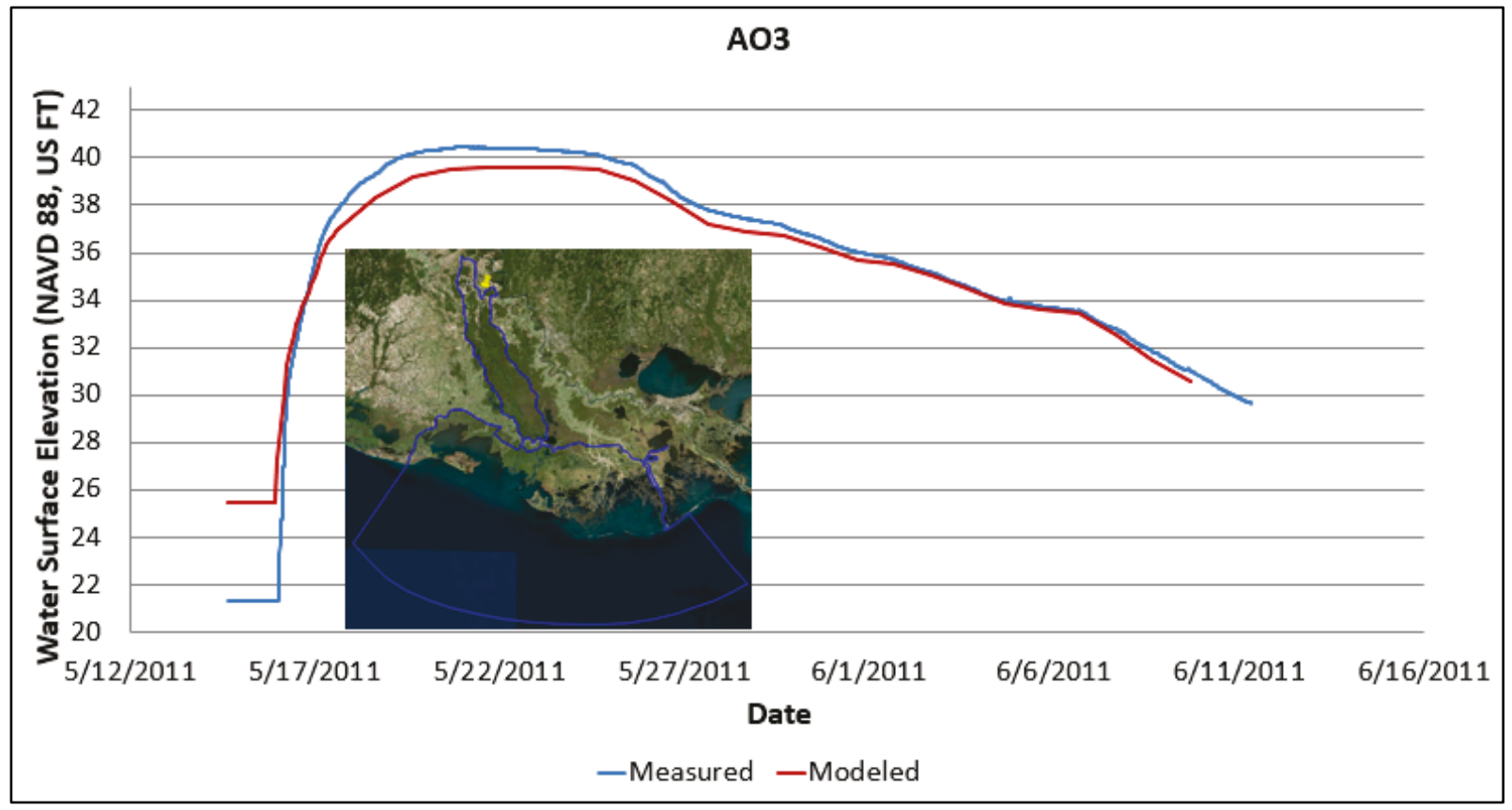


Figure C-4. Gage AO4 Mesh Convergence Sensitivity Model results.

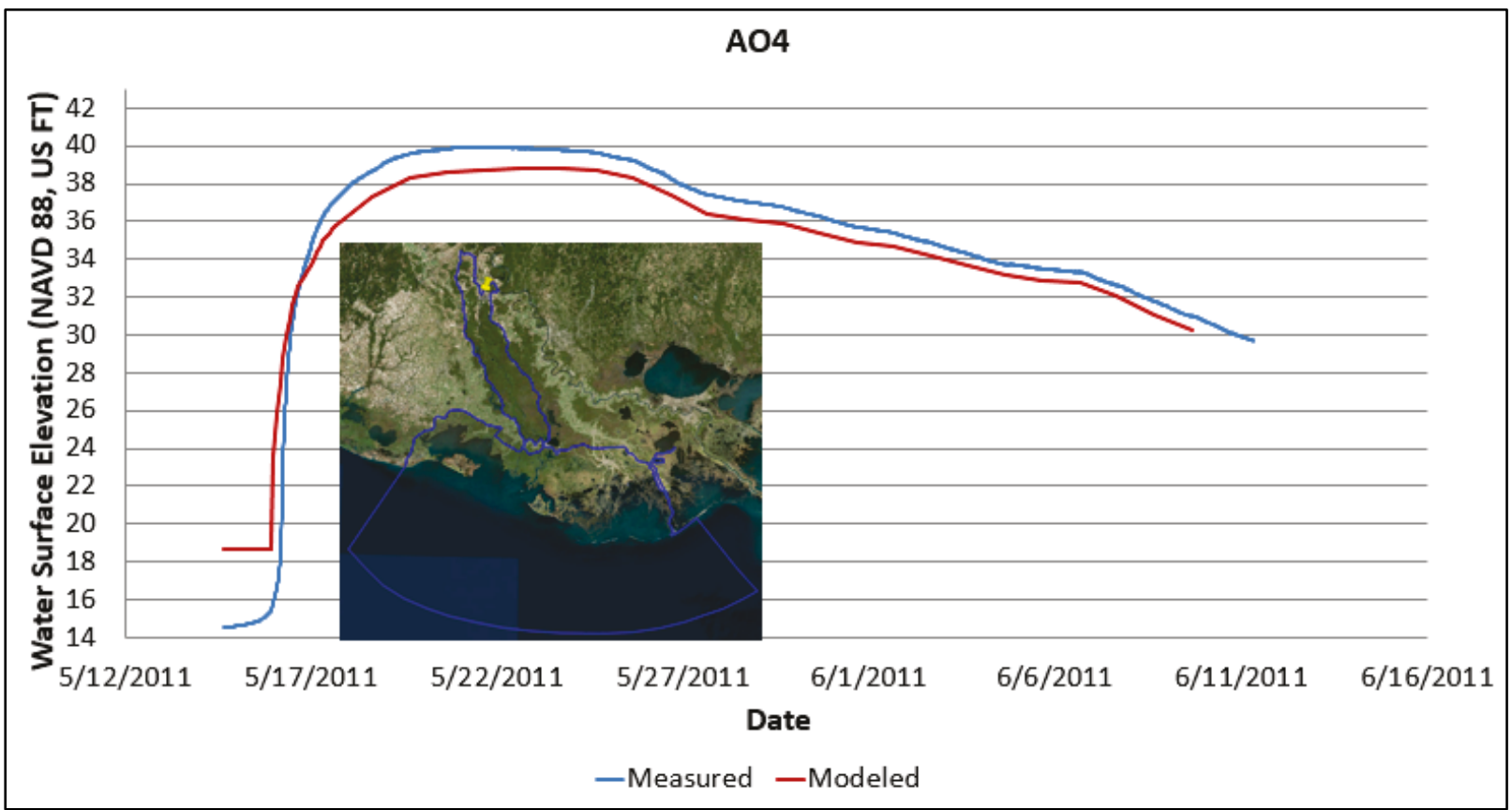

Figure C-5. Gage A06 Mesh Convergence Sensitivity Model results.

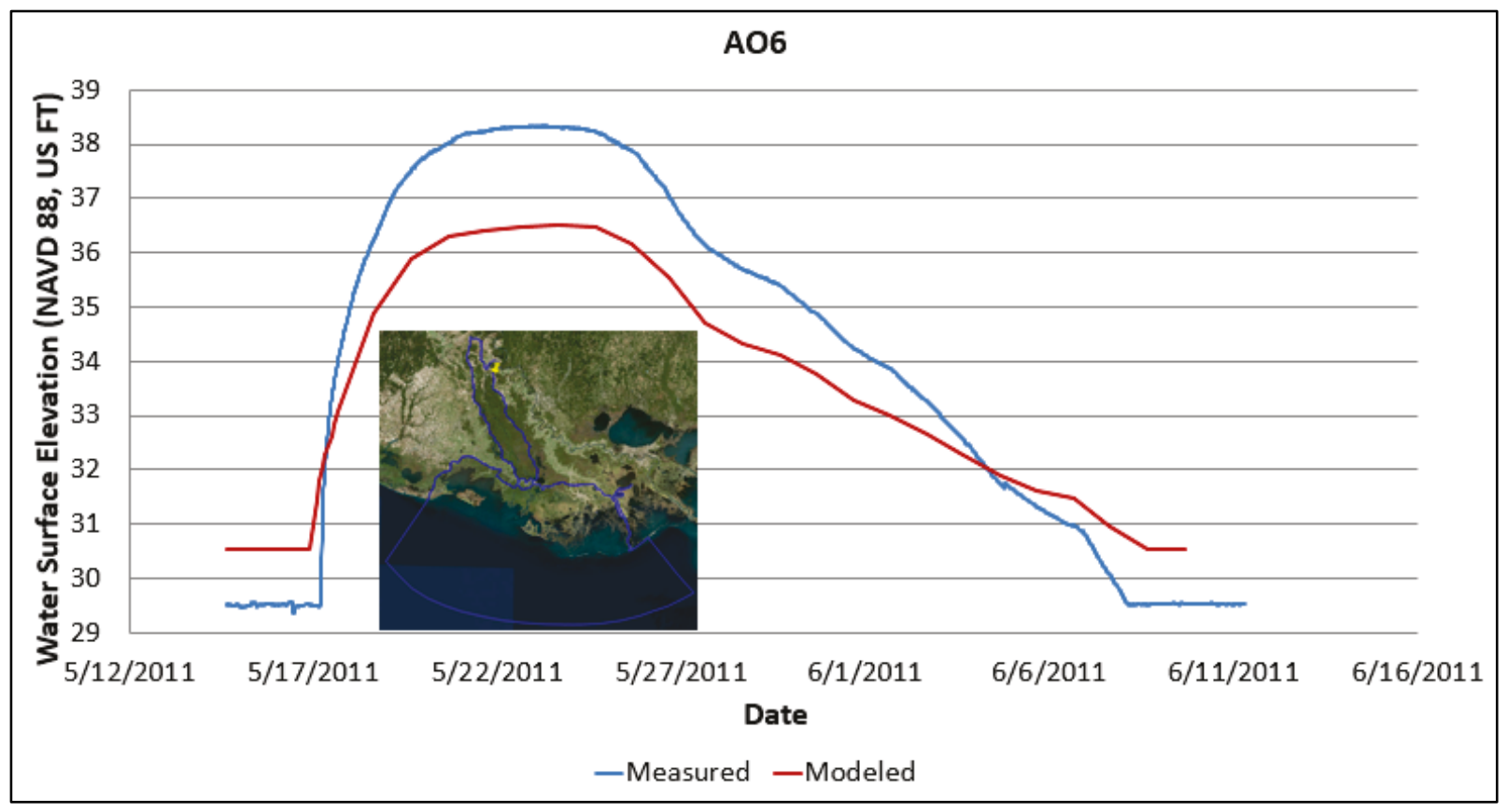


Figure C-6. Gage A07 Mesh Convergence Sensitivity Model results.

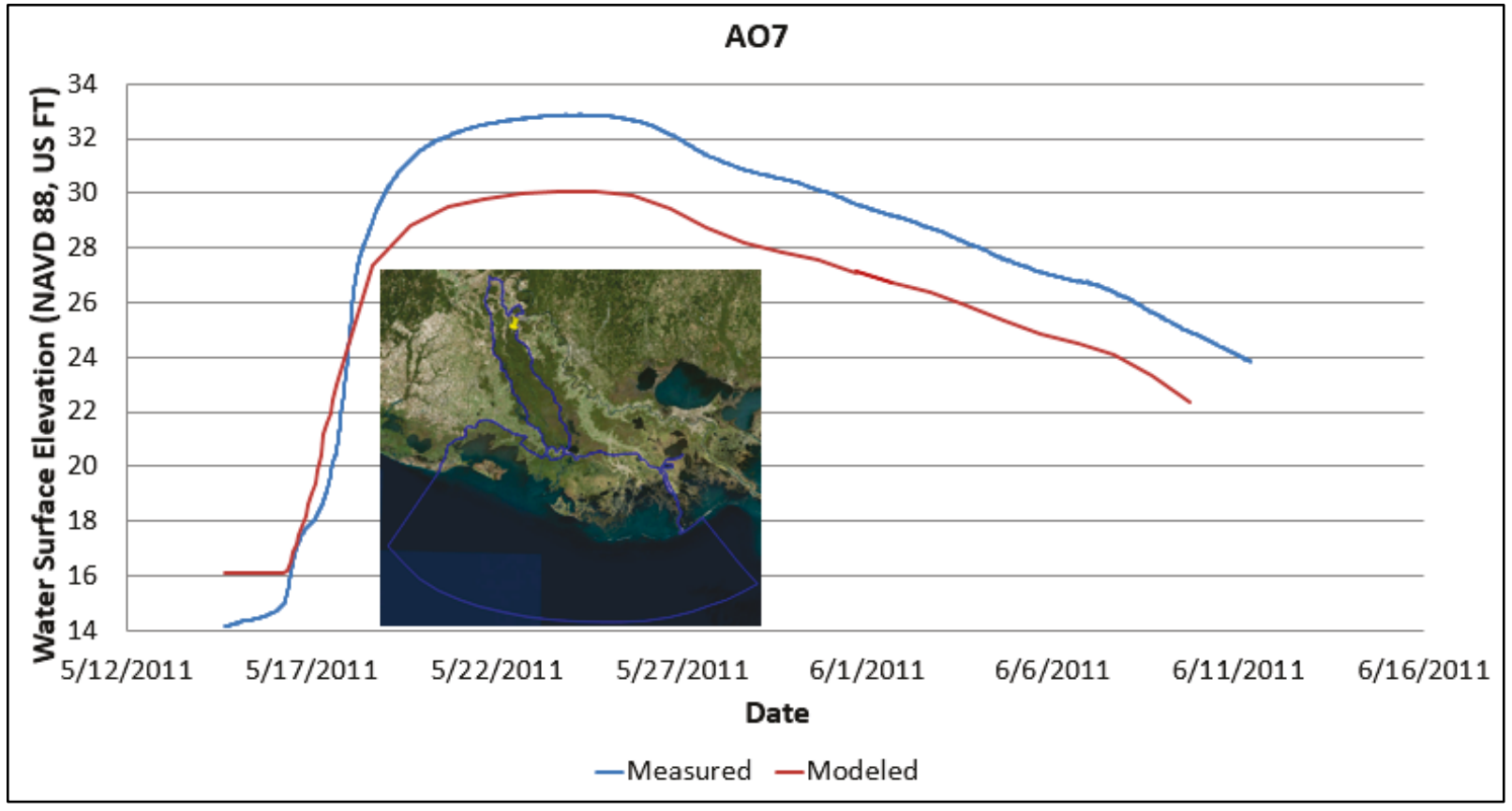

Figure C-7. Gage B04 Mesh Convergence Sensitivity Model results.

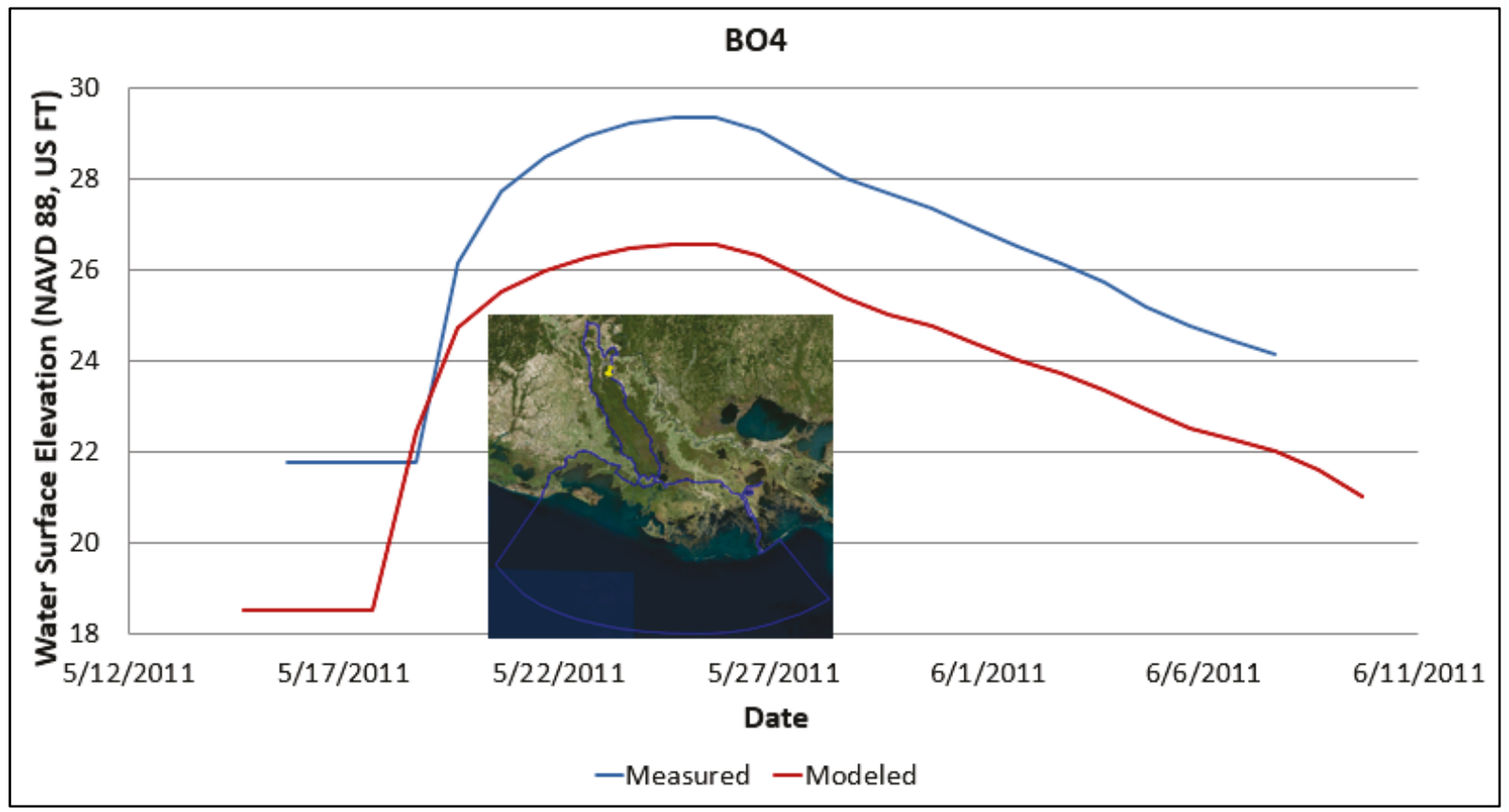


Figure C-8. Gage C04 Mesh Convergence Sensitivity Model results.

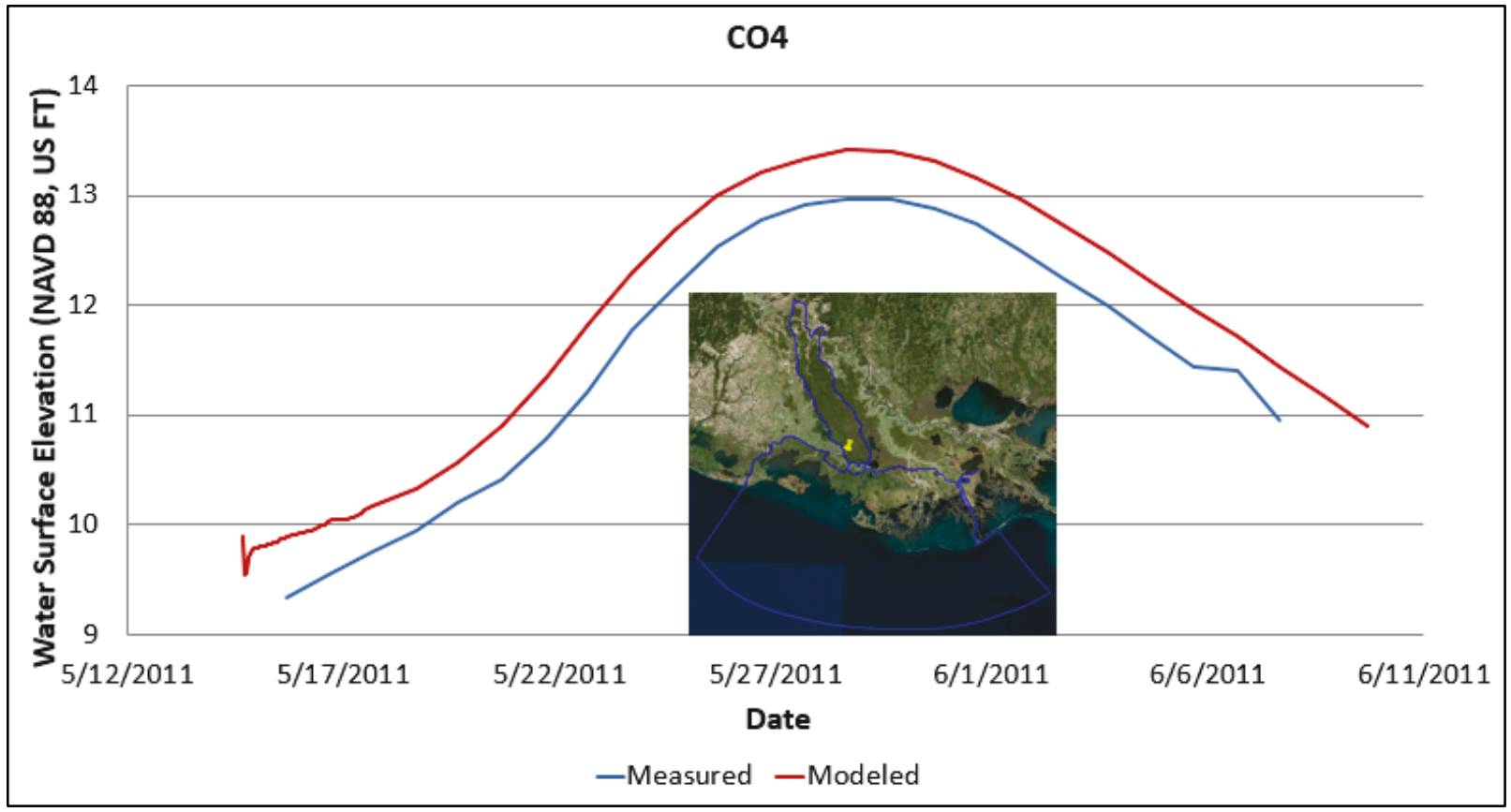

Figure C-9. Gage K2 Mesh Convergence Sensitivity Model results.

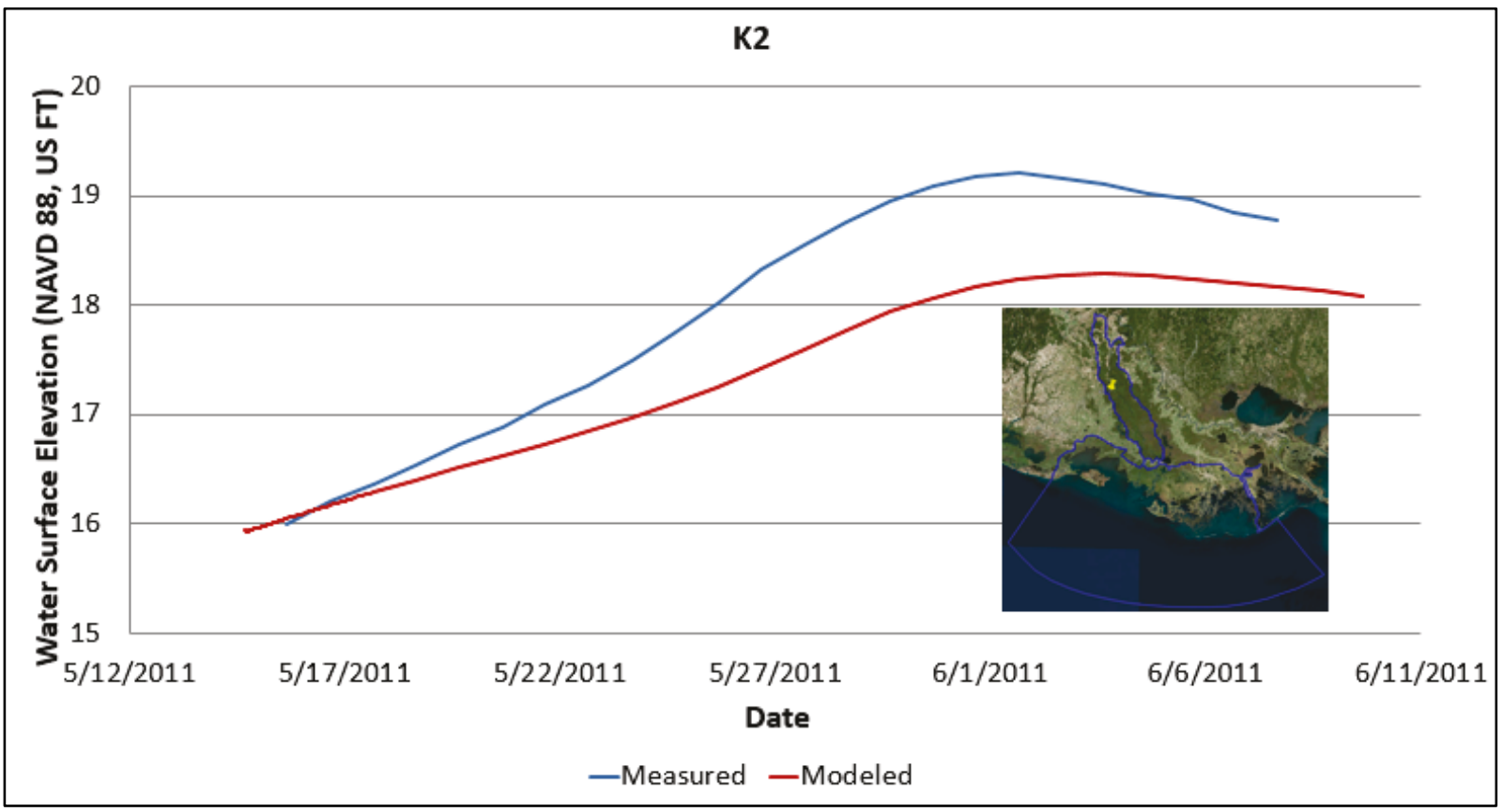


Figure C-10. Gage K3 Mesh Convergence Sensitivity Model results.

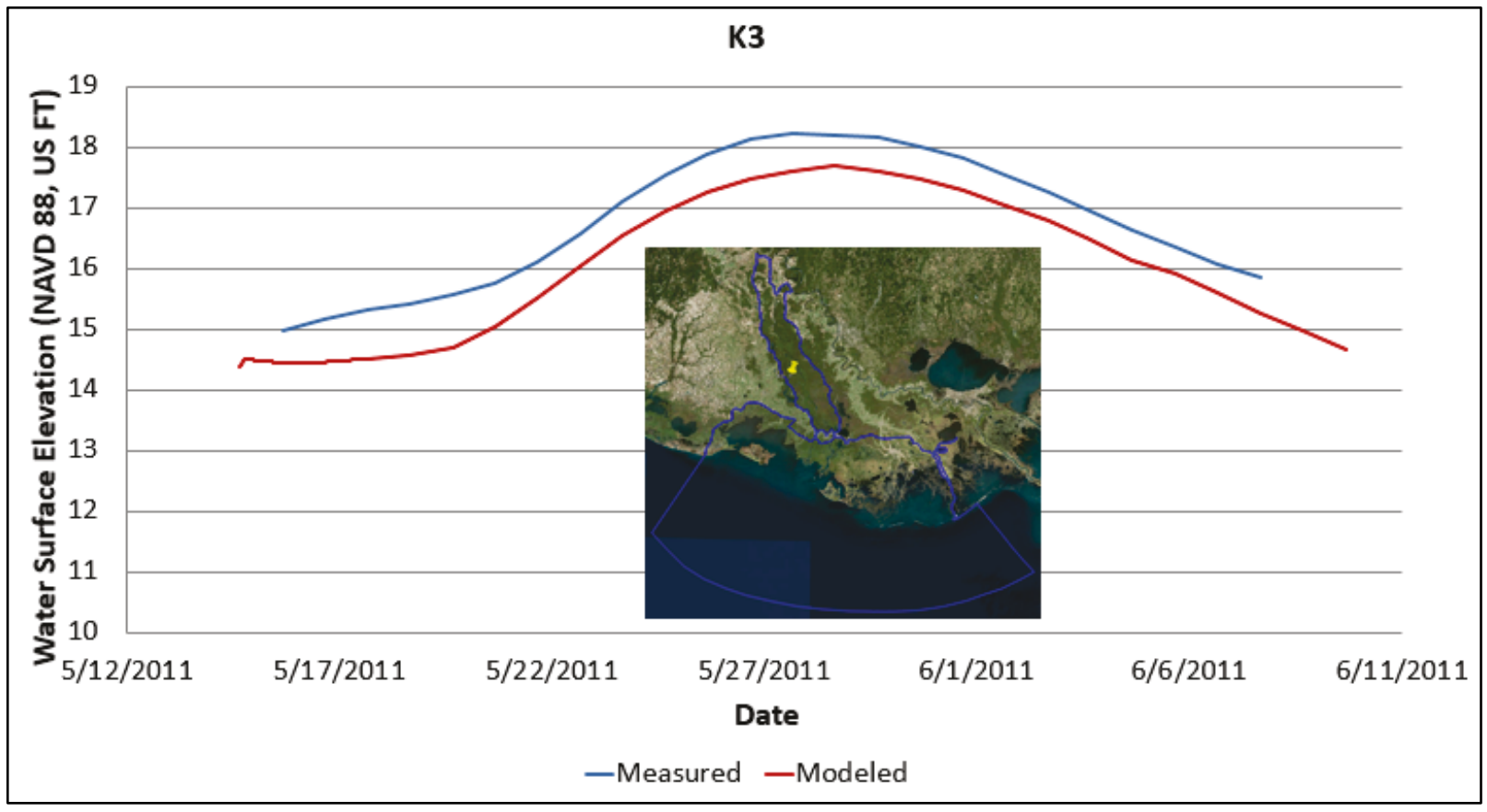

Figure C-11. Gage K4 Mesh Convergence Sensitivity Model results.

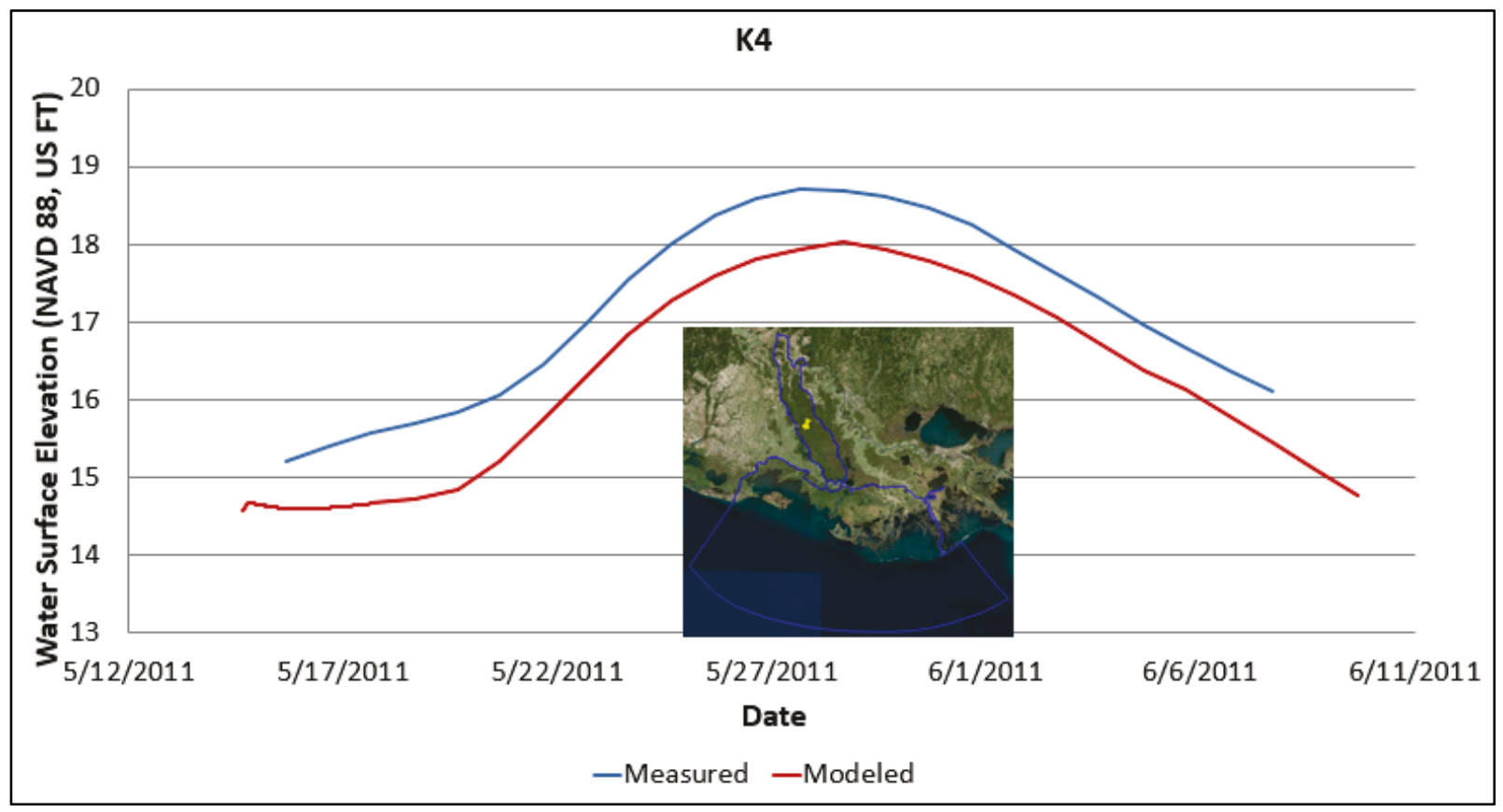


Figure C-12. Gage K5 Mesh Convergence Sensitivity Model results.

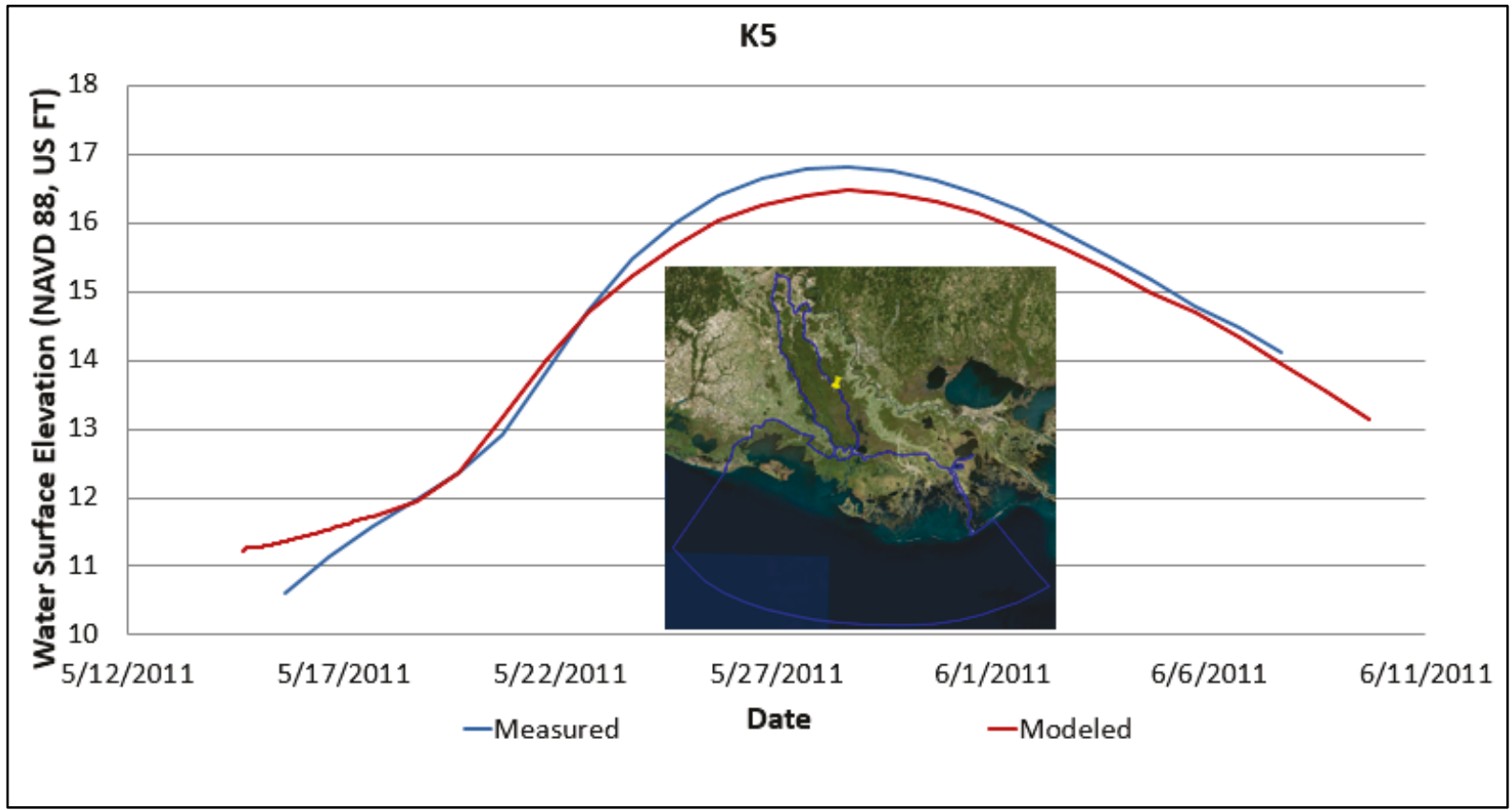

Figure C-13. Gage K6 Mesh Convergence Sensitivity Model results.

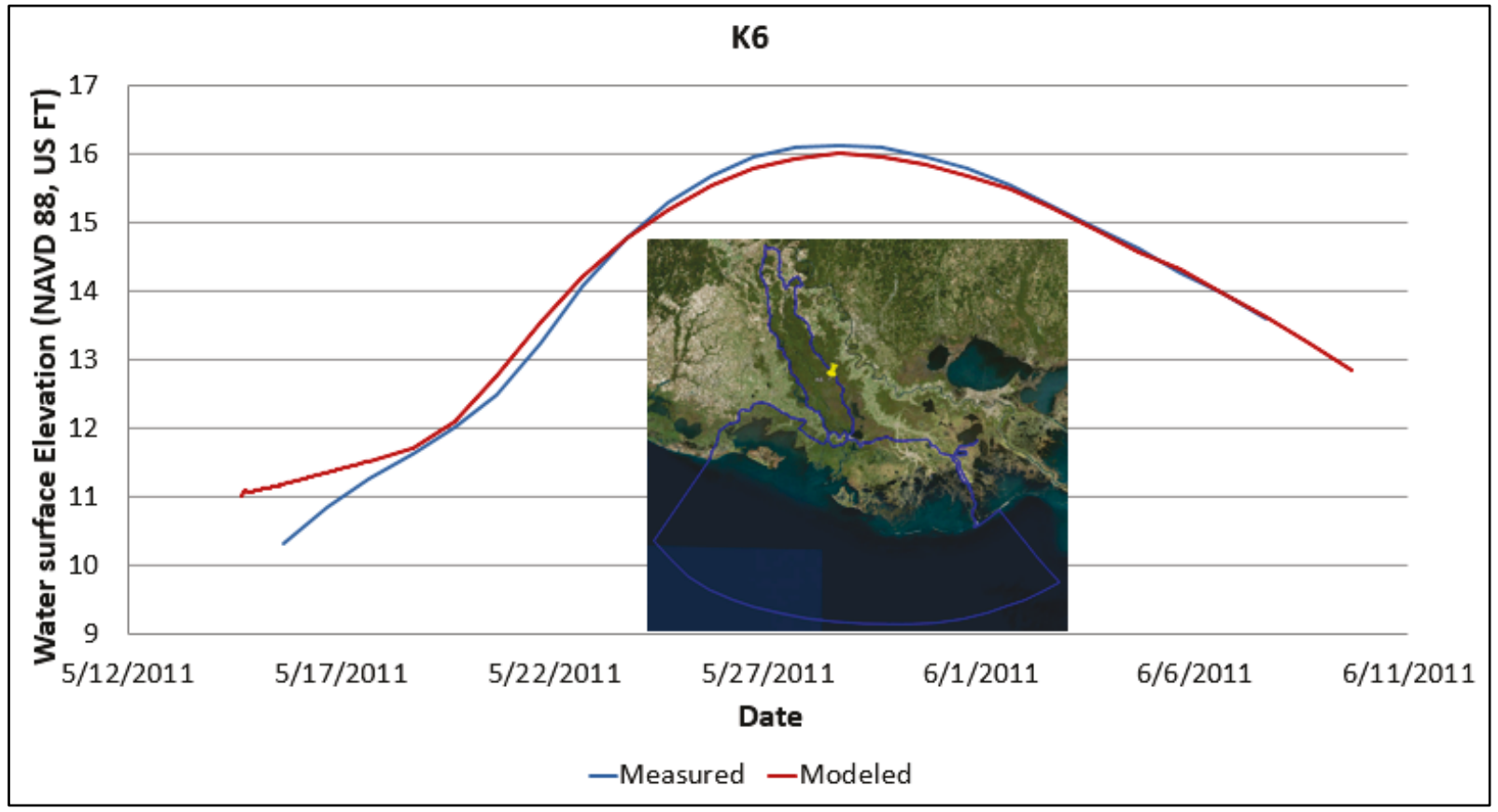


Figure C-14. Gage K7 Mesh Convergence Sensitivity Model results.

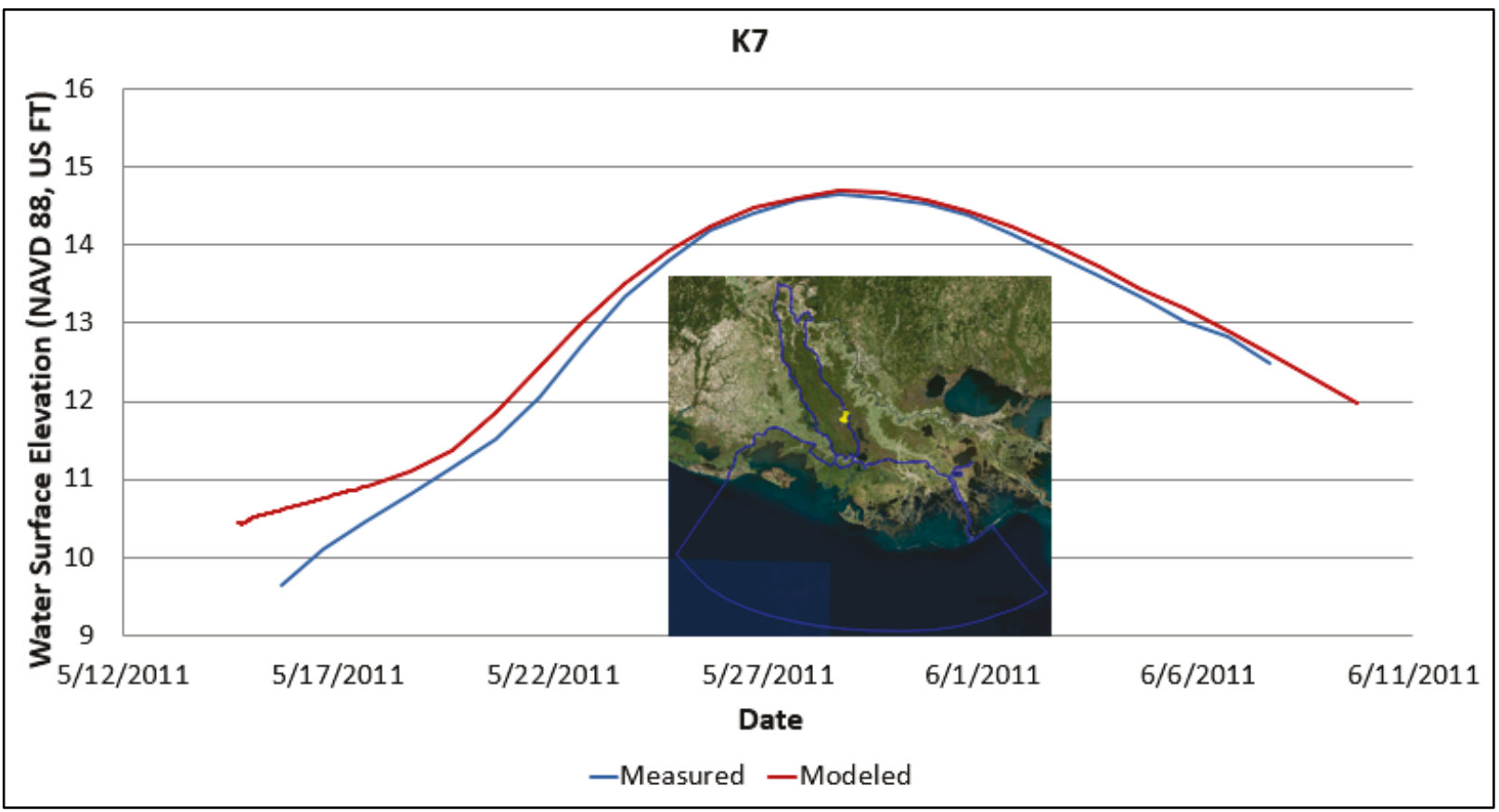

Figure C-15. Gage K8 Mesh Convergence Sensitivity Model results.

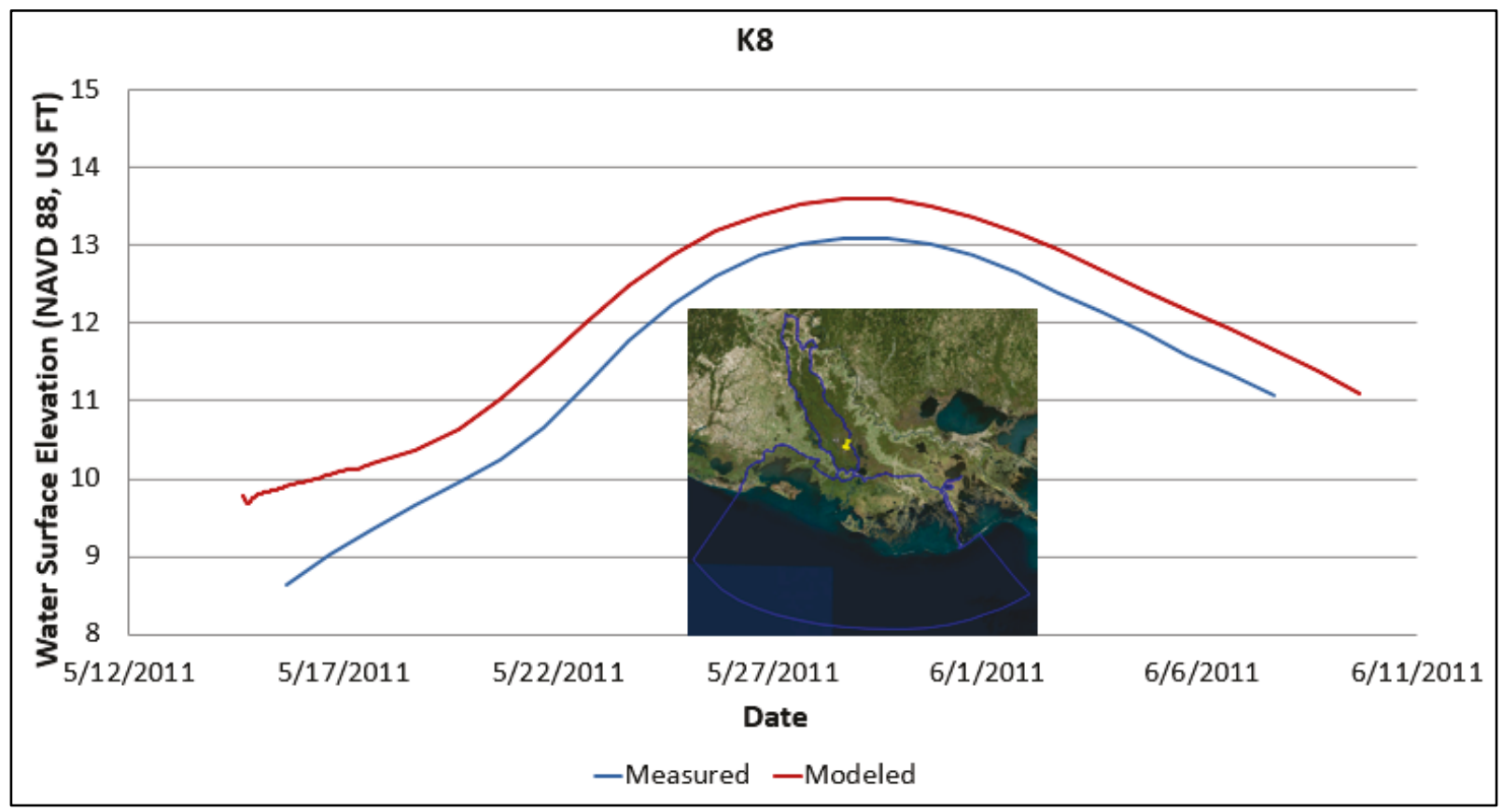


Figure C-16. Gage K9 Mesh Convergence Sensitivity Model results.

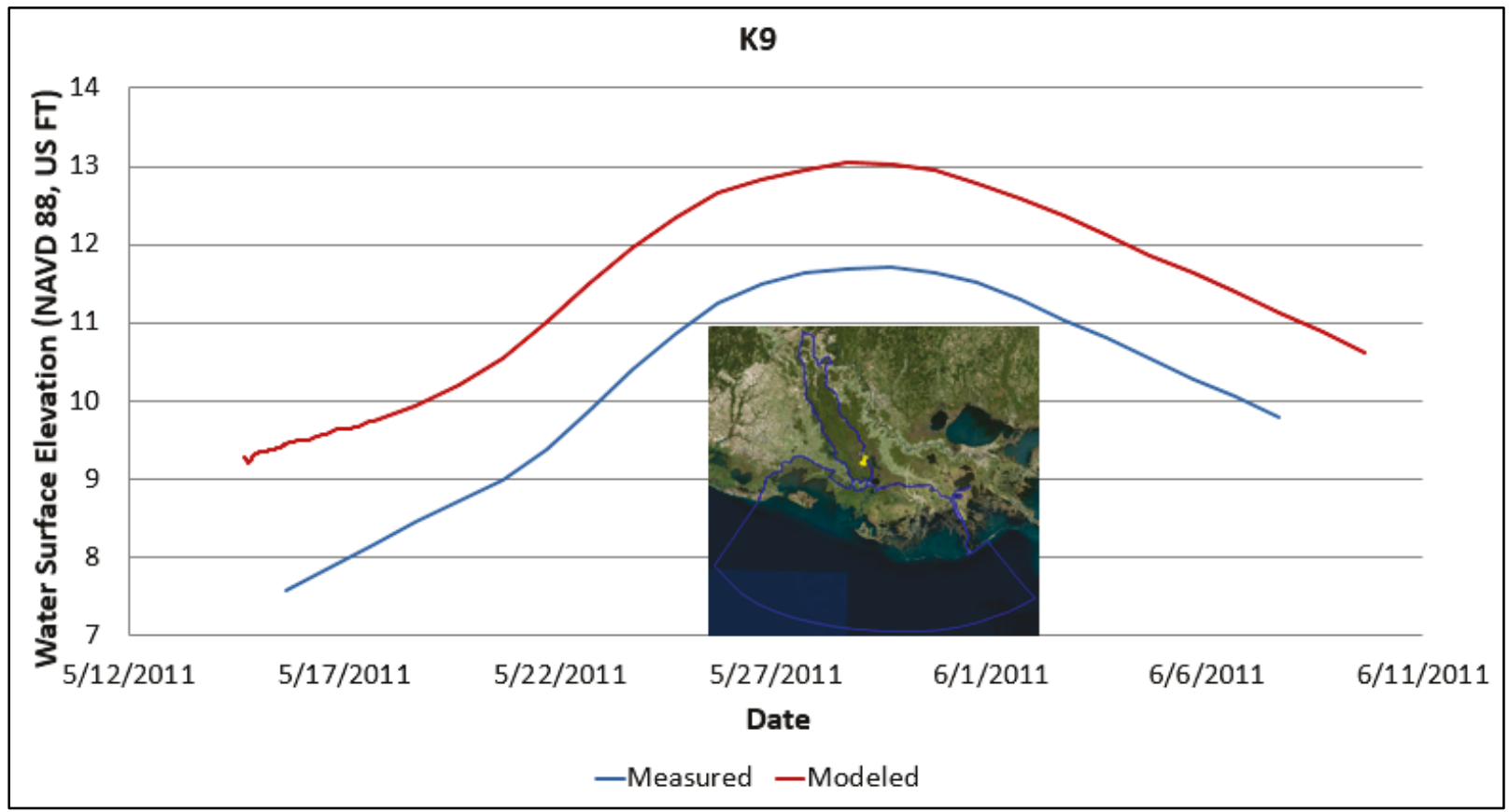

Figure C-17. Gage K10 Mesh Convergence Sensitivity Model results.

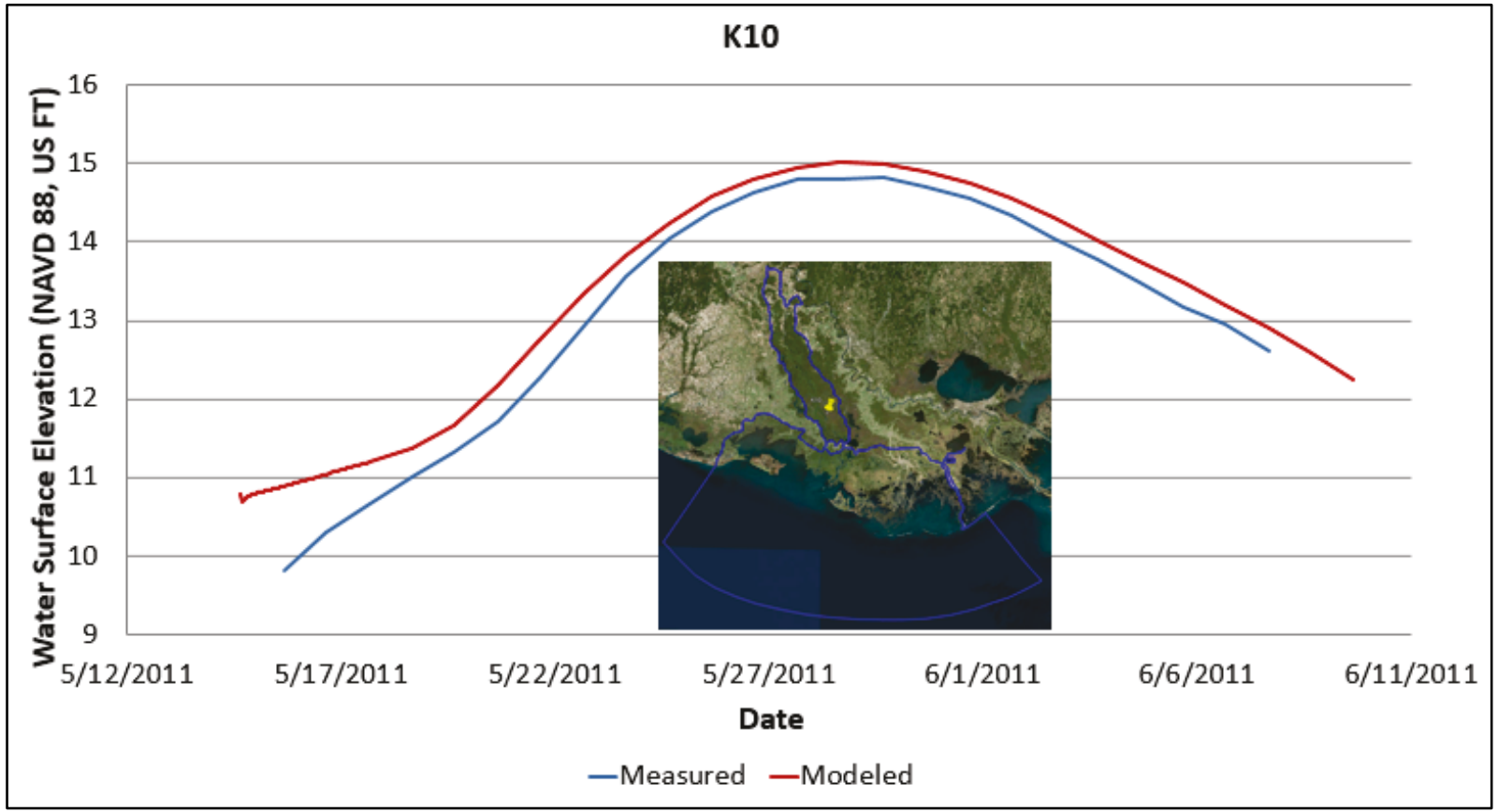


Figure C-18. Gage K11 Mesh Convergence Sensitivity Model results.

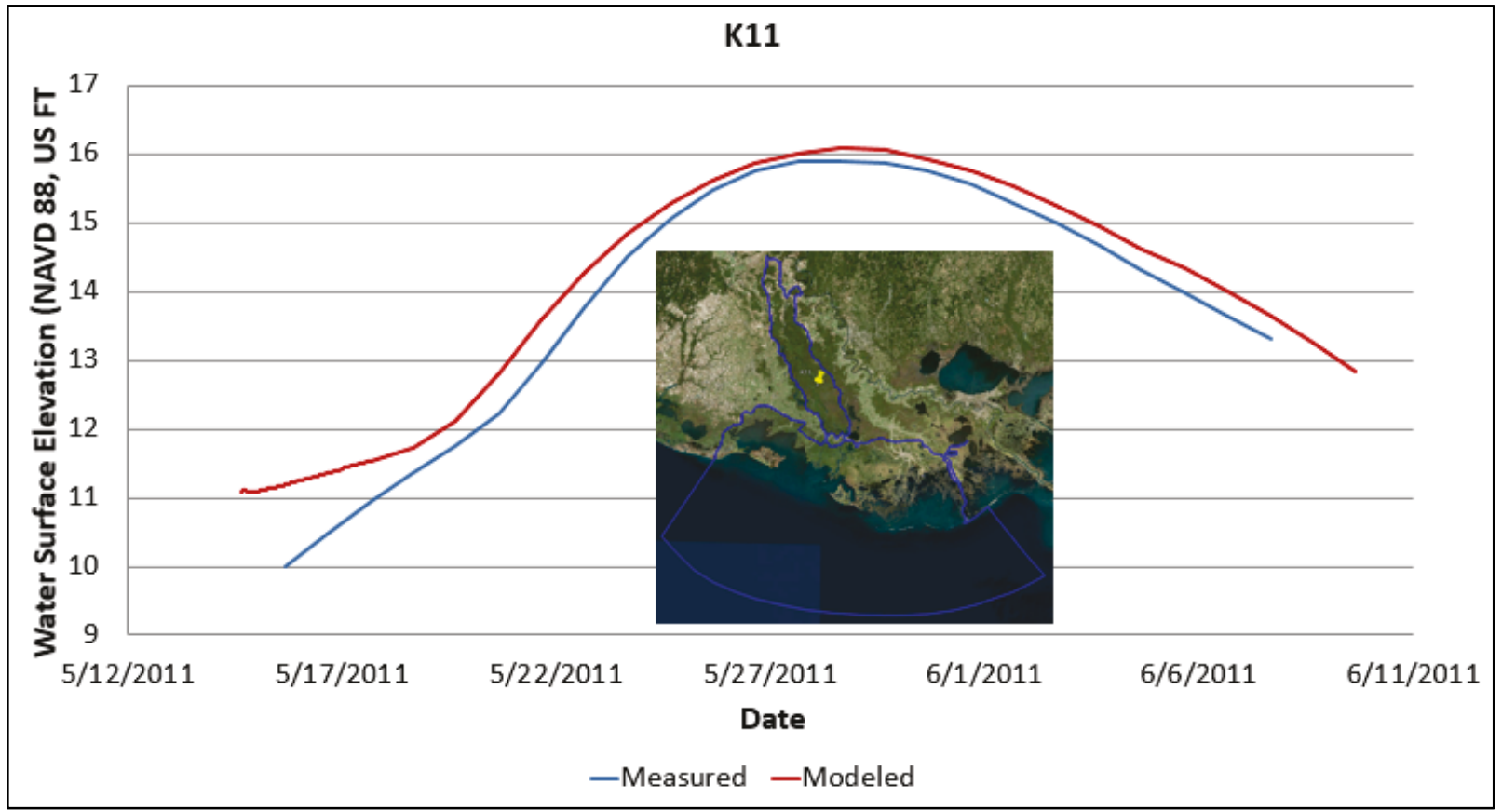

Figure C-19. Gage K12 Mesh Convergence Sensitivity Model results.

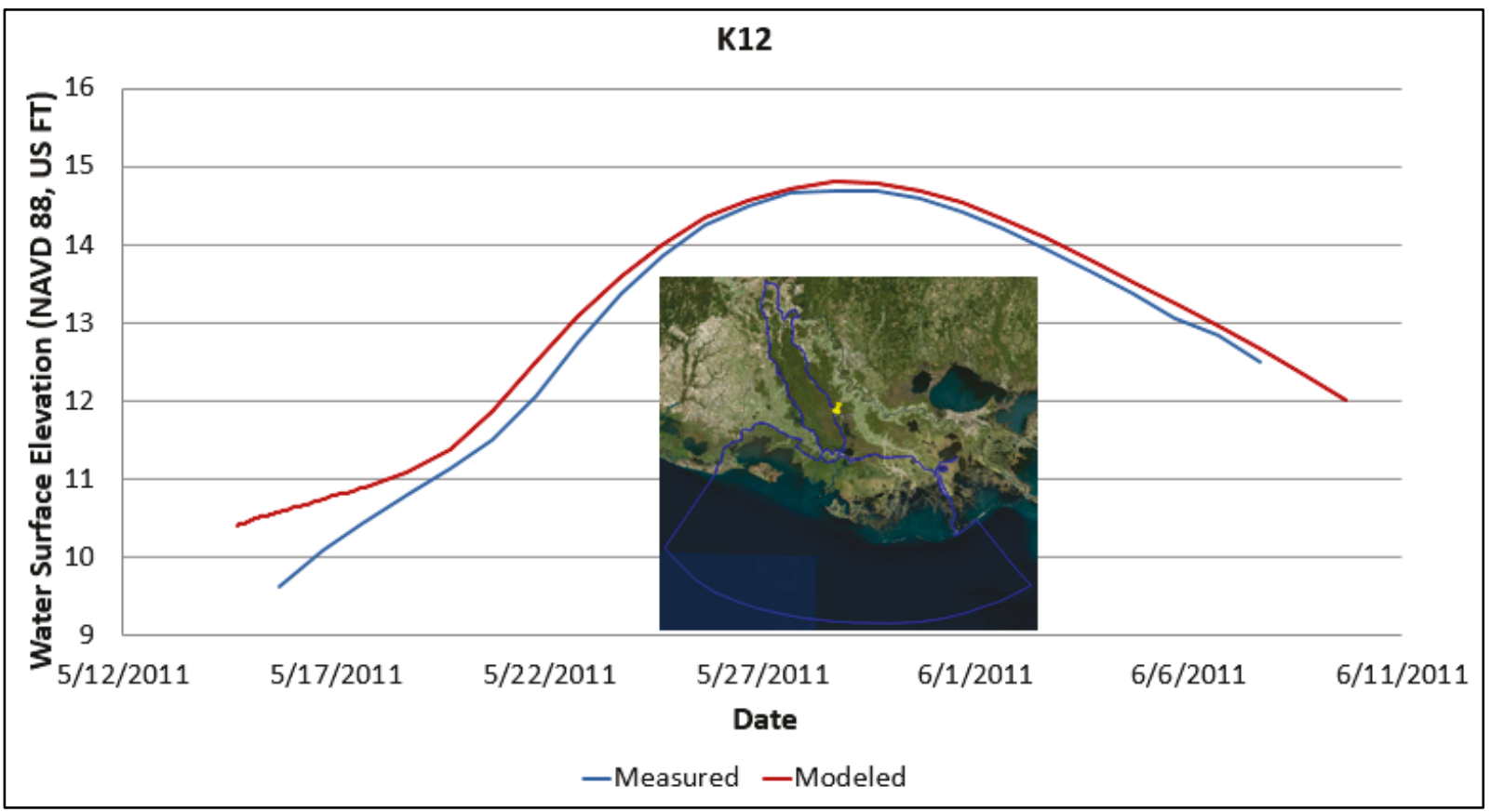


Figure C-20. Gage K13 Mesh Convergence Sensitivity Model results.

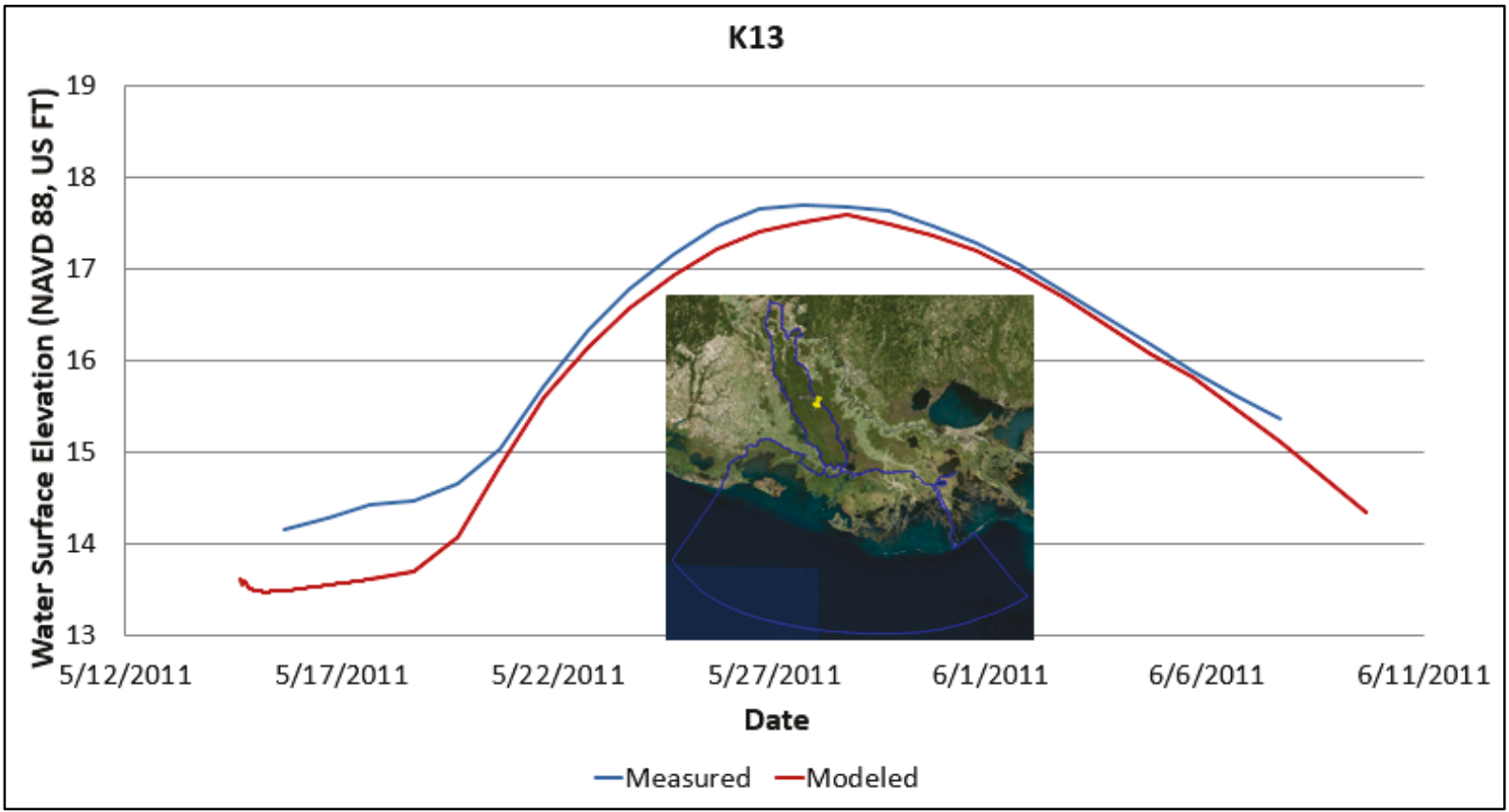

Figure C-21. Gage K14 Mesh Convergence Sensitivity Model results.

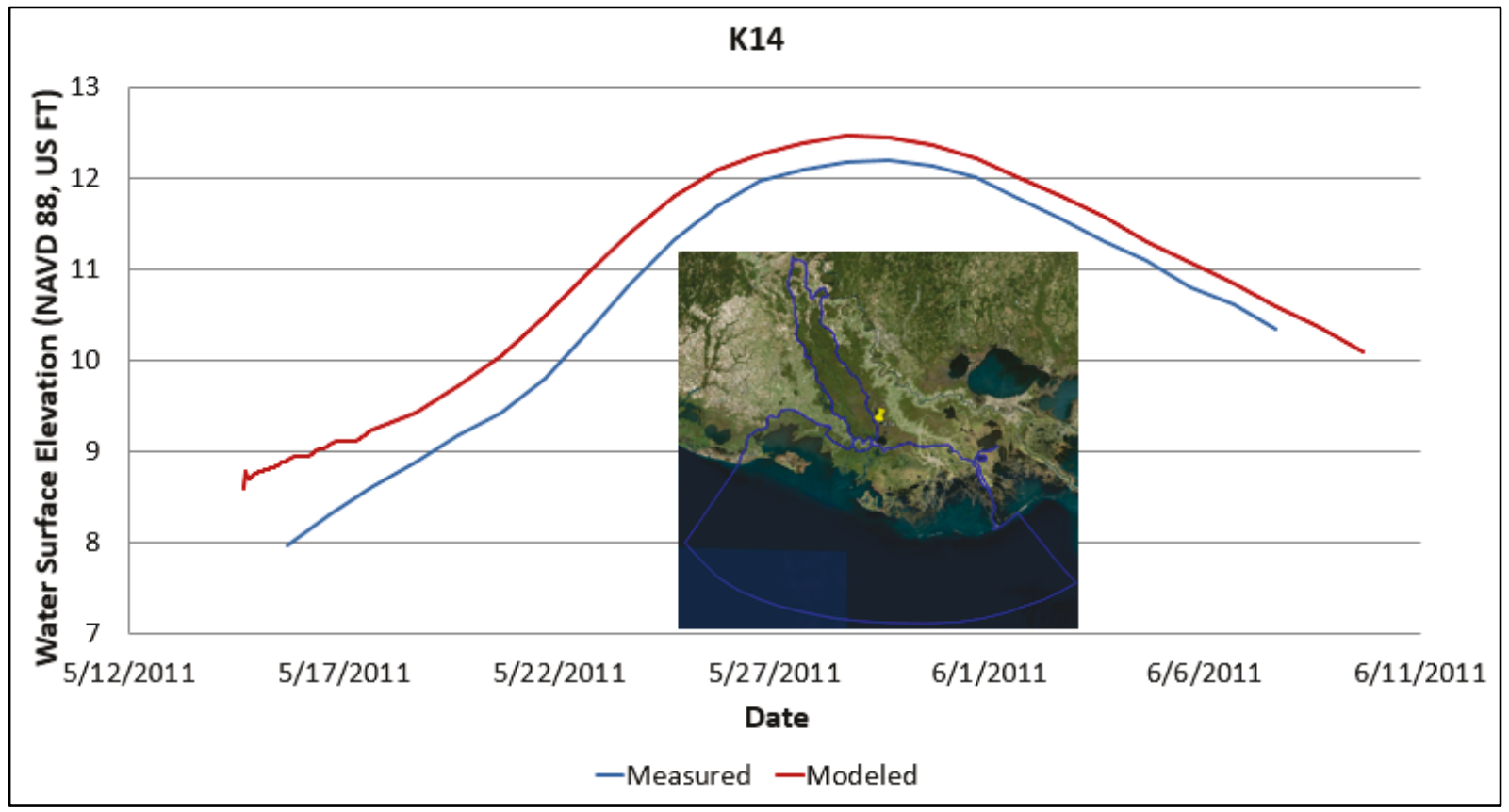


Figure C-22. Gage K15 Mesh Convergence Sensitivity Model results.

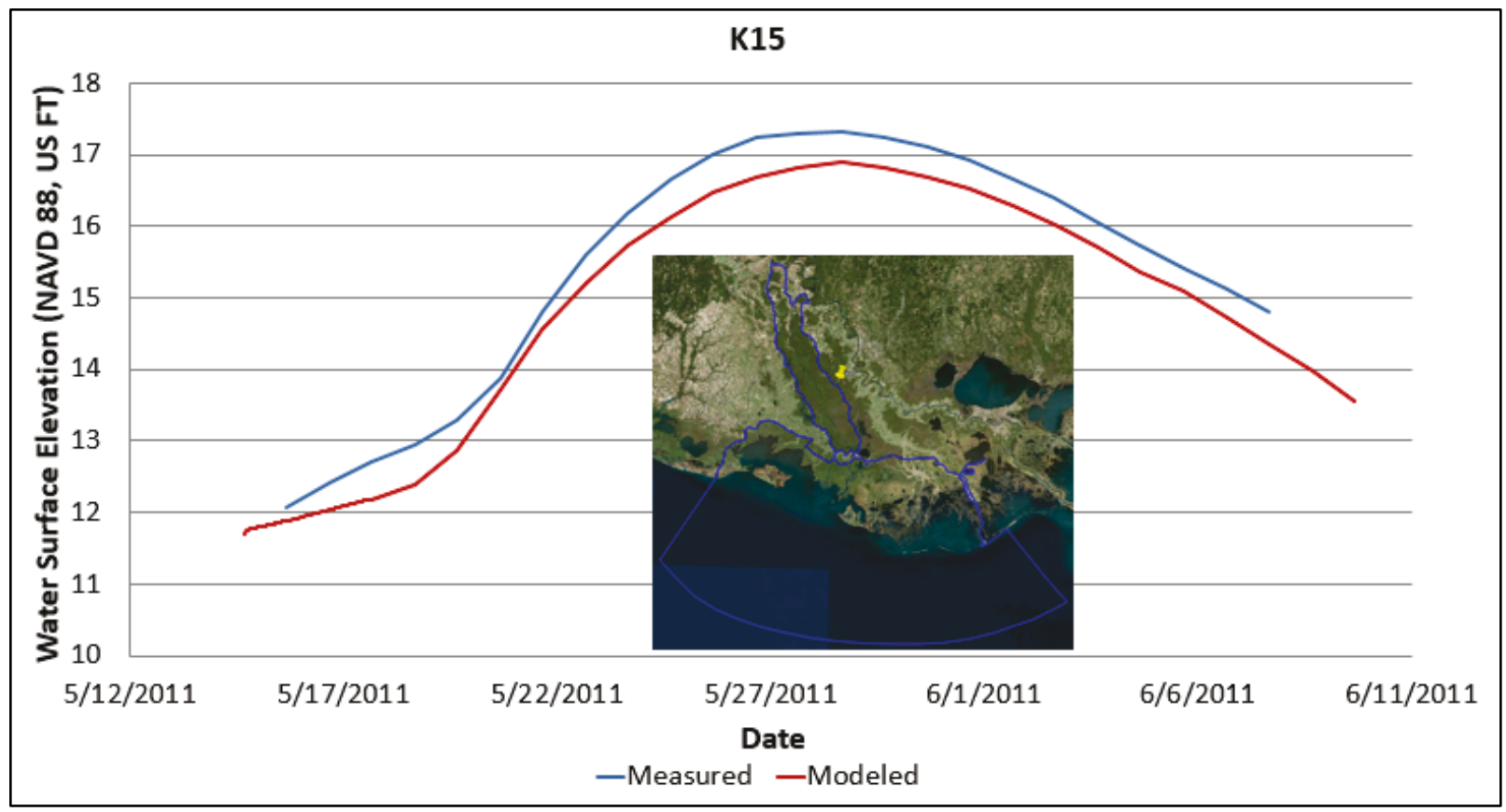

Figure C-23. Gage K16 Mesh Convergence Sensitivity Model results.

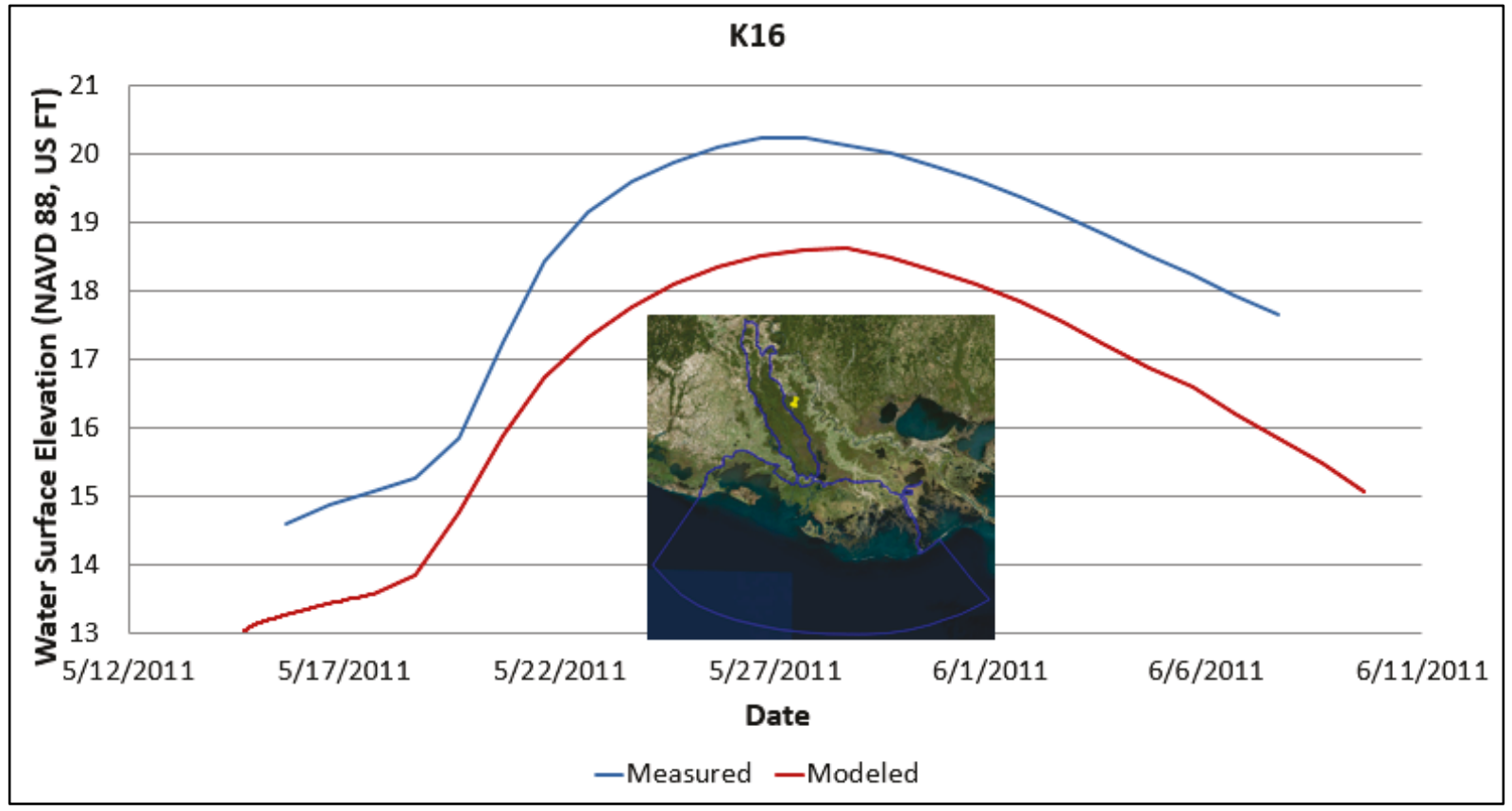


Figure C-24. Gage K17 Mesh Convergence Sensitivity Model results.

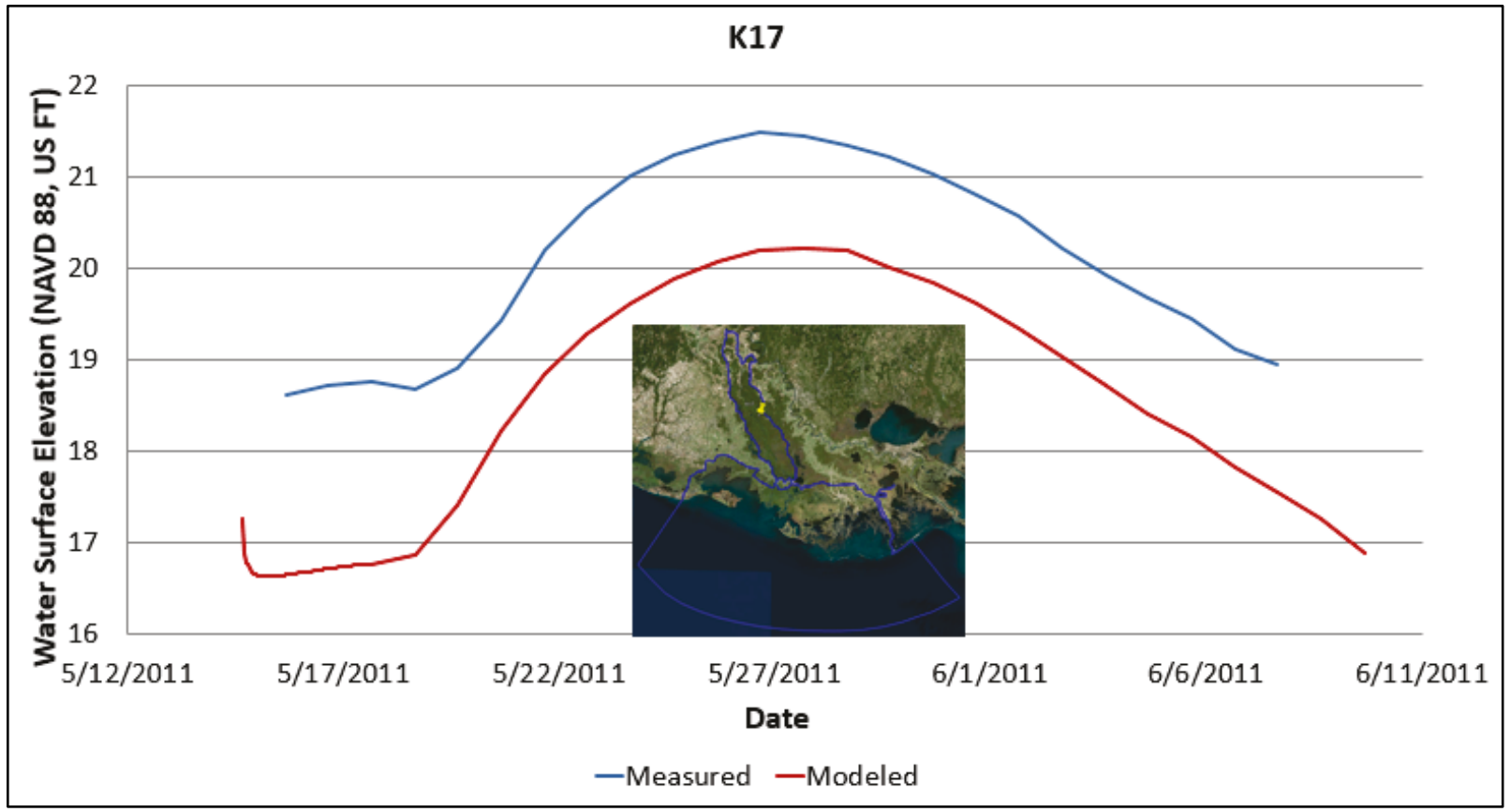

Figure C-25. Gage K18 Mesh Convergence Sensitivity Model results.

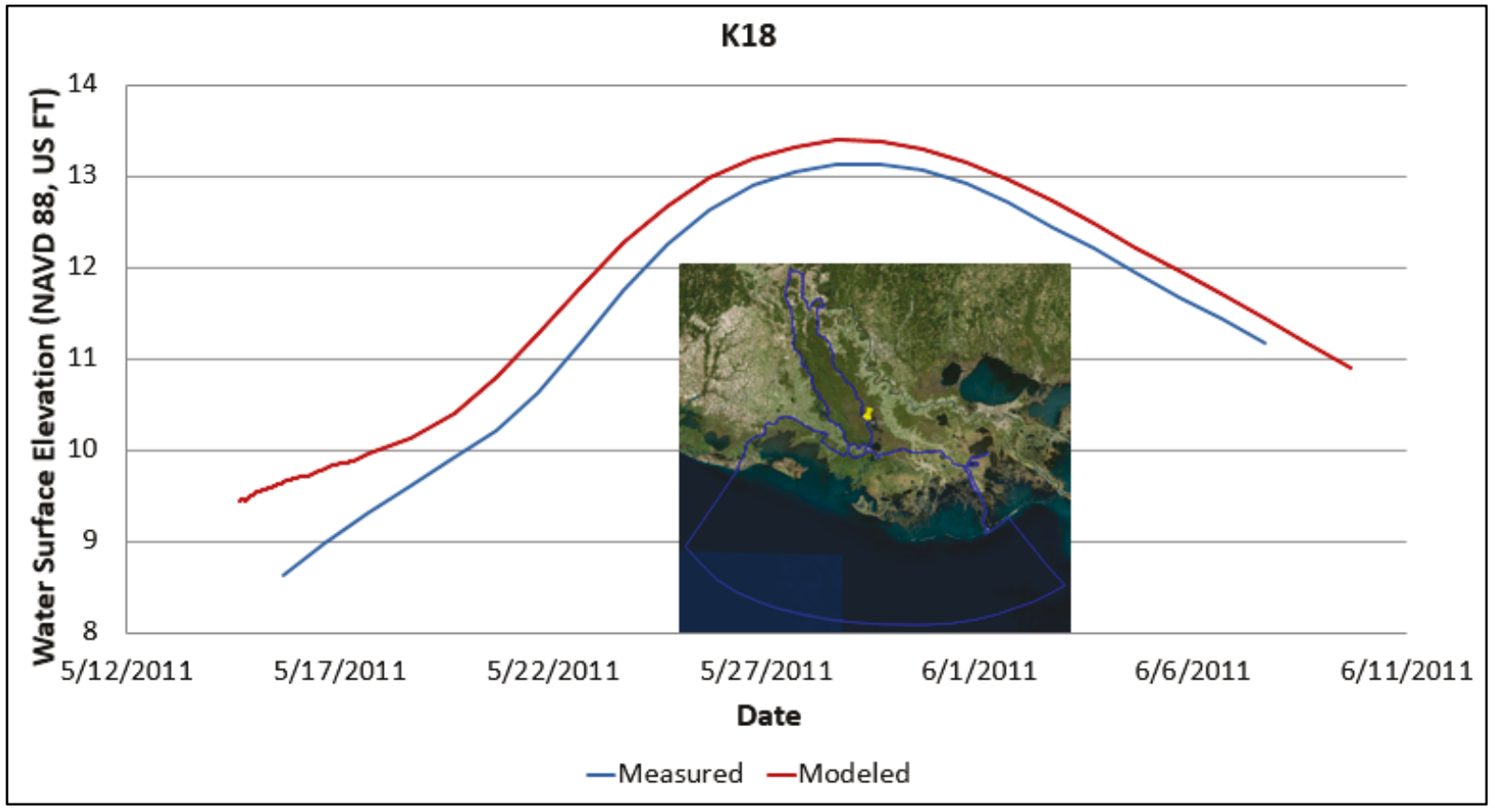


Figure C-26. Gage K19 Mesh Convergence Sensitivity Model results.

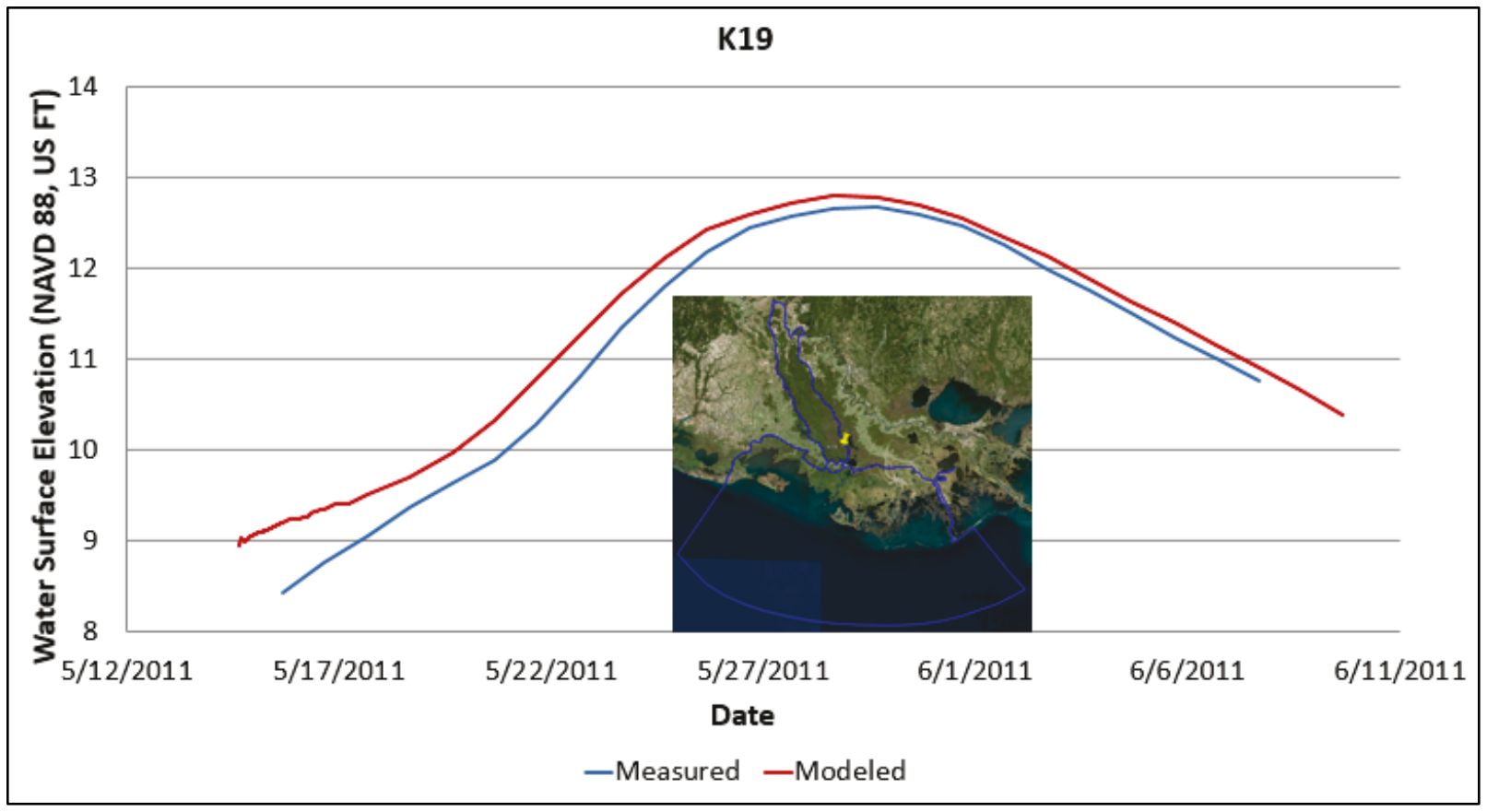

Figure C-27. Gage K21 Mesh Convergence Sensitivity Model results.

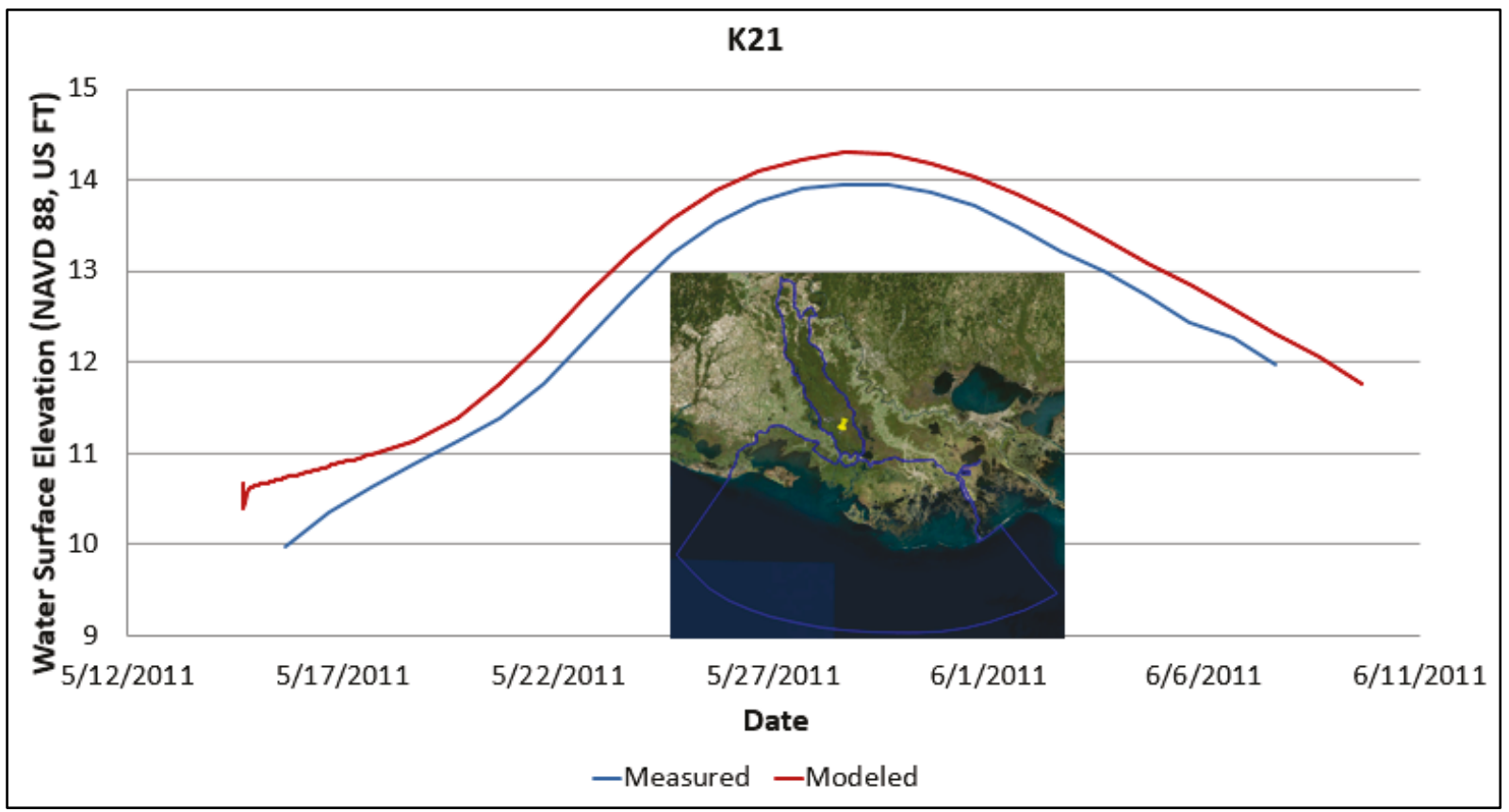


Figure C-28. USGS Gage at Wax Lake Outlet (water surface elevation).

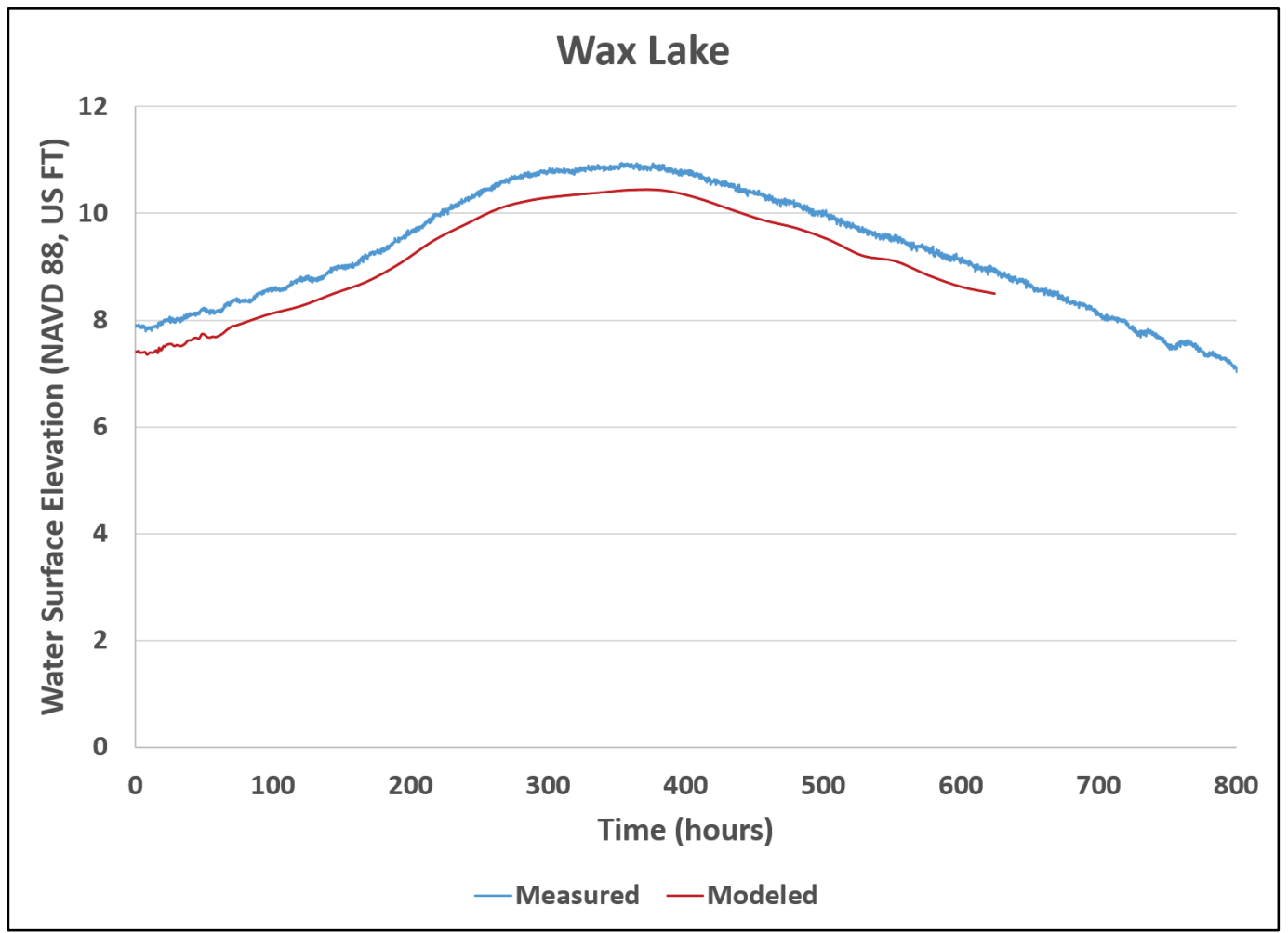

Figure C-29. USGS Gage at Morgan City Outlet (water surface elevation).

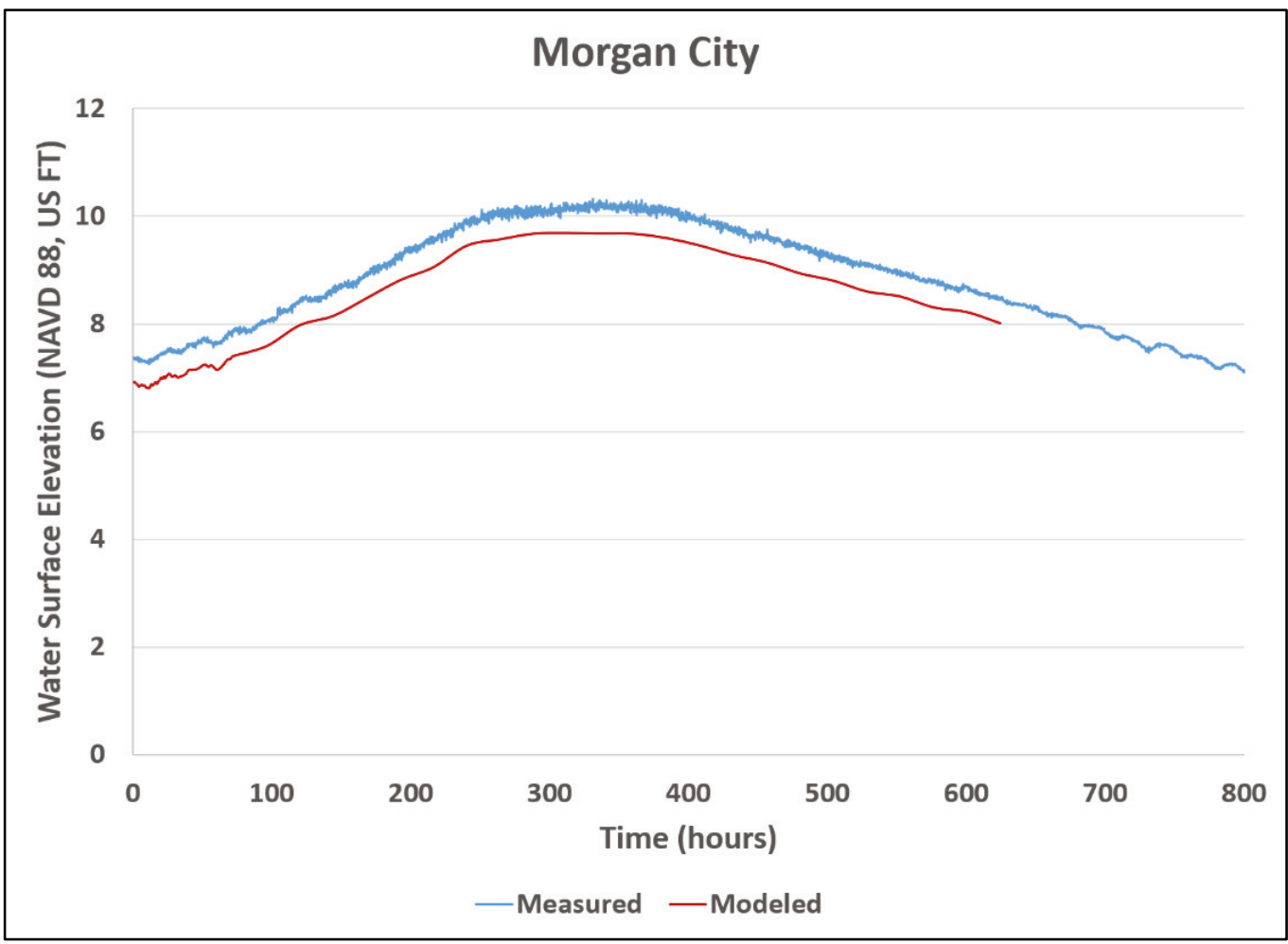


Figure C-30. USGS Gage at Wax Lake Outlet (discharge).

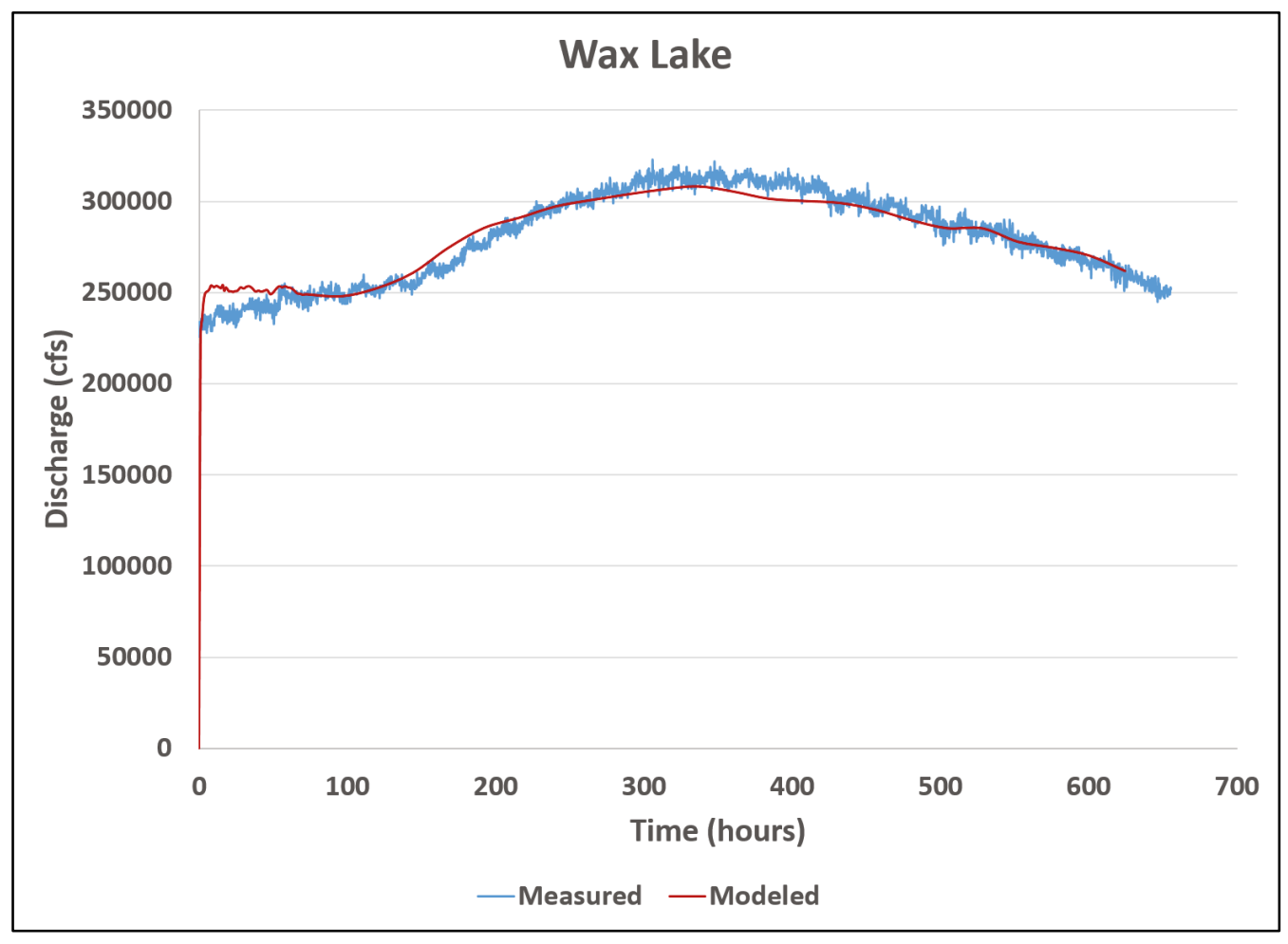

Figure C-31. USGS Gage at Morgan City Outlet (discharge).

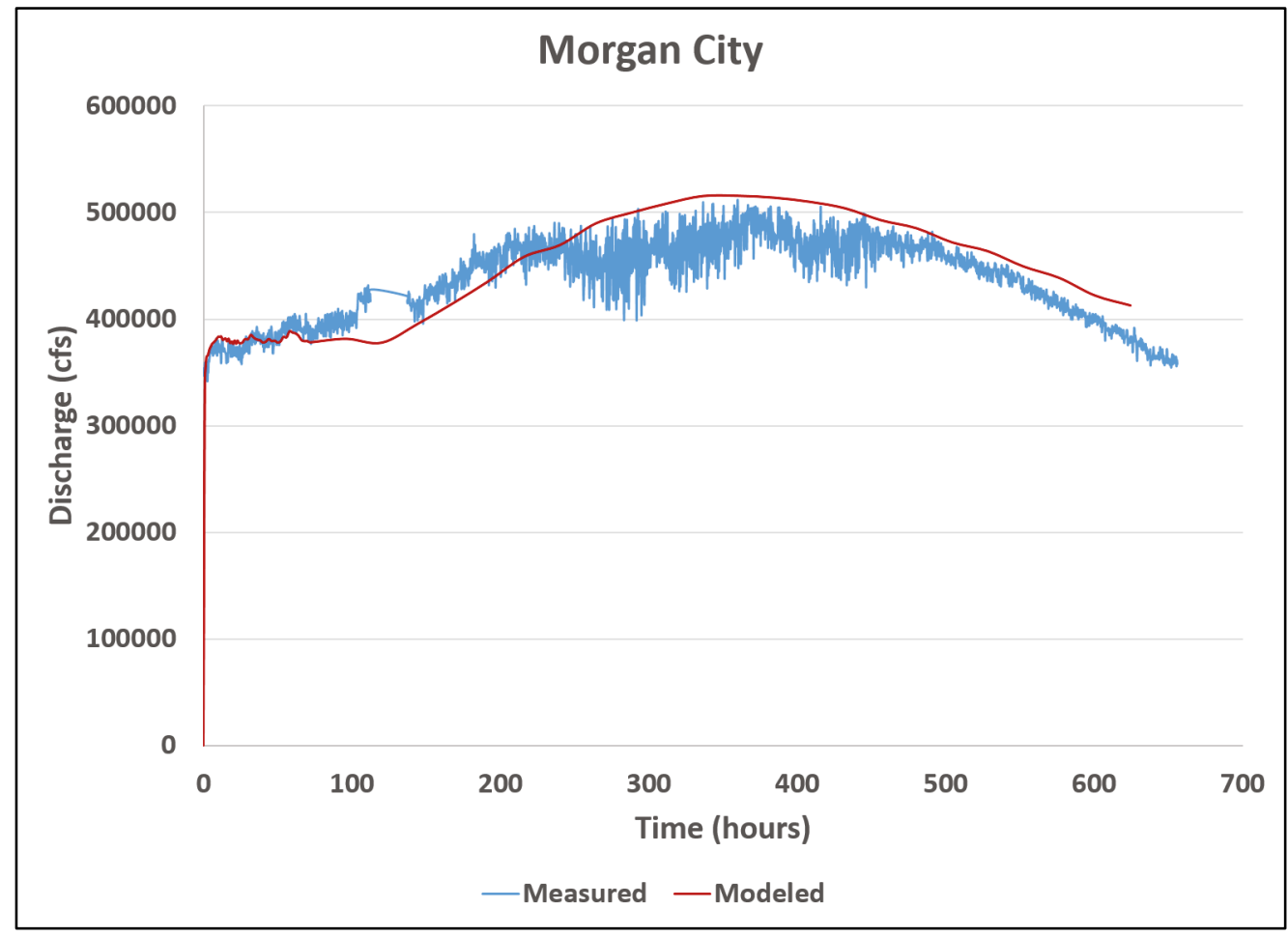




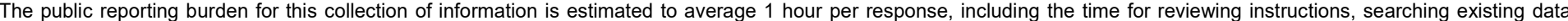

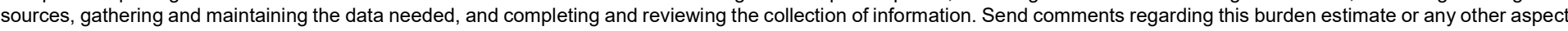

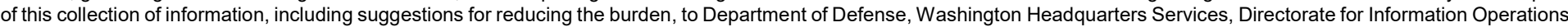

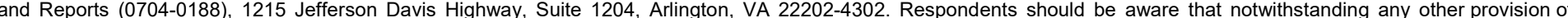
law, no person shall be subject to any penalty for failing to comply with a collection of information if it does not display a currently valid OMB control number.

PLEASE DO NOT RETURN YOUR FORM TO THE ABOVE ADDRESS.

\begin{tabular}{l|l|l}
\hline $\begin{array}{l}\text { 1. REPORT DATE } \\
\text { December } 2018\end{array}$ & $\begin{array}{l}\text { 2. REPORT TYPE } \\
\text { Final Report }\end{array}$ & 3. DATES COVERED (FrOm - To)
\end{tabular}

\section{TITLE AND SUBTITLE}

Hydrodynamics in the Morganza Floodway and Atchafalaya Basin

Report 2: Phase 2; A Report for the U.S. Army Corps of Engineers, MRG\&P 5a. CONTRACT NUMBER

5b. GRANT NUMBER

5c. PROGRAM ELEMENT NUMBER

5d. PROJECT NUMBER

127672

5e. TASK NUMBER

5f. WORK UNIT NUMBER

8. PERFORMING ORGANIZATION REPORT NUMBER

MRG\&P Report No. 26

U.S. Army Engineer Research and Development Center

3909 Halls Ferry Road

Vicksburg, MS 39180-6199

9. SPONSORING/MONITORING AGENCY NAME(S) AND ADDRESS(ES)

U.S. Army Corps of Engineers, Mississippi Valley Division

10. SPONSOR/MONITOR'S ACRONYM(S)

USACE MVD

Mississippi River Geomorphology and Potamology Program

1400 Walnut Street

Vicksburg, MS 39180

11. SPONSOR/MONITOR'S REPORT NUMBER(S)

\section{DISTRIBUTION/AVAILABILITY STATEMENT}

Approved for public release; distribution is unlimited.

\section{SUPPLEMENTARY NOTES}

\section{ABSTRACT}

The Morganza Floodway and the Atchafalaya Basin located in Louisiana west of the Mississippi River were evaluated using a twodimensional Adaptive Hydraulics model. The study was conducted to determine the extent and timing of flood inundation throughout the study area. The input hydrograph covered a range of flows through the Morganza Control Structure that included the 2011 flood as well as the low end of flow values up to the Standard Project Flood of 600,000 cfs. Hydraulic roughness values were set for pre-2011 flood conditions. Prior to this study, a Phase 1 initial model study was completed that included only the Morganza Floodway down to Highway 190. This study (Phase 2) incorporates the Phase 1 study area along with the system south of Highway 190 down to Morgan City as well as the entire Atchafalaya Basin from Simmesport to Calumet. After the model was calibrated to the 2011 flood event, three separate alternative simulations were performed. These alternatives are the beginning of a collection of runs that detail how the floodways will respond given certain boundary conditions.

\section{SUBJECT TERMS}

Atchafalaya River Watershed (La.), Flood control, Floods-Mississippi river, Hydraulics, Hydrodynamics-Mathematical models, Spillways-Louisiana, Stream measurements

\section{SECURITY CLASSIFICATION OF:}

a. REPORT

Unclassified

\begin{tabular}{|l|l|} 
b. ABSTRACT & c. THIS PAGE \\
Unclassified & Unclassified
\end{tabular}

17. LIMITATION OF ABSTRACT

SAR
18. NUMBER OF 19a. NAME OF RESPONSIBLE PERSON PAGES Gary Bell

135 19b. TELEPHONE NUMBER (Include area code) 601-634-4621 